\title{
Ventilator-associated pneumonia: studies on pathogenesis, diagnosis and prevention
}

Citation for published version (APA):

Bergmans, D. C. J. J. (1999). Ventilator-associated pneumonia: studies on pathogenesis, diagnosis and prevention. [Doctoral Thesis, Maastricht University]. https://doi.org/10.26481/dis.19990205db

Document status and date:

Published: 01/01/1999

DOI:

$10.26481 /$ dis. $19990205 \mathrm{db}$

Document Version:

Publisher's PDF, also known as Version of record

\section{Please check the document version of this publication:}

- A submitted manuscript is the version of the article upon submission and before peer-review. There can be important differences between the submitted version and the official published version of record.

People interested in the research are advised to contact the author for the final version of the publication, or visit the DOI to the publisher's website.

- The final author version and the galley proof are versions of the publication after peer review.

- The final published version features the final layout of the paper including the volume, issue and page numbers.

Link to publication

\footnotetext{
General rights rights.

- You may freely distribute the URL identifying the publication in the public portal. please follow below link for the End User Agreement:

www.umlib.nl/taverne-license

Take down policy

If you believe that this document breaches copyright please contact us at:

repository@maastrichtuniversity.nl

providing details and we will investigate your claim.
}

Copyright and moral rights for the publications made accessible in the public portal are retained by the authors and/or other copyright owners and it is a condition of accessing publications that users recognise and abide by the legal requirements associated with these

- Users may download and print one copy of any publication from the public portal for the purpose of private study or research.

- You may not further distribute the material or use it for any profit-making activity or commercial gain

If the publication is distributed under the terms of Article $25 \mathrm{fa}$ of the Dutch Copyright Act, indicated by the "Taverne" license above, 
Ventilator-associated pneumonia:

studies on pathogenesis,

diagnosis and prevention 
C Dennis CJJ Bergmans, Maastricht 1999

ISBN $90-9012364-4$

Cover dlesign: Wanda Lenaers en Jeanny Kaethoven.

Eric Rooijakkers (Regelrecht Eindhoven).

Production: Datawyse | Universitaire Pers Maastricht. 


\title{
Ventilator-associated pneumonia:
}

\author{
studies on pathogenesis, \\ diagnosis and prevention
}

\section{PROEFSCHRIFT}

ter verkrijging van de graad van doctor aan de Universiteit Maastricht,

op gezag van de Rector Magnificus,

Prof Dr AC Nieuwenhuijzen Kruseman, valgens het besluit van het College van Decanen,

in het openbaar te verdedigen

op vrijdag 5 februari 1999 om 14.00 uur

door

Dennis CJJ Bergmans

geboren op 29 april 1970 te Weert 


\section{Promotor}

Prof dr PW de Leeuw

\section{Co-promotores}

Dr MJM Bonten (Rijksuniversiteit Utrecht)

Dr EE Stobberingh

\section{Beoordelingscommissie}

Prof dr PB Soeters (voorzitter)

Prof dr IM Hoepelman (Rijksuniversiteit Utrecht)

Prof dr JWM van der Meer (Katholieke Universiteit Nijmegen)

Dr G Ramsay

Prof dr EFM Wouters

The studies described in this thesis were supported by grant 28-2125-1 from the Praevention Foundation, and a grant from Eli Lilly Nederlana by.

Additional financial support for publication of this thesis was generously provided by ZENECA Farma, Bayer B.V., Wyeth-Lederle, Glaxo-Wellcome bv and Pfizer bv. 
Aan mijn moeder

Ter herinnering aan minn wader 



\section{Contents}

Chapter 1 Introduction 9

Chapter 2 The pathogenesis and prevention of ventilator-associated pneumonia: A review

Chapter 3 Indications for antibiotic use in ICU patients: a one-year prospective surveillance

Chapter 4 Implementation of bronchoscopic techniques in the diagnosis of ventilator-associated pneumonia to reduce antibiotic use

Chapter 5 Risk factors for pneumonia, and colonization of respiratory tract and stomach in mechanically ventilated ICU patients

Chapter $6 \quad$ Clinical spectrum of ventilator-associated pneumonia caused by methicillin-sensitive Staphylococous aureus

Chapter $7 \quad$ Value of phenotyping methods as an initial screening of Pseudomonas aeruginosa in epidemiologic studies

Chapter 8 Colonization with Pseudomonas aeruginosa in patients developing ventilator-associated pneumonia

Chapter 9 Cross-colonization with Pseudomonas aeruginosa of patients in an intensive care unit

Chapter 10 Prevention of ventilator-associated pneumonia by oral decontamination: A prospective, randomized, doubleblind, placebo-controlled study

Chapter 11 General discussion

Chapter 12 Summary

Chapter 13 Samenvatting

Dankwoord

Publicaties 



\section{Introduction}

The present thesis deals with ventilator-associated pneumonia (VAP) which is a frequent complication in mechanically ventilated patients admitted to intensive care. The incidence rates of VAP may vary due to factors like patient population; lype of intensive care unit (ICU) and criteria used to diagnose this infection. Ventilator-associated pneumonia is preceded by colonization of the upper respiratory tract and these pathogens are derived from endogenous or exogenous sources. Several routes of colonization by which these pathogens are transported from their source to the upper respiratory tract have been hypothesized and studied. The epidemiology, routes of colonization and their role in the pathogenesis of VAP will be described in chapter 2 of this thesis. Since prevention of VAP is an important goal for intensive care medicine, the results from studies which evaluate the strategies currently in use or suggested for the prevention of VAP are critically reviewed as well and compared with the recommendations for prevention of hospital-acquired or nosocomial pneumonia as formulated by the American Thoracic Society and the Centers for Disease Control and Prevention.

Critically ill patients frequently have an infection on admission to $1 \mathrm{CU}$ and are prone to develop new infections. The majority of these infections involve the respiratory tract. As a corollary, the total antibiotic consumption is approximately 10 times greater in ICU than in general hospital wards. In addition to the associated costs, antibiotic consumption potentially causes selection and induction of antibiotic resistance. Surveillance studies on the incidence of infections, antibiotic prescription policies and knowledge about antimicrobial susceptibilities of causative pathogens are the first step in managing this problem. In chapter 3 the results of a one-year prospective analysis of the incidence of infections, their etiologic pathogens, antibiotic use and related costs in our generall ICU ward are described. Special emphasis is given to the indications for antibiotic use, which are divided into those related to bacteriologically proven and non-bacteriologically proven infections, and those related to prophylactic use. Another approach to anticipate on the high consumption of antibiotics is to optimize the criteria used for the diagnosis of infection. Ventilator-associated pneumonia is usually diagnosed on a combination of clinical, radiographic and microbiological criteria which have a high sensitivity, but low specificity for VAP. As a result, patients may receive antibiotics unnecessarily. Specificity can be increased by the addition of quantitative cultures of samples of protected specimen brush and bronchoalveolar lavage to the diagnostic criteria. In chapter 4 a prospective study is described which evaluated whether adding the results of protected specimen brush and bronchoalveolar lavage to the generally used criteria for diagnosing VAP influenced antibiotic prescription by intensive care physicians. In addition, we analyzed some costs associated with diagnosis and antimicrobial therapy of VAP.

In the pathogenesis of VAP, gastric colonization with potentially pathogenic 
microorganisms is assumed to be important. In this hypothesis, microorganisms initially colonize the stomach, subsequently colonize the upper respiratory tract, and finally are aspirated into the lungs. Gastric colonization may be stimulated by decreased gastric acidity, secondary to stress-ulcer prophylaxis or gastric nutrition. Several methods have been studied to reduce gastric colonization by attempting to maintain intragastric acidity. However, in several studies by others and previous research in our group, the use of sucralfate for stress-ulcer prophylaxis and modulation of enteral feeding failed to influence the incidence of infection, colonization of stomach and respiratory tract, and levels of intragastric acidity. Moreover, sequential analysis of colonization strongly suggested that the stomach was not an important source of bacteria causing VAP, and that the gastropulmonary route of colonization may not be as important in the pathogenesis of VAP as generally suggested.

Many risk factor analyses for the development of VAP in critically ill patients have been performed. Well known risk factors that have been identified are severity of illness, intubation, duration of mechanical ventilation and a history of chronic obstructive pulmonary disease. Unfortunately, preceding colonization at different body sites has not been included as a risk factor in any of these analyses. In order to further elucidate the pathogenesis of colonization and infection of the respiratory tract in mechanically ventilated patients, we studied risk factors for the development of colonization of stomach, oropharynx and trachea, and the development of VAP with enteric Gram-negative bacteria (EGB) and Pseudomonadaceae. The results of this multivariate analysis are described in chapter 5.

Early-onset and late-onset VAP each have a different etiologic spectrum. Earlyonset VAP is mainly caused by Streptocaccus pneumoniae, Staphylococcus aureus and Haemophilus influenzae, while late-onset VAP is caused by nosocomial pathogens such as Enterobacteriaceae, S. aureus and Pseudomonas aeruginosa. Together these nosocomial pathogens are responsible for the majority of serious infections among critically ill patients and, therefore, often grouped and labelled as potentially pathogenic microorganisms. Although potentially pathogenic microorganisms are regarded as a single group, it should be kept in mind that each species has its own characteristics with regard to preferred site of colonization, routes and vectors of transmission, and clinical spectrum. For instance, quite often, $S$. aureus is the cause of VAP. In contrast to communityacquired pneumonia caused by $S$. aureus, the clinical presentation of staphylococcal pneumonia in mechanically ventilated patients has not been described in great detail. In chapter 6 the incidence of colonization of the upper respiratory tract by methicillin-sensitive $S$. aureus and its association with the development of VAP caused by this species is described. In addition, the clinical spectrum, microbiological results and outcome of patients with VAP caused by $S$, aureus are discussed. 
In many other lCUls, as well as in ours, P. aeruginosa is the most prevalent microorganism causing VAP. A number of microbiological and clinical aspects of this pathogen are highlighted in chapters 7, 8 and 9 . Colonization with P. aeruginosa may originate from exogenous or endogenous sources. The intestine, the oropharynx and the stomach could serve as endogenous sources, whilst the inanimate environment and other patients are potential exogenous sources. Although the sources and reservoirs of $P$. aeruginosa are largely known, the various routes of colonization that lead to VAP have not been established. Moreower, when studying routes of colonization with $P$ aeruginosa, determination of similarity of isolates is crucial, especially since colonization may occur with several different isolates, both at one particular body site and at different body sites. A comparison of phenolypes of isolates of $P$. aeruginosa is relatively easy to perform, but lacks specificity. Genotyping techniques have a higher specificily and discriminatory power and are considered the method of choice to compare bacterial isolates when studying nosocomial outbreaks. However, these techniques are laborious and expensive, and may not be feasible for all laboratories. In chapter 7 the usefuness of four methods of phenotyping, as a method of initial screening for investigating colonization patterns of $P$. aeruginosa, were determined. The results of the phenotyping methods were compared with those of pulsed-fieid gel electrophoresis of enzyme restricted chromosomal DNA. The results of these phenotyping and genotyping methods were used to study routes of colonization with $P$. aeruginosa leading to VAP. Chronological analysis of colonization in the rectum, stomach, oropharynx and trachea, enables determination of initial sites of collonization and the spread of microorganisms to other body sites. In addition, the biotyping techniques can determine whether a patient is colonized with a single or multiple genotypes. These analyses are described in chapter 8 . Pseudomonas aeruginosa may be derived fram exogenous sources. Sinks, distilled water systems, faucets and ventilator equipment are among the many potential sources that have been reported to be the cause of nosocomial outbreaks of colonization or infection. Other patients colonized with $P$. aeruginasa present in the same ICU are also important exogenous sources. Transfer of these pathogens, from source to patient (crosscolonization), most probably occurs via hands of nursing and medical staff or contaminated equipment. Understanding the relative importance of this route of colonization, in epidenic and endemic situations, is crucial in order to develop effective preventive measures against infection. in chapter 9 an analysis of colonization and infection with $P$. aeruginosa following the clinical observation of three episodes of VAP due to $P$. aeruginasa in a short period of the was performed. Since these infections were assumed to be the result of crosscolonization of microorganisms, the importance of this route of colonization for P. aeruginosa was determined using pulsed-field gel electrophoresis for analysis of similarity of isolates.

As stated before, the bacteria causing VAP may also be transmitted from 
endogenous sources. Since the gastropulmonary route of colonization has been considered to be important in the pathogenesis of late-onset VAP, modulation of gastric colomization has been attempted as a measure to prevent VAP. However, none of these interventions have proven unequivocally to reduce the incidence of VAP. Furthermore, sequential anallyses of colonization failed to demonstrate an important role of the gastropulmonary route. Selective decontamination of the digestive tract (SDD) decreases the incidence of VAP. The concept of SDD aims to eradicate microorganisms from the intestine, the stomach and the oropharynx by nonabsorbable antibiotics, which are combined with systemic antibiotic prophylaxis during the first days of ICU admission. Resistance concerns, lack of cost-benefit analyses and absence of beneficial effects on mortality rates have limited the widespread use of SDD. From a conceptual point of view, it has remained unclear which part or parts of SDD prevents VAP. Since the importance of gastric and intestinal colonization has been questioned, and systemic antibiotics during the first days of intubation appear to prevent early-onset but not late-onset VAP, we hypothesized that decontamination of the oropharynx, without modulating gastric and intestinal colonization, and without systemic antibiotic prophylaxis, would reduce the incidence of VAP in critically ill intensive care patients. In chapter 10, the last study of the thesis, this hypothesis was tested in a prospective, randomized, double-blind, placebo-controlled study in 226 patients receiving either topical antimicrobial prophylaxis in the oropharynx or placebo.

In summary, the main questions addressed in this thesis are:

1. What is the incidence of infections in critically ill patients admitted in our ICU? Chapter 3 .

2. What are the indications for antibiotic use and the related costs in a general lCU ward? Chapter 3 .

3. Does addition of quantitative culture results of samples obtained by bronchoscopic techniques to the generally used criteria for diagnosing VAP influence antibiotic prescription? Chapter 4.

4. What are the risk factors for the development of colonization of stomach, orophanyn, and trachea with EGB and Pseudomonadaceae? Chapter 5

5. What are the risk factors for the development of VAP caused by EGB and Pseudomonadaceae? Chapter 5 .

6. Does the clinical spectrum and outcome of staphylococcal VAP differ from that of staphylococcal community-acquired pneumonia? Chapter 6 .

7. Can phenotyping techniques be used as an initial method of screening for $P$. aeruginosa in order to reduce the number of isolates that need to be glenotyped? Chapter 7 .

8. Is the respiratory tract the most important inifial site of colonization with $P$ aeruginosa or is colonization with this pathogen not restricted to the respiratory tract? Chapter 8 .

9. Are patients admitted to ICU colonized with a single or with multiple genotypes of $P$. aeruginosa? Chapter $B$ 
10. Does cross-colonization influence the rates of colonization and infection with $P$. aeruginosa in an ICU where colonization with this species is endemic? Chapter 9.

11. Can VAP be prevented by modulation of oropharyngeal colonization, without influencing gastric arid intestinal colonization and without systemic prophylaxis? Chapter 10 . 


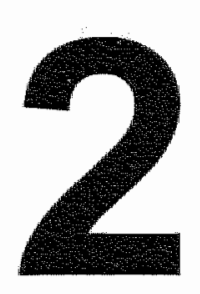

\section{The pathogenesis and prevention of ventilator- associated pneumonia: A review}

Parts of this review will be published in chapters in the Yearbook of Intensive Care and Emergency Medicine, 1999 (Vincent $\mathrm{J}$, editor) and Hospital Epidemiology and infection Control, 2nd ed. (Mayhall $\mathrm{CG}_{\text {, editor) }}$ 


\section{Introduction}

Ventilator-associated pneumonia (VAP) is the most common nosocomial infection among mechanically ventilated patients ${ }^{1}$, and has been associated with increased morbidity, longer hospital stay, increased health care costs and higher mortality rates ${ }^{2,3}$. Prevention of this infection is, therefore, a major challenge for intensive care medicine Pneumonia is defined as VAP when diagnosed in an intubated, mechanically ventilated patient after more than $48 \mathrm{~h}$ of ventilation. On the basis of time of diagnosis, two types of VAP are distinguished: early-onset VAP, occurring within the first $4 \mathrm{~d}$ of mechanical ventilation, and late-onset VAP, occurring thereafter ${ }^{4}$.

\section{Incidence}

Incidence rates of VAP among intensive care unit (ICU) patients depend on the type of ICU, the severity of illiness of patients studied and the criteria for diagnosis Several methods are used to diagnose pneumonia in clinical and research situations. Often, one out of three combinations of criteria is used in clinical studies: the modified criteria of the Centers for Disease Control and Prevention $(\mathrm{CDC})^{5}$, the Clinical Pulmonary Infection Score (CPIS) $)^{6}$, or the criteria of the Memphis Consensus Conference?. The first two methods include only clinical criteria and chest radiograph results (Table 2.1). The Memphis criteria include results of quantitative cultures of samples of secretions from the lower respiratory tract obtained by protected specimen brush, bronchoalveolar lavage or protected bronchoalveolar lavage in addition to the clinical and radiographic criteria (Table 2.1). In a recent study, all three methods were used to assess the incidence of VAP, overall incidences were $21.7 \%$ for $\mathrm{CDC}, 19.9 \%$ for $\mathrm{CP} I \mathrm{~S}$ and $93 \%$ probable and $0.4 \%$ definite pneumonia as defined by the Memphis criteria ${ }^{8}$. Obviously, the overall incidence of pneumonia decreases when the definition of pneumonia becomes more strict. Therefore, whether investigators used bronchoscopic techniques in their diagnosis of VAP or just clinical and radiographic parameters is important with regard to incidence rates of VAP. At present, in the absence of a 'gold standard' for the diagnosis of VAP, the combination of clinical parameters, chest radiograph and quantitative cultures of protected specimen brush and/or bronchoalveolar lavage obtained by bronchoscopy appears to have highest sensitivity and specificity ${ }^{3.910}$. In a number of studies aiming to ascertain incidences of VAP, or to evaluate modalities to diagnose VAP, or studies in which risk factors for VAP were assessed, the incidences of VAP range from 8.6 to $64.7 \%$ (Table 2.2). Moreover, in studies on the effect of preventive measures on the occurrence of VAP, incidences of up to $78 \%$ have been reported in the control groups $^{28}$. 
Table 2.1 Diagnostic criteria of pneumonia used in clinical studies

\begin{tabular}{|c|c|c|c|c|}
\hline \multirow[b]{2}{*}{ Criteria } & \multirow[t]{2}{*}{$\mathrm{CDC}^{*}$} & \multirow[t]{2}{*}{ GPISt } & \multicolumn{2}{|c|}{ MCCA } \\
\hline & & & $\begin{array}{l}\text { probable } \\
\text { pisurinona }\end{array}$ & 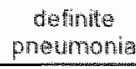 \\
\hline $\begin{array}{l}\text { Rales ar dulness to percussion on physical } \\
\text { examination }\end{array}$ & +1 & * & - & * \\
\hline $\begin{array}{l}\text { Radilographic infiltrate inew, progressive, } \\
\text { persistent) }\end{array}$ & +11 & + & $*$ & + \\
\hline Temperature & - & 4 & $(+)$ & $(+a)$ \\
\hline Bload leukocytosis/eukopenia & - & + & $(*)$ & +1 \\
\hline Purulent sputum & 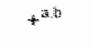 & + & $*$ & + \\
\hline $\begin{array}{l}\text { On Grams stain }>25 \text { granulacytes and }<10 \\
\text { squamous epithelial cells } \$\end{array}$ & - & $\approx$ & - & - \\
\hline $\begin{array}{l}\text { Positiwe culture of transtracheal aspirate for } \\
\text { bronchial brushing. biopsy) }\end{array}$ & $t^{3}$ & $*$ & \# & - \\
\hline Number of tracheal secretions & - & + & - & - \\
\hline Oxygenation $\left(\mathrm{PaO}_{2} / \mathrm{FiO}_{2}\right)$ & n & 4 & $(*)$ & $(+1)$ \\
\hline Quantitative culture of PSB or BAL & - & 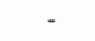 & +6 & - \\
\hline Fositiwe bilood cullute & $+t^{a \cdot 2}$ & $\infty$ & $4^{c}$ & - \\
\hline Pheural fluid culture & $*$ & - & $+c$ & - \\
\hline $\begin{array}{l}\text { Isolation of vinus or detection of virus antigen in } \\
\text { resplatory secretions. }\end{array}$ & $4^{b}$ & $=$ & 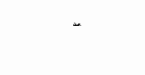 & - \\
\hline $\begin{array}{l}\text { Diagnosic single antibody titer (lgM) or fourfold } \\
\text { incirease in pared sentum samples (lgG) for } \\
\text { pathogen }\end{array}$ & $t^{b}$ & 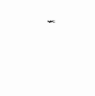 & - & - \\
\hline $\begin{array}{l}\text { Radiographic pulmonary abscess and positive } \\
\text { meedle asprate culture }\end{array}$ & - & - & - & $+n^{d}$ \\
\hline $\begin{array}{l}\text { Opein-lung biopsy or post-mortem lung histologic } \\
\text { examination and negative lung parenchyma } \\
\text { cullure }\left(<10^{4} \text { cfu/g) }\right.\end{array}$ & - & - & $+{ }^{*}$ & - \\
\hline $\begin{array}{l}\text { Open-lung biopsy or post-motem furg thistologic } \\
\text { examination and posilive iung parenchyma } \\
\text { culture } 1>10^{4} \text { cfugl }\end{array}$ & +4 & - & $\omega$ & +4 \\
\hline
\end{tabular}

PSB, protected specmen brush: EAL, bronchoalveolar lavage

* CDa modified criteria of the Centers for Disease Control and Prevertion ${ }^{5}$. Preumonia must meot the criterium I and any of the criteria ${ }^{2}$, or criterium II and any of the criteria

I CPIS, Clinical Pumonary Infection Score $(\mathrm{CP} / \mathrm{S})^{6}$. Scoring system with 1 or 2 points awarded for pressence of criteria, range 0-12. with pneumonia defined by a score of 7 or higher Additional point score for purthent sputum when number of tracheal secretions is 214 .

+ MCC Memphis Consersus Conference. The criteria denoted with "ty are not necessary for the diagrosis but enhance the climical suspicion of pneumonia. Pneumonia must met the criterium cinical suspicion of pneumonia and any of the criteria ${ }^{c}$ for probabie and any of the criterica for definite pneumonia.

5. The number of granulocytes and squamous epithelial cells per low-power field on microscopic examunation of the Gram stan is used in some studies to canfirm the macroscopic diaghosis of purulent sputum. 
Table 2.2 Studes ar the incidence of WAP in various patient populations using different diagnostic criteria

\begin{tabular}{|c|c|c|c|c|c|}
\hline Aluthor & Population & No & Diagnosis & \multicolumn{2}{|c|}{ No VAP $(\%)$} \\
\hline Apte & Medical & 34 & RICISP/TAMHP & 22 & $(64.7)$ \\
\hline Kingston ${ }^{1 / 2}$ & Mixed & 24 & RUCISp/TANI & 10 & $(41.7)$ \\
\hline Craven ${ }^{13}$ & Mixed & 233 & R/CISp/TAM & 49 & $(21.0)$ \\
\hline Revisser ${ }^{14}$ & Neurollogic & 40 & R/CITAMM & 15 & $(37.5)$ \\
\hline Roditiquis & Tratuma & 294 & RICITAMM & 130 & $(4,2)$ \\
\hline Rello & Tratma & 161 & RICHSP & 38 & $(23.6)$ \\
\hline de Latore & Medisurg & 80 & R/Cl/sp & 12 & $(15.0)$ \\
\hline Fiddian Greven ${ }^{18}$ & Mixed & 62 & Clinicalt & 8 & $(12.9)$ \\
\hline Vincent" & Mixed & 10038 & $\operatorname{COC}$ & 967 & $(46.9)$ \\
\hline Beck-Sague & Surgical & 145 & $\mathrm{CDC}$ & 15 & $(10.3)$ \\
\hline ragon $^{20}$ & Mixed & 567 & R/Sp/PSB & 49 & $(8.6)$ \\
\hline Rello & Medrsurg & 264 & R/CISPp/PSB & 58 & $(21.9)$ \\
\hline Papazian ${ }^{22}$ & Med/Surg & 586 & R/CISp/PSB & 97 & $(16.6)$ \\
\hline Garrouste Orgeas ${ }^{23}$ & MedrSurg & 86 & R/CISp/PSB & 31 & $(35.6)$ \\
\hline Fagorit $^{24}$ & Mixed & 1978 & R/Sp/PSE/BAL & 328 & $(16.6)$ \\
\hline Torres $^{2 c}$ & Mixed & 322 & $\mathrm{MCC}$ & 78 & $(24.0)$ \\
\hline Bontlen $^{26}$ & Mixed & 64 & $\mathrm{MCC}$ & 11 & $(17.2)$ \\
\hline Kollef ${ }^{27}$ & Mixed & $52 \|$ & MCOs & 77 & $(14.8)$ \\
\hline
\end{tabular}

Med, Medical: CDC, modified criteria of the Centers for Disease Control and Prevention (see table 2, 1): Surg, Surgical: MCC criteria from the Mempthis Consensus Conference ${ }^{7}$ (see lable 2.1 ).

* The abbreviations used in the description of the diagnostic criteria are: $\mathrm{R}_{n}$ new progressive ar persistent radiographic infiltrate, $\mathrm{Cl}$ chical parameters (faver, leukocytosis or lenkopenia, oxygenation): Sp, purulent sputum: TA, postive culture of tracheal aspirate: M. microscopic assessment of Gram stain (number of gramulocytes and squamous epithellal cells): P, rales or dumbss to percussion on physical examination; PSB, protected specimen brush; BAL bronchoalveolar lavage

$\uparrow$ Endpoint of anitysis in this study was: "a clinical diagnosis of nosocomial pneumonia". No specific criteria were described

+ Bronchoscopy with PSB andor BAL was not performed in all patients with a clinical suspicion of pneiumonia.

\section{Etiology}

Besides the difference in duration of mechanical ventilation at time of diagnosis, early-onset and late-onset VAP also have a different etiologic spectrum. Earlyonset VAP is mainly caused by Streptococcus pneumoniae, Staphylococcus aureus and Haemophilus influenzae, pathogens that presumably already colonize the respiratory tract at the time of intubation. Late-onset VAP is caused by nosocomial pathogens such as Enterobacteriaceae, $S$. aureus and Pseudomonas aeruginosa. Because these nosocomial pathogens are known to cause serious infections under certain circumstances they are usually grouped and labelled as potentially pathogenic microorganisms (PPMO). In many studies, colonization and infection with PPMO is analyzed instead of analysis of the separate species. Aithough PPMO are regarded as a single group, it should be kept in mind that 
each species has its own characteristics with regard to preferred site of colonization, routes and wectors of transmission, and clinical spectrum.

Studies using quantitative cultures of bronchoalveolar lavage and/or protected specimen brush demonstrate that approximately $60 \%$ of all cases of VAP are associated with Gram-negative bacleria, mainly $P$. aeruginosa (20\%), and $35 \%$ with Gram-positive bacteria ${ }^{20,21,29,30}$. S. aureus is the most frequent Gram-positive pathogen causing VAP (20\%). In comatous multiple trauma patients, incidences of S. aureus VAP as high as $56 \%$ have been reported ${ }^{16.3 \%-33}$. VAP is often polymicrobial with incidences ranging from 20 to $60 \%$ of all episodes of $\mathrm{VAP}^{29,34}$. The importance of anaerobic bacteria in the pathogenesis of VAP has not been studied extensively. Isolation of anaerobic bacteria requires specific transpon conditions and culture media, which usually are not systematically achieved during bacteriologic investigation of respiratory tract samples. The incidence of VAP in which anaerobic bacteria are involved, therefore, is probably underestimated. In a prospective study of 130 episodes of VAP, aerobic and anaerobic bacteria were isolated from protected specimen brush ( $\geq 10^{3} \mathrm{cfu} / \mathrm{ml}$ ) in $26(20 \%)$ patients, and anaerobic bacteria only were isolated in four $(3 \%)$ patients ${ }^{30}$.

The proportional distribution of the species causing VAP within the etiologic spectrum, as well as their antibiotic susceptibility, may vary considerable between hospital settings, patient populations and countries.

\section{Risk factors}

The risk factors associaled with the development of VAP have been determined in studies using multivariatie analysis techniques and case-control designs or have been suggested on the basis of reviews. Determination of risk factors for VAP has several clinical implications. They offer prognostic information about the probability of developing VAP, they help to reveal the pathogenesis of VAP, and they may provide possible targets for preventive strategies. By risk stratification, one can determine which patients may benefit most from pneumonia prophylaxis ${ }^{35}$. Risk factor analyses for ICU-acquired pneumonia (i.e. pneumonia diagnosed in $\mathrm{CU}$ patients with or without mechanical ventilationi) have clearly identified mechanical ventilation to be the most important risk factor ${ }^{36.49}$. Moreover. Langer and colleagues $^{41}$ reported on the relation between duration of ventilation and incidence of VAP, which rises from $5 \%$ in patients receiving one day of assisted ventilation to $68.8 \%$ in patients who are ventilated for $>30 \mathrm{~d}$. In general, the risk factors that have been identified can be divided into three groups (Table 2.3). Firstly, risk factors that are well known (intubation, duration of mechanical ventilation etc) but are very difficult to modify and that offer no or only limited possibilities for prevention. Secondly, risk factors which seem to play a role in the pathogenesis of VAP and which have stimulated the development of a number of preventive strategies. Finally, those risk factors which have been identified only incidentally or need further investigations ta assess their significance and the possibility for prevention. 


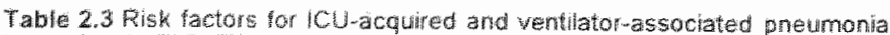

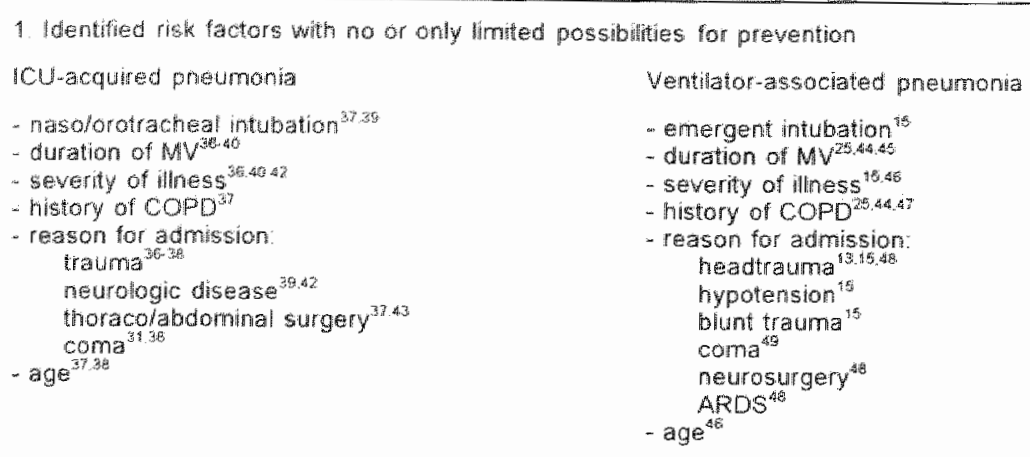

2. Identifed risk factors that offer possibilities for prevention

1CU acquired pneumonim

- antacids

- large wolume aspilation ${ }^{37}$

- presence of nasogastric tube

- impared ainuay repexes 36

- depressed consciousness ${ }^{17}$

\section{Vertillator-associated pneumonia}

- antacids or $H_{2}$-antagonists ${ }^{\text {tan }}$ in

- lairge volume aspiration ${ }^{26,49}$

- enteral nutrition ${ }^{4}$

- contaminated wentilator circuits ${ }^{13 a_{10}}$

- rentubation ${ }^{20,20,49: 51}$

- previous antibiotic use $e^{1944.4752 .53}$

- fonelevated head position ${ }^{46}$

3. Risk factors identhied incidentaly or needing further imvestigations to assess their influence on infection and possibilities for prevention

ICU-acquired pneurnonia

- male gender ${ }^{42}$

- recent bronchascopy ${ }^{43}$

- thoracic drainage

- coagulation products ${ }^{\text {t? }}$
Ventilator-associated pheumonia

- male gender ${ }^{2}$

- fallwinter season ${ }^{\text {H.3 }}$

- fablure of $\mathrm{CASS}^{52}$

- inadequate intracuff pressure ${ }^{5 z}$

- administration of aerosols ${ }^{27}$

- presence of a tracheostomy

-.. Transport out of the ICU ${ }^{27}$

- sinusitis ${ }^{545}$

MV, mechanical ventillation, COPD, chironic obstructiwe pulroonary disease: CASS, conthuous aspiration of subgloticio secretions,

Recently, several risk faclor analyses identified previous antibiotic use to be significantly associated with the development of $V_{A P}{ }^{19,46,52}$. Rello and coworkers ${ }^{44}$ reported that prior use of antibiotics was a risk factor for $P$. aeruginosa VAP. The same conclusion was reached by Talon and coworkers ${ }^{47}$ in patients who received metronidazole. Other investigators concluded that prior broadspectrum antibiotic use was a risk factor for VAP caused by 'potentially drug-resistant bacteria' (methicillin-resistant $S$. aureus, $P$. aeruginosa, Acinetobacter baumanii, and Stenotrophomonas maltophilia) ${ }^{45}$. On the other hand, the absence of prior antibiotic treatment was a risk factor for VAP caused by $H$. influenzae ${ }^{53}$. Lately, attention has been drawn to the association between the mode of mechanical ventilation, ventilator-induced lung injury and inflammation or infection ${ }^{56.57}$. 


\section{Colonization}

The relation between colonization of the upper respiratory tract and the development of VAP was established by Johanson and coworkers in $1972^{58}$. Nosocomial respiratory infections developed in $23 \%$ of ICU patients with upper respiratory tract colonization but in only $3 \%$ of noncolonized patients ${ }^{58}$. Moreover. upper respiratory tract colonization increased with severity of illness. Repeated oropharyngeal cultures obtained from 33 normal subjects revealed Gram-negative bacteria in $6 \%$ of subjects, while these pathogens were cultured from $35 \%$ of moderately ill hospitalized patients and even $73 \%$ of moribund patients ${ }^{5 \%}$. Since then, many variables have been determined that enhance colonization and infection of the respiratory tract in ICU patients ${ }^{\circ 0}$. Although increased exposure to pathogens may play a role, this cannot exclusively explain increased colonization rates. Nursing and medical staff have similar colonization rates as normal subjects not working in a hospital setting ${ }^{59}$. A reduced capacity to clear pathogens and/or increased adherence of microorganisms are more likely mechanisms to account for the higher colonization rates in critically ill patients. The latter mechanisms can be the result of decreased immunologic host function, destruction of epithelial surfaces $^{61,62}$, impaired mucociliary clearance, pro-inflammatory enzymes and fibronectin reducing proteases ${ }^{63}$. Furthermore, during ICU stay, approximately $60 \%$ of patients receive systemic antibiotics. Antibiotic therapy can rapidiy change the commensal oropharyngeal flora, resulting in an increase in oropharyngeal and upper respiratory tract colonization with aerobic Gram-negative or Gram-positive bacilli and yeasts, possibly due to loss of the normal bacterial flor $a^{100,64}$ and to selection of pathogens which are resistant to the antibiotics used ${ }^{65-69}$

\section{Routes of colonization}

Microorganisms reach the lungs after aspiration of colonized oropharyngeal fluid. Microaspiration occurs frequently, both in healthy people as well as in critically ill patients ${ }^{70,71}$. Pathogens colonizing the respiratory tract and causing VAP' are derived from either endogenous or exogenous sources. The stomach and intestine are the most important endogenous sources. In addition, pathogens colonizing the upper respiratory tract (oropharynx, sinus cavities, the nares and those on dental plaque) may be aspirated. Contaminated environment (sinks, faucets, sheets etc.), contaminated equipment (mechanical ventilation devices, ventilator circuits, radiographic equipment etc.), contaminated enteral feeding and other colonized patients in ICU are potential exogenous sources.

Several routes of colonization by which pathogens are transported from their endogenous or exogenous sources to the upper respiratory tract of the patient are possible. In the gastropulmonary route of colonization ${ }^{72,73}$, endogenous bacteria reach the upper respiratory tract via the stomach and subsequently colonize oropharynx and trachea after which the bacteria are aspirated in the lower respiratory tract. This route of colonization has been propagated as important in the pathogenesis of VAP for many years. The rectopulmonary route of colonization 
has attracted less attention. In this route, intestinal microorganisms spread from the rectal area via the patient's skin or the hands of health care personnel to the upper respiratory tract. Finaly, transfer of pathogens from exogenous sources most probably occurs via hands of nursing and medical staff, which enables direct inoculation of microorganisms into the tracheobronchial tree during manipulation of ventilator circuits or tubes ${ }^{74-76}$. This is called the exogenous route of colonization or cross-colonization when another patient is the exogenous source.

\section{Essential conditions to study the pathogenesis of VAP}

Since colonization is not always followed by infection, infection rates with a certain pathogen form only the tip of the iceberg of the complete epidemiology ${ }^{75,77}$. When studying the epidemiology of microorganisms in ICU, survellance of colonization is indispensable. In clinical practice, surveillance is advised only for high-risk patients in specific clinical settings ${ }^{78}$. However, when determining the epidemiology of ICU pathogens in detail, surveillance should include all patients within the ICU, as well as equipment and environmental surfaces for certain pathogens. Survellance cultures from patients should be taken on admission and subsequently with a frequency high enough to study sequences of colonization from initial body sites to other body sites. Moreover, patients may be colonized or infected with multiple genotypes of the same species, both at one particular body site and at different body sites ${ }^{74}$. Therefore, analysis of a single isolate may not accurately represent the bacterial flora. Analysis of several isolates and determination of similarity of isolates is crucial ${ }^{79}$.

Comparison of bacterial phenotypes, such as antibiotic susceptibility patterns, serotypes, phage types and outer membrane protein types, is relatively easy to perform, but lacks specificity ${ }^{79}$. Genomic DNA fingerprinting techniques, such as puised-field gel electrophoresis (PFGE), random amplification of polymorphic DNA and arbitrarily primed polymerase chain reaction, have a higher specificity and discriminatory power while maintaining epidemiological linkage. These techniques are, therefore, considered the methods of choice to determine identity of bacterial isolates in the epidemiology of nosocomial outbreaks ${ }^{80-82}$. However, the techniques are often cumbersome and expensive, and therefore not always feasible in routine practice.

In summary, to be ablle to study routes of colonization that may lead to VAP it is necessary to:

1. determine the incidence of VAP, as diagnosed by bronchoscopic techniques;

2. perform survellance cultures of all patients present in $I C U$, and possibly environment and equipment;

3. culture several body sites on admission and with a sufficient frequency thereafter:

4. analyze several isolates of each species, cultured from each site;

5. determine similarity of isolates of a certain pathogen by genotyping techniques 


\section{Routes of colonization}

\section{Endogenous}

Gastric colonization and the gastropumonary route In critically ill patients, gastric acidity may be decreased (i.e., pH value higher) due to decreased acid production, because of the application of enteral feeding or stress-ulcer prophylaxis (antacids, $\mathrm{H}_{2}$-antagonists, $\mathrm{H}^{*} \mathrm{~K}^{*} \mathrm{ATPase}$ inhibitors). If the gastric environment favours bacterial growth, bacteria may multiply, hence colonization with Gram-negative bacteria occurs frequently at this site ${ }^{34,7273}$. Because of the simultaneous occurrence of glastric colonization and the development of VAP, a causal relationship has been assumed. In the socalled gastropulmonary route of colonization, bacteria presumably reach the upper respiratory tract retrogradely via the colonized stomach, and bacteria are aspirated in the lower respiratory tract. Based on studies reporting correlations between development of VAP and concurrent or preceding gastric colonization with the same species, a central role in the pathogenesis of VAP was assigned to gastric colonization $^{72,83,84}$. However, in five recent studies, the gastropulmonary route of colonization was found to be umimportant with respect to colonization or infection of the upper respiratory tract ${ }^{14,17.26,34.85}$, while another four studies did support a role for gastric colonization ${ }^{83,86-88}$. Un these studies the percentage of patients in whom the stomach served as a source of colonization or infection of the respiratory tract ranged from $4 \%$ to $24 \%$ for colonization and from zero to $15 \%$ for the development of VAP ${ }^{B 9}$. Thus, the role of the stomach and gastropulmonary route of collonization remains a subject of debate ${ }^{90}$. Nevertheless, based on the alleged importance of gastric colonization, modulation of colonization at this site is still being used as a neasure to prevent VAP

\section{Oropharyngeal colonization}

The results of studies performed by Johanson and coworkers ${ }^{5.59}$ in the early seventies, pointed towards an association between colonization of the upper respiratory tract and the development of VAP. However, at that time, VAP could not be diagnosed with bronchoscopy and the diagnosis relied on relatively nonspecific clinical, radiographic and microbiological criteria. Moreover, only antibiotic susceptibility patterns and serotyping were employed to determine similarity of isolates, because molecular genotyping techniques were not yet available. Remarkably, in the following years research on the pathogenesis of VAP almost exclusively focused on the role of gastric colonization and the gastropulmonary route of colonization. Approximately 20 years later, new studies on sequences of colonization in patients who developed VAP provided additional evidence in support of Johanson's earlier findings. The upper respiratory tract was the site of first colonization in 14 out of 15 cases of VAP, in a study in which qualitative endotracheal aspirate cultures were used for the diagnosis of pneumonia ${ }^{14}$. Torres et al. ${ }^{72}$ compared pharyngeal, gastric and respiratory tract colonization in 63 patients with and without VAP, as diagnosed by bronchoscopic 
techniques. They found a strong association between upper respiratory tract colonization and VAP and concluded that both pharyngeal and gastric colonization were important reservoirs for bacteria causing VAP. However, in both studies colonization was not assessed serially, so no conclusions with respect to the actual sequences of colonization could be drawn. In a number of other studies serial cultures of multiple body sites were obtained in order to determine sequences of colomization leading to VAP. In doing so, de Latorre and coworkers ${ }^{\text {"7 }}$ concluded that tracheal colonization precedes VAP in most patients and that pharyngeal colonization, rather than gastric colonization, is the main source of microorganisms found in patients with VAP. Cade and coworkers ${ }^{\text {D5 }}$ studied 100 consecutive patients, of whom 49 had positive throat cultures which were preceded by gastric colonization in $15(25 \%)$ patients. There was no association between the presence of a positive gastric culture and the development of infection. Two studies from our group showed that $85 \%$ and $96 \%$ of the pathogens causing VAP had been isolated previously from tracheal aspirates, and $50 \%$ and $75 \%$ from the oropharynx ${ }^{26,34}$. Gastric colonization preceded VAP in only $30 \%$ and $31 \%$ of the cases ${ }^{26,34}$. Garrouste-Orgeas and coworkers ${ }^{23}$ analyzed oropharyngeal and gastric colonization prior to VAP in 86 patients. VAP was diagnosed by bronchoscopic techniques and identity of strains was based on results of PFGE. Oropharyngleal colonization (either on admission or acquired) correlated better with VAP than gastric colonization. Moreover, PFGE demonstrated that identical strains were isolated from both oropharyngeal and bronchial samples in 28 out of the 31 cases of pneumonia.

In conclusion, the role of oropharyngeal colonization as an antecedent to $\mathrm{VAP}^{60,91}$ has regained attention after having been partially neglected for years. The evidence at hand strongly suggests an important role for the oropharynx in the pathogenesis of VAP and offers a potential target for preventive strategies.

\section{Intestinal colonization and the rectopumonary route}

The intestines are a large endogenous source of Gram-negative bacteria, which may spread to the upper respiratory tract via the patients" skin or hands of health care personnel. This socalied rectopulmonary route of colonization, in reality, is an 'exogenous' route for endogenous microorganisms. Still, due to decreased intestinal peristalsis and gastric emptying in critically ill patients, bacteria can colonize the proximal small intestine and subsequently migrate to the stomach via duodenogastric reflux ${ }^{83.92}$. The rectopulmonary route of colonization has attracted only little attention, especially when compared with other routes of colonization. To our knowledge only four studies have been performed with speciall attention to the rectopumonary route. In one of these, the rectum was the most common primary site of colonization with $P$. aeruginosa among 153 patients admitted to a surgical $10 U^{93}$. In that study, $10(6.5 \%)$ patients acquired colonization with $P$. aeruginosa (seven from rectal swab cultures, three from nasal cultures, and three from tracheal secretions cultures), of whom one patient developed pneumonia ${ }^{93}$. In another study, the rectum was the most commonly observed colonization site for 
P. aeruginosa among 186 admissions to three hospital wards. In all: 20 patients acquired colonization with $P$. aeruginosa in the rectum or oropharynx or both; only two acquired oropharyngeal colonization alone. Unfortunately: data on gastric and oropharyngeal collonization were not reported in the first study ${ }^{93}$ and date on gastric and tracheal colonization ${ }^{94}$ are lacking in the latter study which precludes conclusions regarding routes of colonization. Noone et al ${ }^{74}$ studied 27 intubated $1 \mathrm{CU}$ patients of whom 15 were colonized with $P$. aeruginosa (rectum, pharynx. trachea, groin, toe web, or ear). Among 12 patients with rectal colonization, tracheal colonization occurred in 5 , but in only one case with the same serotype at both sites; tracheal colonization preceded isolation from rectal swabs by $2 d^{74}$. Among cardiac surgery patients receiving cefazolin prophylaxis, 58 of 87 became colonized or infected with Enterobacter spp. At least $48 \%$ of these patients were already colonized before admission to ICU (mainly in the rectum). Moreover, the typing data strongly suggested that the Enterobacter strains came from endogenous sources ${ }^{95}$.

In summary, available data suggest that rectal colonization with Enterabacter spp. and $P$. aeruginosa frequently occurs in critically ill patients, but secondary colonization of the upper respiratory tract seems infrequent. The relevance of rectal colonization and the rectopulmonary route of colonization in the pathogenesis of VAP remains largely undetermined.

\section{Exogenous}

Data on the role of exogenous sources in colonization and infection of ICU patients are derived mainly from case-reports and descriptions of outbreaks. Sinks ${ }^{96-99}$, distilled water systems ${ }^{100}$, faucets ${ }^{101}$, tube-feeding formulas ${ }^{102,103}$ and ventilator circuits ${ }^{104}$ have been reported as exogenous sources of PPMO, causing outbreaks of nosocomial infections. Especially $P$. aeruginosa possess the ability to proliferate in aqueous sources throughout the hospital. In addition, patients themselves are major reservoirs of nosocomial pathogens ${ }^{105}$. It is unlikely that airborne transmission contributes to the spread of staphylococci and Gramnegative bacilli, ${ }^{9105}$. Therefore, transfer of these pathogens most probably accurs via hands of nursing and medicall staff or equipment (stethoscopes, blood pressure meters etc. $)^{74.76 .99}$. Direct inaculation of pathogens into the tracheobronchial tree from contaminated hands is possible during manipulation of ventilator circuits or tubes $^{91}$. If the tracheobronchial epithelium is able to bind pathogens, colonization and subsequent pneumonia may occur. This hypothesis is supported by studies reporting lower incidences of nosocomial infections after increasing handwashing frequency, use of gloves or antiseptic handwashing products ${ }^{106-108}$.

The importance of cross-colonization in nonepidemic situations has rarely been studied. Olson and coworkers ${ }^{75}$ addressed this issue in a study of 270 patients admitted to a medicall-surgical ICU ward; 63 (23\%) patients were colonized with P. aeruginosa on admission, $33(16 \%)$ acquired colonization and twelve $(36 \%)$ of 33 acquisitions resulted from cross-colonization. Simillar results were reported by Allen and colleagues ${ }^{10 s}$, In contrast, Chetchotisakd et al ${ }^{110}$ did not find an 
important role of cross-colonization in ICU. In a prospective survellance in five $1 \mathrm{CU}$ s during six months, they only found $14(10 \%)$ of 137 isolates of bacteria (P. aeruginosa, Eschenchia coli. Klebsiella pneumoniae, Enterobacter cioacae and enterococci) cultured from patients with suspected infection to be acquired by cross-colonization. Alhough molecular biotyping methods were used to determine identity of isolates, it is very likely that the true incidence of cross-colonization has been underestimated. Only a single isolate from a suspected site of infection was analyzed (the tip of the iceberg), without including isolates from colonized patients. Our group studied the influence of nonabsorbable antimicrobial prophylaxis of the stomach and oropharynx on respiratory colonization among patients in two idertical ICUs. Prophylaxis was given to half of the patients in one of the ICUs, while the other half served as a control group. Patients treated in the other ICU, where no prophylaxis was given, formed the second control group. Colonization rates were lowest among patients who received prophylaxis. However, control patients who were treated in the same ward as patients receiving prophylaxis were found to be colonized less frequently and if anything. later than controls in the ward where no prophylaxis was given. These findings strongly suggest that crosscolonization occurs frequently ${ }^{11 !}$.

In summary, the few data available do suggest that cross-colonization, mainly from patient to patient via hands of health care workers or equipment, may be an important route of colonization, even in endemic situations.

\section{Prevention of VAP}

In recent years, guidelines for the prevention of hospital-acquired or nosocomial pneumonia have been formulated by the American Thoracic Society (ATS) ${ }^{112}$ and by the Centers for Disease Control and Prevention (CDC) with the consensus reconmendations of the Hospital Infection Control Practices Advisory Committee $(\mathrm{HICPAC})^{\text {* }}$. (The original texts of both guidelines, concerning the prevention of bacterial pneumonia, are added as addendum it and 2 at the end of this chapter.) Both guidellines incorporate general recommendations regarding infection control practices that undoubtedy decrease incidences of many infections, including VAP. These recommendations, however, are not specifically directed against VAP. For example, preumococcal and influenza vaccination of at risk populations, handwashing protocols and isolation of patients with multiple resistant respiratory tract pathogens are regarded as: 'currently available preventive strategies with probable efficacy, in the ATS guidelines ${ }^{112}$. Similarly, the CDC guidelines strongly recommend staff education, survellance for bacterial pneumonia in high risk ICU patients and vaccination as general measures. Furthermore, an extensive list of recommendations regarding interruption of transmission of microorganisms from human or inanimate sources to patients is described. These recommendations include sterilization, disinfection and maintenance instructions of ventilator systems. and circuits, and handwashing and barrier precautions ${ }^{78}$. Moreover, a number of 
recommendations have been added that are strongly advocated for all hospitals and that are viewed as effective on the basis of strong suggestive evidence. even though comparative sludies have not been done. These recommendations include: discontinuation of enteral-tube feeding and removal of endotracheal andior enteral tubes as soon as possible, routine verification of appropriate placement of the feeding tube, and routine assessment of the patient's intestinal motility, clearing of secretions above the inflated fube cuff prior to tube removal or moving of the tube ${ }^{78}$.

In table 2.4 the recommendations aiming specifically to prevent VAP from both guidelines are listed. The value categorization for each recommendation of both guidelines are included as are the results of the relevant studies evaluating the beneficial effects of these recommendations. Only studies with the occurrence of VAP as endpoint of intervention are considered. The number of patients and episodes of VAP reported by the studies on a certain recommendation have been grouped, and from these data the relative risk reduction (RRR) with $95 \%$ confidence intervals $(95 \%$ Cl) were calculated. The RRR is the reduction of adverse events achieved by a treatment, expressed as a proportion of the controll rate. In other words, it is the difference in event rates between the control and treatment groups, divided by the event rate in the control group. A RRR of 0 means that the incidence of VAP is equal in control and treatment group, while a RRR of 1.00 means that no VAP occurred in the treatment group. So, the closer the RRR approaches 1.00, the more effective the treatment. The use of RRR is sometimes criticized because it does not reflect the magnitude of the risk without therapy (i.e., baseline risk) ${ }^{184,185}$. However, because the incidences of VAP in the control groups of the analyzed studies vary considerably due to differences in the diagnostic criteria, the use of a relative risk measure is desirable. From the incidence rates, also the number of patients needed to treat. (NNT) in onder to prevent one VAP were calculated and presented (Table 2.4). The NNT is a measure that incorporates both the baseline risk and the magnitude of the risk reduction ${ }^{184}$. The preventive strategies most frequently studied and their contribution to the understanding of the pathogenesis of VAP are described in the following section.

\section{Selective decontamination of the digestive tract}

In 1971 the concept of colonization resistance was proposed by van der Waaij. who suggested a beneficial effect of the anaerobic flora in resisting colonization by aerobic Gram-negatiwe bacilli in the digestive tract ${ }^{186}$. Many infections are caused by these enteric bacilli. Selective decontamination of the digestive tract (SDD) was developed to selectively eliminate the aerobic Gram negative bacill and yeasts from the digestive tract, leaving the amaerobic flora unaffected. The first clinical studies with this technique were performed in granulocytopenic patients and showed favourable results ${ }^{187}$. In the early 80 s, Stoutenbeek and coworkers adapted the technique for ICU patients ${ }^{113}$. 


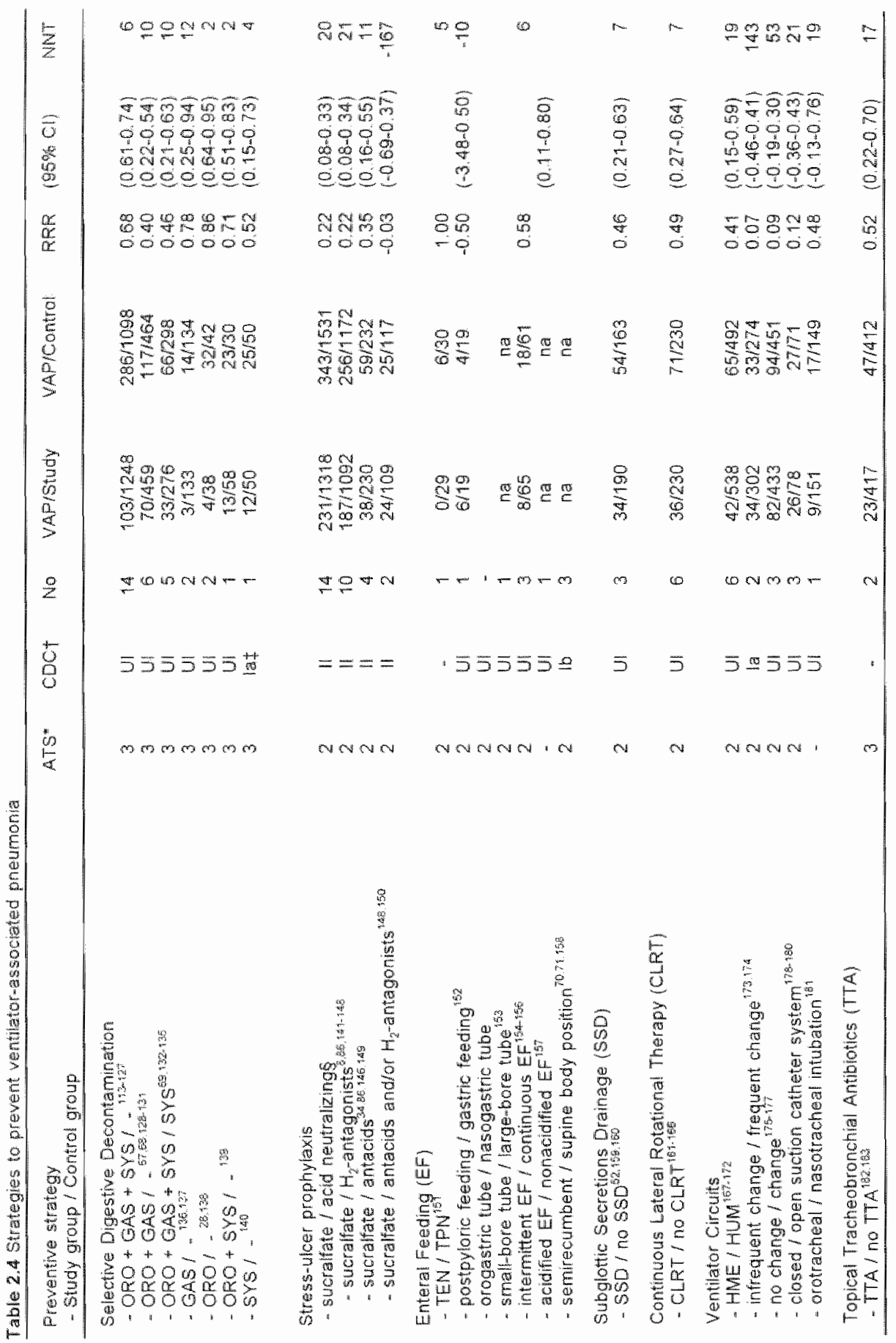


ATS, American Thoracic Soctety: CDC, Centers for Disease Control and Prewention; No, number of stugies VAP, number of Ventilatormssociated Pneunomias, Study. number of study patients Control number of

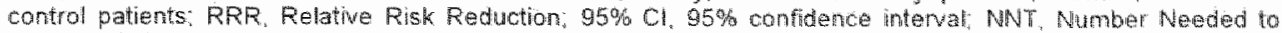
Treat; ORO, Oropharyngeal decontamination: GAS. Gastrointestinal decontanunation, SYS. Systenic antiblatics; TEN. Total Enteral Nutrition: TPN. Total Parenteral Wutrition, na, nodence of VAP not anelyzed, HWE, Heat and Moisture Exchangers; Helly, Heated Humidiers

* Citegorization of preventive strategies by the ATS statement: (1) currenty avalable and probabiy effectwe for specific populations and indications; (2) currently avaibable, promising in efficacy and being used by some hosplalis on a regular basis; (3) currently avalable but of unpiroven walue, being used in investigational studies, or on imited dinical basis and (4) unproven regimens, still being evalualed. 150 e Addendum 1).

i Categorization of CDC recommendations: Ia, strongly recommended for all hasplals and strongly supported by wefl-designed experimenal or epidemiologic studies; ib, strongly recommended for all hospitals and verved as effective by expents in the field and a consensus of HicPAC based on shrong rationale and suggestive evidence, even hough defnitive scientific studies may not have been done; suggested for implementation in many hospitals, recommendations may be supported by suggestive climical or epidemblogic studies, strong theoretical rationale, or defintive studies applicable so some but not al hosplals: UI (UNRESOLVED ISSUE), no recommendation, practices for which insultictent evidence or consensus regarding efficacy exists. (See Addendum 2 ).

* The recommendation NOT to acmimister systemic antimicrobial agents to prevent nosocomial pneumonia was categorized la.

8. The resultsis of studies comparing sucrabate to acid neutraizing prophylaxis hawe all been combined. Data on the comparisons with antacids and $\mathrm{H}_{2}$-antagonists have also been analyzed separately for which the data of two studies ${ }^{96.140}$ comparing sucralfate with antacids and with $\mathrm{H}_{2}$-antagonists were split up. in two other studies ${ }^{42.150}$ this was not possibte because control patients received antacids andor law antagonists. and separate analyses were not performed or reported.

The full concept of SDD aims to eradicate microorganisms from the intestine, the stomach and the oropharynx by nonabsorbable antibiotics, which are combined with systemic antibiotic prophylaxis during the first days of ICU admission. In the SDD regimen the combination of colistin and an aminoglycoside are generally used both of which are effective against Gram-negative bacilli and $S$ aureus. Moreover, both agents are nonabsorbable and do not affect the anaerobic: intestinal flora. Amphotericin B was added to prevent overgrowth with yeasts and systemic prophylaxis to prevent early infections. Since the introduction of this preventive strategy, dozens of studies in a variety of ICU populations have been performed $28,67-69,113-122,125-140,188$. However, SDD has some potential drawbacks such as antibiotic resistance of Gram-negative bacteria and the occurrence or selection of resistant Gram-positive microorganisms. Although a number of studies reported no increased incidences of resistant bacteria $144,118,120,125,126,130-132,138,139$, overgrowth and even infections with Gram-positive bacteria, resistant to the amtibiotics used for SDD, have been reported in several trials ${ }^{65-69,119,121,122,128,134,137,189.191}$, as were increased colonization and infection rates due to Gram-negative resistant bacteria ${ }^{115,119,121,122,191}$. Moreover, the lack of cost-benefill analyses and of beneficial effects on mortality rates have further limited the widespread use of SDD ${ }^{12}$.

\section{Meta-analyses of SDD}

Up till now six meta-analyses of SDD studies have been published, all six with comparable results. They all conclude that SDD decreases the incidence of VAP caused by aerobic Gram-negative bacteria with RRRs ranging from 0.40 to 0.78 However, mortality rates are largely unaffected (RRR ranging from 0.06 to $0.13)^{192-197}$. The authors of four of the six meta-analyses, therefore, state that the routine use of SDD cannot be recommended ${ }^{192,194-196}$. The Selective Deconta- 
mination of the Digestive Tract Trialists Collaborative Group have performed two meta-analyses. After the first one they concluded that: "...definite conclusions about the effect of prophylaxis on mortality cannot be drawn despite the large number of trials available... ${ }^{193}$. In contrast, after the second meta-analysis they recommend the use of a combination of topical and systemic antibiotic prophylaxis to reduce overall mortality in critically ill patients. The RRR of all regimens of SDD together was 0.06 , for the studies using topical and systemic antibiotics it amounted to $0.15^{197}$.

Although meta-anallyses are attractive in many ways, there appear to be major problems with interpretation. Due to publication bias and many other biases that may be introduced in the process of locating, selecting, and combining studies, the findings of meta-analyses may be misleading. For instance, should meta-analyses include unpublished siudies; is the literature search to be restricted to the English language; should triallists be contacted for individual patient data? Specifically with regard to SDD, one wonders whether the results of studies with different SDD regimens, different definitions of the diagnosis of VAP and various study designs can be pooled. Therefore, the findings of the meta-analyses on SDD need to be interpreted with caution.

\section{The full regimen of SDD}

Unfortunately, the full regimen of SDD does not help to elucidate the pathogenesis of VAP. Since SDD aims to modulate colonization at three sites: the oropharynx stomach and intestine in combination with systemic prophylaxis, it has remained unclear which part of SDD prevents VAP. The first study of Stoutenbeek and coworkers addressed this topic. In a prospective open trial they consecutively compared three prophylactic antibiotic regimens (intestinal decontamination $n=17$. oropharyngeal and intestinal decontamination $n=25$, oropharyngeal and intestinal decontamination combined with systemic antibiotics $n=63$ ) with an historical control group who did not receive any prophylaxis $(n=59)$. They concluded that intestinal decontamination alone had no effect on infection rates. The addition of oropharyngeal decontamination effectively prevented secondary pneumonia. Finally, the additive effect of systemic prophylaxis (cefotaxime $50-100 \mathrm{mg} / \mathrm{kg} / \mathrm{day}$ iv, from arrival to ICU until no more pathogens were isolated from oropharynx or respiratory tract), prevented primary pneumonia ${ }^{13.198}$. However, this was a nonrandomized, open study with relatively few patients per group and the diagnosis of pneumonia was not established by bronchoscopic techniques. Nevertheless, the full regimen of SDD was propagated as the method of choice for infection prevention, and since then only a few studies amalyzed the relevance of the various individual parts of SDD.

The full regimen of SDD (including oropharyngeal and intestinal decontamination and systemic prophylaxis) was studied in at least 14 trials $^{113-122,125-127,188}$ with VAP or respiratory tract infections as endpoint (Table 2.4). Only two of these had a double-blind placebo-controlled design ${ }^{17,121}$. Nine reported beneficial effects on incidences of VAP $14,115,118,121,125$ or all respiratory tract infections ${ }^{13,15,119,127}$. Both 
double-blind studies, however, did not. The overall RRR of VAP in these 14 trials was $0.68(95 \%$ Cl: $0.61-0.74)$ with a NNT of 6 .

\section{SDD without systemic prophylaxis}

The effect of selective decontamination of oropharynx, stomach and intestines per se has been determined in 11 studies. In six of these no systemic prophylaxis was employed $^{67.68 .128 .131}$, while in the other five studies all patients (study and control) received systemic prophylaxis ${ }^{69,132-135}$.

Half of the six studies on the effect of SDD without systemic prophylaxis reported beneficial effects on incidences of VAP. For instance, Korinec et al studied 123 neurosurgical patients in a randomized, double-blind, placebocontrolled design and found incidences of VAP, diagnosed by bronchoscopy, of $24 \%$ in SDD and $42 \%$ in control patients ( $p<0.04$ ). With a similar study design, comparable results were found by Quinio and coworkers ${ }^{128}$ in 148 multiple trauma patients on mechanical ventilation with incidences of VAP of $25 \%$ in SDD treated patients and $51 \%$ in controls $(p=0.01)$. Furthermore, Unertl et al. ${ }^{130}$ in a randomized study among 39 neurologic patients reported incidences of VAP of $5 \%$ in SDD and $45 \%$ in control patients ( $p<0.01$ ). In contrast no differences in the incidences of VAP, diagnosed by 'blind' protected specimen brush between study groups ( $27 \%$ in SDD group vs. $26 \%$ in control group) were found in 61 patients in a medical-surgical $1 \mathrm{CU}^{57}$. Gastinne and coworkers ${ }^{68}$ also failed to find beneficial effects of SDD in 445 mechanically ventilated patients admitted to medical ICUs. Pneumonia was diagnosed in $26(12 \%)$ of 220 SDD treated patients and in 33 $(15 \%)$ of 225 control patients. Finally, in addition to these two randamized, doubleblind, placebo-controlled trials, Flaherty and coworkers ${ }^{129}$ studied 107 cardiac surgery patients. Randomization was performed by alternating treatment in 2 wk periods to either oropharyngeal and gastrointestinal application of polymyxin, gentamicin and nystatin or sucralfate for stress-ulcer prophylaxis. One out of 51 patients treated with SDD and five out of 56 patients receiving sucralfate developed pneumonia.

Among the five trials in which all patients recewed systemic prophylaxis, no beneficial effects were reported by the four with a double-blind and placebocontrolled design ${ }^{69,133-135}$. In the study by Hartenauer and coworkers ${ }^{132}$ who included 200 conseculive patients in a cross-over controlled trial "the incidence of VAP was $10 \%$ in study and $46 \%$ in control patients.

In summary, the effects of oropharyngeal and gastrointestinal decontamination per se are doubtful since half of the studies report beneficial effects on incidences of VAP, while no difference in incidence rates were found in the other three. Moreover, the five studies in which all patients (study and control) received systemic prophylaxis suggest that oropharyngeal and gastrointestinal decontamination have only limited additional effect to systemic antibiotics. The RRR of VAP, as calculated from the combined results of these 11 studies is $0.42195 \%$ CI: 0.28-0.53) with a NNT of 10 . 


\section{Gastrointestinal decontamination}

The effects of gastrointestinal decontamination on incidences of VAP have been evaluated in only three studies ${ }^{136,137,189}$. Brun-Buisson et al $^{437}$ administered neomycin, polymyxin $E$, and nalidixic acid in liquid form through the nasogastric tube without systemic prophylaxis or oropharyngeal paste to control a nosocomial outbreak of intestinal colonization and infection with multiresistant Enterobacteriaceae. Although the outbreak was controlled successfully, intestinal decontamination did not reduce the number of nosocomial infections: the incidence of pneumonia was $8.3 \%$ in the treated group and $14.4 \%$ in the control group. In another study, none of 97 patienis receiving intestinal decontamination developed VAP (diagnosed with quantitative cultures of protected specimen brush), compared with eight of 84 control patients $(p<0.05)^{136}$. Finally, Cerra and coworkers ${ }^{139}$ reported a decrease in the overall incidence of infections which almost reached statistical significance $(p=0.08)$. Unfortunately, the incidence of VAP was not reported.

In summary, gastrointestinal decontamination alone seems to have a beneficial effect on overall infection rates, but the influence on incidences of VAP remains unclear with one positive and one negative study. Combination of the results of the studies by Brun-Buisson and Godard yields a RRR of $0.78(95 \% \mathrm{Cl}: 0.25-0.94)$ with a NNT of $12(95 \% \mathrm{Cl}: 7-43)$. The width of the $95 \%$ confidence intervals of RRR and NNT is indicative for the necessity to carry out more studies.

\section{Oropharyngeal decontamination}

The effects of oropharyngeal decontamination alone have been assessed in two studies. In a double-blind trial Pugin et $a_{1 .}{ }^{28}$ randomized 52 patients to receive either a solution of polymyxin $\mathrm{B}$, neomycin and vancomycin or placebo in the retropharynx. Colonization with aerobic Gram-negative bacteria was significantly reduced in oropharynx and stomach, resulting in a relative risk reduction for VAP of 0.79 . Rodriquez-Roldan et al. ${ }^{438}$ used an oropharyngeal paste containing tobraw mycin, amphotericin $B$ and polymyxin $E$. Decontamination of oropharynx and trachea was established in 10 of 13 patients receiving active medication, none of whom developed pneumonia. In contrast, $11(73 \%)$ of 15 patients receiving placebo medication developed pneumonia. Attention must be drawn to the high incidences of VAP in the control groups of both studies $78 \%$ and $73 \%$ respectively), which is probably due to the use of clinical and microbiological criteria, rather than bronchoscopic techniques, to diagnose VAP. Unfortunately, since gastric colonization was significantly decreased in the study by Pugin et al. ${ }^{28}$, their findings do not elucidate the relative importance of gastric and oropharyngeal colonization in the pathogenesis of VAP.

Oropharyngeal decontamination in combination with systemic prophylaxis was studied by Abele-Horn and colleagues ${ }^{139}$ in a randomized, controlled trial. The incidences of both primary (0\% vs. 33\%; $<<0.001)$ and secondary pneumonia ( $22 \%$ vs. $47 \% ; p<0.001)$, were reduced significantly in study patients. Pneumonia was diagnosed by quantitative cultures of tracheal aspirates $\left(>10^{4} \mathrm{cfu} / \mathrm{ml}\right)$. Again, 
the total incidence of pneumonia (primary and secondary) in the control group was very high $(77 \%)$.

Another way to achieve oropharyngeal decontamination, not using antibiotics is the use of chlorhexidine. For instance, an oral rinse of $0.12 \%$ chlorhexidine reduced the incidence of respiratory tract infections anong 353 cardio-surgical patients from $9 \%$ in control patients $103 \%$ in patients receiving oropharyngeal decontamination with chlorhexidine ${ }^{199}$. This difference was mainly due to a reduction of infections with Gram-negative pathogens. However, it is not known to what extent prolonged application of chlorhexidine will affect oral, oesophageal and gastric mucosa in critically ill ICU patients, and neither is the risk of chlorhexidine resistance after long-term application ${ }^{200-202}$.

\section{Systemic prophylaxis}

Prevention of pneumonia with systemic antibiotics was attempted first by Lepper and coworkers in $1954^{203}$. No reduction of tracheal colonization or infection was achieved in 72 tracheotomized poliomyelitis patients. Two other studies from that time also failed to modify the incidence of infection by antibiotic prophylaxis in unconscious patients ${ }^{204}$ and patients with acute heart failure ${ }^{205}$. Moreover, the latter two studies reported selection of resistant pathogens. It was not until 1989 that another attempt was made to prevent pneumonia with systemic antibiotics. Then, Mandelli and coworkers randomized 570 ICU patients, half of which were intubated, to receive either $24 \mathrm{~h}$ of cefoxitin, penicillin $\mathrm{G}$ or no prophylaxis. The incidence of early-onset pneumonia (primary outcome measure) was $6.1 \%$ in patients receiving antibiotics and $7.2 \%$ for controls ${ }^{206}$. More recently, in a prospective, randomized, but not double-blind or placebo-controlled, trial in 100 mechanically ventilated patients with coma, systemic antibiotic prophylaxis with cefuroxime (two 1,500 $\mathrm{mg}$ doses) was studied. Prophylaxis resulted in a lower incidence of VAP compared with the control group (12/50 (24\%) vs. $25 / 50(50 \%)$; $p=0.007$; RRR 0.52\%. This difference was due to a reduction in the episades of early-onset VAP in the cefuroxime group $(8 / 50(16 \%)$ vs. $18 / 50(36 \%) ; p=0.022$; RRR 0.56), while the incidences of late-onset VAP were comparable ( $8 \%$ vs. $14 \%)^{140}$. The impact of this regimen on antibiotic susceptibility of pathogens causing VAP remains to be established

The results of all the trials with various SDD regimens and of the meta-analyses indicate that SDD reduces the incidence of VAP, leaves mortality rates unaffected and increases the accurrence of multiple resistant pathogens. Several contro. versies remain. For instance, although never proven, the beneficial effects of SDD appear to be related to the criteria used to diagnose pheumonia. Incidences of VAP in contral groups range from $18.5 \%^{125}$ to $85.1 \%^{116}$ when the SDD regimen significantly prevented VAP, and ranged from $5.3 \%{ }^{120}$ to $25.8 \%{ }^{67}$ when no significant effects were found. A considerable part of the studies reporting favourable results of SDD are poorly designed (nonrandomized, unblinded, historical control groups, nonbronchoscopic diagnosis of VAP etc.). Moreover, the 
preventive effects of the individual parts of SDD are not fully elucidated. The systemic antibiotics within the regimen seem to prevent early-onset, but not lateonset VAP. The effects of gastrointestinal decontamination are scarcely investigated and remain unclear with one positive and one negative trial. Since the role of gastric colonization and the gastropulmonary route of colonization is regarded unimportant based on the evidence from studies on the pathogenesis of VAP, the additive effect of gastrointestinal decontamination may be considered limited. Although the influence of oropharyngeal decontamination also was studied infrequently, the results at hand are very promising, especially with regard to lateonset VAP. Oropharyngeal decontamination alone or in combination with $24 \mathrm{~h}$ of systemic antibiotic prophylaxis has RRRs that are even higher than those of the full regimen of SDD, although only a fraction of the antibiotics used in the full regimen are needed. Moreover, the data from the sequence studies strongly point towards an important role for oropharyngeal colonization in the pathogenesis of VAP

\section{Stress-ulcer prophylaxis}

Since critically ill patients on mechanical ventilation are prone to develop gastritis and/or gastric ulcers ${ }^{141,142,207}$, stress-ulcer prophylaxis is routinely provided. In this respect, gastric acidity may be reduced by neutralization of gastric acid (antacids) or by inhibition of acid production ( $\mathrm{H}_{2}$-antagonists, $\mathrm{H}^{+} \mathrm{K}^{+}$ATPase inhibitors), both of which will decrease the natural protection against bacterial overgrowth. In contrast to these agents, sucralfate has been claimed to prevent stress-ulcers without influencing gastric acidity ${ }^{208}$. Theoretically, patients who receive sucralfate should maintain lower intragastric $\mathrm{pH}$ values compared with patients receiving antacids or $\mathrm{H}_{2}$-antagonists. Moreover, in vitro studies demonstrated bactericidal and bacteriostatic effects of sucralfate, mainly at high $\mathrm{pH}$ values ${ }^{209-211}$. As a result, sucralfate should prevent bacterial overgrowth in the stomach and, according to the alleged importance of the gastropulmonary route of colonization, also reduce the incidence of VAP. Administration of sucralfate for stress-ulcer prophylaxis has, indeed, shown favourable effects on the incidence of VAP in two studies ${ }^{36,148}$. However, there are 12 studies showing no significant effect on the incidence of VAP ${ }^{3.44 .141-147,148,150.212}$. In a prospective, randomized, double-blind study by our group in which patients were stratified on the basis of their initial gastric $\mathrm{pH}$, sucralfate was compared with a fixed dosage of antacids ${ }^{34}$. Intragastric acidity was determined by means of a computerized intragastric pH monitoring. No significant differences in median $\mathrm{pH}$ values were observed. Colonization rates in the stomach, the oropharynx and the trachea and the incidence of VAP were comparable in both treatment groups. However, patients colonized with PPMO in the stomach had higher median $\mathrm{pH}$ values compared with noncolonized patients.

This underscores the relation between intragastric acidity and gastric colonization ${ }^{34}$. The observation that sucralfate does not prevent VAP could be due to the fact that sucralfate did not decrease intragastric $\mathrm{pH}$ levels below 3.5 in most of the studies ${ }^{8 *}$. Our findings were confirmed by two other double-blind studies 
testing the preventive effects of sucralfate. A study by Artigas and coworkers ${ }^{143}$, comparing sucralfate and ranitidine, was terminated prematurely after inclusion of 146 patients because no difference in incidence of VAP between both study groups was observed (published only in abstract form). In addition, similar data were reported in a prospective, double-blind, placebo-controlled study in which 1200 patients had been randomized to either sucralfate or ranitidine ${ }^{8}$.

\section{Modulation of enteral feeding}

In addition to stress-ulcer prophylaxis, enteral feeding, which usually has a pH of 6 , may reduce intragastric acidity due to dilutional alkalization. If enteral feeding would be a risk factor for the development of VAP, this would support the role of the gastropulmonary route of colonization in the pathogenesis of VAP. Several studies showed high rates of gastric colonization in patients receiving enteral feeding ${ }^{213,214}$. Hence, modulation of enteral feeding has been used as a possible approach to interrupt the gastropulmonary route of colonization and to reduce the incidence of VAP. In this regard, intermittent enteral feeding would be expected to be superior to continuous enteral feeding, as gastric acidity increases during the periods that feeding is discontinued. Three studies have been performed with conflicting results. Lee et al ${ }^{154}$ reported lower intragastric $\mathrm{pH}$ values and incidence rates of VAP in patients receiving intermittent enteral feeding compared with a historical control group who received continuous enteral feeding. Skiest and coworkers ${ }^{155}$ randomized 16 patients to either intermittent enteral feeding or continuous enteral feeding for a five day periad. They concluded that intermittent enteral feeding resulted in lower postfasting gastric $\mathrm{pH}$ and lower rates of gastric colonization with pathogenic organisms. No patients developed nosocomial pneumonia during the five-day study period. Our group ${ }^{156}$ failed to find a beneficial effeci of intermittent enteral feeding on intragastric acidity, gastric colonization and incidence of VAP in a prospective randomized trial in which intermittent enteral feeding and continuous enteral feeding were compared in 60 patients.

The effects of acidified ( $\mathrm{pH} 3.5$ ) enteral feeding ${ }^{15 \%}$ and postpyloric feeding ${ }^{152}$ were determined in one study each. In both studies favourable results with respect to intragastric acidity and gastric colonization were found. However, respiratory tract colonization was not studied and the numbers of patients included were too small to evaluate incidences of VAP. Large, prospective randomized and controlled trials are needed to confirm the effects of modulation of enteral feeding as a means to decrease the incidence of VAP ${ }^{215}$.

\section{Subglottic secretions drainage}

During mechanical ventilation subglottic secretions and oropharyngeal fluids may accumulate above the inflated endotracheal cuff. This fluid will contain large amounts of microorganisms. Microaspiration of these secretions along the tracheal cuff results in colonization and possibly infection of the lower respiratory tract. Drainage of subglottic secretions with specifically designed devices may, therefore, 
prevent VAP ${ }^{219}$. This has been evaluated in wo studies in which bronchoscopic techniques were applied for the diagnosis of VAP. In a prospective randomized study, manual intermittent subglottic secretion drainage was associated with a lower incidence of nosocomial pneumonia (13\%) compared with control patients $(26 \%)^{139}$. In another prospective randomized study, continuous subglottic suctioning was studied in 76 patients of whom $18 \%$ developed VAP, compared with a $33 \%$ incidence of VAP in control patients $(n=77)$. Interestingly, the reduction was caused by a lower incidence of VAP in the first week of ventilation (earlyonset VAP), but not of latemonset VAP ${ }^{160}$. In a recent risk factor analysis among 83 patients, failure of the continuous aspiration of subglottic secretions technique did not influence the development of pneumonia among patients undergoing antibiotic treatment $(33.0 \%$ vs. $38.5 \% ; p>0.20)$, but was strongly associated with pneumonia $(42.1 \% \mathrm{ws}, 8.3 \%, p<0.01)$ among intubated patients not receiving antibiotics ${ }^{52}$. In contrast. Girou and colleagues ${ }^{217}$ concluded from a bacteriological evaluation in 14 patients that the use of continuous subglottic aspiration associated with semirecumbent position does not modify tracheal colonization.

\section{Body position}

Enteral feeding increases gastric volume, especially in critically ill patients who often have reduced gastric motility and delayed gastric emptying due to the underlying disease or as a result of medication ${ }^{21.8}$. In these patients the risk of aspiration of gastric contents is enhanced. Torres and coworkers ${ }^{71}$ analyzed gastroesophageal reflux in ventilated patients on enteral feeding, using radioactive labelled gastric nutrition. They found that patients in supine position had higher counts of radioactivity in endobronchial secretions compared with patients treated in a semirecumbent position. Moreover, the length of time in supine position appeared to be a risk factor for aspiration of gastric contents. In a follow-up study in 15 patients by the same group, it was concluded that gastroesophageal reflux occurs irrespective of body position, and that a semirecumbent position does not protect completely from gastroesophageal reflux ${ }^{158}$. These data confirmed the results reported by lbañez et al. ${ }^{70}$ in a similar study. In addition to the patients posilion, gastroesophageal reflux may be influenced by the presence and even size of the nasogastric tube ${ }^{70,153,158}$. In none of these studies were the effects on incidences of VAP evaluated.

\section{Continuous lateral rotational therapy}

Another potentially effective approach is continuous lateral rotational therapy. Continuous rotation is thought to stimulate mobilization of respiratory tract secretions, thereby preventing the development of atelectasis and pneumonia. Six studies compared continuous lateral rotational therapy with turning by mursing staff every $2 \mathrm{~h}$ in conventional beds. All studies reported reduced incidences of pneumonia in patients on rotation ${ }^{161-166}$, the difference being statistically significant in only one of these ${ }^{163}$. 


\section{Other preventive strategies}

The use of topical tracheobronchial antibiotics, administered either as an aerosol (polymyxin B, gentamicin) or in a solution (gentamicin, colistin), has been attempted to reduce the incidence of pneumonia caused by Gram-negative bacteria, especially $P$. aeruginosa. Four studies, performed between 1973 and 1975 , of which two had a controlled design ${ }^{\$ 2.183}$, reported significantly decreased incidences of upper airway colonization and/or pneumonia caused by these microorganisms ${ }^{182,183,219.220}$. However, the study by Klastersky and colleagues ${ }^{183}$ using endotracheal administration of gentamicin, reported that bacteria isolated from treated patients were slightly more resistant to gentamicin than microorganisms recovered from respiratory tract of controls. Feeley and coworkers $^{220}$ used an aerosol with polymyxin B which successfully prevented $P$. aeruginosa pneumonia. However, the incidence of pneumonia caused by polymyxin-resistant microorganisms (Pseudomonas spp. and Serratia spp.) and intrinsically resistant pathogens (Proteus spp. Flavobacterium spp. and Streptococcus faecalis) was high, and the overall mortality rate for patients with acquired pneumonia was $64 \%{ }^{220}$. Furthermore, a randomized study in 30 thermally injured patients with inhalation injury, using aerosolized gentamicin, reported no differences in the number of patients with infiltrates on chest radiographs, necessity of mechanical ventilation and pulmonary complications between study and control patients ${ }^{221}$. Moreover, continued use of gentamicin in this study resulted in resistant strains of Klebsiella and Pseudomonas emerging in burn wounds and sputum ${ }^{221}$. Because of the frequent occurrence of infection with highly resistant bacieria and the lack of (or even negative) effect on mortality, the use of topical tracheobronchial antibiotics was not recommended. More recently, Rouby and coworkers $^{222}$ performed a nonrandomized study in which 347 consecutive patients receiving intratracheal colistin were compared with a historical control group of 251 patients. The incidences of pneumonia caused by Gram-negative bacteria and polymicrobial pneumonia were significantly reduced in the group receiving colistin. Mortality was comparable in both groups and no increase in the number of VAP caused by colistin-resistant microorganisms was observed

Bacterial contamination of the ventilator tubing circuit may predispose to the development of VAP ${ }^{104}$. Frequent changing of these circuits (including in-line suction catheters, heat and moisture exchangers and heated humidifiers) may be beneficial to decrease the bacterial burden. On the other hand, frequent manipulation of ventilator tubing circuits may lead to introduction of nosocomial pathogens. Five studies have addressed the effects of lengthening intervals between circuit changes on colonization of the patient and circuits, and incidence of VAP ${ }^{173-177}$. They all concluded that decreasing the frequency of ventilator circuit changes did not increase incidences of VAP or patient and circuit colonization. Therefore, substantial reductions in the costs of mechanical ventilation can be obtained without apparent adverse effect. Studies using a closed-suction catheter system for endotracheal suctioning found similar incidences of pneumonia compared with the open-suction system with single-use sterile suction 
catheters $^{178-130}$. Finally, during mechanical ventilation heating and humidifying inspired gases is necessary. Healed humidifiers are used most frequently, but these cause accumulation of water in the circuit that may become colonized with bacteria $^{104}$. Heat and moisture exchangers are a possible atternative in which the formation of condensate in ventilation circuits is avoided due to the combination of humidification with antimicrobial filtering properties. However, heat and moisture exchangers falled to reduce the incidence of pneumonia in five studies comparing both methods ${ }^{167-171}$. Kirton and coworkers ${ }^{172}$ are the only group to report a significant reduction in late-onset WAP, but not early-onset VAP, With the use of heat and moisture exchangers. In gemeral, the influence of the ventilator circuit and secretion management strategies on VAP rates is limited ${ }^{223}$.

\section{Conclusions}

Critical assessment of the various studies on the prevention of VAP is very difficult. Due to the small numbers of patients included in the studies, heterogeneous ICU populations, and differences in diagnostic criteria and quallity of the studies a comparison of the studies is hampered. Moreover, some strategies have only been studied scarcely. Ideally, preventive strategies are studied in well designed multicienter trials, including large numbers of comparable patients. However, for mechanically ventilated patients this is next to impossible in view of the numbers of patients, differences in severity of illness, causes for ICU admission and differences in treatment.

Nevertheless, two guidelines have been formulated for the prevention of VAP The vallidation of the preventive strateglies as described in the guidelines for the prevention of hospital-acquired or nosocomial pneumonia by ATS $^{112}$ and CDC $^{78}$ are to some extent comparable although different ways of categorization have been used (Table 2.4). Still, some remarkable differences exist. The validations of the use of SDD for prevention of VAP are comparable. The ATS considers SDD of unproven value (category 3) while the CDC regards SDD as a practice for which insufficient evidence is available (category UI). However, according to the principles of Evidence Based Medicine, the application of topical antibiotic prophylaxis is the only strategy proven to be effective for prevention of VAP and has been studied most frequently. The validations of both guidelines most likely account for all types of SDD since no information is provided regarding the various individual parts of SDD, with the exception of the administration of systemic antimicrobial agents, a strategy which was NOT recommended in the CDC guidelines (category la).

The use of sucralfate for stress-ulcer prophylaxis is considered promising by ATS (category 2) and is suggested for implementation in many hospitals (category 11) by CDC. However, the majority of clinical trials and all randomized, doubleblind, placebo-controlled trials, have failed to show favourable effects of sucralfate on the incidence of VAP. Moreover, sucralfate was found to be inferior to ranitidine with regard to the prevention of clinically important gastrointestinal bleeding. It must be pointed out that the guidelines under analysis date back to the time 
before the results of the randomized, double-blind, placebo-controlled trials were available. In the revisions of these guidelines the recommendations regarding the use of sucralfate undoubtedly will be adjusted.

The various preventive strategies associated with enteral feeding and (prevention of) gastric aspiration are thought to be efficacious by ATS (category 2), although very few studies on their efficacy have been performed, the results of which are controversial. The CDC considers these regimens to be an unresolved issue (category UI), although a semirecumbent body position during mechanical ventilation is strongly recommended (category lb) by this institution even though definitive scientific evidence for this recommendation is lacking.

Subglottic secretions drainage and continuous lateral rotational therapy both are regarded as: 'promising in efficacy and being used by some hospitals on a regular basis' by ATS (category 2), which is in line with the scientific evidence. Presently, a number of studies are being executed on subglottic secretions drainage which will provide additional information on its efficacy in the near future. Continuous lateral rotational therapy has only been studied in selected patient populations and favourable results on incidence rates of VAP have been reported. The mechanism for this beneficial effect remains to be established. Whether this technique is applicable to large numbers of patients is also unclear, especially since the associated costs of this technique are considerable. The CDC considers both these strategies to be practices for which insufficient evidence or consensus regarding efficacy exists (calegory Uil).

Although preventive strategies aimed at ventilator circuits are categorized as promising in efficacy (category 2) by the ATS, the accessory guidelines in fact indicate that the proposed measures (i.e., heat and moisture exchangers, frequent, infrequent or no change of circuits and closed-suction systems) do not seem to add to the risk of developing VAP. This is congruent with the categorization of the CDC (category UI).

Topical tracheobronchial antibiotics are not included in the guidelines of the CDC and considered to be of unproven value by ATS.

In conclusion, the strategies which have proven to be the most effective for preventing VAP are not part of both guidelines due to side-effects and a lack of effect on secondary outcome parameters. The use of sucralfate is the only measure that is recommended in both guidelines although scientific evidence indicates that this method is ineffective. The CDC classifies modulation of enteral feeding, subglottic secretions drainage and continuous lateral rotational therapy for the prevention of VAP as unresolved issues. The ATS does recommend enteral feeding associated strategies although only few and inconclusive studies have been performed, while subglottic secretions drainage and continuous lateral rotational therapy are recommended which is in line with the promising results of the first clinical trials. The guidelines concerning ventilator circuit associated strategies from both ATS and CDC are in line although the categorizations are different. 


\section{References}

1. Vircent JL, Bhari Di, Shter PM. Bruning HA. Whit J. NicolaswChamoin MH. Wolf M, Spencer RC, and wismerm. The prevalence of nosocomial infection in intensive care units in Eutope. Resuths of the european prevalence of infection in intensive care (EP|C) study. Jourial of the American Medical Association $1995,274: 639-644$.

2. Kapptein I, Schulgen $G$, Beyer U. Belger $K$, Sichumacher $M$, and Daschner FD. Prolongation of hospital stay and extra costs due to ventilator-associated puneumonia in an intensive care unit. European Journal of Clinical Microbiology and infacious Diseases $1992 ; 1: 504-502$

3. Fagon JY, Chastre J, Hance Ad, Montravers P. Noware $A_{\text {, }}$ and Giber $C$. Nosocomial pneumonia in ventilated patients: a cohort situdy evaluating attributable mortality and hospital stay. Amertican Joumal of Hedicine 1993; 94 $281-288$

4. Langer $M$. Cigada $M$, Mandelli $M$, Mosconi $P$. and Tognoni $G$. Early-onsel pneumonia: a multicenter study in intensive care units. Intensive Care Medicine 1987; 13:342-346.

5. Centers for Disease Control (CDC) CDC definitions for nosocomial infections, 1988. American Review of Respiratory Disease 1989: $139: 1058-1059$

6. Pugin J, Auckenthater R. Mili $\mathbb{N}_{\text {, Janssens JP. }}$ Lew PD, and Suter PM. Diagnosis of ventilator-associated pheumonia by bacteriologic anaysis of bronchoscopic and nombronchoscapic "blind" bronchoakeoler lavagie fluid. American Reviow of Rospiratory Disease $1991: 4: 43: 1121-1129$

Pingleton SK. Fagon IY, and Leper KV, Jr. Patient selection for clinical investigation of ventilatorassociated pneumonia: criteria for evaluating diagnostic techniques. Chest 1992 $1025535-5565$.

Cook D, Guyatt O, Marshall \&, Leasa D. Fuller H. Hail R. Peters S, Rutledge F. Griffith L, Mclellan A, Wood $G$. Kirby $A$, and The Canadian Critical Care Trials Group. A comparison of sucralfate and ranitidine for the prevention of upper gastrointestinal bleeding in patients reguring mechanical wentuation. New Engtand Joumel of Medicine 1998; 338 : $791-797$

9. Chastre $\rfloor$ and Fagon $J Y$. Invasive diagnostic lesting should be routinely used to manage wentiated patients with suspected preumonia. American Jaumal of Respiratory and Critical Car Medicine 1994: 150.570-574

10. Wimberley $M$, Faling $L J$, and Bartlett $\mathrm{J} G \mathrm{~A}$ fiberoptic bronchoscopy technique to obtain uncontaminated lower aiway secretions for bacterial culure. American Rewiew of Respiratony Disease $1979 ; 119: 337-343$

11. Apte NM, Karnad DR, Medhekar TP, Tiwe GH, Morye S, and Bhave GG Gastric colonization and pneumonia in intubated critically ill patients receiving stress ulcer prophylaxis: a randomized, controlled triat Critical Care Medicine $1992,20.590 .593$

12. Kingston GW. Phang PT, and Leathley MU. Increased incidence of nosocomial pneumonia in mechanically ventilated patients with subclinical aspiration. American Joumal of Surgery $199 \% ; 161: 589-592$

13. Craven DE, Kunches LM, Kilinsky $W$, Lichtenberg DA, Make BJ, and MoCabe WR. Risk factors for pneumonia and fatality in pattents receiving continuous mechanical ventilation. American Review of Respiratory Disease $1986 ; 133: 792-796$

14. Reusser P, Zimmerli W. Scheldegger D. Marbet $G$, Buser $M$, and Gyr K Role of gastric colonization in nosocomial infections and endotoxemia: a prospective study in neura surgical patients on mechanical ventation. Journat of Mneclious Diseases $1989 ; 160$. $414-421$

15. Rodriguez UL, Gibbons KJ, Btzer LG, Dechert RE, Steinberg RE, and Flint LM. Pneumonia: Incidence, risk factors, and outcome in injured patients. Jounal of Trauma 1991:31:907-914.

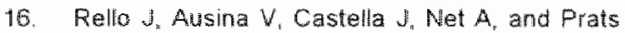
G. Nosocomial respiratory tract infections in multiple trauma patients: influence of level of consciousness with implications for therapy. Chest $1992 ; 102525-529$ 
17. de Latorre FJ, Pont T, Furrer A, Rossello J, Palomar M, and Planas M. Pattern of tracheal colonization during mechanical wentilation. American Joumat of Respiratory and Crilical Care Hedicine 1995: 152:1028 1033

18. Fiddam-Green RG and Baker S. Nosocomial pmeumonia in the critically ill product of aspiw ration or translocation? Cnitical Care Medicine $1991 ; 19: 763-769$.

19. Beck-Sague C. Sinkowitz R, chinn R, Vargo J. Kaler W, and Jarvis $W$. Risk factors for ventilator-associated pneumonia in surgical intensive-care-umit patients. Infaction Control and Hospital Epiolemiology 1994; 17:374-376.

20. Fagon J, Chastre J, Domart $Y$, Troullet J, Pierre J, Darne $C$, and Gibert C. Nosocomial pneumonia in patients receiving continuous mechanical ventilation prospective analysis of 52 episodes with use of a protected specimen brush and quantitative collture technique. American Review of Respiratory Disease $1989 ; 139: 877.884$

21. Rello ${ }^{\prime}$, Quintana $E$, Ausina $W_{\text {, Castella }}$ Luquin: M, Net A, and Prats $G$. Incidence, etiology, and ouccome of nosocomial pneumonia in mechanically ventillated patients. Chest $1991 ; 100: 439-444$.

22. Papazian L, Bregeon $F$ "Thirion $X$, Gregoire $R$, Saux $P$, Denis $J$,Perin $G$, Charrel $J$, Dumon J.

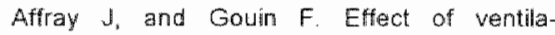
tor-associated pneumonia on mortality and morbidity. Amenican Jounal of Respiratory and Critical Care Mediche 1996; 154:91-97.

23. Garrouste-Orgeas M. Chevet S, Arlet G, Marie 0 . Rouveau $M_{*}$ Popoff $M$, and schlemmer $B$. Oropharyngeal or gastric colomization and nosocomial pneumonia in adult intensive care unit patients. A prospectwe study based on genomic DNA analysis. American Journal of Respiratory and Critical Care Medicine 1997; $156: 1647-1655$

24. Fagon JW, Chastre J, Wuagnat A, Troullet fll, Novara $A$, and Gibert C. Nosocomial pneumonia and mortalty among patients in intensive care units. Jouma of the American Medical Association 1996; 275:866-669

25. Torres A, Aznar R, Gatell JM, diménez $P$, Gonzallez J. Ferrer $A$, Celis $F$, and Rodri-
Qteaz-Roisin R Incidende, risk, and prognos factors of rosocomial pneumonia in mechentcally ventlitated patients. Amerioan Roview of Respiratory Disease 1990: $142,523-528$.

26. Bonten MUN, Sailard CA Van Tiel FH, Smets HGW. van der Ceest S, and Stobbarmgh EE. The stomach is not a source fot colonization of the upper respiratory tract and pneumonia in icu patients. Chest 1994, 105:878m884

27. Kollef $M H$, Vom Herz B. Prentice D, Shapiro SD. Silver P. Sildohn R, and Trowiltion E. Patient transportation from infensiwe care increases the risk of deweloping wentilator-associated pheumonia Chast 199 \% $112: 765-773$

28. Pugin J. Auckenthaler $R$, Lew DP, and Sutar PM. Oropharyngeal decomtamination dacreases incidence of ventilator-associated pheumonia: a randomized, placebo-controlled, doulble-blind clinical trial Joumal of the Amorican Medical Association 1991; 265:2704-2710.

29. Rello J, Ausina: $V$, Ricart M, Castella J and Prats G. Impact of prewious antimicrobial therapy on the whology and outcome of wentlator-associated pneumonia. Chest 1993; 104: $1230-1235$.

30. Doré P, Robert R, Grollier G. Rouffineau $J$ Lanquetot H, Charrière JM, and Fauchere JL incidence of anaerobes in ventillator-associated pnetumonia with use of a protected specimen brush. American Journal of Respiratony and Critical Care Medicine $1996,153: 1292-1298$.

31. Rello J, Quntana $E$, Ausina $V$, Puzo $C_{\text {, Nat }} A_{\text {. }}$ and Prats $Q$. Risk factors for Staphylococcus aureus pasocomial pneumonia in critically ill patients. American Roview of Rospiratory Disease $1990: 42: 1320 \cdot 1324$

32. Espersen fin and Gabrielsen J. Pneumonia due to Staphyococcus aureus during mechanical ventilation Joumal of infectious Diseases $1981: 144: 19-23$

33. Rello W, Torres A, Ricart M, Valles J. Conzalez $J$ Artigas $A$ and Rodriguez-Roisin Re Ventilator-associated preumonia by Staphyococous aureus: comparison of metticilln-resistant and methicillin-sensitive episodes. American Jour nal of Respiraiory and Critical Care Medicine 1994: $150: 1545-1549$ 
34. Bonten WM Gailiard CH, wan der Geest $s$.

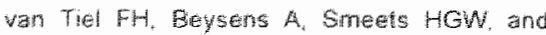
Stobberingh EE. The role of intagastric acioty and stress wher proptylaxis on colonization and intection in mechanically ventilated patents. H stratified, randomized. double blind stucy of sucralfatic versus antacids. American Jounat of Respiratory and Critical Care Medicine 1985; 152: 1829 1834

35. Cook Qu and Koller MH. Risk factors for ICU-âcuired pnewimonita. Jownal of the American Medical Association 1998; 279. $1605 \cdot 1606$

36. Chever $S$, Hemmer M, Carlet J, Langer M and European Cooperative Group on Nosocomial Preumonia. Incidence and risk factors of pneumonia acquired in intensive care units. resutts trom multicenter prospective study or 996 patients. Intensive Care Madicine 1993 19:256-264

37. Celis R, Torres A, Gatell JM, Ameta M Rodriguez-Roisin $R$, and Agusti-Vidal A NosoComial pneumonia: a multivariate analysis of risk and prognosis. Ches $1988 ; 93318-324$

38. Amtonelli $M$. Moro M. Capelli $O$, de Blasi RA. D'Errica RR, Conti $G$, Bufi $M$, and Gasparetto A. Risk Factors for early orset pneumonia in irauma patients. Chest 1994; 105:224-228.

39. Mosconi P, Langer M, Cigada M, and Mandeli M. Epidemiology and risk factors of pneumonia in critically ill patients. European Journal of Epideniology 1991; 7:320-327.

40. Cunnion KM, Weber DJ, Broadhead WE. Harison LC, Pieper CF, and Rutala WA. Risk factors for nosocomial pheumonia: Comparing adult critical-care populations. Anovican Journal of Respinatory and Critical Care Medicine $1996,153-158-162$

4. Langer M, Mosconis, Cigada M, and Mandelli M. Long-tem respiratory support and risk of pmenmonia in critically ill patients. American Rewow of Respiratory Disease 1989: 140. $302-305$

42. Kropec A, Schulgen $G_{n}$ Just $H_{4}$ Geiger $K$ Sohumachar M, and Daschner $F$. Scoring system for nosocomial pheumonia in ICUS hemsike Care Medicine 1996: 22*1155-1161.
43. Josh 4 , Locanto $A R$ and Hemory BH. A predictive risk index for nosocomial pneumonia in the intensive care unit. Anmarican Jounal of Medicine 1952 $93: 135-42$.

44. Rello J. Ausina V. Ricart $M_{6}$ Puzo $C$, Quntana $E_{2}$ Net $A$ and Prais $G$. Risk tactors for infection by $P$ sevdomonas aeruginosa in pationts with ventilator-associated pnieumonia iniensive Care Medicine 1994: 20:193-198.

45. Trouillet $M L$, Chastre J, Juagnat $A$, Jaly-Guillou ML. Combaux D, Dombret MC, and Giber C. Ventilator-associated pneurnonia caused by potentially drug-resistant bacteria. American Journal of Respiratory and Critical Care Medicine 1998; 157:531-539.

46. Kollef MH. Wentilatormassociated pretimonia. A multivariate analysis. Journal of the Amencan Medical Association 1993; 270:1365-1970.

47. Talon D, Mulin $B$. Rouget $C$, Baily $P$, Thouverex $M_{\text {, and }}$ Viel JF. Risks and routes for ventilator-associated pneumonia with Pseudomonas deruginosa. Anmencan Joumal of Respiratory and Critical Care Medicine 1998: 157:978-984

48. Barabar J, Comea H. Mariscall D. Gallego M. Valles $J_{n}$ and Rello $J$. Risk factors for infection by Acinelobacter baumannis in intubated patients with nosocomial pheumonia. Chest 1997; 112:1050-1054

49. Elatrous $S$, Boujdaria $R_{n}$ and Merghli $S$ Incidence and risk factors of vertilator-associated pneumonia: a onemyear prospective survey, Clin Intensive Care 1996, 7 . $276-281$

50. Pingleton sk. Enterall nutrition as a risk factor for nosocomial pneumonia. European Joumal of Chmical Microbiology and Infectious Diseases 1908: 8:51-55.

51. Torres A, Gatell MP, Aznar E, EL-Ebiary M. Puig de la Bellacasa J Gonzalez J. Ferrer $M$, and Rodriguez-Roisim $R$. Re-intubation increases the risk of nosocomial pneumonia in patients needing mechanical ventiation. American Journal of Respuratory and Critica Care Medicine $1995: 152: 137 \cdot 141$

52. Rello J, Sonora R. Jubert P. Artiglas A, Rue M. and Vallés w. Preumonia in indubated patients. 
role of respiratory ainway care. Aryerican Jour hal of Respiratory and Chitical Care Mechome $1996,1541111-115$

53. Rello J Ricart M, Ausina $V$, Net A and Prats Q. Pheumonia due to Haemophifus infuenzae amonig mechanically wentilated patients: inctdence, outcome, and risk factors, chest 1992 . $102: 1562-1565$

54. Rouby JJ, Laurent P. Gosnach M. Cambau E. Lamars $G$, Zouaoui $A$, Leguillou J J Bodin $L_{m}$ Khac TD, Marsant $C$. Poete P. Nicolas MH Jarlier $V$, and Viars $P$. Risk factors and clinical relevance of rosocomial maxillary sinusitis in the critically ill American Joumal of Respiralory and Critical Care Medicine 1994: 150: $776-783$

55. Bert $F$ and Lambert-Zechorsky $N$. Sinusitis in mechanically ventilated patients and its role in the pathogenesis of nosocomial pneumonia. European Journal of Climical Microbiology and Infectious Diseases 1996, 15,533544 .

56. Dreyfuss D and Saumon G. From wentilator-induced lung injury to muttiple argan dysfunction? Intensive Care Medicine 1998: 24. $102-104$

57. Sutsky AS and Tremblay LN. Multiple system orgam failure is mechanical ventilation a contributing factor? American Joumal of Respim ratory and Critical Care Medicine 1998; 157 : 1721.1725

Johanson WG, Jr. Pierce AK, Sanford JP, and Thomas GD. Nosocomal respinatory infections with Gram-negative bactli the signilicance of coonization of the respiratory tract. Arrnats of Intarna Hedicne 1972;,77,701-706.

Johamsion WG, Pierce AK, and Siantord .JP. Changing pharyngeal bacterial flora of rospitalized patients. New Engrend Journal of Medicine 1969: 281:1137-1140

60. Penn $R$, Sanders $W$, and Sanders $C$. Coloriziation of the onopharymx wh gram-negattive barilli: A major antucedent to nasocomial phenmonie. American Jownal of Infection Controt $1981,925-34$

61. Ramphal $R$. Small PM. Shands WW. Fischlsctweiger $W$, and Small PA. Adherence of Pseudomonas aerughosa to tracheal cells infured by intuenza infoction or by endotracheal intubation. Infection and immunology $1980,27,614019$

62. Wiederman MS, Merrill WW. Fertanti RD. pagano KM, pamer LB, and Reynolds $M Y$ Nutritional status and bacteral binding in the lower respiratory tract in patents with chonic tracheosumy. Annals of Intemal Mudine $198,100,795-300$

63. Woods DE. Role of fibronectin in the pathogenesis of Grammegative bacillary pheumonia. Rev Jfect Dis 1987; 9:\$386-8390

64. Estes RJ and Meduri GU. The pathogenesis of wentalutor-associated pneumona: I. Mechanisms of bacterial transcolonization and airway imoculation Intensive Cars Medicine 1995:21: $365-383$.

65. Bonten MJM, Gailard CA, van Tiel FH, van den Geest $S$, and Stobberingh EE, Colonization and infection with Enterococcus fagcalls in intensive care units: the role of antimicrobial agents. Antmicrobral Agents and ChemoWhapy 1995; 39:2783-2786

66. Sijpkens YWJ, Buurke Ed, Ulrich $C$, and van Asselt Gu. Enterococcus faecalls colonisation and endocardits in five intensive care patients as late sequelae of selective decontamination intersive Care Medicine 1995, 21,231-234

67. Wiener J, ltokazu $G$, Nathan $C$, Kabins SA and Weinstein RA. A randomized double-blind placebo-controlled trial of selective theontamination in a medicalusurgical intensivis care unit Clinical Infactious Diseases 1995, 20 $861-867$

68. Gastinine H, Wolff M. Crelatour F. Faurisson F and Chavret S. A controlled trial in intensive care units of selective decontamination of the digestive tract with nonalbsoribebla antibiotics. New England Joumal of Medicine 1992.326 $594-599$

69. Hammond JMJ, Potgieter PD, Saunders GL, and Forder $A_{A}$. Double-blind study of selective decontamination of the digestive tract in intensive care. Lancel 1992, 340,5-9.

70. Ibañez $\Downarrow$. Peñafiel A. Raurich JM. Marse P Worda $R$, and Mata $F$. Gastroesophageal reflux in intubated patients receving enterat rutrition 
eftect of supine and semitecumbent positions. $J$ Parent Enteral Nutr 1962: 16:419-422.

71. Torres A, Serra-Batles d Ros E, Plen C Puig da la Bellacasa J. Cobos $A$. Lomenta $F$, and Rodriguez-Foisin R. Putmonary aspiation of gastric contents in patients receilurg mechanicel yentilation. the effect of body position. Annats of Internal Medicine 192: 118 $540-543$

72. Torres $A$, El-Ebiary Manzález J, Ferrer M, Puin de la Bellacasa J. Gené A, Martos A and Rodriguex-Roisim Rastric and pharyngeal fora in nosocomial pneumonia acquired during mechanical ventilation. American Rewew of Respiralory Disease 1993; 148:352-357.

73. Hillman KM, Riordan T, OFarrell SM, and Tabagchali $S$. Colonization of the gastric contents in critically il patients. Crithal Care Madicine 1982; 10444447

74. Noone MR, PIIt TL, Bedder M, Hewhet AM. and Rogers KB. Pseudomonas aturginosa colonisation in an intensive therapy unit: role of cross infection and host factors. British Medical Jownal 1983; 286:341-344

75. Otson $\mathrm{B}$. Weinstein $\mathrm{R}$, Nathan $\mathrm{C}$, Chamberlin

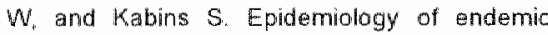
Pseudomonas aswghosa: why infection control efforts have failed. Journal of hnfectious Diseases $1984: 150: 808-816$

76. Widmer AF, Wenzel RP, Trilla A, Bale MJ, Jones RN, and Doebbeling BN. Outbreak of

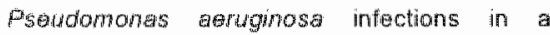
surgical intersive care unit probable transmission via hands of a health care worker. Chincal Intections Diseases 1993; 16:372 375.

77. Bonten MJM and Weinstein RA. The role of colonzation in the pathogenesis of mosocomial infections. Infoction Control and Hosptal Epidemiology $1996,47.193-200$

78. Tablan OC. Andersion LU, Arden NH. Breiman RF, Butler JC, MCNeil MM, and Hospital Infection Control Practices Advisory Committee (HCPAC). Guideline for preventiom of noso. comiay pneumonia. Part I. Issuesion prevention of nosocomial pneumonia, 1994. Infection Comirol and Hospital Epidemialogy 1994; 15 : $588-627$
79. Pyt TL. Epidemiological typing of Pseudo monas aeruginosa. European Joumal of Chint. cal Morobioigy and Intectious Diseases 1988: $7: 238-247$

80. Mastow JUl, Mulligan ME, and Arbeit RO. Molecular epidemiology: application of con temporary techniques to the typing of microm organisms. Chmicat Infectious Diseases 1993: $17: 153-164$

81. Tompkins LS. The use of molecular methods in infectious diseases. New England Jounal of Medicine 1992; $327: 1290-1297$

82. Bonten MUM, Gaillard CA, van Tiel FH, wan der Geest $S$, and Stobberingh EE. A typical case of cross-acquisition? The importance of genotypic characterization of bacterial strains. Infection Control and Hospital Epidemiology 1995: 16:415.416

83. du Moulin GC, Paterson DG. Hedley-Whyte J. and Lisbon A. Aspiration of gastric bacteria in antacid-treated patients: A frequent cause of postoperative colonisation of the airway. Lancet 1982; 1:242-245.

84. Garvey BM, MeCambley JA, and Tuxen DV. Effects of gastric alkalization on bacterial colonization in critically ill patients Critical Care Medicine 1989; 17:211-216.

85. Cade JF, McOwal $E$, Siganporia $R$, Keightey $C$. Presneill $J$, and Sinickas $V$. Uncertain rele. vance of gastric colonization in the seriously ill. Intenswe Care Medicine 1992:18:210-217.

80. Prodhom $G$, Latumberger $P$, Koenfer J, Blum

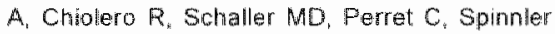
$O$, Blondel $J$ siegrist $H$, Saghafi L, Blanc $D$, and Francioli P. Nosocomial pneumonia in mechanically wentiated patients receiving antacid, ranitidine, or sucralfate as prophylaxis for stress ulcer a randomised controlled trial. Annals of infemat Medicine 1994: 120 : $653-662$

87. Daschner FD, Reuschenbach $K$, Pfisterer $J$, Kappstein I. Vogel W, Krieg $N$, and Just H. Der Enflup von Strepulcusprophylaxe auf die Haufigkeit einer Beatmuirgspneumonie Anaesthesist 1987: $36: 9-18$.

88. Inglis TJJ Sherratt MU, Sproat $\lfloor J$ Gibson $1 S$, and Hawkey PM. Gastroduodenal dysfunction 
and bacterial colorization of the wentilated lung Larnce: 1993; 341.914-913

89. Bonten MuM Gaitard $C A$ de Leew PW, and Stobbeingh EE. Riole of colonization of the upper intestinal tract in the pathogenesis of venillator-associated pneumonia. Clinical infechous Diseases 1997:24309-319

90. Niedermar MS and Crawen DE. Editonial response: Devising strategies for prewenting nosocomial preumonia - should we ignore the stomach? Clinical Imectious Diseases 1997 . $24: 320-323$

91. Sanderson PJ. Colomisation of the trachea in ventilated patients: What is the bacterial pathway? Jounnal of Hospital hnection 1983; 4 $15-18$

92. Inglis TJU, Sproat Lu, Sherratt MJ, Hawkey PM Gibson JS, and Shah MV. Gastroduodenail dysfunction as a cause of gastric bacterial overgrowth in patients undergoing mechanical ventilation of the llungs. Brit I Anaesthesia 1992: 68:499-502

93. Kropec A, Huebner $d$, Riffel $M$, Bayer $U$. Benzing $A$, Geiger $K$, and Daschner FD. Exogenous or endogenous reservoirs of nosocomial Pselidomanas aerliginasa and Staphylococcus aureus infections in a surgical intensive care unit. Intensive Care Medicine 1993: 19:161-165

94. Murthy SK, Baltch Alm, Smith RP, Desjardin EK, Hammer MC, Conroy $S V$, and Michetsen PB. Oropharyngeal and fecal carriage of Pseudomonas anuginosa in hospital patients. Nournat of Clinical Microbiology $1989 ; 27 \cdot 35-40$

95. Flyn DMt, Weinstern RA, Nathan C, Gastom $M A$, and Kabins SA. Patients endogennus flora as the source of "nosocomial" Enterobacter in cardiac surgery. Joumal of Intectious Diseases 1987; $156 ; 363-368$

96. Teres $D_{1}$ Schweers $P$. Bushnelt $L S_{n}$ Hedey-Whyte $J_{4}$ and Feingold DS Sources of Pseudontanas aeruginosa infection in a resplratonysurgicall intensive-fherapy unit. Lancet $1973,415-417$

97. Whitby JL and Rampling A. Pseudomomas aeruginosa contamination in domestic and hospital environment lancel 1972 ; $115-17$.
98. Grifth Su, Nathan C, Selander RK Chamberlin W. Gordon $S$, Kabins $\mathrm{S}$. and Wentsin R

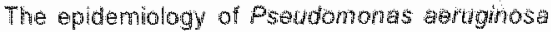
in oncology patients in a general hospital. Jourrat of mrectiots Diseases 1989 160: $1030-1036$

99. Bert $F$, Maubec E. Brumeau $B$, Berry fond Lambert-Zeohorsky N. Multiresistant Pseudomomas aenginosa outbreak associated whth contaminated tap water in a neurosurgary intersive care unit. Joumal of Mosputal hrecfion $1998 ; 39: 53-62$

100. Favaro MS, Carson LA, Bond MM, and Petersen NJ. Pseudomonas arughosa: growth in distilled water from hospitals. Solence $1971 ; 173: 836-838$.

101. Grumdmann H, Kropec A, Hartung D. Bemer R. and Daschner F. Pseudomonas aruginos in a neonatal intersive care urit: reservoirs and ecology of the nosocomiall pathogen. Jourmal of infectious Diseases 1993; 168:943-947

102. Thum J, Crossley $K$, Gerdts $M_{1}$ Maki $M_{\text {, and }}$ Wohnson $\downarrow$ Enteral hyperalimentation as a source of nosocomial infection. Jounal of Hospilal Infection 1990: 15:203-217

103. Levy $\Downarrow$, wan Laethem $Y$, Vertaegen $G$, Perpête C. Butzler JP, and Wenzel RP. Contalminated enteral nutrition solutions as a cause of nosocomial bloodstream infection: a study using plasmid fingerprinting I Parant Enteral Nurr 1989: $13228-234$

104. Craven DE, Soulante TA, and Makd BJ. Conta minated condensate in mechanical vertilator citcuits: a risk factor for nosoconial pneumonia? American Revion of Respiratory Drsease $1984 ; 129625-628$

105. Maki DG Control of colonzation and transmission of pathogenic bacteria in the hospital. Annals of Internal Madicine 1978; 90 . $777-780$

106. Mayer JA, Oubbent PM, Miller M, Burkett PA, and Chapman SW. Increasing handwashing in an intenslve care unit Infection control 1985 . $7: 259-262$

107. Maki DG, Avarado C., Hassiemer CA and Zhz MA. Relation of the inarimate hospital environment to endemic nosocomial infection 
Now Englano Journar of Mediche 1902, 307. $1662-1566$.

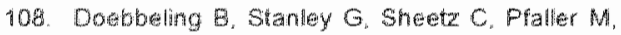
Houston $\mathrm{H}_{\mathrm{i}}$ Annis L. Lit and wenzel R Com parafye efficacy of atternative handwashing agents reducing nosocomial intections in intensive care units. New England Lowmal of Medicing $1992,327: 88-93$.

109. Allen K. Bartzokas C, Granam R, Gibson M. and Gibertson A. Acquisition of endemic Pseudomonas asruginose on an intersive therapy unill Journal of Hospital Intection 1987: $10: 156 \% 164$

110. Chetchotisakd P. Phelps CL, and Hartsten Al. Assessment of bacterial crossuramismion as a cause of intections in patients in intensive care units Climical infactious Diseases 1994; $18,929-937$

111. Bonten MM, Gaillard CA, Johanson WO, at. wan Tel FH, Smeets HOW, van der Geest 5 , and Stobberingh EE. Colonization in patients receiving and not receiving topical antimicrobial prophylaxis. American Jounnal of Respiratory and Critical Care Medicine 1994: 150 : $1332-1340$

112. Americain Thoracic Society Ad Hoc Committee of the Solentific Assembly on Microbiology, Tuberculosis, and Pulmonary mfections. Hospital-acquired pheumonia in adults: Diagnosis, assessment of severity, initial antinnicrobial therapy and preventative strategies. A consensus stattement. American Joumal of Respiralory and Cnical Caxe Madicine 1995. 153 $17+1-4725$

113. Stoutenbek $C$, van Saene $H$, Miranda D. and Zandstra $D$. The effect of selective decontamination of the digestive tract on colonzation and infection rate in mutiple trauma patients. mtensiva Cure Medicine 1934; 10:185-192

114. Macke D. van Hetum W. Schumburg T. Kuiper $\mathbb{E}_{\text {and }}$ Knape P. Prevention of infection in bums: preiminary experience with selectice decontamination of the digestime tract in pationts whith extensive injuries. Journat of Trauma $1992 ; 32: 570-575$.

115. Blair P, Rowlands BU, Lowry K. Webo $H$. Armstrong $P$, and Smilie $J$ Selective decontamination of the digestive tract a stratified, randomized, prospectve study in a mixed intensiwe care unit. Suggery 1991.110 $303-310$

116. Aards 3 . van Dalen R. Clasener H. Festen J. van Ller Ha and Vollaard $E$. Antibiotic prophy laxis of respitatory tract infection in meche nically ventifted patients: a prospective. binded, randomized trial of the eftect of a novel regimen. Chest 1991: 100: $783-791$

117. Hammond JMJ and Potgieter PD. Is thefe a role for selective decontamination of the diges. tive tract in primarly infected patients in the lCU? Anasthesia and intensive Care 1995 $23 \cdot 168-174$

118. Kerver $A$, Rommes $\rfloor$ Mevissen-Varhage $E$, Hulstat $P$. Vos A, Verhoef J, and Wittebol $P$ Prevention of colonization and infection in critically ill patients: a prospective randomized study. Crifical Care Medicine 1988; 16 $1087-1093$

119. Uirich $\mathrm{C}$, Harnck-de Weerd JE, Bakker $\mathrm{NC}$, Jacz $K$, Doornbos $L$, and de Ridder $V A$. Selective decontamination of the digestive tract with norfoxacin in the prevention of lCU-acquired imfections: a prospective randomized study. Intensiwe Care Medicine $1989 ; 15,424-431$

120. Cockerill FR. III, Muller SR. Anhalt JP, Marsh HAM, Fandi MB. Mucha P. Gillespie DJ, Ilstrup DM, Larson-keller JJ, and Thompson RL. Prevention of infection in critically in patients by selective diecontamination of the digestive lract Annals of Internal Medicine 1992, 117 $545-553$.

121. Roche LA, Martin MU, Pita S, Paz J, Seco C. Margusino $L$, Willanueva $R$, and Durăn MT Prevention of nosocomial infection in critically ill patients by selective decontamination of the digestive tract a rantomized whuble blind, placebo-controlled study. Intensve Care Medicne 1992, 18:398,404

122. Verwaesil $C$, Verhaegen J. Ferdinande $P$. Schetz $M$, wan den Berghe $G$, Verbist $L$, and Lauwers $P$. Randomized, controlled trial of selective digestive decontamination in 600 mechanically ventilated pattems in a multidisciplinary intensive care unit. Critical Care Madicine 1997; 25:63-71. 
123. Edionial Stress ulcer prophylaxis in critically he patients. Lancel 1989; if: 1255-1256

124. Mason CM. Nelson S, and Summer WR Bacterial colonization. pathogenesis and clinical significance. Immunology and Adergy Cliniss of Worth Amanica 1993; 13.93-108.

125. Winter R. Humphreys H, Pick A, MacGowan A, Wrilates $S$, and Speller D. A comtrolled trial of selective decontamination of the digestive tract in intensive carte and its effect on nosocomial infection. Joumal of Anbmicrobjar Chemon herapy $1992: 30: 73-87$.

126. Ledingham M, Eastaway AT Mckay $1 C$ Alcock SR, MCDonalds JC, and Ramsay $\mathrm{G}$. Triple regimens of selective decontamination of the digestive tract, systemic cefotaxime, and microbiologicall surveillance for prevention of acquired infection in intensive care. Lancet $1988: 785-790$

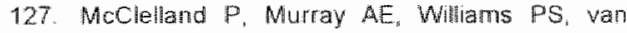
Saene HKF, Gilbertson AA, Mostafa SM, and Bone JM. Reducing sepsis in stwere combined acute renal and respiratory failure by selective decontamination of the digestive tract. Cratical Care Mediche 1990; 18:935*939:

128. Qunio $B$. Albanèse J, Bues-Charbit M. Viviand $X_{n}$ and Martin $C$. Selective decontamination of the digestive tract in multiple trauma patients. Chest 1996: 109:765-772.

129. Flahery' J, Nathan $\mathrm{C}$, Kabins $\mathrm{S}$, and Weinstein R. Pilot trial of selective decontamination for prewention of bacterial infection in an intersive cara unit Jounal of hrectious Diseases 1990; $162: 1393-1397$

130. Unert $K$. Ruckdeschel $G$. Selbmann $H K$ Jensen U, Forst $M$, Lenhart FP, and Peter $K$. Prewention of colonization and respiratory infections in long-term ventilated patients by local antinicrobial prophylaxis, Intensive care Medicine $1987,13: 106-113$

131. Konnek AM. Laisne MJ, Micolas MH. Raskine L. Deroun $V$ and Sanson-Lepors MJ Selective decontamination of the digestive tract in neurosurgical intensive care unit patients: a double-blind, randomized, placebo-controlled study Crithal Care Medicine 1993, 21 $1466+1473$
132. Hertenauer U, Thatg 5 , Diemer $W$, Lawin $P$ Fwegeler W Kehrel R, and Rituteld W. Eftect of sellectue flora stupresion on colonitation. infection, and mortalis in critcally ill patients: one-year, prospective consecutive study Critical Care Medicina 1991: 19:463-473

133. Ferter M, Tortes $A$, Gonzulaz \&, Pug de la Bellacasa $J$ EHEDrary M. Ron M. Gatell IM. and Rodriguez-Roisin $R$. Utillty of selective digestive decontamination mechanisally ventiated patients. Mnnals of Intemal Medione $1994 ; 120: 389-395$

134. Hammond JMJ, Potgieter PD, and Saunders GL. Selectwe decontamination of the cligestive tract in multiple frauma patients - Is there a role? Results of a prospective double-blind. randomized trial. Cribcal Care Medicine 1994 $22,33-39$

135. Hammond JMN and Potgieter PD. Neurologic disease requiring longterm ventilation. The role of selecthe decontamination of the digestive tract in preventing hosocomial infection. Chest 1993; 104:547-551.

136. Godard J Guillaume C. Reverdy ME. Bachmann $P$, Bui-Xuan $B$, Nageotte $A$, and Motin $\rfloor$ Intestinal decontamination in a polyvalent ICU: a double-bind study. Intonsive Care Medicine 1990; 16:307-311

137. Brun-Buisson C, Legrand P, Rathss A, Richard C. Montravers F, Besbes M. Meakins JL, Soussy Cl, and Lemaire $F$ Intestinat decontamination for control of nosocomial multresistant Gram-negative bacillin: study of an outbreak in an inttensive care unit. Anvers of Internal Mediche 1969; 110.673-861.

138. Rodriguez Roldân UM, Amtha-Cugsta A Lobez A, Carrito A, Garcia $d$ León $d$, and Matthez-Pellis AJ. Prevention of hosocomial lung infection in ventilated patients: Use of an anthmerobial pharyngeal nonabsanbable paste Cnica Care Medione 1990, 18-1239-1242.

139. Abelewtorn N. Datber $A$, Batumiand $A_{n}$ Russwurm W Seyfarth Metzoer 1 , Gleich $P$. and Ruckdeschel $\mathrm{G}$. Decrease in nosocomial pneumonia in wentlated patients by selectives oropharyngea decontamination. intensive Care Medicine 1996: 23:197-195

140. Sirvent JM, Torres A, ElEbiary M Castro $P$. 
de Batle : and Bonet $A$. Protective effot of intravenousy administered cefuroxime against noscocomal pneamona in patients with structural coma Amencan Loumat of Respiratory and Crifical Care Madicine 1997, 45 $1729 \times 1734$

149. Fabian TC, Boucher BA, Croce MA, Kun! DA Janning SW, Cottey $\mathrm{BC}$, and Kudsk KA. Pneumonia and stress ulceration in severely injured patients. A prospective evaluation of the effects of stress ulcer prophylaxis. Archives of surgery 1983; 128:185-192

142. Ben-Menachem T. Fogel R. Patel RV Touchette M, Zarowitz B., Hadzijahic N. Diwine Q. verter J, and Bresalier RS. Prophylaxis for stressurelated gastric hemorhage in the rnedical intensive care unit a randomized, controled, singlemblind study. Annals of Internat Medicine 1994: 121:568-575

143. Artigans $A$, Campilio $M$, Cartiona $A$, Bonsoms $N$, Valles J, and Collaborative $\angle A M G$ Working Group. Nosocomial preumomia and gastrointestinal bleecting in mechanically ventilated patients receiving ranitidina or suctalfate. American Journal of Respiratomy and Critical Care Medicine 1995; 151.A721.

144. Kappstein 1. Schulgen $G$. Friedrich $T$, Hellinger $P$, Benzing $A$, Geiger $K$, and Daschner FD. Incidence of pneumoria in mechanically ventillated patients treated with sucralfate or cimetidine as prophylaxis for stress bleeding: bacteriat colonization of the stomach. American Journal of Medicine 1991: 91(suppl 2A) 1255.4319

145. Eddleston J, Vohra A, Scott $P$. Tooth J Pearson R. McCloy R, Morton A, and Doran B A comparisom of the frequency of stress tiloeration and socondaly pheumonia in sucralfate or ranitidine-freated intensive care unit patients. Critca Care Medicho 1991: 19 $1491-1496$

146. Simms HH, DeMarie E, MoDonald L. Peterson D. Rubinson $A$, and Burchard $\mathrm{KW}$. Role of gastric colonization in the development of pneumonia in critically ill frauma patients: results of a prospective randomized trial. Journat of Truma 1991:31:531-536.

147. Ryan P, Dawson J. Teres $D$. Celoria $G$, and Navab F. Nosocomial pneumonia during stress
Ucer prophylaxis with cimeidine and sucratate. Archives of Surgery 1993 ; 128 $1353-1357$

148. Draks MR, Craven DE, Celli BR, Manning M. Burke RA, Garvin OM, Kunches LM, Farber HW, Wedel SA, and Mccabe WR. Nosocomial pneumonia in intubated pattents given sucratfate as compared with antacids or histamine type 2 blockers: the role of gastric colonisation: New England Journal of Mediche $1987 ; 317 ; 376 m 1382$

149. Tryba M. Risk of acute stress bleeding and nosocomial prewmonia in ventilated intensive care unit patients: sucralfate versus antacids American Joumal of Medicine 1987; B3/suppl 3B) $117-124$

150. Cioffif W, McManus A, Rue L. MI, Mason A, McManus W, and Pruitt $B$, Jir, Comparison of acid neutrahizing and non-acid neutralizing stress ulcer prophylaxis in thermally injured patimts. Joumat of Trauma 1994:36:541-547.

151. Tyler $K D$. Wang $G$. Tyter $S$, and Johnson $W$ Factors affecting reliability and reproducibilty of amplification-based DNA fingerprinting of representatwe bacterial pathogens. Joumal of Climical Microbiology 1997; 35, 339-346

152. Montecalwo MA, Steger KA, Farber HW, Smith BF, Dennis RC, Filzpatrick GF, Pollack SD. Korsberg TZ, Birkett $\mathrm{DH}_{\text {, }}$ and Hisch EF. Nutritional outcome and pneumonia in critical care patients randomized to gastric versus jejunal feedings Critical Care Medicine 1992. $20: 4377-1387$

153. Dotson RQ, Robinson RG, and Pingleton $S K$ Gastroesophageal reflux with nasogastric tubes. Effect of nasogastric tube stze American Joumal of Respiratory and Critical Care Mediche 1994; $1491659-1662$.

154. Lee $B$ Chang RWS, and Jacobs $S$ Intermittent nasogastric feeding: a simple and eftective method ta reduce pneumonia among ventilated ICU patients. Clin Intensive Care 1990; 1 $100-102$

155. Skiest OJ, Khan N. Feld R, and Metersky ML The role of enteral feeding in gastric colonisation: a randomised controlled trial comparing continuous to intermittent enteral feeding in mechanically ventilated patients. Chin 
Intensive Care 1996, $7: 138,1,43$

156. Bonten MUM, Gaillard CA van der Hulst $R$ de Leeuw PW. van der Geest $S$, Stobberingh $E E$. and Soeters PB. intermittenl enteral feeding: The influence on respiratory and digestive tract colonization in mechanically ventilated intensive-care-unit patients. American Joumal of Respiratory and Critical Care Medicne $1996 ; 154,394-399$

157. Heyland D. Bradley $C$, and Mandebl LA. Effect of acidified enteral feedings on gastric colonization in the critically it piatients. Critical Care Medicine 1992; 20:1388-1394.

158. Orazco-Lew M. Torres A, Ferrer M. Phera $C_{0}$

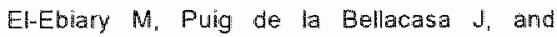
Rodriguez-Roisin R. Semirecumbent position protects from pulmonary aspiration but not completely from gastroesophageal refux in mechanicaly ventillated patients. American Jounal of Respiratory and Critical Cars Medicine 1995; 152:1387-1390.

159. Mahul $P$. Auboyer $C$, Jospe $R$, Ros $A$. Guerin C. El Khouri $Z$. Galliez Mu Dumont $A_{\text {, and }}$ Gaudin O. Prevention of nosocomial pnetimonia in intubated patients: respective role of mechanical subglottic secretions drainage and stress ulcer prophylaxis. Intensive Care Medicine 1992; $1820-25$.

160. Valles J, Artigas A, Rello J, Bonsoms $N$, Fontanals $D_{n}$ Blanch L. Fernandez R, Baighorri $F_{n}$ and Mestre $\downarrow$. Continuous aspiration of subglottic secretions in preventing ventilator-associated pneumonia. Anmals of internal Medicine 1995; 122:179-186

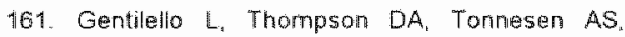
Hernandez D. Kapadia AS, Allen $S J_{\text {. }}$ Houtchens $B A$ and Mirier ME. Eftect of a rolating bed an the incidence of pumonary complications in critically ill patients. Critical Care Medicine 1988; $167783-786$

162 Kelley RE, Vibullesth $S$, Gell $L$, and Dumcan RC. Evaluation of kinetic therapy in the prevention of complications of prolonged bed rest secondary to stroke. Strone 1987 ; 18 : $638-642$

163. Fink MP. Helsmoortel CM. Stein KL Lee PC. and cohn SM. The efficacy of an osicillating bed in the prevention of lower respiratory tract infection in criticaly ill victums of bunt tratmat Chest 1990; $97,132 \times 137$

164. Summer WR, Curry Paponik EF, Nelson S. and Elston $R$. Continuous mechanical turning of intensive carte patients shortians lengh of stay in some diagnostichereted groups. Joumal of Cntal Cane 1989:4:453.

165. deBoisblanc BP, Castro M, Evertet 9 , Grender J. Waker CD. and Summer WR. Effect of air-supported, contimuous, postural oscillation on the risk of early lCU pheumonia in nori. Iraumatic critioal illness. Ches? 1993, 103 $1543-1547$.

166. Whiteman K, Nachtmann L. Kramer D. Sereika $S$, and Bierman $M A$. Effects of continuous lateral rotation therapy on pulmonary complications in liver transiplant patients. American Joumal of Critical Care $1995 ; 4: 133 \cdots 139$.

167. Dreyfuss D, Djedaini $K$, Gros I. Mier L. Te Bourdelles $G$, Cohen $Y$, Estagnasid $P$, Coste $F$, and Baussougant $Y$. Mechanical wentilation with heated humidifiers or heat and moisture exchangers: Effects on pattient colonization and incidence of nosocomial pneumonia. American Journal of Respiratory and Criticas Care Medicine 1995: 151:986-992

168. Branson RD, Davis K, Un, Campabell RS, Johnsom DJ, and Porembka DT. Humidification in the intensive care unit. Prospective study of a new protocol utilizing heated humidification and a hygroscopic condeniser humidifier. Chest 1993; $104: 1800$ - 1805

169. Roustan JP, Kimlen J. Aubras P, Aubas S, and du Cailar $J$. Comparison of hydrophobic heat and maisture exchangens with heated humidifer during prolonged mechancal ventilation. Intensivo Care Hedicino 1998: 18 $97-400$

170. Martin C, Perrin G, Gewaudan MU, Saux P, and Goun F. Heat and roisture exchangers and vaporizing humidifiers in the intensive care unit. Chest $1990,97: 144,149$

171. Kollef M. Shapiro $S$, Boyd $V$. Silver $P$, Von Harz B, Trovilion E, and Prertice D. A randomzed chirical trial comparing aru extended-use hygroscopic condenser humidifer with heatedwater humidification in mechanically ventitated patients. Chost 1998 ; $13759-767$ 
172. Fincr OC, Dewaver E. Morgan \& Marejon 0 . and civetia d. prospective randomized comparison of an im-line heat moisture exw changer fither and heated wire thumbitiers. Rates of vertilator-asoctated eariy-onset (communty-acquired) or late-orset thospital-acquired) preumonia and incidemce of entotracheal tutu occlusion. Chest 1997,112 $1055-1059$

173. Dijarin $K$, Billard M, Mier $L$, Bourdenles $Q$. Grun P. Maknowicz P. Estagnasie P. Coste F. Boussougant $\%$, and Dreyfuss $D$. Changing heat and moisture exchangers every 48 hours rather than 24 hours does not affect their efficacy and the incidence of nosacomiat pneumonia. American Journal of Respiratory and Crilical Care Medicine 1995: 152 $1562-1569$.

174. Long MN Wickstrom $\mathrm{C}$, Gimes A, Benton CF. Beicher $B$, and Stamm AM. Prospective, randomized study of ventiatorassociated pheumonia in patients with one versus three ventilator circult changes per week infection Controf and Hospital Epidemiology 1996: 17 . $14-19$

175. Dreyfuss $D$, Dgedaini $K$, Weber $P$. Brun $P$. Lanore $d$. Rahmani $d$ Boussougant $W_{\text {i }}$ and Coste F. Prospective study of nosocomial preumonia and of patient and circuit colonization during mechanical ventilation with chrcuit changes every 48 hours versus no chlonge. American Revew of Respiratory Discase 4991: 143:738-743.

176. Kallef MH, Prentice D, Shapiro SO. Fraser WJ Silwer $P$. Trovition E, Welliz P. Von Harz B. and St John R. Machainical ventitation with or wittiout daly changes of in-line stiftion cahneters. American jownat of Respratory and Critcal Cane Madiche 1997; $156466-472$.

177. Kollef MH, Shapiro SD, Fraser VJ, Silver P. Murphy DM. Trovilion E. Hearns ML. Richards RD. Cracchilo L, and Hossin L. Mechanical ventilation with or without 7-day circuit changes: A randomized contirolled trial Amnals of Internal Medicine 1995; $123 \cdot 168 \cdot 174$

178. Deppe S, Kelly J. Thoi L, Chudy J, Langfield $R_{n}$ Ducey w, Truwit $C$, and Antopol MR. Incidence of colonzation. nosocomial pneumonia, and mortality in critically ill patients using Trach care ciosed-suction system versus an opensution system: Prospective randomizeo study. Cribal Care Medicine 1990, 18 $1389+1393$

179. Conrad 5. George R. Ramero $M$, and Owens M. Comparison of nosocomial pneumonia rates in closed and open tracheal suction system. Procededings of the XW World Congress on Diseases of the Chest and 55 h Annual Sciontific Assembly $1989 ; 1845$.

180. Johnson KL, Keamey $P A$, Johnson $S E$, Nblett JB, Mackillan NL, and Mcclain RE. Closed versus open endotracheal suctioning. Costs and physhologic consequences. Crifical Care Mediche 1994:22:658-666.

181. Hotzaptel $L$, Chewret $S$, Madinier $G$, Ohen $F$. Demingeon $G$, Coupry $A_{\text {r }}$ and Chaudet $M$. Infiuchce of long-term orom or nasoliacheat intubation on nosocomial maxillary sinusitis and phieumonia: Results of a prospective, randomized, clinical rial. Critical Care Madicine 1993, 21:1132-1138.

182. Klick d. du Moulin $\mathrm{G}$. Hedley-Whyte J, Teres D, Bushnell $L_{n}$ and Feingold $D$. Prevention of Grammegatve baciliary pnetumonia using polymyxin aerosol as prophyaxis the incidence of preumonia in seriously ill patients. J Chin Invest" 1975" 55:514-519.

183. Klastersky $J_{n}$ Huysmans $E$ Weerts $D$. Hensgens $C$, and Daneau D. Endotracheally administered gentamicin for the prevention of infections of the respiratory tract in patients with tracheostomy: a double blind study chesi $1974,65: 650-654$

184. Laupucis A, Sackett DL, and Roberts RS. An assessment of chnically useful measures of the consequences of treatment. Wew England Joumal of Medicine 1988; 318:1728-1733

485. Waeschke R. Guyatt $G$, Shannon $H$, Watter $S$, Conk $D$, and Heddle $N$ Basic statistics for clinicians: 3. Assessing the effects of treatment measures of association. Can Med Assoc $1995 ; 152351-357$.

186. wan der Waal D, Berghuismde Vries JM, and Lekkerkekk-wat der Wees JEC. Colonization resistance of the digestive tract in conventional and antibiotic-treated mice. I Hyg 1974. 69:405-411. 
187. Semer $D$, Mulder $N$ de Vnes-Hospers $H$ Fidler V, Nuweg 1H, Van dar Waail D, and van Saene $H$. Infection prevention in granulocytopenic patients by selective decontamination of the digestive tract. European Joumal of Cancer 1980, 16:859-869.

188. Jacobs $S$. Foweraker JE, and Roberis SE Effectiveness of selective decontamination of the digestive tract in an licu with a polcy encouraging a low gastric pH. Chin htensive Care 1992, $3: 52-58$

189 Cerra FB. Maddaus MA, Dunn DL, Wells CL. Konstantinides. NN, Lehmann SL, and Mann Hu. Sellective gut decontamination reduces nosiocomial infections and length of stay but not mortality or organ faiture in surgical intensive care unit patients. Archives of Surgery 1992; 127:163m-169

190. Kauthold A, Eehrendt W, Kräuss $T$, and van Saene HKF. Selective decontamination of the digestive fract and methicillin- resistant Staphylococous aureus. Lancet 1992; 339 : $\| 411-1412$.

194. Lingnau $W$, Berger J, Javorsky $F$, fille $M$, Alterberger $F_{*}$ and Benzer $H$. Changing bacterial ecology during a five year period of selective intesirnal decontamination. Jomnal of Hospital infaction 1998; 39:195-206.

192. Vandenbroucke-Grauls $\mathrm{C}$ and Wandenbroucke J. Effect of selective decontamination of the digestive tract on respiratory tract infections and mortality in the infensive care unit. Lancet 1991: $338: 859.852$

193. Selective Decontamination of the Digestive Tract Trialists" Collaborative Group. Meta-anialysis of randomised controlled trials of selective decontamination of the digestive tract British Medical Joumal 4993: 307:525-532

194. Heyland DK, Cook DJ, Jaeschke R, Grifint $\mathrm{L}$ Lee HN, and Guyatt $\mathrm{GH}$. Selective deconta mination of the digestive tract: an averwew. Chest 1994: 105:122-1229

195. Kollef MH. The role of selective digestive tact decontamination on mortality amd respiratory tract infections a metamanalysis. Chesi 1994 ; 105.1101-1108.
In wentidated patients: selective decontaw mination or selective cross-inection? Ant microbial Agents and Chemolnatapy 4995 . 39 $94.1-947$.

197. DAmico R. Piffer S, Leonett $C$, Torr $V$. Tinazzi A, and Liberati A. Effectiveness of andibiotic prophylaxis in eriticaly ill aduth pathents: Systomatic rewilew of randomised controllew trials. British Medicat Joumal 1998 . 316 $1275-1285$

198. Stoutenbeek CP, van Saene HKF Miranda DR. Zandstra DF, and Langrehr $D$. The effect of oropharyngeal decontamination using topical nomabsorbable antibiotics on the incidence of nosocomial respiratory tract infections in multiple trauma patients. Joumal of Trama $1987: 27: 357-364$

199. DeRiso AJ. II., Ladowski JS, Dillon TA, Justice Wh, and Peterson AC. Chlorhexidine ghuconate $0.12 \%$ oral finse reduces the incidence of totat nosocomial respiatory infection and nonprophylactic systemic antibiotic use in patients. undergoing heart surgery. Chest 1966; 109 15564.1561

200. Russell AD and Day MJ. Antbacterial antivity of chlorhexidine. Journal of Hosplat Infection 1993: $25: 229-238$

201. Russell AD. Chlorhexidine: Antibacterial action and bacterial resistance Imfaction 1986; 14 $212-215$

202. Shimaish $T$ and Nakagrwa $Y$. Revisw of disinfactant susceptibility of bacteria isolatad in hospltal to commonly used dsinfectantss Postgrad Medical Joumal 1993, 69 57 \% $57 \%$

203. Lepper MH, Kofman S, and Blat N. Effect of eight antibiotics used singly and in combination on the tracheal flore following tracheostonny in pollomyentis. Antibiolios and Chamolburapy 195:4: $4829-843$

204. Petersdorf RG, Curtin JA, and Hoeprich PO. A study of antibiotic prophylaxis in uncomscious patients. Now England Journal of Madicime $1957 ; 257: 1001-1009$

205. Petersdorf RG and Herchant RK, A study of antibiotic prophylaxis in pattents with aculte heart failure. New Enghand Journal of Medicino $1959,260,565-575$ 
205. Manden M, Moscon $P$, Larger M. and Cigada M. Prewantor ofpnoumonia in an intersive care unit: a rantomized muftucenter cinical trat Critia Care Medicine 1989; $17501-505$.

207. Reusser $P$, Gy $K$, Scheidegger D. Buchmann Q. Buser M, and Zimmeni UW Prospective endoscopic study of stress erosions and ulcers in critically ill metrosurgical patients: current incidence and effect of acidreducing prophylaxis Critical care Medche 1990: 18. $270-274$

208. MoCarthy DM Sucrathate. New England Journat of Medicine 1991; 325:1017+1025.

209. Kappstein I and Engels I. Antibacterial activity of sucralfate and bismuth subsallicylate in simulated gastric fluid. European Journal of chinical Microbiotogy and Infectious Diseases 1987: 6:216-217

210. Tryba M and Mantey-Stiens F. Antibacterial activily of sucralfate in human gastric juce. American Joumal of Madicine 1987; 93 (suppl 3B): $125-127$.

211. Bergmans $D$, Bonten M, Gaillard $C$, valn Tiel $F$. van der Geest $S_{n}$ and Stobberingh $E E$. In vitro antibacterial activity of sucralfate. European Joumal of Clinical Microbiology and Infectious Diseases 1994, 13:615m-620.

212. Pickworth KK, Falcone RE, Hoogeboom JE, and Santanello SA. Occurence of nosocomial pneumonia in mechanically ventilated trauma pationts: a comparison of sucralfate and ranitidine Critical Caro Medicing 4953 ; $21: 1856-1962$

213. Pingleton SK, Hinthom OR, and LiU C. Enteral mutrition in patients receiving mechanical ventiletion. American Jothmal of Medicin 1580; $80.827 \% 832$

214. Bonten MN, Gaillard CA, van Tiel FH, van der

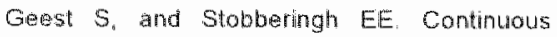
anteral feeding counteracts preventive measures for gasinic colonization in intensive care unit patients. Critical Care Medicine 1994: $22939-944$

215. Cook $\mathrm{D}_{n} \mathrm{De}$ Jonghe $\mathrm{B}$, and Heytand $\mathrm{D}$. The relation between nutrition and nosocomial pheumonia: randomized trials in critically ill patients Critical Care 1997; 1:3-9.
216. Wehta $S$. The risk of aspiration in presence of cuffed endotracheal tubes. Brit I Anaesthesia 1972: 44:6011-605

217. Girou E, BuU-Hol A, Stephan F, Novara $A$, Gumanin $L$, Satar M, and Fagon JY Bacteriological evaluation of continuous sub. glottic aspiration for preventing tracheal colonization in ventitated patients. American Journat of Respiratoy and Critical Care Medicine 4995, 151:420. [Abstract]

218. Dive $A$, Moulant $M$, Jonard $P$, Jamart and Mahieu P. Gasitroduodenal motilty in mechanicalfy ventilated critically ill patients: a manometric study. Critical Care Medicine $1994: 22: 441-447$

219. Greenfield $S$. Teres D, Bushmell LS.

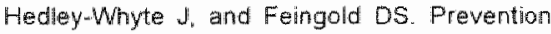
of Gram-nagative bacilary pneumonia using aerosal polymyxin as prophylaxis. 1. Effect on the colomization patterm of the upper respiratory tract of seriousiy ill patients. J Chin invest 1973 $522935-2940$

220. Feesey TW, du Moulin GC, Hedley-Whyte $\mathrm{J}$ Bushnell LS, Gibert JP, and Feingold DS Aerosol polymyxin and pmeumonic in seriously ill palients. New England Joumal of Medicino $1975 ; 293: 471-475$.

221. Levine BA, Petrott PA, Slade CL, and Pruit BA. Ir. Prospective tirials of dexamethasone and aerosolized gentamicin in the treatment of inhallation injury in the burned patient. Joumal of Traume 1978; 18:188-193

222. Rouby W, Poete $P$, Martin de Lassalle E, Wicolas $M H$, Bodin $L$, Jarlie $V$. Konnek AM and Vars $P$. Prewention of Gram negative nosocomial bronchopneumonia by intratrachea: colistin in critically ill patients. Histologic and bacteriologic study. Intensive Care Medicine $1994 ; 20: 187-192$

223. Cook D, De longhe 8 , Brochard 1 , and Brun-Buisson $C$. Influence of alrway management on ventilator-associated pneumonia. Evidence from randomized trials. Joumal of the American Medical Association $1998 ; 279 ; 781-797$ 


\section{Addendum 1}

Copied in part from the official statement of the American Thoracic Society. prepared by an ad hoc Committee of the Scientific Assembly on thicrobiology. Tuberculosis and Pumonary Infections, which was abopted by the American Thoracic Society board of directors, nowember 1995

The entire statement is published as: Hospital-acquired Pneumonia in Adults: Diagnosis, Assessment of Sewerity, nitial Antimicrobial Therapy, and Preventive Strategies. A Consensus Statement Aprerican Jourial of Respiratory and Critical Care Madicine 1995; 153.1711-1725

(page $1720-1722)$

\section{Prevention of hospital-acquired pneumonia}

Although there is widespread interest in the prevention of hosphtal-acquired pneumonia (HAP), there are no regimens that are proven to be effective for wide range of hospitalized patients. A number of proventiwe strategies have been applied and fall into one of four categories: (1) currently awalable and probalbly effective for specific populations and indications; (2) currently avalable, promising in efficacy, and being used by some hospitals on a regular basis: $(3)$ currently avallable but of unprowen value, being used in investigational studies or on limited clinicall basis; and (4) unproven regimens, still being evaluated.

\section{Regimens with Probable Efficacy for Specific Indications}

In this category are pneumococcal and influenza waccination, handwashing and isolation of patients with ritultiply resistant respiratory tract pathogens. The efficacy of vaccirvatons against 5 pheumonae and influenza virus in preventing HAP is unknown, but they are effective for preventing respiratory infection and hospitalization in specific at risk populations. Indirectly, by preventing respiratory infection and hosplialization, these vaccines may reduce the incidence of HAP, and they represent sound medical care for patients qualifying for the vaccines. Handwashing between patient contact is a basic and often meglected behaviour by medical personnel. This simple manoeuvre can prevent the transfer of pathogens from patient to patient and can keep the hands of medical personnel free of potentidly pathagenic bacteria. Such exogenous sources of organisms can lead to the direct inoculation of organisms into the tracheobronchial tree and if the tractheobranchial epithelium is able to bind such arganisms, colonization and subsequent pnesumonia may occur Similarly, the transfer of resistant pathogens from patient to patient may be prevented by isolating patients with highly resistant organisms such as MRSA. Umfortunately "such "barrier methods" will not be effective in preventing infection with organisms that are part of the critically it patient's endogenous flora; thus, most Gram-negative pneumonias carnot be avoided by isolation methods.

\section{Regimens with Probable Effectiveness Used Widely in Some Clinical Settings}

The approaches that fit into this descriptive category include nutritional support, attention to the size aild nature of the gastrointestinal reserwoir of microorganisms, careful handling of ventilator tubing and associated equipment, subglottic secretion drainage, and lateral rotational bed therapy.

Nutritional support is commonly used in hosplalized patients because of the obsemation that malnutrition can increase the risk of pneumonia. Nonetheless, there is no clear-cut evidence that nutritional support can reduce the risk of HAP. If nutritional support is given, careful attention to the route and volume of feeding, as. well as to a number of other methodologic factors, is necessary and may influence the incidence of HAF When enteral nutrition, delwered by a feeding jejumostomy, has been compared will total parenteral nutrition (TPN), it has been associated with a lower incidence of HAP. Although the mechanism for this occurrence is unknown, 酛 has been speculated that enteral nutrition stimulates the intestinal mucosa. ithereby preventing bacterial translocation (a possible mechanism for pnewmonia), and that enteral nutrition compared with TPN, changes the synthesis of inflammatory mediators by the liwer to a favourable balance for host defense function.

The superionty of enteral nutrition has been demonstrated whth distal enteral feeding, while feedings. delivered to the stomach may not have the same effect. If feedings are detwered to the stomach, a number of methodologic issues must be considered. These include the effect of feedings on gastric volume and pHt. because elevation of either of these variables can expanid the size of the gastric bacterial reservoir, which can 
potemtally yels an froculurin of bacteria that contd reach the lower respiratory tract. In addition if patients being fed into the womach are kept supine tather than semerect, pneumonia is more likely. Wht the use of large-bor feeding tubes and bolus feedings, aspiration may aiso occus more often than whth the use of smaller tubes and contintous feeding methods. One other consideration is the site of feeding tube insertion. on sudy has shown that the wse of orogastio tubes, rather than nasogastre lubes. car reduce the mcidence of nosocomial sinusits, an infection that may lead to subsequent HAP

Athough there are no FDA approwed regimens for intestinal bleeding prophylaxis. mary critically il patiants hecewe this interwention, and debate continues about ils effect on the incidence of HAP. It is probably too simptictic to say that any intervention that rases gastric pH is undesitable, because gastric volume as well as pit must be considerad, along with some of the onter factors aiready mentioned. Hn three meta-analyses. the use of sucralfate (which does mot increase gastric pHliwas associated with reduced incidence of pheumorla, when compared with the use of either andicids alone fwhich increase both gastric ph and volume) or in combination with $\mathrm{H}_{2}$ antagonisus. However, there is disagreement about whether the use of $H_{2}$ antagonists alone will lewd to a higher rate of preumonia when compared with sucralfate or placebo. In some recenth studies, $H_{y}$-blockers did not increase the risk of pneumonta when compared with placebo, athough the Use of sucrallate may reduce the incidence of pneumonia when compared with Ha-antagonists. lf sucrallate is protective, it may work best for late onset HAP rather than for eariy forms of infection. The conflicting results with $H_{2}$ antagonsts may reflect the fact that these agents elevate gastric ph without increasing gastric volume in addition, many of the analyses have not considered the impact of concomitantly administered gastric feedings. If the goal of nutritional sipport is to delver enteral leeding into the distal intestine, iz may be uninecessary to place a second tube into the stomach just to give sucralfate, and the use of $\mathrm{H}_{2}$-blackers in patients wilh smallwowel feeding wubs may be safe. Howewer, antacids should be avoided in patients who are at risto for HAP

Bacteria can proliferate in respiratory therapy equpment, and the incidence of preumonia is increased if the tubing is manipulated frequently rather than infrequently. Fecently, has been shown that even if vantilator tubing is never changed during the course of mechanical wentation, the risk of pneumonia is not increased. Most hospitals have a policy to change ventilator tubing every $48-72 \mathrm{~h}$, but there are no data to indicate that any particular schedule to tubing changes is likely to reduce the incidence of pneumonia. When tubing is handled. the comdensate should always be drained away from the patient because it can contain large concentrations of bacteria. The use of a heat and moisture exchanger (HME) avoids such condensate and does not seem to add to the risk of pneumonia. In-fine medication nebulizers should be washed and cleaned after each use to avoid contamination with high levels of bacteria. Closed suction catheters do not appear to alter the incidence of preumonia but may increase the rate of airway colonization.

In a few medical centers, subglotic secretion aspiration is achieved with the use of a special endotracheal tube, designed with a suction port abowe the endotracheal tube cuff, in the subglotic area. By removing contaminated respiratory secretions bercre they enter the lung, subglottic secretion aspiration has been reported to reduce the imcidence of some types of HAP in intubated patients. The suctioning can be done intermitenty or continuously, and continuous aspiration appears to delay the onset of HAP, prevanting early forms of infecion. This approach cannol prevent infection with organisms that have the capacity to colonize the lung after direct inoculation, and thus, it has not effectively prevented preumonia caused by $P$. aeruginosa and other forms of late onset HAP. Once chdotracheal tubes capable of allowing subglottic secretion drainage are more widely axallable. this approach may be used more fogularly.

Lateral rotational bed therapy has been used in both medical and surgioal patients and can reduce the incidence of pneumonia in certain populations. These include surgical trauma patients and some medical patients, particularly those with sepsis. The mechanism for this beneficial effect is unknown but probably rolates to mobilization of racheobronchial secretions. The cost association with this intervention has limited its widespiad use and mphastes the need to apply it to carefuly selected patients

\section{Regimens of Unproven Value Used on Limited Investigational or Clinical Basis}

Included in this category is the selective digestive decontamination (SDD) regimen of topical and systemic antibiotic prophylaxis and topical Iracheobronchial antibiokics.

Sto has been studied for many years and involves the use of topical oral and intestinal antibiotics, often with a systemic antibiotic added for the first few days of the regimen. with the goal bieng elimination of all potential pathogens from the gastrointestinal tract whth sterilization of 'endogenous bacterial sources. infection may be awolded. In the many SOD studies there is a general trend towards reducing the incidence of pneumonia, but this has usualy occured in unblinded studies. In blinded studies, the incidence of pneumonia 
has not aways been feduced, particularly if invaswe methods were used to dehine the presence of thap in general the efficacy of the regimem has been questioned because mortaty rediction is offen not seen. atthough one recent analysis suggested a modesi reduction in mortiality with the use of soo. prowder that

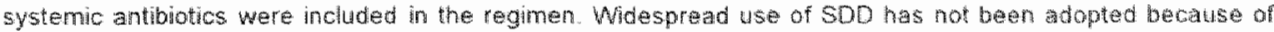
concerns about the emergence of antibioticresistant organisms, the cost of the regimen, and the limiter benefit of SDD on mortaty. SDD may be effective for specific populations, particuarly surgical patients rathar than medical patients. More data are needed to detine the patients who may benefit from this intervention.

Topical antbiotics delwered to the lower respiratory tract atone have been studined and were showin to have no effect on motiality. Although this approach was able to reduct the incidence of pnewimonis in some studies, it frequently led to infection with highly resistant pathogens. and when patients developed pneumonia on this regimen, it was often a fatal event. At the present time this aptoroach carnot be recommended

\section{Unproven Regimens Still Being Evalluated}

This category includes the use of biologic response modiflers, monoclomal antibodies to specitic bacterial antigens, and manipulations of endogenous sources of bacteria by mechancat means. In this latter categon is the potential to prevent the accumulation of a bacterial biofilm on the endotracheal tuba. The endotracheal wube can harbour the growth of large numbers of bacteria along its irner surface, and bacteria at this silte will persist in the airway. free from the effect of antibiotics and host defense. The development of new bio materials for endotracheal trubes could lead to the elimination of a tracheal tube biofitm and the eradication of a reservoir of large numbers of bacteria in the airway.

Biologic response modfiers that hold promise for reducing the incidence of HAP are being investigated. These substances are immuromadulators and have the ability to either upregulate or downdegulate most defense mechanisms, which in the appropriate setting may have beneficial effects on putmonary host defenses aganst inwading pathogens. Because extrapumonary infections have buen associated whth abnormalities in pumonary defense mechanisms, strategies that effectively reduce the severity of systemu infection (Such as sepsis) might be beneficial in lowering rates of secondary HAP. To date, there are no proven inteventions that accomplish this goat. Efforts to intervene in the cytokinelmediator cascade intiated by Grammegative bacteria and/or lipopolysaccharide, which is thought to be responsible for the daleterious consequences of the sepsis symtrome, are ongoing. Anthipopolysacoharide antibodies (ES and HA. 1 A hava not proved efficacious in improwing outcome in patients with Grammegative bacterial sepsis. Ongoing studies of other bologic response modifiers include antibodies to the cytokine tumor necrosis factor, interleukin-1 receptor antagonist, and the cyclooxygenase inhibitor, ibuprofien. Other potential modulators incilude platelettacivating factor antagonists

Oher strateghes have been investigated to accelerate the resoltution of pneumonia atter it is acquired and to prevent the development of pneumonia. Passive immunization with hyperimmune antimpsaudononas immume globulin for patients with documented $P$, aeruginosa preumonia has failed to result in any bernefit in

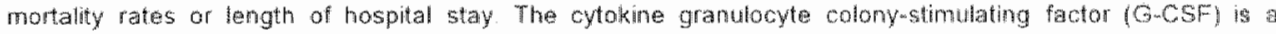
hematopoietic cytokine that enhances both the number and function of circlating netsophats. Preclinical evaluations in models of infection and results of trals in neutroperic oncologic patients show bemefich affects of G-CSF in hastening the resolution and preventing the acqusition of intecthons. A necent trial has showh that the administration of G-CSF is safe in patients with community acquired pneumonia

Another cytokime of potential utility in preventing pneumonia or acceterating its resolution is intarfaron. gamma (IFN). While systemicaly admistered $M F R$ is not aways effective in models of sepsis or in patients at risk for sepsis, bcal administration into the lung appears effective in decreasing the burden of infecting organisms and augmenting local host defenses in several animall models of pneumona. Aerosole administration of IFN to nomal thumans results in activation of the allweolar hacrophage, whithoul concturrent activation of systemic mononuclear cells IFN remains a potential therapeutic modality for bactorial and nonbacterial pathogens in the lung. and clinical investigations will likely proceed in the near fufure

Thus, while there are no proven modalites for immunoprophylaxis of map, investigations are ongoing with biologic response modfiers as both preventive and therapeutio strategies in this disease setting. Ht is possiblo that single agents or combinations thereot, alone or in conjunction with awailable antibiotics, may prove effective in reducing the mortatity on morbidity of HAP 


\section{Addendum 2}

Copied in part lom the Centers for Distease Control and Prevention Guideline for Prevention of Nosocomial Pneumonia

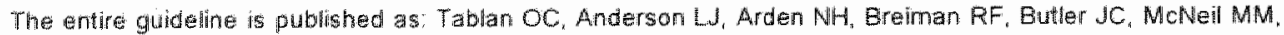
and The Hospat Infection Control Practices Advisory Committee. Guideline for Prevention of Nosocomial Pneumonia. Infection Control and Hosphal Epidemiology $\$ 994 ; 15$ (9) $588-627$.

\section{(page 604-607)}

\section{PART II. RECOHNENDATIONS FOR PREVENTION OF NOSOCOMIAL PNEUMONIA} The Hospital Infaction Control Practices Advisory Committee

\section{Intraduction}

The recommendations are presented according to the etiology of the infection, in the following order bacterial pneumonia, irtuding Legionnaces disease; fungal pneumonia (aspergillasis); and wirus-associated pheumonia (respiratory syncytial wirus (RSV) and influenza infections) Each tapic is subdiwided according to the following general approaches for nosocomial infection conthrol, as applicable to the infection:

1. staff education and infection shmeillance

2. interruption of transmission of microorganisms by eradicating infecting microorganisms from their epicemiologically important resievoirs, andfor preventing person-ko-person transmission

3. modifying host risk for infection.

As in prewious CDC guidelines, each recommendation is categorized on the basis of existing scientific evidence, theoretical rationale, applicability. and economic impact. However, the previous CDC system of categorizing recommendations has been modified as follows:

CATEGORY IA. Strongy recommended for all hospitals and strongly supported by welludesigned experimental or epidemiologic studies.

GATEGORY 1B. Strongly recommended for all hospitais and viewed as effective by experts in the field and a consensus of HCPAC based on strong tationale and suggestive evidence, even uhough definitive scientific studities may not have beer done.

CATEGORY II. Suggested for implementation in many hospitals. Recommendations may bo supported by suggestive climical or epidemiolagic studies, a strong theoretical rationale, or definitive studies applicable ta sorne butik not aril hospilats.

NO RECOMMENDATION: UNRESOLVED ISSUE. Practices for which insufficient evidence or consensus regarding afficay exists.

\section{Bacterial pneumonia:}

\section{Staff Education and Infection Survellance}

\section{A. Staff education}

Educate healif care workers reganding nosocomal bacteriall pneumonias and infection control procedures to prevent their occurrence

\section{CATEOORYA}

\section{B. Survelliance}

1. Conduct survellaryce for bacterial pheumonia in 104 patients at high fisk for nosocomial bacterial pheumonia (eg. patients with mechanicaly assisted ventilation selected postoperative patients) to determine trends and identify potential problems. Include data regarding the causative microorganisms and their antimicrobial susceptibility patterns. Express data as rates (eg. number of infected patients or infections per 100 LCU days or per 1,000 ventilator days! to facilitate intra-hospital comparisons and determine trends.

\section{CATEGORY IA}

2. Do not routimely perform surveilance cultures of patients or of equipment or devices used for respiratory therapy, pumonary-function testing. of delivery of inhalation anesthesia.

CATEGORYIA 


\section{Interruption of Transmission of Microorganisms}

A. Sterilization or Disinfection, and Maintenance of Equipment and Devices
1. General Measures
a. Thoroughly clean all equipmert and devices to be sterisized or disinfected.
CATEGORYIA

b. Sterilze or use thigh-level disinfection for semicritical equipment or devices, ie, items that cone into dired or indirect contact with mucous membranes of the lower respiratory tract. High-level disinfection can ba achieved either by wet heat pasteurization at $76^{\circ} \mathrm{C}$ for 30 minutes or by using liquid chemical disinfectents approwed as sterilants/disinfectarts by the Envitronmental Protection Agency and cleared for marketing for use on medical instruments by the Office of Device Evaluation, Center for Devices and Radologic Health, Food and Drug Administration. Follow disinfection with appropriate rinsing, dryilla, and packaging, laking care not to contaminate the items in the process.

\section{CATEGORY 13}

c. 1) Use sterile (not distilfed, nonsterile) water for rinsing reusable semicritical equipment and devices used on the respiratory trant after they have been chemically disinfected.

\section{CATEGORWIB}

2) No recommendation for using tap water (as an altemative to sterite water) to rinse reusable semicritical equipment and devices used on the respiratory tract after they have been subjected to high-level disinfection. whether or not rinsing is followed by drying with or without the use of alcohol

\section{UMRESOLVEO ISSUE}

d. Do not reprocess an equipment or device that is manufactured for single tuse only, unless data show that reprocessing the equipment or device poses mo threat to the patient, is costuffective, and daes not chathge the structural integrity or function of the equipment or device.

\section{CATEGORY IB}

\section{Mechanical Ventilators, Breathing Circuits, Humidifiers and Heat-Moisture Exchangers}

\section{a. Mechanical Ventilators}

Do not routinely sterilize or disinfect the internal machinery of mechanical ventiliators.

\section{CATEGORYIA}

\section{b. Ventilator Circuits with Humidifiers}

1) Do not routihely change more frequently than every $48 \mathrm{~h}$ the breathing circuit, including tubing and exhalation watue, and the attached bubbling or wick humidifier of a ventilator that is in use on an individual pattient.

\section{CATEGORYIA}

2) No recommendation for the maximum length of time after which the breathing circuit and the attached bubbling or wick humidifier of a ventilator in use on a patient shoulld be changed

\section{UNRESOLVED ISSUE}

3) Sterilize reusable breathing circuts and bubbling or wick thumbifiers, or subjact them to high-lavel disinfection between their uses on different patients.

\section{CATEGORKIB}

4) Periodically drain and discard any condensate that collects in the tubing of mechenicall ventilator. taking precautions not to allow condensate to drain towards the patient. Wash hands after purfornng tive procedure or handing fluid

\section{CATEGORY $B$}

5) No recommendation for placing a fither or trap at the distal end of the expiratory-phlase tubing of the bireathing circuit to collect condensate.

\section{UNRESOL VED ISSUE}

6) Do not place becterial fitters between the humidifier reservoir and the inspiratorywase tubing of the breathing circuit of a mechanical ventilator.

\section{CATEGORYIB}

7) Humidifier fluids

a) Use sterile water to fill bubbling humidifiers

\section{CATEGORYH}

b) Use sterile, distilled, or tap water to fill wick humidifiers

CATEGORY

c) No recommendation for the preferentias use of a clased, continuousweed humidification system. UNRESOLVED ISSUE 
c. Ventifator Breathing Circuits with Hygroscopic Condenser-Humidifiers or Heat-woisture Exchangers

1) Wo recommendation for the preferential use of hygroscopic condenser-humidifier or heat-moisture exchanger rather that a heated humidfler to prevent nosocomial preumonia.

UNRESOLVEDSSUE

2) Change the hygroscopic condenser-humidfer or heatmoisture exchanger according to manufachurer's recommeridation and/or when evidence of gross contamination or mechanical dysfunction of the device is present:

CATEOORY HA

3) Do not routhely ohange the breathing circut attached to a hygroscopic condenser-humidifier or heatmoisture exchanger white it is in use on a patient.

CATEGORVIS

3. Wall Humilifiers

a. Follow manulacturers instructions for usiv and maintenance of wall oxygen humidiers unless data show that the modification in their use of maintenance poses no threat to the pationt and is cost-effective.

CAREOORYIB

b. Setween patients, change the tubing. including any nasal prongs or mask used to delfwer oxygen from a Wall outet

CATEGORY IB:

4. Small-Volume Medication Nebulizers: 'In-line" and Hand-held Nebulizers

a. 1) Between treatments on the same patient, distinfect, rinse with sterile water, or air-dry smallvolume medication nebulizers.

OATEGORYHB

2) No racommendation for using tap water as an alternative to sterile water to rinse reusable smallwolume medication nebulizers between treatments on the same patient.

UNRESOLVEO 1SSUE

b. Beween patients, replace nebulizers with those that have undergone sterilization or high-level disinfection.

CATEGORYIB

c. Use only sterile fulids for mobulization, and dispense these funds aseptically.

CATEGORY IA

d If multidose medication vials are used, handle, dispense, and store them according to manufacturers" instructions.

CATEGORY IA

5. Large-Volume Nebulizers and Misit Tents

a. Do not use lange-valume roommair humidifiers that create aerosols (eg, by wenturi principle, ultrasound, or spinning disk) and thus are really nebulizers, unless they can be sterilzed or subjected to high-level disinfection at least delly and filled only with sterilo water.

CATEOORY IA

b. Sterilix large-volume nebulizers that are used for inhalation therapy, eg, for tracheotomized patients, or subject them to high-level disinfection beween patients and atter ewery $24 \mathrm{~h}$ of use on the same patient.

CATEGORYIB

c. 1) Use mist-tent nebulizers and reservoirs that have undergone high-level disinfection and reptace them between patients.

CATEGORYIB

2) No recommendation regarding the hequency of thanging mist-tent nebulzers and reservoirs while in wse on one patient

\section{UNRESOLVED ISSUE}

6. Other Devices Used in Association with Respiratory Therapy

a. Between patients, sterize or subject to high-level disinfection portable respirometers, oxygen seinsors, and other respiratory dewices used on multiple patients.

\section{CATEOORY IS}

b. 1) Between patients, sterilze or subject to high-lewel disinfection reusable hand-powered resuscitation bags (for example. Ambu bags).

\section{CATEGOFY IA}

2) No recommendation regarding the frequency of changing hydrophobic filters placed on the connection 
port of resuscitation bags.

UNRESOLVED ISSUE

7. Anaesthesia Machines, and Breathing Systems or Patient Circuits

a. Do not routinely sterilze or disinfect the internal machinery of aneshathesia equipment

CATEGORYHA

b. Clean and then sterilize or subject to high-level liquid chemical disifection or pasteurization rusable

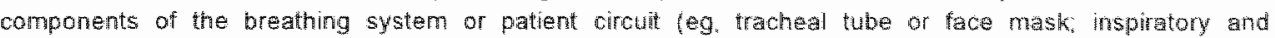
expiratory breathing tubing: y-piece: reservoir bag; humidier and tubing between us on different patients. by following the device manufacturers instructions for their feprocessing

CATEGORYAB

c. No recommendation for the frequency of routhely cleanith and disinfecting thintirectional valwes and carbon dioxide absomber chambers.

UNRESOLVED ISSUE

d. Follow published guidelines audor manufacturers" instructions regarding in-use matrenance, cleaning and disinfection or sterilization of other components or attachments of the breathing system or patient circuit of anesthesia equipments

CATEGORYAB

e. Periodically drain and discard any condensate that collects in the tubing of a breathing circuit taking precautions not to allow condensate to drain towards the patiert. After penforming the procedure or handing fluid, wash hands whith soap and water or with a wateriess hancwashing preparation

CATEGORYHB

1. No recommendation for placing a bacterial filter in the breathing system or patient cincuit of anesthesia equiprent.

UNRESOLVED /SSUE

8. Pulmonalry-Function Testing Equipment

a. Do not routinely steritze or disinfect the internal machinery of pulmonary-function testing machines between uses on differemt patients.

CATEGORYH

b. Sterilize or subject to hugh-level liquid chemical disinfection or pasteurization reusable mouthpieces and tubings or connectors between uses on different patients, or follow manufacturers' instructions for their reprocessing.

\section{CATEGORY IB}

\section{B. Interruption of Person-to-Person Transmission of Bacteria}

1. Handwashing. Wash hands after confact with mucous membrames, respiratory secretions, or subjects contaminated with respiratory secretions, whether or not gloves are worn. Wasth hands before and after contact with a patient who has an endotracheal or tracheostomy tube in place, and before and after contact whin any respiretory dewice that is used on the patient, whether or not gloves are worn.

CATEGORYIA

\section{Barrier Precautions}

a. Wear glowes for handilng respiratory secretons or objects contaminated with respiratory secretions of any patient.

\section{CATEGORYIA}

b. Change glowes and wash hands between patients: after tranding respiratory secretions or objects contaminated with secretions from one patient and before contact with another patient object. or enwiromental surface: and between contacts with a contamirated body silfe and respiratory tract of or respiratory device on, the same patient.

CATEGORYIA

c. Wear a gown when soiling with respiratory secretons from a patient is anticipated, and change the gowir after such contact and before providing care to another patient

CATEGOPY 18

3. Care of Patients with Tracheostomy

a. Perform tracheostomy under sterle conditions.

CATEGORYIB

b. When changing a tracheostorny tube, use aseptic technique and replace the twbe with one that has undergone sterilization or high-level disinfection.

CATEGORYIB 
4. Suctioning of Respiratory Tract Secretions

a No recommendation for wearing sterile rather than clean gloves when suctioning a patient's respiratory secfetions

UNRESOLVEDISSUE

b. If the open suction system is employed, use a sterile single-use catheter.

CATEGORY II

c. Use only sterite flufd to remove secretions from the suction catheter if the catheter is to be used for reentry into the patient's lower respiratory tract.

CATEGORY IE

d. No fecommendation for preferential use of the multi-use closed-system suction catheter ar the single-use open-system catheter for prevertion of preumonia.

UNRESOLWED ISSUE

C. Change suction collection tubing (up to the canister) between patients.

CATEGORY IB

f. Change suction collection canisters between uses on different patients except when used in short-term care units.

CATEGORY IB

\section{Moudifying Host Risk for Infoction}

\section{A. Preciautions for Prevention of Endogenous Preumonia}

Discontinue enteral-tube feeding and remove devices such as endoiracheal, tracheostorny, and/or enteral (1.e., org-or naso-gastric, or jeitumal) tubes from patients as soon as the clinical indications for these are resolved.

\section{C.ATEGORY IB}

1. Prevention of Aspiration Associated with Enteral Feeding

a. If there is no contraindication to the manoeuvre, elevate at an angle of $30-45^{\circ}$ the head of the bed of a patient at high risk of aspiration pneumonia; eg. a person receiving mechanically assisted ventilation and/or has an enteral tube in place.

\section{CATEGORYIB}

b. Routinely verify appropriate placement of the feeding tube.

\section{CATEGORYIB}

c. Routinely assess the patient's intestinal motility (eg. by auscultating for bowel sounds and measuring residual gastric volume or abdominal girth) and adjust the rate and volume of enterall feeding to avoid regurgitation.

CATEGORY IB

d. No recommendation for the preferential use of small-bore tubes for enteral feeding UNRESOLWED ISSUE

e. No recommendation for administrating enteral feeding continuously or intermittently.

UNRESOLVED ISSUE

f. No recommendation for preferentially placing the feeding tubes, eg. jejunal tubes, distal to the pylorus.

UNRESOLWED ISSUE

\section{Prevention of Aspiration Associated with Endotracheal Intubation}

a. No recommendation for using oro-tracheal rather than naso-tractheal tube to prevent nosocomial pneumonia

\section{UNRESOLVED ISSUE}

b. No recommendation for routinely using an endotracheal tube with a dorsal lumen above the endotracheal cuff to allow drainage (by suctioning) of tracheal secretions that accumulate in the patient's subiglottic area.

UNRESOL VED ISSUE

c. Before deflating the cuff of an endotracheal tube in preparation for tube removal or before moving the tube, ensure that secretions are cleared from above the tube cuff.

CATEGORY $1 B$

3. Prevention of Gastric Colonization

a. If stress-bleeding prophylaxis is needed for a patient with mechanical assisted ventilation, use an agent that does not raise the patient's gastric $\mathrm{pH}$.

CATEGORY II

b. No recommendation for selective decontamination of a critically ill, mechanically ventilited, or ICU 
patents digestive tract wh oral andor intravenous antimicrobials to prewent Grammegathe bachlary tor Candida spp.) phationia.

UNRESOL VEO ISSUE

c. No recommendation for routine acidification of gastric feeding to prevent nosocomial pretmonia UNRESOLVEO ISSUE

\section{B. Prevention of Postoperative Pneumonia}

1. Instruct preoperative patients, especially those at high rsk of developing piteumonia, regarding traquent coughing. taking deep breaths, and ambulating as soon as medically indicated in the postoperative period. High-risk patients include those who will receive anaesthesia, especially those who will have abdominal, thoracic, head, or neck operation; or who have substantial pumonary dysfunction, such ars patients with chronic obstructive lung disease, a musculoskeletal abnomality of the chest, or abnomal pulmonary function tests.

\section{CATEGORYIB}

2. Encourage postoperative patients to cough requenty, take deep breaths, mowe about the ben, and amoulate unless it is medically contraindicated.

\section{CATEGORY IB}

3. Control pair that interferes with coughing and deep breathing during the immediate postoperative period by using systemic analgesia including patient-controlled analgesia, with as little cough-suppossant effect as possible: appropriate support for abdominal wounds, such as tightly placing a pillow across the abdomen, or regiona! (eg. epidural) analgesia.

\section{CATEGORYIB}

4. Use an incentive spirometer or intermittent positive pressure breathing on patients at high risk of developing postoperative pneumonia

\section{CATEGORYH}

\section{Other Prophylactic Procedures for Pneumonia}

1. Vaccination of Patients. Vaccimate pattents at high risk for complications of pneumococcal infections with pneumocaccal polysaccharide vaccine. High-risk patients include 265 yr old; adults with chronic cardiovascular or pulmonary disease. diabetes mellitus, acoholism, cirhosis, or cerebrospinal fluid leaks; and children and adults with immunosuppression ${ }_{n}$ functional or anatomic asplenia, ar HV infection.

\section{CATEGORY IA}

2. Antimicrobial Prophylaxis. Do not routinely administer systemic antimicrobial agents to prevent mosiocomial presmonia.

\section{CATEGORY IA}

\section{Use of rotating 'kinetic' beds or continuous lateral rotational therapy}

No recommendation for the routine use of 'kinetic" beds or continuous lateral rotational therapy (ie. placing patients on beds that turn on their longitudinal axes intermittently or continuously) for prevention of nosocomial pneumonia in patients in the ICU, critically ill patients, or patients immobized by illness andor frauma

UNRESOLVDO $15 S U E$ 


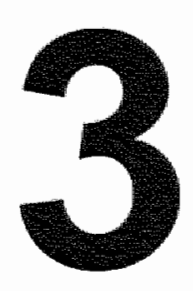

\section{Indications for antibiotic use} in ICU patients: a one-year prospective surveillance

Bergmans DCJJ, Bonten MJM, Gaillard CA, van Tiel FH, van der Geest S, de Leeuw PW, Stobberingh EE 


\section{Abstract}

\section{Background}

The high prevalence of nosocomial infections in critically III ICU patients is associated with high antibiotic consumption. Besides its economic impact, there is the constant threat of selection and induction of antibiotic resistance. Surveillance studies recording the incidence of infections, antibiotic use, and antimicrobial susceptibilities of pathogens supply vital information regarding infection control and prevention of antibiotic resistance.

\section{Methods}

In order to analyze antibiotic consumption we recorded antibiotic use in a general ICU during one year by categorizing the indications for antibiotic use into three groups: (1) prophylaxis; (11) therapy for a bacteriologically proven infection (BPI); (III) therapy for a non-bacteriologically proven infection (non-BPI). Bronchoscopic techniques were used to diagnose pmeumonia. In practice, BPI must be treated, but a proportion of antibiotics prescribed for non-BPl may be unnecessary. The subdivision in BPI and non-BPI may help to identify these cases.

\section{Results}

In all, 515 patients were admitted to ICU and $36 \%$ of these had at least one infection. Of all infections, $53 \%$ were $10 \mathrm{C}$-acquired and $99 \%$ of these occurred in intubated patients. Antibiotics were prescribed in $61 \%$ of admissions. Of all antibiotics prescribed for therapy, $49 \%$ were for respiratory tract infections, $19 \%$ for abdominal infections and $13 \%$ for sepsis e.c.i. Categorized by indication. 59\% of all antibiotic prescriptions were for BPI, $28 \%$ for non-BPI, and $13 \%$ for prophylaxis. A theoretical reduction of $25 \%$ in the number of non$\mathrm{BPI}$ prescriptions would result only in a $7 \%$ decrease of total antibiotic use.

\section{Conclusions}

We conclude that almost all antibiotics prescribed were for intubated patients and for BPI. Respiratory infections were the single most common infection and accounted for $49 \%$ of all antibiotics used. Therefore, in our setting, prevention of respiratory tract infections is probably the most effective mode to reduce antibiotic use. 


\section{Introduction}

The last decade has witnessed the increasing problem of antibiotic resistance as a consequence of excessive or inappropriate antibiotic use. Indeed, contemporary literature has addressed the doom scenario of 'the post-antimicrobial era"t.

Collecting data on motives for antibiotic use is the first step in managing this problem. Therefore, surveillance studies regarding the incidence of infections, antibiotic prescription policies and knowledge about antimicrobial susceptibilities of pathogens are crucial ${ }^{t-5}$.

Critically ill patients treated in ICUs frequently have an infection or are prone to develop new infections. As a corollary, the total antibiotic consumption is approximately ten times greater in ICU wards than in general hospital wards ${ }^{6}$. A considerable part of total hospital antibiotic consumption and cost are for antibiotics use, in ICU ${ }^{3,4}$. Data from the National Nosocomial Infection Surveillance System (NNISS) describe 'rough' changes in epidemiology and antibiotic susceptibility of pathogens in US hospitals over a 20 year period, while the European Prevalence of Infection in Intensive Care study (EPIC) determined prevalence of infections, antibiotic use, and susceptibilities of isolated pathogens in a continent-wide point-prevalence study. Only few detailed longitudinal surveillance studies exist on infections and antibiotic use in $I C U s^{6,7}$. As a result, little is known about the indications for and costs of antibiotic therapy for different patient populations within a general ICU. We, therefore, prospectively analyzed antibiotic use and related costs in a general ICU ward over a one-year period. Special emphasis was given to the indications for antibiotic use, which were divided into bacteriologically proven infections, mon-bacteriologically proven infections, and prophylactic use.

\section{Patients and methods}

\section{Setting}

The University Hospital Maastricht is a 700-bed facility. Critically ill medical, surgical, neurological/neurosurgical and trauma patients requiring haemodynamic monitoring and/or mechanical ventillation are admitted to one of two similar general ICUs. The total capacity is 15 beds of which two are reserved for paediatric patients. Coronary-care patients and patients recovering from cardiac surgery are cared for in other separate units as are neonates. The ICU is managed by a multidisciplinary staff (internal medicine, surgery, anaesthesiology), with daily assistance from the departments of medical microbiology. pulmonology and radiology. During the study period no changes in the composition of the medical staff occurred. 


\section{Data collection}

Study population

From January 1, 1994 through December 31, 1994 all adult patients (age>15 years), ventilated or nonventilated, who had been admitted to ICU were studied prospectively. On admission the following data were recorded: age, sex, medical specialty, pre-existent diseases, APACHE II-score ${ }^{3}$, and length of hospital stay before admission to the ICU. Subsequently, the number of days in ICU, number of days on mechanical ventilation, surgical procedures, type of nutrition and mortality were monitored. During ICU stay, parameters of infection (temperature, leucocyte count and differentiation, X-ray results, culture results) and types and doses of prescribed antibiotics, with the exception of topical applications, were registered daily. Selective decontamination of the digestive tract (SDD) was not used during the study period.

\section{Microbiology}

Semi-quantitative and quantitative microbiological analysis of samples collected for culture were performed according to standard microbiological methods ${ }^{9.10}$. Besides the cultures performed of samples that were collected on indication, all patients had routine urine and sputum cultures taken twice weekly (monday and thursday). Antibiotic susceptibility was determined by means of a microbroth dilution method according to the NCCLS guidelines. Pseudomonas aeruginosa ATCC 27853. Escherichia coli ATCC 25922 and ATCC 35218, Staphylococcus aureus ATCC 29213 and Enterococcus faecalis ATCC 29212 were used as reference strains. The criteria for susceptibility and resistance, according to the NCCLS guidelines, were used to determine the percentages of strains susceptible to the mosi frequently used agents.

\section{Data analysis}

All collecled data were analyzed by one investigator according to the definitions described below. The multidisciplinary staff of the ICU wards were not informed of the sludy to prevent bias.

\section{Definitions}

\section{Infections}

The Centers for Disease Control definitions for surveillance of nosocomial infections, were used". However, an additional classification was made based upon the culture results as described below in order to categorize infections and associated antibiotic use in groups in which a clinical suspicion of infection was or was not microbiologically confirmed. More detailed criteria were used for pneumonia (see below). Infections occurring within $48 \mathrm{~h}$ of admission to ICU were considered mon-ICU-acquired (i.e. community-or hospital-acquired). Infections that were clinically suspected and diagnosed more than $48 \mathrm{~h}$ after admission to ICU were considered to be ICU-acquired. 
A clinical suspicion of infection was based on the following infection parameters: (I) temperature $>38^{\circ} \mathrm{C}$ or $<35.5^{\circ} \mathrm{C}$; (II) leukocytosis $>10 \times 10^{3} / \mathrm{mm}^{3}$ with or without left-shift in differential count or leukopenia $<3 \times 10^{3} / \mathrm{mm}^{3}$. In addition, clinical findings such as a new or progressive infiltrate on chest $X$-ray, cloudy urine, purulent sputum or phlebitis in the absence of above mentioned criteria were considered indicative of possible infection. If a clinical suspicion of infection was present, samples of the suspected site of infection (urinary tract, respiratory tract, blood, wound drainage, ascites, cerebrospinal fluid, catheters etc.), were taken for culture. Depending on the culture results, the infections were divided into two groups: (1) non-bacteriologically proven infection (non-BPI): all cases of clinical suspicion of infection, with negative or nonsignificant bacterial culture results, but necessitating antibiotic therapy in view of the clinical condition of the patient; (II) bacteriologically proven infection (BPI): all cases of clinical suspicion of infection with significant culture results of the samples collected from the suspected infection site that were treated with antibiotics.

Decisions regarding the presence of a clinical suspicion of infection, the orders to take samples for culture, the interpretation of culture results, and the institution of antibiotic therapy were made by the primary care team assisted by the department of medical microbiology.

\section{Pneumonia}

When pneumonia was clinically suspected, bronchoscopy with protected specimen brush and bronchoalveolar lavage were performed as described elsewhere ${ }^{12}$. The diagnosis of pneumonia was established according to the criteria listed in Table 3.1. When criteria $A$ and $B$ were met it was considered a non-bacteriologically proven pneumonia and the infection regarded as non-BPI. When criteria $A_{i} B$ and $C$ were met, pneumonia was bacteriologically proven and the infection considered to be a BPI.

\section{Antibiotic use}

Antibiotic use was analyzed either in prescriptions or in courses. The term 'prescription' was used to describe the uninterrupted use of a single antibiotic. A 'course' was defined as an episode of clinical or suspected infection in which antibiotics, either consecutively or in combination, were prescribed.

Antibiotic consumption was analyzed in prescribed daily doses (PDD) or as PDD per 100 bed days ${ }^{6}$. The costs of antibiatic therapy were calculated using the prices per PDD paid by the hospital pharmacy, including the costs of monitoring serum antibiotic concentrations for aminoglycosides and vancomycin (average three times weekly).

The indications for antibiotic use were categorized into three groups: (I) prophylaxis, either for a surgical procedure or endocarditis; (II) therapy for a BPI; (III) therapy for a non-BPI 
Table 3.1 Criteria used in the diagnosis of pnewmonfar

Gitteri⿵

A 23 positive of the following 4 :

1. rectal temperature abowe $30.00 \mathrm{C}$ or below $35^{\circ} 55^{\circ} \mathrm{C}$

2. Biood leukocytosis $\left(>10 \times 10^{3} / \mathrm{mm}^{2}\right)$ and/or left shit or blood leukoperia $\left(<3 \times 10^{3} / \mathrm{mm}^{3}\right)$

3. $>10$ leukocytes per highwower field in Gram stain of hacheal aspirate

4. positive culture from tracheal arspirate

and

3 new, persistent or progressive infittrate on chest radiograph

and

c $\gtrsim 1$ pasitive of the following 3 :

1. positive guantitative culture of a sample obtained by BAL (cut-off point $310^{4}$ ofu/mi) or PSB (cutoff point $\geq 10^{3} \mathrm{cfu} / \mathrm{ml}$ )

2. positve blood culture unrelated to amother source and obtained within $48 \mathrm{~h}$ before and after respiratory sampling

3. positive pleural fluid culture in the absence of previous pleural instrumentation

BAL, Bronchoalveolar Lawage: PSB, Protected Specimen Birush.

$A+B=$ non-bacteriologically prowern pneumonia $A * B+C=$ bacteriologically proven pneumoma.

\section{Statistical anallysis}

Data are expressed as absolute numbers with or without percentages, as means with standard deviation or as medians with ranges. Antibiotic costs are expressed in Dutch florins (Dfl) (100 Dfl approximately equals 60 US $\$$ and $£ 40$ sterling). Frequency comparisons were performed by chi-square test or Fisher's Exact test. A probability value less than 0.05 was considered to denote statistical significance.

\section{Results}

\section{Patient characteristics}

During 1994, 469 patients were admitted to ICU. Since 30 patients were admitted twice and eight patients three times, the total number of admissions was 515 (Table 3.2).

\section{Infections}

Of all patients admitted to $\mathbb{C U}, 36 \%$ had at least one infection during ICU stay: $19 \%$ had $\geq 1 \mathrm{BPI}, 13 \%$ had $\geq 1$ non-BPI and $4 \%$ had both $\mathrm{BPI}$ and non-BPI.

In all, $179 \mathrm{BPI}$ were observed in 121 patients: $77(43 \%)$ of these originated in the respiratory tract, $29(16 \%)$ were of abdominal origin and $73(41 \%)$ originated from other sites. Of all BPI, $164(92 \%)$ occurred in intubated patients and the majority of these infections ( $n=116,71 \%$ ) were ICU-acquired. Among nonintubated patients, $15 \mathrm{BPI}$ were diagnosed of which one was ICU-acquired (Table 3.3). 
Table 3.2 Characterictics of the patients

\begin{tabular}{|c|c|c|c|}
\hline & $\begin{array}{c}\text { All } \\
(n=515)\end{array}$ & $\begin{array}{c}\text { Intubated } \\
n=276)\end{array}$ & $\begin{array}{c}\text { Nonintubated } \\
(n=239)\end{array}$ \\
\hline Median age (range)* & $61(16-93)$ & $63(16.90)$ & $56(19-93)$ \\
\hline Male/Female & $279 / 190$ & $166 / 88$ & $113 / 102$ \\
\hline Median APACHE II Uangelt & $15(0-50)$ & $18(2-50)$ & $9(0-40)$ \\
\hline Days on ICU median (range) & $3(1-75)$ & $7(1.75)$ & $2(1-12)$ \\
\hline Number of patient bued days $(\%)$ & 4091 & $3434(84 \%)$ & $657(16 \%)$ \\
\hline \multicolumn{4}{|l|}{ Medical speciality: } \\
\hline - medicalt: & 209 & 107 & 102 \\
\hline - surgerys & 259 & 137 & 122 \\
\hline - trauma & 47 & 32 & 15 \\
\hline \multicolumn{4}{|l|}{ Surgical procedures: } \\
\hline - abdominal surgery & 110 & 90 & 20 \\
\hline - thoracic surgery & 26 & 23 & 3 \\
\hline - neurosurgery & 97 & 21 & 76 \\
\hline Mortalitity in ICU $(\%)^{*}$ & $102(22 \%)$ & $92(33 \%)$ & $90(4 \%)$ \\
\hline Mortalitity after ICU discharge (\% $\%)^{*}$ & $32(9 \%)$ & $20(11 \%)$ & $12(5 \%)$ \\
\hline
\end{tabular}

* Second and third admissions not analyzed (first admissions, $n=469$ ).

I APACHE II score was determined for 386 admissions

+ Including pulmonology, cardiology, neurology and anesthesiology.

\$ Including meurosurgery. ENT, cardiopulmonary surgery, gyneacollogy and urology.

Percentage of patients that died after discharge from ICU to hospital ward.

A non-BPI emerged 95 times in 86 patients: in $64(67 \%)$ cases this related to the respiratory tract, in $16(17 \%)$ cases to the abdomen. There were nine $(10 \%)$ cases of clinical sepsis and six (6\%) cases originated from other sites. As with $\mathrm{BPI}$, the majority of non-BPI were seen in intubated patients $(n=81,85 \%)$, and 29 $(36 \%)$ of these were ICU-acquired (Table 3.3). All non-BPI $(n=14)$ seen in nonintubated patients were non-ICU-acquired.

All diagnoses of $\mathrm{BPI}$ of the respiratory tract were established on positive quantitative culture results of samples obtained by protected specimen brush and/or bronchoalveolar lavage. Twenty-two patients were treated for pneumonia despite nonsignificant culture results from bronchoscopy. These cases, therefore, did not fulfil the criteria for $\mathrm{BPl}$. Although bronchoscopy is not recommended within $48 \mathrm{~h}$ after institution or change of antibiotic therapy, this procedure was, in fact, performed within this time period in nine patients. Despite negative culture results, new antibiotics were prescribed for these patients. Although the remaining 13 patients had not received antibiotics before bronchoscopy and had negative or nonsignificant culture results, their clinical condition necessitated antibiotic therapy in the opinion of the physician in charge. In $42(66 \%)$ cases of a non-BPI of the respiratory tract no bronchoscopy was performed, either because of logistical problems $(n=12)$, or because the infection was considered to be community- or 
hospital-acquired (non-ventilator-associated) in which cases we do not routinely perform bronchoscopy $(n=30)$. Moreover, a number of these patients are not intubated. During the study period another 48 bronchascopies were performed when pneumonia was suspected, but culture results were negative and no antibiotic treatment was instifuted. These episodes were not labelled as non-BPI.

\section{Microorganisms and antibiotic susceptibility}

Among the isolated microorganisms considered as the causative agent of infection (Table 3.4), Gram-negative bacteria were isolated most frequently (mainly Pseudomonadaceae and $E$, colin.

All isolates cultured during 1994 from samples from both ICUs were analyzed to determine the percentage of isolates of $P$. aeruginosa, $E$ coli, $S$. aureus, and $E$ faecalis that were susceptible to the tested antibiotics. All strains of $S$. aureus were susceptible to methicillin and flucloxacillin, and all isolates of $E$. faecalis were susceptible to amoxicillin and vancomycin. Of the Gram-negative microorganisms, all isolates of $E$. coll were susceptible to ceftazidime, ciprofloxacin and gentamicin and $>90 \%$ were susceptible to cefuroxime and co-amoxiclav. More than $95 \%$ of $P$. aeruginosa isolates were susceptible to gentamicin, piperacillin, ceftazidime and ciprofloxacin; all isolates were susceptible to imipenern.

\section{Indications for Antibiotics}

Antimicrobial therapy was prescribed in $312(61 \%)$ of 515 admissions. Among intubated patients, $74 \%$ received antibiotics as compared with $45 \%$ of nonintubated patients (chi-square test, $p<0.00001$ ).

In all, 710 prescriptions of antibiotics were recorded; $574(81 \%)$ prescriptions for intubated and $136(19 \%)$ for nonintubated patients. In the intubated patients, $51 \%$ of antibiotic prescriptions were used for $\mathrm{BPI}$, as compared with $31 \%$ for non$\mathrm{BPI}$ and $18 \%$ for prophylaxis. For nonintubated patients these percentages were $19 \%, 15 \%$ and $66 \%$ respectively. Moreover, intubated patients, when compared with nonintubated patients, were treated with more prescriptions (means of 3 and 1 per patient, respectively). more courses of antibiotics (means of 2 and 1 per patient, respectively), and for a longer period (means of 11 and $3 \mathrm{~d}$, respectively).

Patients were treated with antibiotics for 2430 of 4091 patient days $(59 \%)$. Intubated patients received antibiotics for 2145 of 3434 patient days $(63 \%)$, and nonintubated patients for 285 of 657 patient days (43\%) (chi-square test, $p<0.00001$ ). Of all prescriptions of antibiotics indicated for therapy, $49 \%$ were administered for respiratory tract infections, $19 \%$ for abdominal infections and $13 \%$ for sepsis e.c.i.

Respiratory tract infections, the most important site of infections in ICU patients, accounted for $41 \%$ of total antibiotic use for $\mathrm{BPI}$ and for $63 \%$ of antibiotic use for non-BPI. 


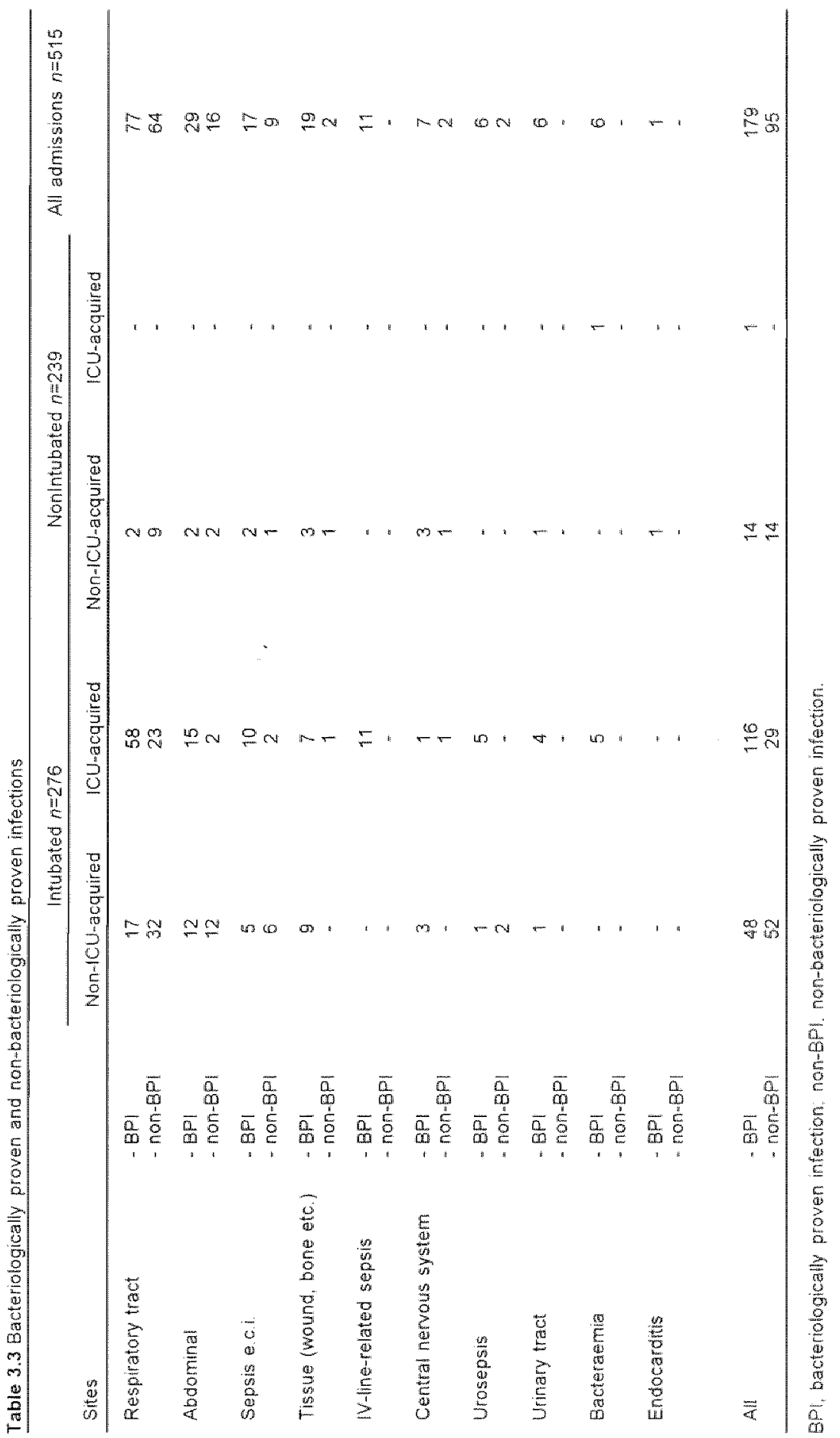




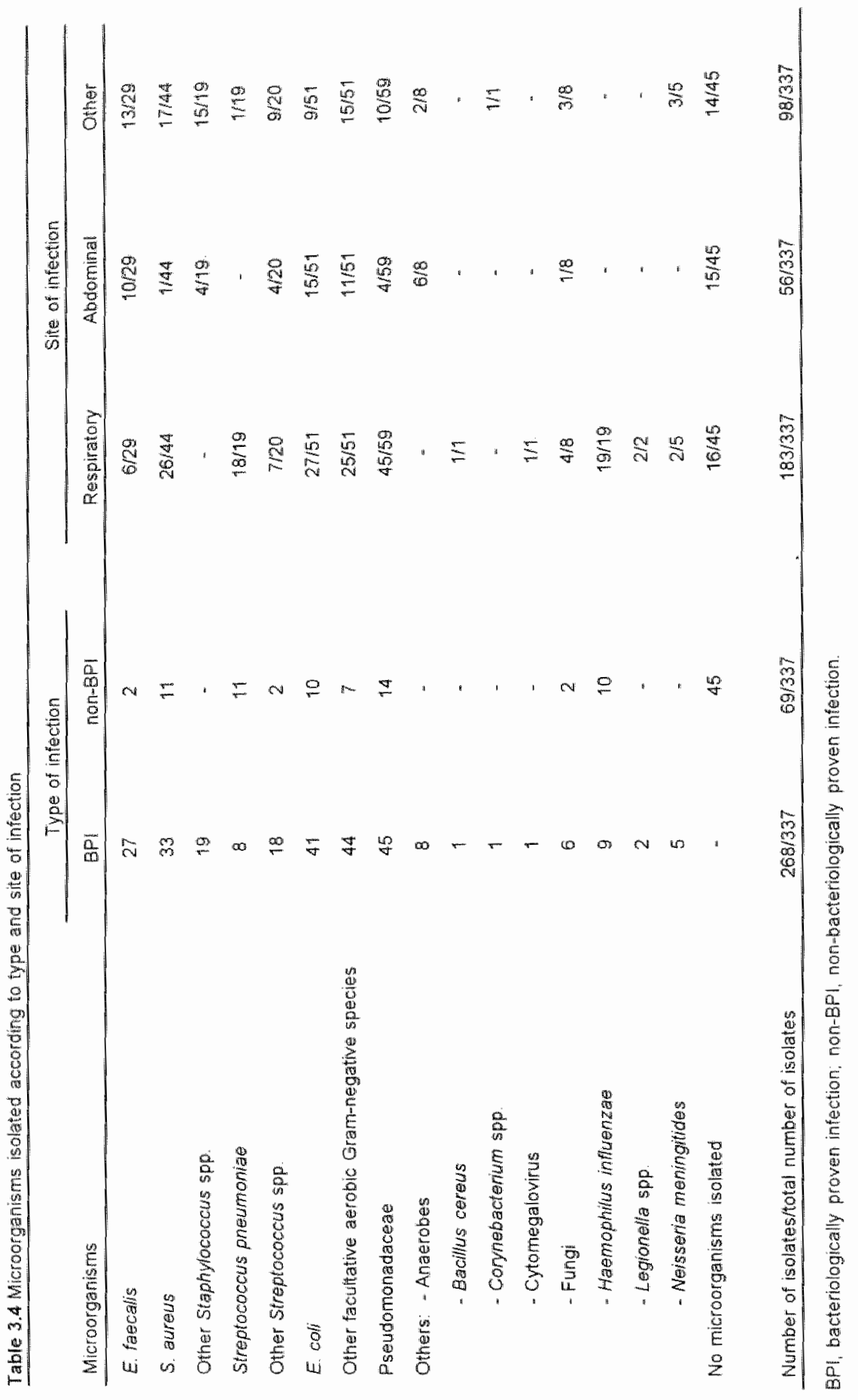




\section{Types of antibiotics}

The five most frequently used antibiatics in BPI (expressed as percentage of total number of prescriptions used) were: co-amoxiclav (26\%), aminoglycosides (24\%), piperacillin $(8 \%)$, ciprofloxacin $(8 \%)$ and glycopeptide antibiotics $(6 \%)$. For the group of non-BPI the most frequently used antibiotics were quite similar: co-amoxiclav $(38 \%)$, aminoglycosides $(23 \%)$, piperacillin $(10 \%)$, ciprofloxacin $(5 \%)$ and metronidazole $(4 \%)$. The five most frequently used antibiotics for prophylaxis were: flucloxacillin (43\%), cefuroxime (17\%), aminoglycoside antibiotics (14\%), co-amoxiclav $(13 \%)$ and metronidazole $(9 \%)$. The frequent use of flucloxacillin in this group is due to the routine prophylaxis with this agent in neurosurgical patients.

\section{Total consumption in PDD and costs of antibiotic therapy}

Altogether, 3767 PDD were prescribed for a total amount of Dfl 212,823. In intubated patients, 3387 (90\%) PDD were prescribed corresponding to Dfl 200,195 ( $94 \%$ of total cost). In nonintubated patients $380(10 \%)$ PDD were prescribed thus accounting for Dfl $12,629(6 \%$ of total cost).

The largest proportion of PDD (58\%) were used for $\mathrm{BPI}$, accounting for $68 \%$ of all costs for antibiotic use. Approximately $29 \%$ of total PDD were prescribed for non-BPI which represented $25 \%$ of the total costs. Finally, only $13 \%$ of all PDD ( $7 \%$ of all costs) were administered for prophylactic use.

Overall, B-lactam antibiotics accounted for $56 \%$ of the usage in PDD, corresponding to $56 \%$ of the total cost. The aminoglycoside antibiotics accounted for $21 \%$ of the usage in PDD, but corresponded to only $12 \%$ of the total cost (Table 3.5).

The antibiotic consumption was $92.1 \mathrm{PDD} / 100$ bed days accounting for 52 Dflibed day. Comparison of these ratios for the three groups of patients yielded the following results: 84.9 PDD/100 bed days and 47 Df//bed day for medical patients, $100.5 \mathrm{PDD} / 100$ bed days and 56 Dfl/bed day for surgical patients and $80.5 \mathrm{PDD} / 100$ bed days and 52 Dfl/bed day for trauma patients.

\section{Discussion}

The results of this one-year longitudinal surveillance show that $36 \%$ of patients admitted to a general ICU had at least one infection during their ICU stay. Of all ICU-acquired infections, 99\% occurred in intubated patients. As a result, $90 \%$ of total antibiotic use and $95 \%$ of the costs for antibiotics were spent in this group. Furthermore, the respiratory tract was by far the most important site of infection, accounting for $43 \%$ of $\mathrm{BPI}$ and $67 \%$ of non-BPI. Under the circumstances tested, reduction of antibiotic use may be achieved most successfully by shortening duration of therapy for respiratory tract infections or reducing prescriptions for $\mathrm{BPI}$ by means of infection prevention 


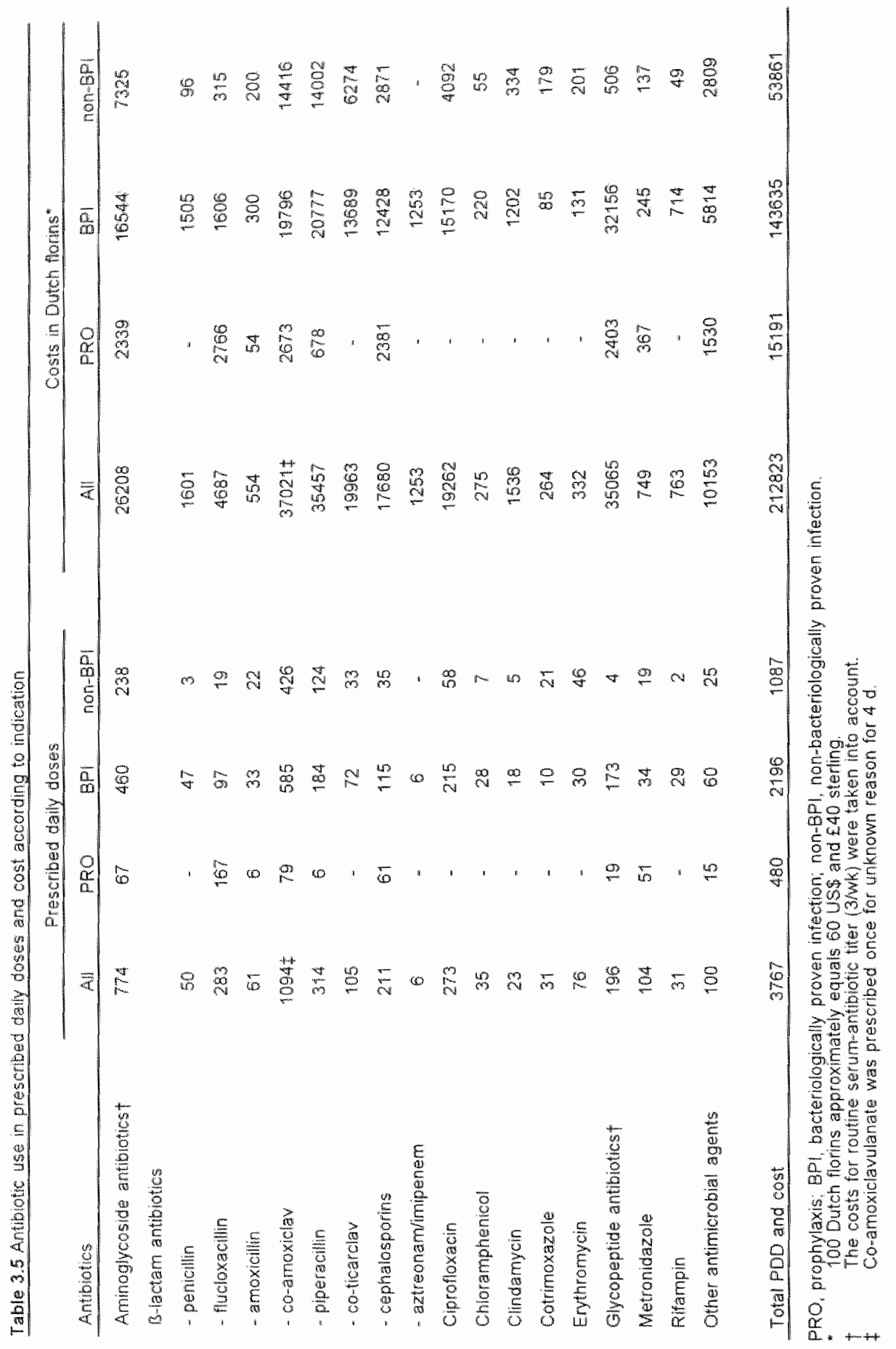


The methods used in the present study provide a simple way to analyze incidence and prevalence of infection and the amount of antibiotic use. We feel that this method of registration would be suitable for others to use, both in other intensive care wards, and in general hospital wards. The most important aspect in this regard is, in our opinion, the distinction between $\mathrm{BPI}$ and non- $\mathrm{BPI}$. In addition, by using predefined criteria for infection, the impact of different types of infection on antibiotic use and costs can be easily calculated and flaws such as the variations in interpretation of diagnostic criteria for infection, inevitable in large multi-centre studies, are avoided. The EPIC study was performed by questionnaire and the investigators had to rely on the correct use of the CDC definitions for nosocomial infections by physicians of the 1417 participating $\mathrm{ICUS}^{5.13}$. Difficulties in diagnosis of infection in critically ill patients pertain, in particular to respiratory tract infections ${ }^{14}$. Moreover, differences between centres regarding antibiotic susceptibilities weaken the relevance of resistance data obtained from a continentwide study. This is clearly demonstrated by the antibiotic susceptibilities of the pathogens in our ICU: all S. aureus strains were methicillin-sensitive, $97 \%$ of $P$. aeruginosa strains were susceptible to gentamicin and $100 \%$ to imipenem, and all enterococci were susceptible to amoxicillin and vancomycin. The relation between antibiotic use and the emergence of antibiotic resistance has been demonstrated frequently ${ }^{15,16}$. Qur data, therefore, suggest that the relative lack of significant resistance in nosocomial pathogens in our $\mathrm{ICU}$ is a result of restrictive antibiotic policy in our hospital for many years.

Despite major differences in study epidemiology we compared several outcome data from our study with those from the EPIC study. In the EPIC study, which was a one-day point-prevalence study, the prevalence of infection was $45 \%$. This probably means that $45 \%$ of the patients were treated for infection (at the day of the study). In our study, $36 \%$ of the patients had at least one infection during their ICU stay, but were treated for infection on $48 \%$ of all patient days, similar to the percentage found in the EPIC study. Infections of the respiratory tract were diagnosed most frequently in both studies, $65 \%$ of all infections in the EPIC study and $51 \%$ in the present one. Urinary tract infections also are frequently implicated in nosocomial infections ${ }^{2.7}$. This type of infection was seen in $18 \%$ of patients in the EPIC study but only $5 \%$ of patients in our study. This difference may be explained by our policy to perform routine bladder irrigation with chlorhexidin $0.02 \%$ if a bladder catheter is in situ and twice weekly routine replacement of urinary catheters in case of asymptomatic bacteriuria (i.e. positive urinary cultures without clinical evidence of infection). Antimicrobial therapy is instituted only when urine cultures are persistently positive in spite of the above mentioned regimen and clinical signs of infection develop. Another interesting difference between the EPIC studly and ours, is the use of cephalosporins. Forty-four per cent of patients on antibiotics received cephalosporins in the EPIC study as compared with only $8 \%$ in the present study. The excellent susceptibility patterns of the isolates cultured in our study partly explains this difference. 
Many conditions are known to mimic the signs of infection, especially in critically ill patients ${ }^{17}$. Consequently: antibiotics will often be prescribed unnecessarily. Although it is clear that $\mathrm{BPI}$ must be treated, the distinction between $\mathrm{BPI}$ and non$\mathrm{BPI}$, according to the definitions applied in the present study, may help to identify unnecessary antibiotic use. However, due to delay in obtaining culture results and the possibility of false negative results, we accept that in a proportion of the non$\mathrm{BPI}$ treatment should be given anyway. Reduction in antibiotic use in this group of infections may only be achieved by decreasing the prescriptions. In our setting even an estimated reduction of $25 \%$ in antibiotic prescriptions for non-BPI would only result in a $7 \%$ decrease in the total number of PDD in ICU and a $6 \%$ reduction in total antibiatic costs. Therefore, in our ICU, a significant reduction in antibiotic use could be achieved either by preventing infection or by shortening the duration of antibiotic therapy.

Few data are available on the optimal duration or route of antibiotic therapy for ICU-acquired infections. For example, although the guidelines of the American Thoracic Sociely advise that community-acquired pneumonia is treated for 7-10 d, no comparative trials on this issue are available ${ }^{18}$. Therefore, future studies evaluating the minimal duration of therapy for nosocomial infections may eventually lead to a decrease in antibiotic use.

Prevention of infections has the highest potential to reduce the enormous antibiotic use in ICUs. Surveillance of infection may help to determine the most prevalent infection and the most important pathogens involved. In our $1 \mathrm{CU}$, and many other European ICUs, respiratory infections thave the highest incidence. The use of more specific criteria to diagnose nosocomial pneumonia, for instance with bronchoscopic techniques, may help to rationalise antibiotic use, although a prospective study addressing this question is not yet available.

Implementation of contral of infection measures are critical in order to limit the possibility of crass-infections ${ }^{19}$. Many other specific measures have been shown to reduce the incidence of nosocomial pneumonia ${ }^{20}$. However, their true impact and cost-effectiveness are as yet unclear.

In conclusion, surveillance studies on antibiotic use, indications for prescription, incidence of infection and distinguishing between bacteriologically proven and nonbacteriologically proven infections may help to develop local strategies to reduce antibiotic use. The findings of this study suggest that in our setting prevention of respiratory tract infections has the greatest potential to reduce overall antibiotic use and costs. In addition, studies evaluating the optimal duration of antibiotic therapy may help to reduce unnecessary antibiotic use. 


\section{References}

1. Goldmann D, Weinstein R, Wanzel $R$, Tablan O. Duma $R$ : Gaynes $R$, schlosser J, and Martone W. Strategles to prevent and control the emergence and spread of antimicrobialmesistant microorganisms in hosptals. A chatlenge to hospital leadership. Journal of the American Medical Association 1996: 275 : 234-240

2. Chandrasekar P. Kruse J, and Mathews M Nosoconial infection among patients im different types of intellsive care units at a cily hospital Critical Care Medicine 1986; 14 : $508-510$

3. Griffiths L, Bartzokas $C$, Hampson $J$, and Ghose A. Antibiotic costs and prescribing patterns in a recently commissioned Liverpool teaching hospital. Part antimichobial therapy. Journal of Hosplat sufection 1986; 8:159-167.

4. Marschmer JP. Thurmann $P$, Harder $S$, and Rielbrock N. Drug tutilzation revilew on a surgical intensive care unit. International Journal of Chinical Pharmacology and Therapevitics $1994: 32.447 .451$.

5. Vincent 3 , Bhari $D$, Suter $P$, Bruining $H$, White W. Nicolas Chanoin M. Wolff $M$, Spencer $R$ : and Hermmer $M$. The prevalence of mosocomial infection in intensive care units in Europe. Results of the european prevalence of infection in intensive care (EPIC) study: Joumal of the American Medical Association $1995,274639-644$

Roder $\mathrm{B}$. Nielsen $\mathrm{S}$, Magnussien P. Engquist A. and Frimodtwaller $N$. Antibiotic usage an intensive care unitu in a Damish universily hospital Jounal of Antimiorabiat Chemotherapy $1993 ; 32: 633-642$.

Daschrer $F$. Nosocomial infections in intensive car units. Indensive Care Medicine 1985 , 14:284-287

Knaus WA, Draper EA, Wagner DP, and Zinmeman JE. APACHE II: a severity of disease dassificatton system Crilical Care Medicine 1985: 13:818-629.
10. Isenberg HD. Clinical microbiology procktures handbook. Washingtom, D.C. Amencan Sociely for Microbiology" 1992

1. Gamer J Jarvis W. Emori T. Horam T, and Hughes J CDC definimons for nosocomial infections, 1988. American Jothmal of infection Control 1988; $16,129-140$

Bonten M, Gaillard C. War Tid F, Smeets H. van der Geest $S$, and Stobberingh $E$. The stomach is not a source for colonization of the upper resplatory tract and pnetmonia in $1 \mathrm{CU}$ patients. Chesit 1994; $105.878-804$.

13. Spencer R. Epidemiology of infection in $\mathrm{ICW}$ intensive Care Medicine 1994: 20: $52-56$.

4. Bonten M, Gailard C, Wouters E, wan Tiea F. Stobbringh $E$, and van der Geest $S$. Problems in diagnosing nosocomias pnetumania in mechanically vertilated patients: a review. Critical Care Medicine $1994: 22$ : 1683-1691.

15. Verbist $\mathscr{L}$. Incidence of mutturesistance in gram-negative bacterial isolates from intensive care units in belgium: a curvellance study Scandinavian Jountal of infocious Disoasis $1991 ; 78: 45-53$

16. Tenover $F$ and Hughes $d$. The challenges of energing infectious diseases. Development and spread of multiply-resistant bacterial pathogens. Joumal of the Americar Medical Association 1950; $275,300-304$.

17. Meduri $G$, Maudin $G$, Wunderink R, Leper K. Jones $C$, Tolley $E$ and waylut $G$. Couses of fever and pulnonary demsitias in patients with clinical manifestations of ventilator arssociated pneumonia Chast 1994 ; $106221-235$

18. Niederman M. Bass $J$ Campbell $G$. foin $A_{*}$ Grossman F, Marde!l L, Marrie T. Sarost $G$. Torres $A$, and $Y u V$. Guddines for the intlal management of adwits with community acquired pneumonia: diagnosis, assessment of severity, and hnitial antimicrobial therapy. American Reviow of Respiratory Disease 1993. $148.1418-1426$ 


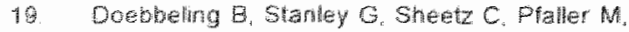
Houston A, Arris L. U W and Wenzel F Comparaty elticacy of atternative hand-washing agents in reducing nosocomial infections in imtensive care units. New England Joumad of Medicine 1992; 327:38-93.
Serective Decontamination of the Digestive Tract Trialists" Collaborative Group. Meta-analysis of randomised controtled trials of selecthe decontaminator of the digestive tract British Modical Journal 1893; $307 \cdot 525-532$ 


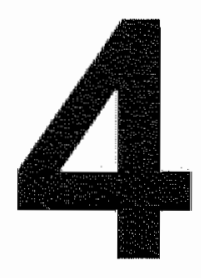

\section{Implementation of bronchoscopic techniques in the diagnosis of ventilator-associated pneumonia to reduce antibiotic use}

Bonten MJM, Bergmans DCJJ, Stobberingh EE, van der Geest S, de Leeuw PW, van Tiel FH, Gaillard CA 


\section{Abstract}

\section{Background}

In intensive care units a large proportion of antibiotics are prescribed for presumed episodes of ventilator associated pneumonia (VAP). WAP is usually diagnosed on a combination of clinical, radiographic and microbiologic criteria with a high sensitivity but IOW specificify for VAP. As a result, patients may receive antibiotics unnecessarily. Specificity can be increased by the addition of quantitative cultures of samples of protected specimen brush (PSB) and bronchoalveolar lavage (BAL) to the diagnostic criteria.

\section{Methods}

We prospectively analyzed the effects of implementation of PSB and BAL in the diagnosis of VAP on antibiotic prescription. PSB and/or BAL were performed in patients who fulfilled the clinical, radiographic and microbiologic criteria for VAP. Based on quantitative cultures of PSB and/or BAL, patients were categorized in three groups: VAP microbiologically proven (group $1 ; n=72$ ); cinical suspicion of VAP not confirmed microbiologically (group 2; $n=66$ ); and patients in whom bronchoscopy could not be performed (group $3 ; n=17$ ).

\section{Results}

In group 1. antibiotic therapy was instituted empirically in 40 patients (56\%) (group 1a) and after obtaining culture results in the other 32 patients (group $1 \mathrm{~b}$ ). Adjustment of therapy, based on culture results, occurred in $14(35 \%)$ patients in group 1a. In group 2 , empiric therapy was instituted in $34(52 \%)$ patients (group 2a) and discontinued within 48 $\mathrm{h}$ in 17 of them $(50 \%)$. in group $3,17(100 \%)$ patients were treated with antibiotics. Among the 66 patients in whom a clinical suspicion of VAP was not confirmed, only 18 $(27 \%)$ were treated with antibiotics, and antibiotic therapy was withheld in $48(35 \%)$ of 138 patients who underwent bronchoscopy. Withholding of antibiotic therapy had no negative effect on the recurrence of a clinical suspicion of VAP or on mortality rates.

\section{Conclusions}

We conclude that addition of bronchoscopic techniques to the criteria for VAP may help to reduce antibiotic use. However, the definite benefits and cost-effectiveness of these techniques should be analyzed in a randomized study. 


\section{Introduction}

More than $50 \%$ of antibiotic use in intensive care units (ICUs) is instituted to treat presumed respiratory tract infections, especially in mechanically ventilated patients". Establishing the diagnosis of ventilator "associated pneumonia (VAP). however, is difficult ${ }^{2}$. Generally, a combination of cinical parameters such as fever, leukocytosis, a positive culture of tracheal aspirate and an infiltrale on chest $X$-ray are used for this purpose. Although the combination of these criteria may have a high sensitivity, specificity is $l o w^{3}$. As a result, many patients may unnecessarily receive antibiotics. The addition of quantitative cultures of samples obtained with bronchoscopic techniques, such as protected specimen brush (PSB) and bronchoalveolar lavage (BAL), to these clinical parameters increases speciffcily and may decrease unnecessary antibiotic use.

Although many studies have determined predictive values of positive or negative results from samples obtained by $\mathrm{PSB}$ and BAL for the diagnosis of pneumonia in selected groups of ventilated patients, little data is available on the clinical consequences of the implementation of these techniques in daily practice. We prospectively studied whether adding the results of PSB and BAL to the generally used criteria for diagnosing VAP influenced antibiotic prescription by intensive care physicians. In, addition, we analyzed some costs associated with diagnosis and antimicrobial therapy of VAP.

\section{Methods}

The study was performed in the 16-bed general ICU of the University Hospitall Maastricht. All patients admitted between January 1 and December 31, 1994 were included. Demographic characteristics and APACHE II score were recorded on admission, and clinical parameters were followed daily. All episodes of infection and antibiotic use were registered prospectively.

In mechanically ventilated patients, a clinical suspicion of pneumonia was defined by the criteria listed in table 4.1. These clinical, microbiologic and radiographic criteria were used as an indication to perform bronchoscopy with PSB and BAL as described elsewhere $e^{4}$. Depending on the results of bronchoscopy, the cases of a clinical suspicion of pneumonia were divided into three groups. Group 1 contaned those patients for whom the clinical suspicion of pneumonia was microbiologically proven (ie., when quantitative cultures of PSB yielded $\geq 10^{3}$ cfu/mll andior of BAL yielded $\geq 10^{4}$ cfu/ml). Group 2 contained those patients in whom the clinical suspicion of pneumonia was not confirmed (ie., when the quantitative cultures of PSB and BAL were sterile or below the above mentioned cut-off points). Finally, group 3 contained those patients that had not undergone bromchoscopy. 
423 positive of the following 4 :

1. Mechal tomperature above $3 \mathrm{~g} 0 \mathrm{0}$ or below $35^{\circ} 5^{\circ} \mathrm{C}$

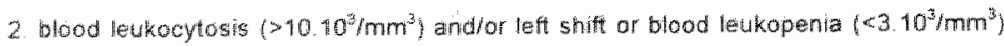

3. 10 lewkocytus per high-power held in Gram staim of tracheal aspirate

4. posinge culture fromi tracheal aspirate

and

1

naw. persistent or progressve infiftede on chest radiograph

The diagnosis of a clinca! suspicion of pneumonia was made whun the criteria $A$ and $B$ were were postive.

Antibiotic therapy was prescribed by the responsible attending critical care physician, and was in no way dictated by protocol. However, the choice of compounds was guided by the hospital formulary. In general, the results of Gram staining of samples obtained by BAlw were available within $2 \mathrm{~h}$ after bronchoscopy, preliminary culture results were avallable after $24 \mathrm{~h}$ and define culture results with in vitro susceptibility testing results were available after $48 \mathrm{~h}$. Empirical therapy was directed towards pathogens isolated from clinical and surveillance cultures of tracheal aspirates, and patients with VAP were treated with antibiotics for 2 wk. Survellance cultures of tracheal aspirates were obtained on admission and twice weekly from all patients. In case of a suspicion of VAP, clinical cultures from tracheal aspirates were obtained unless surveillance cultures had been taken within $24 \mathrm{~h}$. In the follow-up of each patient, the duration of antibiotic therapy and the recurrence of a new clinical suspicion of pneumonia was registered.

In case of a clinical suspicion of pneumonia, antibiotic therapy was only instituted after bronchoscopy had been performed. When a patient was receiving antibiotics $>48$ h for another unrelated infection or for prophylaxis on the day that the criteria for a clinical suspicion of pneumonia were met, antibiotics were not changed until bromchoscopy.

Antibiotic consumption was analyzed in prescribed daily doses (PDD). The costs of antibiotic therapy were calculated using the prices per PDD paid by the hospital pharmacy, including the costs of monitoring serum antibiotic concentrations for aminoglycosides and vancomycin (average three times weekly). The costs of bronchoscopy as used in this study (\$453.00) (1 United States dollar $=1,70$ Dutch florin), were the actual costs calculated by the hospital and included physician's charges and costs for material and microbiologic analysis.

Data are presented as mean values \pm SD and analyzed by the chi-square test for categorical variables and Student's $t$ test for parametric continuous variables. 


\section{Results}

\section{Study population}

A total of 469 patients (515 admissions) were admitted to the ICU during the study period, and $274(58 \%)$ patients were intubated and mechanically ventilated for a mean duration of $13 \mathrm{~d}$. The majority of the patients were admitted because of medical $(n=182$, ventilated $n=89$ ) or surgical ( $n=197$, ventilated $n=140$ ) reasons. The criteria for a clinical suspicion of pneumonia were met in 155 patients. Bronchoscopy was performed in 138 cases: BAL was done in 126 episodes, PSB in 104 cases; both procedures were done in 92 cases. No bronchoscopy was performed in 17 episodes, because of medical contraindications such as hypoxemia despite ventilation with high positive end expiratory pressure (PEEP) and high $\mathrm{FiO}_{2}(n=6)$, critical clinical situation $(n=5)$, neurological objections $(n=2)$, coagulopathy $(n=1)$, or technical problems $(n=3)$. The mean APACHE $\|$ scores on admission were comparable for patients in each of the three groups: $19 \pm 6$ for group 1, $19 \pm 7$ for group 2 and $18 \pm 6$ for group $3(p=N S)$.

\section{Microbiologic results.}

Group 1 (patients in whom the clinical suspicion of pneumonia was microbiologically confirmed) contained 72 patients. These episodes of VAP were polymicrobial in 30 cases and were caused by Pseudomonas aeruginosa $(n=30)$, Staphylococcus aureus $(n=18)$, Enterobacteriaceae $(n=44)$, Streptococoi $(n=7)$. Haemophilus influenzae $(n=7)$, and Xanthomonas maltophilia $(n=1)$. In 42 patients $(58 \%)$, culture results of tracheal aspirates and bronchoscopy were concordant (e.g., the same species of microorganisms were isolated from tracheal aspirates and bronchoscopic samples); in 19 patients (26\%), more species of bacteria were isolated from tracheal aspirates than from bronchoscopic samples and in 11 patients (15\%), species of bacteria were isolated at concentrations above the threshold for VAP from bronchoscopic samples that had not been cultured from tracheal aspirates. Twenty patients $(28 \%)$ were on antibiotics when bronchoscopy was performed.

Group 2 (patients in whom the clinical suspicion was not confirmed microbiologically) contained 66 patients. In 35 patients (53\%), culture results from tracheal aspirates and bronchoscopic samples were concordant; in 24 patients (36\%), more species of bacteria were recovered from tracheal aspirates than from bronchoscopy; and in seven patients $(11 \%)$, bacteria were isloated from bronchoscopic samples that had not been cultured in tracheal aspirates. The diagnosis of VAP was not confirmed microbiologically because no bacteria grew from bronchoscopic samples $(n=37,56 \%)$ or because quantitative culture results did not reach the predefined cut-off points $(n=29,44 \%)$. Six patients without bacterial growth in previously obtained cultures of tracheal aspirates had nonsignificant bacterial growth in bronchoscopic samples. Twenty-eight patients $(42 \%)$ were on antibiotics when bronchoscopy was performed, but in all cases for $>48 \mathrm{~h}$. 


\section{Antibiotic use}

In group 1, empiric antibiotic therapy was instituted directly after bronchoscopy in $40(56 \%)$ patients (group $1 a)$ and, in the remaining 32 patients antibiotics were started after culture results were available (group 1b) (Figure 4.1). Antibiotic therapy was adjusted after culture results of bronchoscopy were available in 21 (53\%) of 40 patients in group 1a. In 11 patients, the spectrum of empiric antibiotic therapy, which was based on the bacteria isolated from previously obtained tracheal aspirates, could be narrowed. The reasons to adjust empiric antibiotic therapy in the remaining ten patients were as follows: the occurence of line sepsis at day $2(n=2)$; abdominal sepsis at day $4(n=1)$; a drug-induced rash $(n=1)$; the choice of an agent with better penetration because the patient also had intraabdominal abscesses $(n=1)$; colonization of tracheal aspirates with a new pathogen at day $5(n=1)$; clinical deterioration of the patient despite in vitro susceptibility for the empirical treatment of the pathogen causing VAP $(n=1)$; and in vitro resistance to the empiric antibiotic therapy $(n=1)$. Finally, in two patients significant numbers of a pathogen that had not been isolated from tracheal aspirates were isolated from bronchoscopic samples and these pathogens were not covered by empirical therapy. Therefore, the changes in antibiotics did reflect a correction of inappropriate empirical antibiotic therapy in three patients. As a result, in patients in whom VAP was microbialogically confirmed by quantitative cultures from bronchoscopic samples, antibiotic therapy was adjusted because of these culture results in 14 patients (19\%); by narrowing of the antibiotic spectrum in 11 patients; by adjusting therapy because of a pathogen not isolated from tracheal aspirates in two patients and because of resistance to empirical therapy in another patient.

In patients in group 2, empiric antibiotic therapy was instituted directly after bronchoscopy in $34(52 \%)$ of 66 patients (group 2a), and antibiotic therapy was discontinued within $48 \mathrm{~h}$ (when culture results were available) in 17 patients (Figure 4.1). The decision not to discontinue antibiotic therapy in the other 17 patients was made by the attending critical care physicians. In all cases, there was a high clinical suspicion of VAP, and in two patients, this decision was possibly influenced by a concomittant abdominal source of infection. No antibiotic therapy was instituted in 32 patients (group 2b). However, in one of these patients, antibiotic therapy was started $2 \mathrm{~d}$ after bronchoscopy because of a deteriorating clinical condition of the patient, despite nonsignificant culture results. This patient was treated with antibiotics for $7 \mathrm{~d}$ with a good clinical response and was discharged from ICU $15 \mathrm{~d}$ after initiating of therapy. Antibiotic therapy was instituted in $17(100 \%)$ patients in group 3 . 


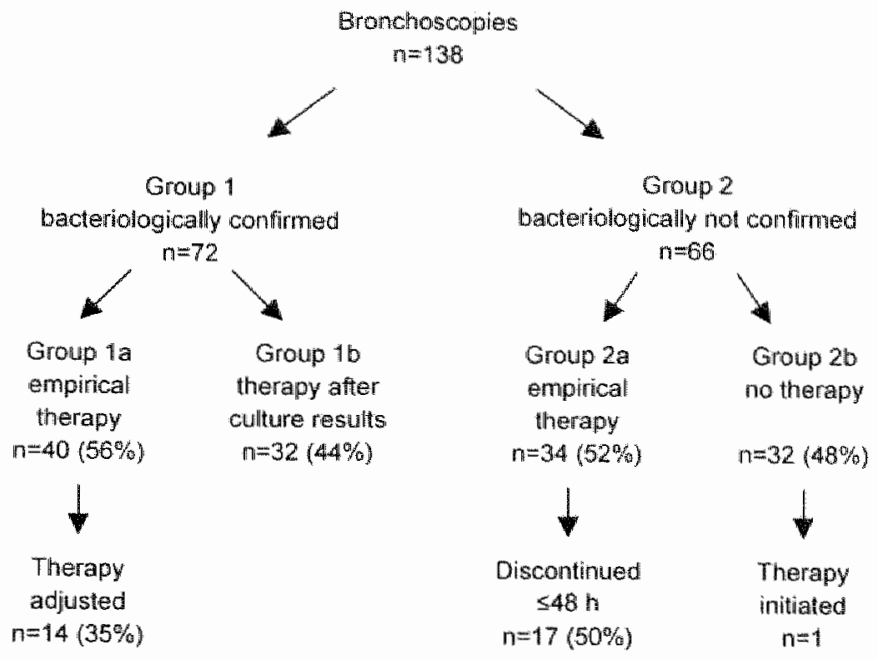

Filgure 4.1 Number of patients who underwent branchoscopy, in whom the cillinical suspiciom of Wap was confirmed or not, and in whom antibiotic therapy was instituted on adjusted

When patients were analyzed with regard to institution of empirical antibictic therapy, antibiotics were started immediately after bronchoscopy in 74 patients (groups $1 \mathrm{a}$ and $2 \mathrm{a}$ ). The clinical suspician of VAP was subsequently confirmed in 40 of these patients (group 1a); antibiotics were continued in all of them, and therapy was adjusted in 14 patients $(35 \%)$. In group 2 a (VAP not confirmed) antibiotics were discontinued within $48 \mathrm{~h}$ in 17 patients $(50 \%)$. In 64 patients, the decision to start antibiotics was postponed until culture results of bronchoscopic samples were available (groups $1 \mathrm{~b}$ and $2 \mathrm{~b}$ ). Among these palients, the diagnosis of VAP was confirmed in 32 patients (group 1b), and all were treated with antibiotics. In group 2b, one patient received antibiotics.

Consequently, among 66 patients in whom a clinical suspicion of pheumonia was nof confirmed by bronchoscopic culture results (group 2), 18 (27\%) patients received a full course of antibiotic therapy, while 48 patients (73\%) did not; 17 were treated for $<48 \mathrm{~h}$, and 31 were not treated. Overall, antibiotic therapy was withheld in $48(35 \%)$ of 138 patients that had undergone bronchoscopy (groups 1 and 2) and in none of 17 patients who did not undergo bronchoscopy (group 3) $(p=0.0002)$. In addition, in 14 of 72 patients (19\%) in whum VAP was confurmed by bronchoscopy, empiric therapy based on previousily obtained tracheal aspirates was adjusted. The mean duration of antibiotic therapy in $1 \mathrm{CU}$ was $10.6 \mathrm{~d}$ in group 1. $8.4 \mathrm{~d}$ in group 3, and $9.6 \mathrm{~d}$ for those patients in group $2(n=18)$ who were treated despite nonsignificant cullure results. The significant difference in duration of antibiotic therapy between groups 1 and $3(p<0.05)$ was a result of the fact that more patients in group $3(10$ of $17,58 \%)$ were discharged from ICU while still 
receiving antibiotics as compared with patients in group 1 (22 of $72,31 \%$ ). In group 2, nine (50\%) of 18 patients were still treated with antibiotics for the clinical suspicion of pneumonia when discharged from the ICU.

\section{Recurrence of a clinical suspicion of pneumonia and mortality}

A second clinical suspicion of pneumonia occurred in seven (15\%) of 48 patients in whom antibiotic therapy was witheld because of bronchoscopy results and in $18(17 \%)$ of 107 patients who had been treated with antibiotics ( $P=N S$ ). The duration until the second clinical suspicion of pneumonia was similar for patients who had or had not received antibiotic therapy; 15.8 and $13.1 \mathrm{~d}$ respectively $(p=N S)$.

Hospital mortality was $35 \%(17$ of 48$)$ in patients in whom antibiotic therapy had been withield and $39 \%$ (42 of 107 ) in patients who had received antibiotics $(p=N S)$. The APACHE II scores on admission were $19 \pm 6$ for patients who had been treated initially and $18 \pm 6$ for thase in whom antibiotics had been withheld $(p=N S)$. There were no significant differences in recurrence rates of clinical episodes of pneumonia or mortality rates between the three study groups (dala not shown). For patients in group 1, mortality rates were $50 \%(n=7)$ for patients in whom initial antibiotic therapy was changed based on bronchoscopic culture results $(n=14), 35 \%(n=9)$ for those with no change of therapy $(n=26)$, and $47 \%$ $(n=15)$ for those who received therapy when culture results were available. Statistical comparison of these groups did not approach significance $(p \geq 0.34)$. The delay in starting antibiotics in group $1 \mathrm{~b}$ did not influence outcome: The mortality rate in this group was $47 \%$, as compared with $40 \%$ in group $1 a$ ( $p=N S$ ), and the APACHE II scores in both groups were $20 \pm 6$ and $19 \pm 6$, respectively ( $p=N S$ ). For patients in group 2 , mortality rates were comparable for patients with no growth in bronchoscopic samples $(28 \%)$ and those with growth below the cutoff point for $\operatorname{VAP}(37 \%)(p=N S)$

\section{Cost analysis}

The mean costs of antibiotic therapy per episode of VAP, calculated from all episodes of pneumonia that were treated were $\$ 549.00$, corresponding to $\$ 39.00$ per day of treatment. The actual costs of an episode of bronchoscopy (including physicians' charges and microbiologic analysis) were $\$ 453,00$. As a result, 48 episodes of suspected VAP were not treated (projected costs: $\$ 26,352.00$ ) at the expense of 138 episodes of bronchoscopy (actual costs: $\$ 62,514.00$ ). The costs of nursing and phamacy administration as well as the costs of antibiotics that were given for $<48 \mathrm{~h}$ (total: $\$ 1,481.00$ ) were not included in this analysis.

Under the circumstances tested, the introduction of bronchoscopic techniques would only be costeffective if the costs of bronchoscopy would be $\$ 191.00$, when the proportion of patients in whom therapy would be withheld would increase to $114(83 \%)$ of 138 , or when the costs of antibiotic therapy per episode of VAP would be $\$ 1,302.00$, corresponding to $\$ 93.00$ per day. 


\section{Discussion}

The results of this study suggest that implementation of bronchoscopic techniques to the criteria for diagnosing VAP may help to reduce antibiotic use in ICUs. In addition, empiric antimicrobial therapy was adjusted in $19 \%$ of the patients with proven VAP, in most cases by narrowing the antibiotic coverage. In patients with a clinical suspicion of pneumonia but with nonsignificant quantitative cultures from respiratory samples obtained by bronchoscopic techniques, withholding of antibiotic therapy was not associated with an increased mortality rate or a higher recurrence rate for VAP.

Treatment of respiratory infections accounts for the largest part of antibiotic consumption in ICUs in a recent one-day point-prevalence study of nosocomial infections in 1,047 ICUS in 17 European countries including 10,038 patients, $44.8 \%$ of all patients had one or more infection, mostly nosocomial and $64.7 \%$ of these infections were respiratory tract related ${ }^{\prime}$. On the day of study, $62.3 \%$ of all patients received antibiotics; $51 \%$ more than one agent". However, in that study, bronchoscopic techniques were not used to diagnose respiratory tract infections, which probably resembles the current situation in many ICUs. As a result, the prevalence of respiratory tract infections may have been overestimated, which may have led to unnecessary antibiotic use.

We implemented bronchoscopic techniques in the routine work up of a clinica! suspicion of nosocomial pneumonia in ventilated patients. A clinical suspicion of pneumonia was based on a combination of clinical radiograpic and microbiologic criteria, which are generally used in clinical practice. These criteria have a high sensitivity but a low specificity for VAP ${ }^{5.6}$. Many studies have demonstrated that addition of quantitative culture results of PSB or BAL increase the specificity for VAP in selected patient groups $s^{2,6,7}$. However, few studies prospectively analyzed the effects of implementation of these new diagnostic techiniques on clinical practice. The results of the present study show that addition of bronchoscopic techniques to the diagnostic criteria for pneumonia resulted in adjustment of empirical antimicrobial therapy in $19 \%$ of patients with bronchoscopically proven episodes of VAP and in withholding of antibiotics in $48(35 \%)$ of 138 patients However, the study design employed does not allow us to conclude that bronchoscopy alone was responsible for this reduction. For example, in some patients, fulfilling the criteria of pneumonia, the physicians' clinical judgement allowed them to withhold antibiotics, and bronchoscopy confirmed this clinical judgement. Importantly, withholding of antibiotics in these cases did not result in a higher recurrence rate of a clinical suspicion of pneumonia during the same period of admission and was not associated with a higher mortality rate. The absence of differences in mortality was compatible with similar APACHE $\| 1$ scores on admission in these patient groups. On the other hand, there were 17 patients who were continued on antibiotics because of the physicians' clinical judgement, despite negative results from bronchoscopy. In these cases, the responsible 
physicians did feel reluctant to discontinue antibiotics. The decision to institute and continue antibiotic therapy was in the hands of the responsible attending physicians and was in no way prescribed by protocol. Indeed, false-negative results of bronchoscopic techniques have been reported and may occur because of prior antibiotic therapy or because of 'borderline' results of quantitative analysis, possibly indicating that the infection is in an early stage ${ }^{3}$.

Our data confirm data reported by croce and coworkers ${ }^{9}$. They calculated that addition of bronchoscopic techniques for diagnosing VAP could significantly reduce associated charges. In a pilot study of 10 trauma patients, the diagnosis of VAP was rejected in sewen patients. Discontinuation of empiric therapy had no negative influence on the clinical condition of these patients and, in that medical center, witholding of complete therapy resulted in net savings of $\$ 47.060 .12^{9}$. In contrast. other investigators reported that addition of BAL for diagnosing WAP did not improve patient outcome ${ }^{10}$. In that study, the adequacy of antibiotic therapy, administered before VAP was diagnosed, seemed to be the mast important variable influencing outcome: $50(77 \%)$ of 65 patients in which the clinical suspicion of VAP was confirmed by BAL received antibiotics before bronchoscopy. was performed. If these antibiotics were adequate for the microorganisms recovered from $\mathrm{BAL}$, mortally was $38 \%$, whereas mortality rates were $91 \%$ and $60 \%$ when these antibiotics were inadequate or when no antibiotics had been adminsitered, respectively ${ }^{10}$. However, since in that study, $77 \%$ of patients with VAP received antibiotics before bronchoscopy, and overall mortality was $67 \%$ (similar for patients with and without confirmed pneumonia). with $50 \%$ of the nonsurvivors dying within $48 \mathrm{~h}$ after diagnosis of VAP, it seems difficult to compare the findings in that population to our situation.

Costmeffectiveness is an important criterion for introduction of a new diagnostic test. The present study shows that, in our ICU, addition of bronchoscopic techniques to the generally used criteria for VAP may have helped to reduce antibiotic therapy in $35 \%$ of cases. In 17 patients, antibiotics were discontinued because of bronchoscopy results, but, as discussed above, in those cases that empirical antibiotic therapy was withheld (in 31 patients); bronchoscopy just helped to confirm the clinical judgement of the physician. The superficial analysis of costs as performed should not be regarded as an appropriate cost-benefit analysis. However, the results show that a formal cost-benefit analysis will be influenced by variables that will not be the same among different settings. For instance. antibiotic therapy depends on locah susceptibilities of microorganisms, with a general rule that more resistant bacteria must be treated with more expensive antibiotics. In our ICU, all strains of $S$. aureus were susceptible to methicillin, extended-spectrum beta-lactamases had not been isolated, and all strains of P. aeruginosa were susceptible to piperacillin and gentamicin. Therefore, the calculated costs for therapy in the present study (\$39.00 per day) probably are low when compared with other centers with more resistant pathogens. For example, in 
the study of Croce and coworkers performed in the United States, standard empric therapy (ceftazidime and vancomycin) costs $\$ 221.56$ per day. Another important variable is the proportion of 'negative' culture results of bronchoscopic techniques. The incidence of suspected pneumonia, based on the generally used combination of radiographic, clinical and microbiologic criteria, may seem thigh in our study However, our study population consisted of patients with a mean duration of ventilation of $13 \mathrm{~d}$ and the proportion in which the clinical suspicion was not confirmed $(48 \%)$ is similar to or lower than those reported by others. Timsit and coworkers studied 112 patients with a clinical suspicion of VAP and this suspicion was confirmed by quantitative cultures from samples obtained by bronchoscopic techniques in 50\% ${ }^{11}$, and Luna and colleagues reported that BAL did not confirm a clinical suspicion of pneumonia in $49 \%{ }^{10}$. Others, however, excluded VAP after performance of PSB in $71 \%$ of the cases', thereby increasing the 'benefit' of bronchoscopy. In addition, the costs for bronchoscopy, although regarded as expensive, may differ between centers. Interestingly, several recent reports suggested good correlations between quantitative culture results of PSB or BAL with quantitative culture results of samples obtained by deep endotracheal aspiration ${ }^{12,13}$ or blind $\mathrm{PSB}^{14}$. If these cheaper, and less invasive, techniques prove to be equivalent to quantitative cultures of bronchoscopic techniques, they are much more likely to be cost-effective for diagnosing VAP. Besides of the financial aspects of diagnosing VAP, aspects like toxic effects of unnecessary prescribed antibiotics and their long-term influence on antibiotic susceptibilities should be considered. On the other hand, complications of bronchoscopy: although occurring infrequently, include a drop in $\mathrm{PaO}_{2}$, arrhytmias, pneumothorax, transient progression of pulmonary infiltrates, and fever ${ }^{15,16}$. No serious adverse effects of bronchoscopy were encountered during the present study.

In conclusion, bronchoscopic techniques may be helpful and safe tools in the diagnosis of VAP. Under the circumstances tested, implementation of these techniques in the routine workup of a clinical suspicion of VAP influenced clinical practice, decreasing the number of patients receiving antibiotic therapy. Withholding antibiotics to these patients did not affect the recurrence rate of a clinical suspicion of pneumonia and was not associated with a higher mortality rate. The clinical impacts and a formal cost-benefit analysis of these new diagnostic tools should be determined in a prospective randomized fashion 


\section{References}

1. Vincent J. Bhan D, Suter Pi, Buning Hit White 3. Nicolas-Chanom M, Whof M. Spencer $R$. and Herminer M the prevalence of nosocombin infection in intensive care unts in Europe Results of the european prevalence of infection in intensive care (EPIC) study fournal of the American Madical Association

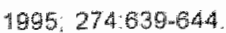

Bonten M, Gaillard $G$, Nouters $E$, wan Tiel $F$. Stobberingh $E$, and vam der Geest S. Problems in diagnosing nosocomial pneumoria in mechanically venthated patients: a review. orilical Cane Wedicine 1994; 22:1683-691.

Johanson W. Seidenfeld Somez P. de Los Santos R. and Coalson 3. Bacteriologic diag. nosis of nosocomial pneumonia following prom longed mechenical ventflation. American Review of Respiratory Dis 1908; 137.259-264.

Thorpe J Baughman R. Frame P. Wesseler $T$, and Stameck J. Bronchoalveolar lavage for diagnosing acule bacterial pneumonia. Jour nal of Infectious, Diseases $1987 ; 155 ; 855-86$ 1.

Chastre J, Fagon J, and Trouillet J Diagnosis and treatment of nosocomial preumomia in patients in intensive care units. Clinical Jnfectious Diseases 1995: 21:5226-5237.

Torres A. Puig de la Bellacasa J, Xaubet $A_{1}$ Gonzalez J, Rodriguez-Roisin $R$, limenez de Antla MT, and Agusti-Widal A. Diagnostic value of quantitative culures of bronchoalveolar Havage and telescoping plugged catheters in mechanicaliy ventilated patients with bacterial preumona. Amterican Rewiew of Respiratory Discase 1909; 140:306-310

Niedemain $M$, Torres $A$, and Summer $W$ Inwasive diagnostic testing is not newed routinely to manage suspected ventilatorassociated pneumoria. American Jounal of Paspiratory and Critral Care Medicine $1994: 150: 565-560$
9. Croce Mabian T. Shaw B. Stewart $R$ Prtchard F" Minard $G$. Kudsk $K$ and Baselski V. Analysie of charges assoolated with diag nosis of nosocomial pneumonia: can routhe bronchoscopy be justrfied? Jowrnal of Trauma $1984 ; 37: 721-727$

10. Luna C, Vujacich $P$, Niedermian M. Vay $C$ Gherardi $C$, Matera $J$ and Jolly E. Impact of BAL data on the therapy and outcome of ventilator-associated pneumonia. Chest $199 \%$ $111: 676.685$

11. Timsit JF, Chevret $S$, Valcke $J$, Misset $B$. Renaud $\mathrm{B}$, Goldstein FW Vaury $P$, and Carlet J. Mortality of nosocomial pneumonia in vertilated pattients: influence of diagnostic tools. American Jounal of Respiratoy and Critical Care Medicine 1996; $154: 16-123$.

12. Marquette C, Georges $M$, valet F, Ramon $P$.

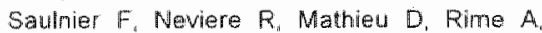
and Tonnel A. Diangnostic efficiency of endotracheal aspirates with quanitative bacterial cuttures in intubated patients with suspected preumonia. Comparison with the protected specimen brush. Amorican Review of Respiratory Disease $1993 ; 148: 138-144$

13. El-Ebiary M, Torres A, González J, Puig de la Bellacasa J Garcia $C$, Jimenez de Anta M. Ferrer M, and Rodriguez-Roisin $R$. Quantitative cultures of endotracheal aspirates for the diagnosis of vertilator-associated pmeumonat. American Rowew of Respiralory Disease 1993: 148:1552-155\%.

14. Pugin J, Aumenthaler $\mathbb{R}$, Mili $N$ Janssens $d$ Lew $P$, and Suter P. Diannosis of ventilator-assoclated pneumonia by bacterialogic analysis of bronchoscopic and nonbronchoscopic "bind" bronchoalveolar lavage flud. American Revizm of Rospiratory Disarse $1991 ; 43: 1121-1129$.

15. Guerra L and Baughman R. Use of bronchoakeolar lavage to diagnose bacteriail preumonia in mechanically vertilated patients. Crithal Care Medicine 1990; 18:169-173

46. Pugin J and Suter P. Diagnastic bronchow alveolar lavage in patients with preumonia produces sepsis-like systemic eftects. Intensive Care Medicine 1992, 18:6-10 


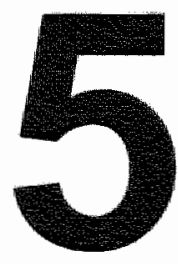

Risk factors for pneumonia, and colonization of respiratory tract and stomach in mechanically ventilated ICU patients

Bonten MJM, Bergmans DCJJ, Ambergen AW, de Leeuw PW, van der Geest S, Stobberingh EE, Gaillard CA 


\section{Abstract}

\section{Background}

Ventilator-associated pneumonia (VAP) is a frequent infection among ICU patients. Colonization of the upper respiratory and intestinal tract is assumed to be important in the pathogenesis of VAP. Although a number of risk factor analyses for the development of $\checkmark A P$ have been performed, preceding colonization at different body sites has not been included as a risk factor in any of these analyses.

\section{Methods}

To further elucidate the pathogenesis of VAP we determined the risk factors for the development of WAP and colonization of the respiratory tract and stomach with enteric Gram-negative bacteria (EGB) and Pseudomonadaceae in 141 patients receiving mechanical ventilation for at least $3 \mathrm{~d}$, using univariate analysis and the Cox proportional hazards model.

\section{Results}

VAP was caused by EGB in 14 patients $(10 \%)$, and by Pseudomonadaceae in 19 patients $(13 \%)$. The duration of ventilation was a significant risk factor for VAP caused by EGB and Pseudomonadaceae, and for acquired colonization in oropharynx, stomach and trachea with these species. Of 20 other variables, oropharyngeal colonization with $E G B$ on admission (hazard ratio $(H R)=4.5)$ and an infection on admission $(H R=2.7)$ were selected as risk factors for VAP caused by EGB. Acquired colonization with Pseudomonadaceae in oropharynx $(H R=5.0)$ was the most important risk factor for VAP caused by these species. Gastric colonization with EGB or Pseudomonadaceae were no risk factors for VAP. For acquired oropharyngeal colonization with EGB only the duration of ventilation was a risk factor, whereas preceding colonization of the trachea with Pseudomonadaceae and duration of ventilation were risk factors for acquired oropharyngeal colonization with these species. in the Cox model, only the duration of ventilation was significantly related to acquired gastric colonization with EGB. Preceding colonization of the oropharymx and of the trachea with Pseudomonadaceae were risk factors for acquired colonization with these species in the stomach. Twelve patients with VAP (46\%) and 38 without VAP (33\%) died $(p=0.21)$

\section{Conclusions}

Duration of ventilation and colonization of the upper respiratory tract are the most important risk factors for VAP caused by EGB or Pseudomonadaceae. 


\section{Introduction}

Ventilator-associated pneumonia (VAP) is a frequent infection among intensive care unit (ICU) patients and has been associated with increased morbidity, mortality and a longer hospital stay for survivors of this condition ${ }^{12}$. In the pathogenesis of this infection, gastric colonization with potentially pathogenic microorganisms is assumed to be important ${ }^{3-5}$. In this hypothesis, microorganisms initially colonize the stomach, subsequently colonize the upper respiratory tract, and finally are aspirated into the lungs. Gastric colonization may be stimulated by decreased gastric acidity, as a result of stress ulcer prophylaxis or gastric nutri$\operatorname{tion}^{5.7}$

The use of sucralfate, a stress ulcer prophylactic agent which does not influence intragastric acidity, has been associated with lower gastric colonization rates and a lower incidence of VAP, compared with patients receiving antacids andior $\mathrm{H}_{2}$-antagonists 7, However, in a recent randomized, placebo-controlled, double-blind study, we failed to demonstrate differences in incidence of infection, colonization of stomach and respiratory tract, and levels of intragastric acidity between patients receiving either sucralfate or antacids". Moreover sequential analysis of colonization strongly suggested that the stomach was not an important source of bacteria causing VAP. These results confirmed previously reported data, indicating that the gastropulmonary route of colonization may not be as important in the pathogenesis of VAP as generally suggested ${ }^{10-12}$.

A risk factor analysis of the data, obtained from patients who have been entered in the previously mentioned double-blind study, may provide additional information about the pathogenesis of VAP. Risk factors analyses for the development of VAP and mortality in ICU patients have been performed before ${ }^{13+15}$. Unfortunately, however, preceding colonization at different sites has not been included as a risk factor in any of these analyses. Moreover the outcomes of these studies may have been flawed by inaccuracies in diagnosis. In all studies the diagnosis was based on a combination of cinical parameters and chest radiographs $^{13-15}$. Therefore, erroneous diagnoses might have occurred in approximately $30 \%$ of cases ${ }^{10}$.

In order to further elucidate the pathogenesis of colonization and infection of the respiratory tract in mechanically ventilated patients, we studied risk factors for the development of colonization of stomach, oropharynx and trachea, the development of VAP with enteric Gram-negative bacteria (EGB) and Pseudomonadaceae, and death in univariate and multivariate analysis in patients receiving mechanical ventilation for at least $3 \mathrm{~d}$. The results of the comparative study between sucralfate and antacids have been published recently". 


\section{Methods}

Aduit mechanically ventilated patients $(n=141)$ admitted to the ICU of the University Hospital Maastricht between August 1992 and August 1993 were included in this analysis. All patients were ventilated for at least $48 \mathrm{~h}$ and were prospectively followed. Because of predefined criteria ${ }^{g}$, patients were not eligible for this study in case of massive gastric haemorrhage or bleeding oesophageal varices, after oesophageal or gastric surgery, or when receiving $\mathrm{H}_{2}$-antagonists or $\mathrm{H}^{+} \mathrm{K}^{+}$ATPase inhibitors. Patients were randomly allocated to receive either sucralfate $(1 \mathrm{~g}$ every $4 \mathrm{~h})$ or antacids $(30 \mathrm{ml} \text { every } 6 \mathrm{~h})^{9}$. Samples of gastric and tracheal aspirates and aropharyngeal swabs were collected on admission and subsequently twice weekly. Additional tracheal aspirates were collected and analyzed as required by the attending physician. The attending physician was unaware of the culture results of oropharyngeal and gastric samples, and the results of $\mathrm{pH}$ monitoring. Patients were studied until extubation, death, or the institution of therapy influencing gastric acidity. In general, all patients were in supine position during controlied mechanical wentilation and if possible in semirecumbent position during weaning. There were no changes in body position during the course of the day, and promotility agents were not used

Informed consent was obtained from the patient or, if this was not possible because of the clinical condition, from a representative of the family. The study protocol was approved by the hospital ethical committee

\section{Definitions}

Ventilator-associated pneumonia

In case of clinical suspicion of pneumonia, bronchoscopy with protected specimen brush (PSB) and bronchoalveolar lavage (BAL) was performed as described elsewhere ${ }^{12}$. The diagnosis of VAP was established on the criteria listed in table 5.1. Episodes of preumonia diagnosed within the first $24 \mathrm{~h}$ of admission were considered present on admission.

\section{Colonization}

Colonization was defined as the isolation of EGB or Pseudomonadaceae from gastric aspirate, oropharyngeal swab, or tracheal aspirate, in the absence of infection. Colonization on admission was established by a positive culture obtained within $24 \mathrm{~h}$. Colonization was designated as 'acquired' if at least two positive cultures from consecutive samples yielded the same species, without colonization with that species on admission. Patients colonized on admission with one species of EGB might acquire colonization with another species of EGB during the study. Since the group of Pseudomonadaceae consisted almost entirely of Pseudomonas aeruginosa, patients colonized with this species on admission were excluded for acquired colonization with Pseudomonadaceae. 
Table 5.1 Criteria used for the diagnosis of ventiator-associated preumonia

Criteria

A $\geq 3$ positwe of the following 4

1 rectal temperature above $35.0^{\circ} \mathrm{C}$ or below $35.5^{\circ} \mathrm{C}$

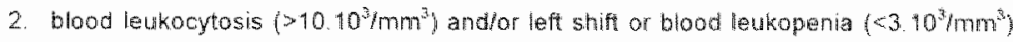

3. $>10$ leukocyes per high-power field in Gram stam of tracheal aspirate

4. positue culture from tracheal aspirate

and

B new, persistent or progressive infiltrate on chest radiograpls

and

C $\quad 21$ positive of the following 3 :

1. positive quanitative culture of a sample obtained by BAL (cut-off point $10^{4}$ ofu/m) or PSB cout-oft point $\geq 10^{\circ} \mathrm{cfu} / \mathrm{ml}$

2. positive blood culture unrelated to another source and obtained within 48 th before and after respiratory sampling

3. positive pleural flud culture in the absence of previous pleural instrumentation

Pneumonia was diagnosed if $A$ and $B$ and $C$ were positive

BAL, bronchoakeolar lavage; PSB, protected specimen brush.

\section{Bacteriologic examination}

Colonization was analyzed semiquantitatively as described previously". EGB included Escherichia coli, Klebsiella spp. Enterobacter spp., Proteus spp., Morganella morganii, Citrobacter freundir, Pseudomonadaceae included $P$, aeruginasa and Xanthomonas maltophilia.

\section{Intragastric $\mathrm{pH}$ monitoring}

Continuous computerized intragastric $\mathrm{pH}$ monitoring was performed as described previously ${ }^{9}$. From each measurement the median $\mathrm{pH}$ value was calculated.

\section{Administration of enteral feeding}

Enteral feeding (Nutrison, Nutricia, The Netherlands) was administered continuously and intragastrically, and delivered in sterile containers, containing volumes for $24 \mathrm{~h}$, by the nutritional service department.

\section{Risk factor analysis}

Separate analyses were performed in order to determine risk factors for VAP caused by EGB and Pseudomonadaceae; risk factors for acquired colonization with EGB and Pseudomonadaceae in the stomach, the oropharynx, and trachea; and risk factors for mortality. The analysis of mortality was restricted to mortality in ICU. The risk factors that were analyzed are listed in table 5.2. The APACHE II score was determined as described by Knaus and coworkers ${ }^{17}$. Persistence of a 
Glasgow Coma Score (GCS) $<8$ was scored positive when a patient had a GCS $<8$ (due to coma or sedatives) for at least five of the first $10 \mathrm{~d}$ in ICU, or at least half of the days in ICU when the duration of ICU stay was less than $10 \mathrm{~d}$. Sepsis syndrome and septic shock were defined as described by Bone ${ }^{18}$. The amounts of gastric residue per $24 \mathrm{~h}$ were monitored daily, and a gastric residue $>400 \mathrm{ml}$ was tested as risk factor.

Table 5.2 Characteristics of the pattents siluded

\begin{tabular}{|c|c|}
\hline & No of patients $(n=441)$ \\
\hline Mean age 1 SO (range) & $58+19(18-91)$ \\
\hline Maler Female & 88.53 \\
\hline $\begin{array}{l}\text { Admittimg senice } \\
\text { Surgery } \\
\text { Trauma } \\
\text { Medical } \\
\text { Puimonology } \\
\text { Meurology }\end{array}$ & $\begin{array}{l}54 \\
20 \\
33 \\
20 \\
14\end{array}$ \\
\hline mean APACHE II score \& SD hrange) & $21 \pm 9(1-46)$ \\
\hline $\begin{array}{l}\text { Stress uhe prophylaris } \\
\text { Antacids } \\
\text { Sucrallate }\end{array}$ & $\begin{array}{l}74 \\
67\end{array}$ \\
\hline $\begin{array}{l}\text { Intragastric pH on first day of adrutission } \\
<30 \\
230\end{array}$ & $\begin{array}{l}69 \\
72\end{array}$ \\
\hline $\begin{array}{l}\text { Computerzed intragastric pH montoring } \\
\text { mean pH \# SD (range) }\end{array}$ & $4.2+2.1(0.8 .7 .9)$ \\
\hline Infection on adnission & 39 \\
\hline $\begin{array}{l}\text { Sepsiss syndrome or septic shock } \leq 10 \\
\text { days of admission }\end{array}$ & 25 \\
\hline Persisting Glasgow Coma score $<8$ & 69 \\
\hline Abdominal or thoracic surgery & 40 \\
\hline Bastric residus & 96 \\
\hline Gastric nutrition & 82 \\
\hline Vontillation with PEEP $>5$ cm & 6 \\
\hline Mean thumber of days in 10U 150 (ranga) & $17+33(3-350)$ \\
\hline Mortality in $\mathrm{lCu}$ & 50 \\
\hline
\end{tabular}

For the development of VAP caused by EGB or Pseudomonadaceae, colonization with species from the same bacterial group in oropharynx, stomach, or trachea on admission, or acquired before VAP was diagnosed were tested as risk factors. For acquired colonization, colonization on admission and acquired colonization at the other sites with species from the same bacterial group were tested as risk factors as well. In addition, the number of patients with preceding colonization with the same species (rather than species from the same bacterial group) at the two other sites were determined. In order to be a potential risk factor 
for the endpoint of a certain analysis (such as development of VAP or acquired colorization), acquired colonization (at the other sites) had to be established before the endpoint was met. As a result, the number of patients with acquired colonization could be different in the separate analyses.

As for acquired colonization, the institution of enteral feeding was analyzed up to the day that the endpoint of analysis was met. Therefore, the number of patients receiving enterall feeding could be different in separate analyses.

In the initial study design, patients were stratified on the first day of admission to ICU based on their initial intragastric $\mathrm{pH}(\mathrm{pH}<3.0 \text { or } \mathrm{pH} \geq 3.0)^{9}$. When possible, continuous intragastric monitoring was performed as well, and the median pH value of this long-term measurement in each individual patient was used in the analysis.

\section{Statistical analysis}

Risk factors for VAP, colonization and mortality were identified using $t$ test, MannWhitney $U$ test or chil-square statistics when appropriate. For binomial variables, crude odds ratios (OR) were calculated by the formula $\left(\mathrm{P}_{\mathrm{a}} /\left(1-\mathrm{P}_{\mathrm{a}}\right)\right) /\left(\mathrm{P}_{\mathrm{b}} /\left(1-\mathrm{P}_{\mathrm{b}}\right)\right)_{\mathrm{s}}$ where $P$ is the outcome for patients with one of both variables tested. Variables found to be associated ( $p<0.05$ ) with the endpoint tested (VAP, colonization, or death) were entered into a Cox proportional hazards model. Each variable was separately analyzed in a Cox regression model, and the best-fitting model was constructed by the simultaneous inclusion of the significantly related variables. Hazards ratios (HR) with corresponding $95 \%$ confidence intervals $(95 \% \mathrm{Cl}$ ) were computed. A hazard ratio of a variable with two categories is the ratio of the two category-dependent probabilities for occurrence the event. For a continuous variable such as age, the hazard ratio is the ratio of two age-dependent probabilities for occurrence the event. Here the two ages differ one unit (i.e., 1 yr).

\section{Results}

\section{Patient characteristics}

A total of 141 patients were studied (Table 5.2). Seven patients, included in the study, needed $\mathrm{H}_{2}$-antagonists or $H^{*} K^{*}$ ATPase inhibitors after $4-14$ d. However, none of these patients reached an endpoint in any of the risk factor analyses after institution of acid-influencing medication; two patients developed VAP and five acquired colonization, all before institution of medication. Therefore, these patients are included in the analyses. The number of patients with acquired colonization and colonization on admission with EGB or Pseudomonadaceae is listed in table 5.3. 
Table 5.3 Colonzation wh cheric mam-rogative sacteria (ECB) and Pseudomonadaceae (Pseu in patients with and whous ventiator-asscolited pheurnonia"

\begin{tabular}{|c|c|c|c|c|c|c|c|c|c|c|}
\hline & \multicolumn{5}{|c|}{ Colonization Wha EGe } & \multicolumn{5}{|c|}{ Colonization with pest } \\
\hline & \multicolumn{3}{|c|}{ Pateris devoloping VAP } & \multirow[b]{2}{*}{$\begin{array}{l}\text { 斯的 VAP } \\
M=115\end{array}$} & \multirow[b]{2}{*}{ Totalt } & \multicolumn{3}{|c|}{ Palonis developing VIAP } & \multirow{2}{*}{$\begin{array}{l}\mathrm{M} Q \mathrm{VAP} \\
n=115\end{array}$} & \multirow[b]{2}{*}{ Totalt } \\
\hline & $\begin{array}{l}E G B \\
n=7\end{array}$ & $\begin{array}{l}P \text { Pset } \\
n=12\end{array}$ & $\begin{array}{l}\text { Both } \\
n=7\end{array}$ & & & $\begin{array}{l}E S B \\
n=7\end{array}$ & $\begin{array}{l}\text { Psed } \\
n=12\end{array}$ & $\begin{array}{l}\text { Botn } \\
n=7\end{array}$ & & \\
\hline \multicolumn{11}{|l|}{ Oropharym } \\
\hline On aldmission & 4 & 5 & 5 & 304 & 52 & 0 & 3 & 1 & $14 t$ & $\$ 7$ \\
\hline Actulured & 4 & 6 & 5 & 39 & $58(4)$ & 2 & 8 & 6 & 21 & $39(2)$ \\
\hline \multicolumn{11}{|l|}{ Stomiach } \\
\hline On adnitussion & 2 & 2 & 3 & 25 & 32 & 0 & $i$ & $\mathbb{1}$ & 48 & 6 \\
\hline Acounred & $4^{18}$ & 8 & 4 & 38 & $59(5)$ & al & 4 & 4 & 105 & $27(3)$ \\
\hline \multicolumn{11}{|l|}{ Trachea } \\
\hline On aumissich & 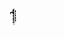 & 2 & 3 & 15 & 21 & 0 & 2 & 1 & 134 & 16 \\
\hline Acquiled & 3 & 3 & 4 & 17 & $33(6)$ & 1 & 8 & 5 & 25 & $25(3)$ \\
\hline
\end{tabular}

* In patients with VAP, acquired colonization is analyzed until the day of diagnosis.

Number of patients acquiring colonization after development of WAP.

Resulits of 2 piatients not avalubie.

Results of 8 patients not avaliable.

Results of 1 patient not awailabile.

\section{Ventilator-associated pneumonia}

Twenty-six patients (18\%) developed an episode of VAP caused by EGB and/or Pseudomonadaceae; in 12 patients VAP was caused by Pseudomonadaceae, in seven patients by EGB, and in seven patients VAP was polymicrobial and species from both groups were isolated. Five other patients developed an episode of VAP caused by Staphylococcus aureus, Streptococcus pneumoniae or Haemophilus influenzae, and were, therefore, not included in the risk factor analyses. None of these five patients developed a second episode of VAP caused by EGB or Pseudomonadaceae. In the 26 episodes of VAP caused by EGB and/or Pseudomonadaceae, 33 pathogens were isolated: 19 Pseudomonadaceae and 14 EGB. Preceding colonization with the same species as isolated from bronchoscopic samples was demonstrated in the oropharynx for $32(97 \%)$ of 33 species (19 Pseudomonadaceae and 13 EGB), in the trachea for $28(85 \%)$ of 33 species (19 Pseudomonadaceae and 9 EGB) and in the stomach for $14(42 \%)$ of 33 species (5 Pseudomonadaceae and 9 EGB).

\section{Enteric Gram-negative bacteria}

VAP caused by EGB $(n=14)$ was demonstrated after $8.9 \pm 5.3 \mathrm{~d}$ (median=7 $\mathrm{d}$ ). The total duration of ventilation was $22.4 \pm 17.8 \mathrm{~d}$ (median=16 d) for patients developing VAP with EGB compared with $10.9 \pm 14.2$ d (median=8 d) for those without VAP caused by $E G B(p=0.006)$. The median duration of hospitalization before admission to ICU was $5 \mathrm{~d}$ (range 2-21) and $3 \mathrm{~d}$ (range 1-203) for patients with and without VAP caused by EGB respectively ( $p=N S$ ). VAP was demonstrated in eight 
(11\%) of 70 patients receiving and six $(10 \%)$ of 62 patients not receiving enteral feeding $(p=N S)$. In univariate analysis, four factors were associated with a higher risk for VAP caused by EGB: acquired colonization with EGB in the trachea (7) $(26 \%)$ of 27 vs. 7 (6\%) of $114, \mathrm{OR}=5.86, \mathrm{p}=0.006)$, an infection on admission to ICU $(8(21 \%)$ of 39 vs. $6(6 \%)$ of $102, \quad O R=4,43, p=0.01)$, oropharyngeal colonization with EGB on admission $(9(17 \%)$ of 52 vs $5(6 \%)$ of $87, \quad O R=3.41$, $p=0.03)$, and acquired colonization with EGB in the oropharynx $(9(17 \%)$ of $54 \mathrm{vs}$ $5(6 \%)$ of $87, O R=3,41, p=0.04)$. In seven $(78 \%)$ of these nine patients, bacterial species colonizing the oropharynx on admission eventually caused VAP.

The event-free survival was analyzed by the Cox regression model with oropharyngeal colonization with EGB on admission, acquired tracheal colonization with $E G B$, acquired oropharyngeal colonization with $E G B$, and an infection on admission as covariates. The event-free survival was negatively influenced by oropharyngeal colonization with EGB on admission ( $p=0.006$ ), an infection on admission $(p=0.06)$, and acquired colonization in the trachea $(p=0.08)$. The bestfitting model selected oropharyngeal colonization on admission (HR=4.5. $95 \%$ $C l=1.5-13.7, p=0.009)$ and an infection on admission (HR=2.7, 95\%Cl=0.9-7.7, $p=0.07$ ) as most important risk factors for WAP caused by EGB (Figure 5.1).

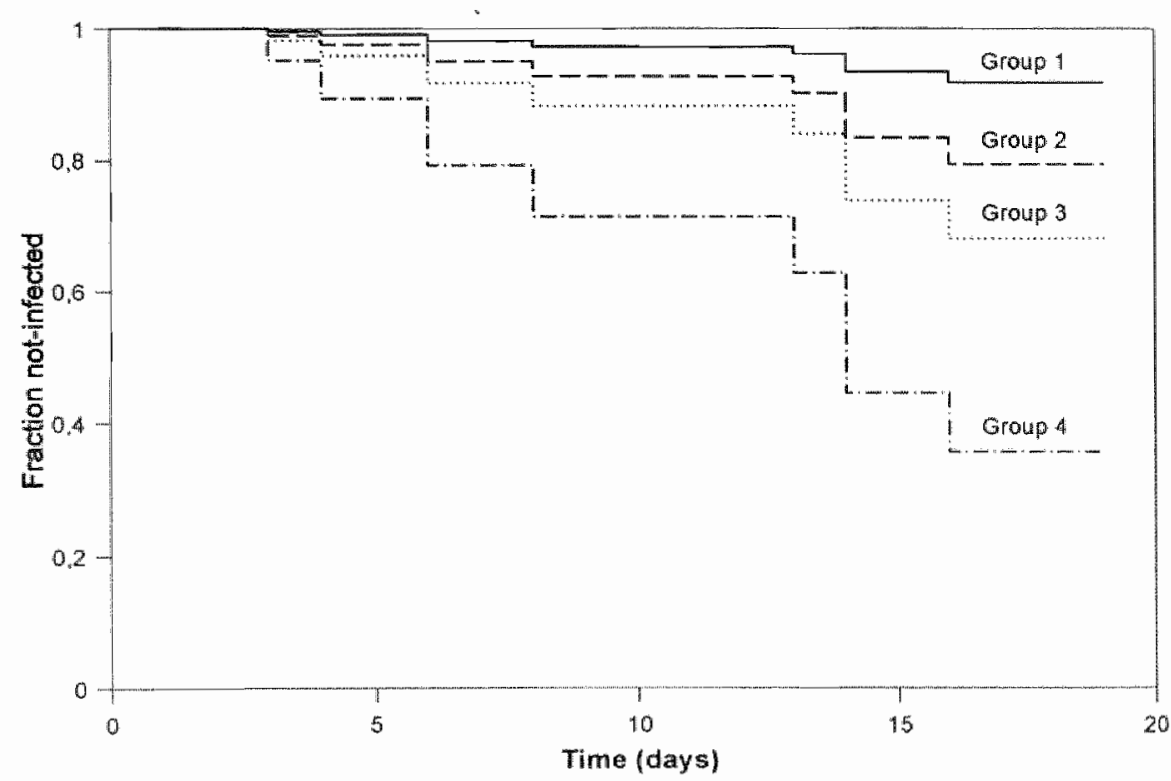

Figure 5.1 Event-free survial analysis of VAP cawsed by EGE. Group 1=patients without oropharyngeal colonization with EGB on admission and wibhout an infection on adrission. Group 2 patients without oropharyngeal colonization with EOB on admission but with an infection on admission. Group 3-patients with oropharyngeal colonzation with EGB on admission and without an infection on admission. Group 4 foptients with oropharygeal colonization with ESB on admasion and with an infection on admission. 


\section{Pseudomonadaceae}

VAP caused by Pseudomonadaceae $(n=19)$ was demonstrated after $11.7 \pm 8.6 \mathrm{~d}$ (median $=8 \mathrm{~d}$ ). However, the total duration of ventilation for these patients was $30.5 \pm 30.1 \mathrm{~d}$ (median=19 d) and $9.2 \pm 7.9 \mathrm{~d}$ (median=7.5 d) for unaffected patients $(p<0.00001)$. The median duration of hospitalization before ICU admission tended to be longer for patients developing VAP caused by Pseudomonadaceae: $7 \mathrm{~d}$ (range 1-203) and $3 d$ (range 1-125) respectively ( $p=0.07$ ). VAP developed in 14 $(18 \%)$ of 79 patients with enteral feeding and in five $(8 \%)$ of 62 patients who had not received enteral feeding $(p=0.09)$. VAP caused by Pseudomonadaceae was associated with acquired colonization with these species in the oropharynx (14 $(38 \%)$ of 37 vs. $5(5 \%)$ of $104, O R=11.59, p<0.00001)$, the trachea $(13(33 \%)$ of 39 vs. $6(6 \%)$ of $102, O R=7.68, p=0.00006)$, and the stomach $(8(33 \%)$ of 24 vs. $11(12 \%)$ of $114, O R=3.59, p=0.006)$, and the presence of sepsis syndrcme or septic shock $(7(28 \%)$ of 25 vs. $12(10 \%)$ of $116, O R=3.51, p=0.03)$. The eventfree survival was analyzed in the Cox regression model with acquired colonization with Pseudomonadaceae of the oropharynx, the trachea, and the stomach, and the presence of sepsis syndrome or septic shock as covariates. Both acquired colonization of the oropharynx $(p=0.002)$ and of the trachea $(p=0.009)$ negatively influenced the event-free survivall. In the best-fitting model acquired oropharyngeal colonization had an HR of $5.0(95 \% \mathrm{Cl}=1.6-15.3, p=0.005)$ (Figure 5.2).

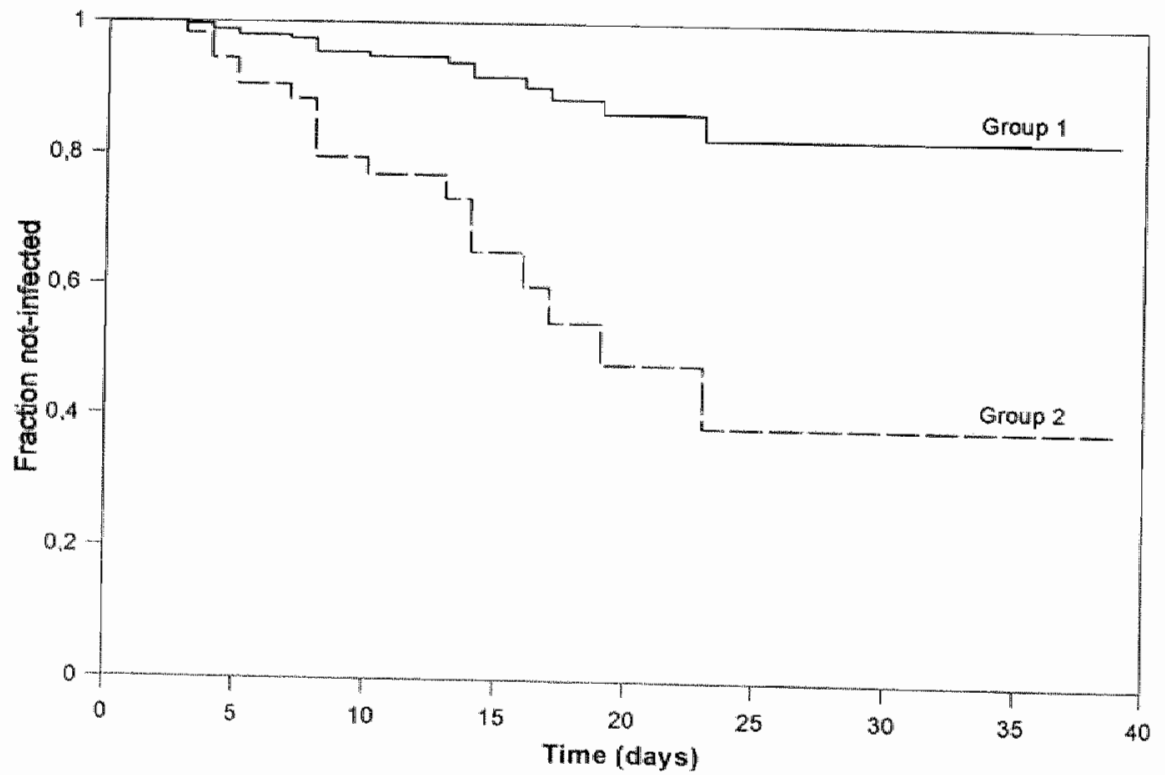

Figure 5.2 Event-free survival anaiysis of VAP caused by Pseudomonadaceae. Group 1=patients without acquired oropharyngeal colonization with Pseudomonadaceae. Group $2=$ patients with acquired aropharyngeal colonization with Pseudomonadaceae. 


\section{Acquired oropharyngeal colonization}

\section{Enteric Gram-negative bacteria}

Acquired colonization in oropharynx with EGB was demonstrated in $58(41 \%)$ patients after $7.8 \pm 7.0 \mathrm{~d}$ (median=7 d). Patients acquired colonization with EGB were ventilated for $18.7 \pm 19.4 \mathrm{~d}$ (median=13.5 d) compared with $7.4 \pm 8.1 \mathrm{~d}$ (median $=5 \mathrm{~d})(\mathrm{p}<0.0001)$ in the others. Surgical and trauma patients tended to acquire colonization more frequently than patients admitted for medical or neurologic reasons $(36(49 \%)$ of 74 compared with $22(33 \%)$ of 67 patients, $\mathrm{OR}=1.92, \mathrm{p}=0.06)$, as did patients receiving enteral feeding $(35(49 \%)$ of 72 compared with $23(34 \%)$ of 67 patients, $O R=1.86, p=0.06)$. Preceding colonization with the same species was demonstrated in the stomach in $11(19 \%)$, and in the trachea in five $(9 \%)$ of 58 patients acquiring oropharyngeal colonization ( $p=N S$ ). Moreover, the median durations of hospitalization before ICU admission did not differ statistically between patients acquiring and not acquiring colonization with EGB: $3 d$ (range 1-59) and $5 d$ (range 1-203) respectively $(p=N S$ ).

\section{Pseudomonadaceae}

On admission, $18(13 \%)$ of 141 patients were colonized with Pseudomonadaceae in the oropharynx. Because colonization persisted in all of them, these patients were excluded from the analysis of acquired oropharyngeal colonization. Acquired colonization with Pseudomonadaceae was demonstrated in $39(32 \%)$ of 123 patients after $7.7 \pm 4.0$ d (median $=7$ d). Patients acquiring oropharyngeal colonization with Pseudomonadaceae were ventlated for $19.8 \pm 14.6 \mathrm{~d}$ (median $=14$ d) compared with $7.3 \pm 5.8 \mathrm{~d}$ (median=6 d) for those without acquired colonization $(p<0.00001)$. Acquired colonization was demonstrated in $24(36 \%)$ of 67 patients receiving enteral feeding and in $15(27 \%)$ of 56 patients who did not ( $p=N S$ ). The median durations of hospitalization before admission to ICU were $3 \mathrm{~d}$ (range 1-33) and $4 \mathrm{~d}$ (range 1-203) for patients with and without acquired colonization respectively $(p=N S)$. Two risk factors were significantly related to acquired colonization with Pseudomonadaceae in univariate analysis. Tracheal colonization preceded oropharyngeal colonization in $12(71 \%)$ of 17 occasions, whereas acquired oropharyngeal colonization was found without tracheal colonization in 27 (25\%) of 106 patients (OR=7.35, $p=0.0004)$. Furthermore, $27(42 \%)$ of 65 patients with a persistent GCS $<8$ acquired colonization compared with $12(21 \%)$ of 58 patients ( $O R=5.28, p=0.01$ ).

In the Cox regression model, the duration until acquired colonization was negatively influenced only by preceding colonization of the trachea $(p=0.08)$

\section{Gastric colonization}

\section{Enteric Gram-negative bacteria}

Fifty-nine $(42 \%)$ patients acquired gastric colonization with EGB. The duration of ventilation before acquired colonization was $7.9 \pm 4.5 \mathrm{~d}$ (median=7 d). The total durations of ventilation were $18.7 \pm 20.6 \mathrm{~d}$ (median=12 d) and $7.9 \pm 8.4 \mathrm{~d}$ (median= 
5 d) for patients who did and did not acquire colonization ( $p=0.0001$ ). The periods of hospitalization before ICU admission were comparable between patients acquiring and not acquiring gastric colonization: $5 d$ (range 1-203) and $3 d$ (range $1-125)$ respectively $(p=N S)$. Thirty-six $(48 \%)$ of 75 patients receiving enteral feeding acquired colonization compared with $15(23 \%)$ of 65 patients who did not $(O R=3.08, p=0.002)$. Continuous intragastric $\mathrm{pH}$ monitoring was performed in 112 out of 141 patients. The $\mathrm{pH}$ values of individual measurements were $4.7 \pm 2.1$ (median=5.4) and 3.9 \pm 2.1 (median=3.8) for patients acquiring and not acquiring gastric colonization $(p=0.04)$. None of these risk factors were significantly related to acquired gasiric colonization in Cox regression analysis.

\section{Pseudomonadaceae}

Six $(5 \%)$ patients were colonized with Pseudomonadaceae in the stomach on admission and were, therefore, excluded from this analysis. Acquired gastric colonization with Pseudomonadaceae was demonstrated in $29(21 \%)$ of 135 patients after $10.5 \pm 5.5 \mathrm{~d}$ (median $=10 \mathrm{~d}$ ). The total duration of ventilation was $18.7 \pm 20.6 \mathrm{~d}$ (median=12 d) for patients with acquired colonization and $7.9 \pm 8.4 \mathrm{~d}$ (median $=5$ d) for other patients $(p<0.0001)$. Patients with and without acquired gastric colonization with Pseudomonadaceae had similar median durations of hospitalization before ICU admission: $4 \mathrm{~d}$ (range 1-203) and $4 \mathrm{~d}$ (range 1-125) respectively $(p=N S$ ). Acquired gastric colonization was frequently preceded by colonization at other sites. Colonization of the oropharynx without gastric colonization was found in 37 patients and was followed by gastric colonization in $17(46 \%)$ patients. Twelve other patients (out of 98 patients) acquired gastric colonization without preceding oropharyngeal coionization (OR=6.23, $p=0.00006$ ). Tracheal colonization preceded gastric colonization in $18(46 \%)$ of 39 patients and $11(11 \%)$ of 96 patients acquired gastric colonization without preceding tracheal colonization (OR=6.88, $p=0.00003$ ). Patients admitted because of surgery or trauma had a higher acquisition rate compared with patients admitted for medical or neurologic reasons $(20(29 \%)$ of $70 \mathrm{vs.} 9(14 \%)$ of 65 (OR=2.52, $p=0.04)$.

The event-free survival was analyzed in the Cox regression model with preceding colonization of the oropharynx and the trachea as covariates. Both variables almost equally influenced the duration until colonization; $p=0.09$ for preceding colonization of the oropharynx and $p=0.05$ for the trachea. The bestfitting model included preceding colonization of the trachea $(\mathrm{HR}=2.1,95 \% \mathrm{Cl}=0.97$ 4.6, $p=0.06$ ) as most important risk factor for acquired gastric colonization with Pseudomonadaceae (Figure 5.3). 


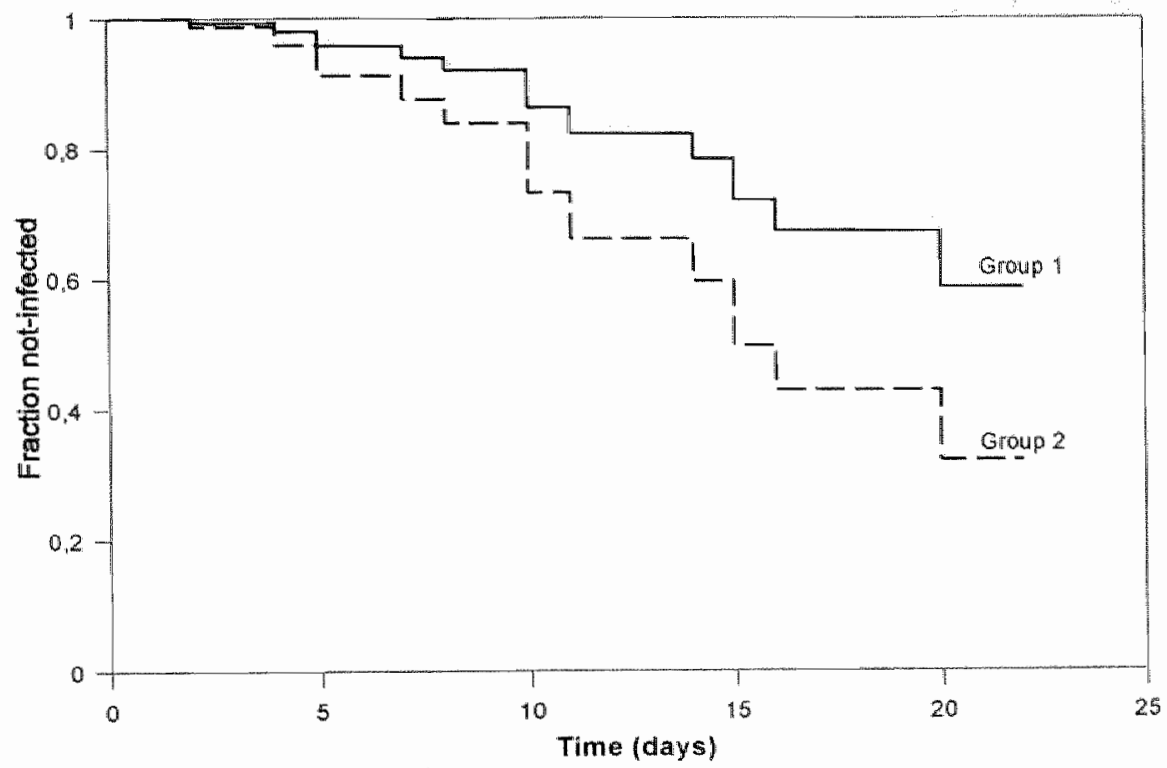

Figure 5.3 Event-fiee survival analysis of acquired gastric colonization with Pseudomonadaceare. Group $1=$ patients without preceding colonization of the rachea with Pseudrononadacaae. Group $2=$ patients with preceding colonization of the trachea with Pseudomonadaceae.

\section{Tracheal colonization}

Enteric Gram-negative bacteria

Acquired tracheal colonization with EGB was observed in 33 patients (23\%), after $11.9 \pm 14.3 \mathrm{~d}$ (median=8 d). The total durations of ventilation were $21.9 \pm 24.3 \mathrm{~d}$ (median $=15 \mathrm{~d}$ ) for patients who acquired tracheal colonization and $8.7 \pm 8.6 \mathrm{~d}$ (median=6 d) for those who did not ( $p<0.00001$ ). The median durations of hospitalization before admission to ICU were $4.5 \mathrm{~d}$ (range 1-48) for patients with and $3 d$ (range 1-203) for patients without acquired tracheal colonization with EGB respectively $(p=N S$ ). Moreover, none of the other risk factors were significantly associated with acquired colonization.

\section{Pseudomonadaceae}

Sixteen (12\%) patients were colonized with Pseudomonadaceae on admission and were excluded from this analysis. Acquired tracheal colonization was found in 42 ( $34 \%$ ) of 125 patients after $7.7 \pm 4.0 \mathrm{~d}$ (median $=7 \mathrm{~d}$ ). The total durations of ventilation were $18.7 \pm 1.4 \mathrm{~d}$ (median=13 d) for patients with acquired colonization and $6.9 \pm 5.5 \mathrm{~d}$ (median=6 d) for patients who did not acquire colonization $(p<0.0001)$. Again, no statistical significant differences were found in the median number of days of hospitalization before ICU admission: 3 d (range 1-58) for 
patients with acquisition and 4 d (range 1-203) for patients without acquisition $(p=N S)$. Oropharyngeal colonization without tracheal colonization was found in 19 patients and preceded tracheal colonization in $14(74 \%)$, whereas tracheal colonization occurred without preceding oropharyngeal colonization in $28(26 \%)$ of the remaining 107 patients $(O R=8.11, p=0.00008)$.

Table 5,4 Risk factors associated whth montality in umiwariate analysis

\begin{tabular}{|c|c|c|c|c|c|}
\hline Mistis factor & & 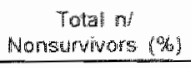 & $\begin{array}{l}\text { Odds Peato } \\
\text { of chi-square }\end{array}$ & Mean s $\mathrm{SO}$ & $\begin{array}{l}\text { p value of } \\
\text { chi-square }\end{array}$ \\
\hline Glasgona Comp score $<$ & $\begin{array}{l}\text { yes } \\
\text { no }\end{array}$ & $\begin{array}{l}69 / 36(55) \\
7212(17)\end{array}$ & 5.97 & & 00,00001 \\
\hline $\begin{array}{l}\text { Stepsis syndrome of septic } \\
\text { shoek }\end{array}$ & $\begin{array}{l}\text { yes } \\
\text { no }\end{array}$ & $\begin{array}{l}25 / 18(72) \\
11532(28)\end{array}$ & 6.61 & & 0.00004 \\
\hline Infectorn on adrutission & $\begin{array}{l}\text { yes } \\
\text { no }\end{array}$ & $\begin{array}{l}3924(54) \\
10229(28)\end{array}$ & 3.02 & & 0.005 \\
\hline $\begin{array}{l}\text { Orophatymgat colonization } \\
\text { with EGB on admisioni }\end{array}$ & $\begin{array}{l}\text { yes } \\
\text { no }\end{array}$ & $\begin{array}{l}5225(48) \\
37 / 25(29)\end{array}$ & 225 & & 0.02 \\
\hline $\begin{array}{l}\text { Gastric colonization wiln } \\
\text { EOB on admitasion }\end{array}$ & $\begin{array}{l}\text { yes } \\
\text { no }\end{array}$ & $\begin{array}{l}32160(50) \\
10130(30)\end{array}$ & 233 & & 0.04 \\
\hline $\begin{array}{l}\text { Admintstration of enteral } \\
\text { foeding }\end{array}$ & $\begin{array}{l}\text { yes } \\
\text { no }\end{array}$ & $\begin{array}{l}72 / 12(17) \\
69 / 38(55)\end{array}$ & 596 & & 80,00001 \\
\hline Speciatly of admission & $\begin{array}{l}\text { Surgerylatuma } \\
\text { medicalineurciogy }\end{array}$ & $\begin{array}{l}74 / 21)(28) \\
67 / 25,43\end{array}$ & 1.93 & & 0.06 \\
\hline APACHE U SCORE & $\begin{array}{l}\text { surviwors } \\
\text { norssurvivors }\end{array}$ & & & $\begin{array}{l}25.3 \pm 9.4 \\
90.0 \pm 72\end{array}$ & $<0.00001$ \\
\hline Age & $\begin{array}{l}\text { survivars } \\
\text { nonswrvivors }\end{array}$ & & & $\begin{array}{l}62.4 \pm 16.9 \\
550.19 .5\end{array}$ & 0.04 \\
\hline
\end{tabular}

\section{Mortality}

In all, 50 patients (35\%) succumbed during their stay in ICU. In the univariate analysis eight factors were significantly related to mortality (Table 5.4): a persistent GCS<8 ( $p<0.00001$ ), a clinical condition of sepsis syndrome or septic shock $(p=0.00004)$, an infection on admission $(\beta=0.005)$, oropharyngeal colonization with EGB on admission $(p=0,02)$. gastric colonization with $E G B$ on admission $(p=0.04)$, and inability to administer gastric nutrition $(p=0.01)$. In addition, the mean APACHE II score of patients who died was $25.3 \pm 9.4$ compared with $18.0 \pm 7.2$ for surviving patients $(p<0.00001)$, and the mean ages were $62.4 \pm 16.9 \mathrm{yr}$ and $55.6 \pm 19.5 \mathrm{yr}(\mathrm{p}=0.04)$ for both patient groups respectively. Furthermore, patients admitted for medical or neurologic reasons tended to have a higher mortality ratte compared with patients admitted because of trauma or surgery $(p=0.06)$. The development of VAP, caused by EGB or Pseudomonadaceae or both, was not associated with mortality: $12(46 \%)$ of 26 patients who developed VAP died, compared with $38(33 \%)$ of 115 patients who did not develop this infection ( $p=0.21$ ). Moreover, neither VAP caused by $E G B$ nor VAP caused by Pseudomonadaceae were associated with mortality $(p=0.57$ and $p=0.24$, respectively)

In univariate analysis, nime variables were associated with mortality (Table 
54). In Cox regression analysis, the best-fitting model pointed to admission for a medical or neurologic reason $(H R=2.2,95 \% \mathrm{Cl}=1.2-4.1, p=0.01)$, age $(H R=1.02$, $95 \% \mathrm{Cl}=1.00-1.04, \mathrm{p}=0.03)$, and oropharyngeal colonization with $\mathrm{EGB}$ on admission ( $\mathrm{HR}=2.0,95 \% \mathrm{Cl}=1.2-4.1, \mathrm{p}=0.03$ ) as most important risk factors. The HR of 1.02 for age means that the risk increases with $2 \%$ for each year. Furthermore, the ability to administer enteral feeding was a negative risk factor for mortality ( $H R=0.18,95 \% \mathrm{Cl}=0.09-0.35, p<0.0001$ ).

\section{Discussion}

The results of these risk factor analyses demonstrate that duration of mechanical ventilation and colonization of the oropharynx and trachea are the most important risk factors for the development of VAP. Colonization of the stomach did not appear to be a risk factor for VAP. Iin addition, there appeared to be considerable differences in risk factors for colonization with Pseudomonadaceae or EGB.

The data of the present study were collected during a randomized placebocontrolled study comparing sucralfate and antacids, which have already been published ${ }^{9}$. Nevertheless, we feel that the results of these risk factor analyses add important new information regarding the pathogenesis of colonization and infection of the respiratory tract in mechanically ventilated patients. A detailed risk factor analysis of infection and colonization with a discrimination between Pseudomonadaceae and EGB was beyond the scope of the prior report.

Of 21 variables, two entities were selected as risk factors for the development of VAP caused by EGB and Pseudomonadaceae: the duration of mechanical ventilation and colonization of oropharynx and trachea. The relationship between the duration of ventilation and an increased risk for VAP has been reported previously ${ }^{19,20}$. Moreover, the association between tracheal colonization and VAP seems obvious, since tracheal colonization is one of the diagnostic criteria for VAP.

The results of the present analyses corroborate previous data about the importance of oropharyngeal colonization in the pathogenesis of VAP. Johanson and coworkers studied the same relation in critically ill patients and found an incidence of pneumonia of $23 \%$ in colonized and of $3 \%$ in noncolonized patients ${ }^{21}$. However, in that study the diagnosis of VAP was not based on quantitative cultures obtained by bronchoscopic techniques.

The oropharyngeal microflora changes at times of illness, with the occurrence of EGB and Pseudomonadaceae as the most common shift ${ }^{22}$. The incidence of oropharyngeal colonization with these species in healthy subjects has been reported to be as low as $2 \%{ }^{23}$. Moreover, inoculation of the oropharynx with EGB did not result in colonization in healthy volunteers ${ }^{24}$. Hilwever, the incidence of 
colonization gradually increased with the severity of illness from $16 \%$ in moderately ill patients to $57 \%$ in critically ill patients ${ }^{23}$. Although the exact mechanisms of oropharyngeal colonization are not well understood adherence probably depends on changes of the structure of epithelial cells, making the cells 'stickier' for $\mathrm{EGS}^{22}$. Therefore, oropharyngeal colonization with $\mathrm{EGB}$ may be regarded as a marker of the severity of underlying illness. Moreover, the fact that an infection on admission also was a risk factor for VAP caused by EGB may represent a clinical condition in which the host is susceptible for other infections as well.

Risk factors for oropharyngeal colonization may also increase the risk for VAP. In the present study acquisition of oropharyngeal colonization with EGB merely was a matter of thime, generally occurring during the first week in $\| C U$. For EGB, surgical and trauma patients tended to acquire colonizathion more frequently compared with medical and neurologic patients, as did patients receiving enteral feeding. The relation between gastric nutrition and subsequent oropharyngeal colonization with EGB could have been a result of retrograde aspiration. Two studies demonstrated microaspiration of radioactive labelled enteral nutrition, especially in patients treated in supine position with a nasogastric tube in place ${ }^{25,26}$. However, previously reported chronological analyses failed to demonstrate that the pattern of colonization from the stomach to the respiratory tract occurred frequently in mechanically ventilated patients ${ }^{9-12,27}$. Moreover, although acquired gastric colonization with EGB was associated with enteral feeding and the intragastric pH in the present study, gastric colonization did not appear to be a risk factor for the development of VAP or oropharyngeal and tracheal colonization with EGB. The relation between gastric nutrition and gastric colonization underscores data reported by Pingleton and coworkers ${ }^{6}$ and us $^{26}$. Therefore, the importance of the gastropulmonary route of colonization for EGB has not yet been elucidated.

In contrast, a clear pattern of colonization was found for Pseudomonadaceae The upper respiratory tract was the initial site for acquired colonization with these species: acquired colonization of the oropharynx was associated with preceding tracheall colonization, and reversely, acquired tracheal colonization was frequently preceded by oropharyngeal colonization. As for $E G B$, duration of mechanica! ventilation also was an important risk factor for colonization with Pseudomonadaceae. The importance of the upper respiratory tract as the initial site of colonization was also obvious in the analysis of acquired colonization of the stomach with Pseudomonadaceae. Acquired gastric colonization was strongly related to prior colonization of the oropharynx and trachea. These data strongly suggest that colonization with Pseudomonadaceae starts in the upper respiratory tract, thereby confirming data reported by Niederman ${ }^{29}$ and by us $^{12}$.

There appeared to be considerable differences in risk factors for colonization with Pseudomonadaceae and with EGB. However, the power of these analyses to detect differences in risk factors for VAP caused by either of these species may be small, notably because $50 \%$ of the patients developing VAP caused by EGB had a polymicrobial infection in which Pseudomonadaceae were also involved. In our 
experience a large proportion of VAP is polymicrobial, and larger study populations will be needed to determine whether VAP caused by either of these pathogens have different risk factors

The method of multivariate analysis to identify risk factors for pneumonia in mechanically ventillated patients has been used before ${ }^{13-15}$. Unfortunately, a comparison of our data with those of other studies is hampered for several reasons. For instance, the duration of mechanical ventilation for patients who did not develop VAP, was remarkably shorter in two other studies. A duration of mechanical ventilation $<3$ d was reported for $57 \%$ of patients in one study ${ }^{14}$, and a duration of mechanical ventilation $<5$ d for $75 \%$ of patients in another ${ }^{15}$. In the present study, on the contrary, the minimal and median number of days of ventilation for patients not developing VAP were 3 and 6 d respectively. Furthermore, one should bear in mind that in all these studies only clinical criteria in combination with radiography were used to establish the diagnosis of VAP ${ }^{13-15}$, a method with a lower specificity than the additional use of bronchoscopic techniques like $\mathrm{PSB}$ and $\mathrm{BAL}^{16,30}$. Finally, in none of these studies was a discrimination made between VAP caused by EGB or caused by Pseudomonadaceae.

In these previous three studies, 13 variables were detected by multivariate analysis as risk factors for VAP ${ }^{13-15}$. In the study of Craven and coworkers intracranial pressure monitoring, changing of ventilator filters every $24 \mathrm{~h}$, the fallwinter season, and the use of cimelidine for stress ulcer prophylaxis were significantly associated with the development of VAP ${ }^{13}$. The first two variables could not be included in the present study, and seasonal differences were not found (data not shown). However, the influence of different stress ulcer prophylactic agents could be analyzed. As reported previously, we found no differences in intragastric acidity, colonization of stomach and respiratory tract and incidences of VAP in patients randomized to receive sucralfate or antacids".

None of the five risk factors for VAP as reported by Torres and colleagues ${ }^{14}$ (ie., a duration of mechanical ventilation $>3 \mathrm{~d}$, reintubation, ventilation with positive end-expiratory pressure (PEEP) $>5 \mathrm{~cm} \mathrm{H}_{2} \mathrm{O}$, gastric aspiration, and presence of chronic obstructive pumonary disease (COPD)), turned out to be significant in the present study. The relation between VAP and duration of mechanical ventilation $>3$ is obvious, but patients receiving mechanical ventilation for less than 3 d were excluded in the present study. In addition, reintubation and massive gastric aspiration occurred only seldom and could not be incorporated in the analysis. Ventilation with PEEP $>5 \mathrm{~cm} \mathrm{H}_{2} \mathrm{O}$ was used in six patients only and was not related to the development of VAP. Because the presence of COPD was not monitored, the influence of this risk factor was not analyzed in the present study.

Kollef reported four risk factors for VAP ${ }^{15}$. Three of these, an organ system failure index $>3$, supine head position during the first $24 \mathrm{~h}$ of ventilation, and previous antibiotic use, were not included in the present analysis. The other risk 
factor, an age $>60 \mathrm{yr}$, did not come up as risk factor.

Several factors, related to severity of illiness on admission or to a lack of clinical improvement during ICU stay, were related to mortality. The APACHE II score, an infection on admission, coma, sepsis syndrome or septic shock, and gastric and oropharyngeal colonization with EGB on admission have been related to a poor clinical condition and a grim prognosis ${ }^{13,77,23,31-33}$. The inability to administer gastric nutrition should, in our opinion, be regarded as an epiphenomenon of the severity of underlying iliness. It is our policy to start gastric nutrition as soon as possible in each patient receiving mechanical ventillation. In general, gastric nutrition was withheld only when continuous massive gastric residue was present. This probably reflects a subgroup of severely critically ill patients. Of course, institution of gastric nutrition is delayed in patients with gastric and oesophageal surgery, but these patients were excluded from the present analysis.

In conclusion, the duration of mechanical ventilation and colonization of oropharynx and trachea were the most important risk factors for VAP caused by EGB or Pseudomonadaceae; gastric colonization was not a risk factor for VAP; and the upper respiratory tract was the most important initial site of colonization for Pseudomonadaceae. These data do not support an important role of the gastropulmonary route in the pathogenesis of VAP caused by Pseudomonadaceae or EGB. 


\section{References}

1. Leu HS, Kaiser DL Mori M, Woolson RF, and Whenzel RP. Hospital-acouired pneumonia. atributable mortality and morbidity. American Journal of Epidemiology 1999; 129 $1258-1267$.

2. Fagon UY, Chastre J. Hance Au, Montravers P. Novara A, and Gibert C. Nosocomiai pneumonia in ventilated patients. a cohort study evaluating attributable mortality and hospital stay. American Journa of Medicine $1993 ; 04281-288$.

3. Heyland D and Mandell LA Gastric colomization by Gram+negative bacilili and nosocomial pneumonia in the interusive care unit patient evidence for calsation. Chesit 1992; 401: 197-193

4. Inglis TJU, Sherratt MJ, Sproat LU, Gibson JS and Hawkey PM. Gastroduodenall dysfuncilon and bacterial colanization of the ventilated lung. Lancet 1993: 341:911-913.

5. Torres $A$, EllEbiary $M$, Gonzáez J. Ferrer $M$, Puilg de la Bellacasa $d$, Gené A, Martos A, and Rodriguez-Roisin R. Gastric and pharyngeal flora in nosocomal pneumonia accluned during mechanical ventilation. American Review of Respiratory Disease 1993. 148: $352-357$.

6. Pingleton SK, Hinthorm DR and Liu C. Enteral mutrition in patients receiving mechanical verutiation. American Journal of Medicine $9986,80-827-832$

Driks MR, Clavel DE, Cellit BR, Manming Mi, Burke RA. Garvin GM, Kunches LM, Farber HW. Wedal SA, and McCabe WR Mosocomial preumonia in intubated patients given sulcrallate as compared with antacids or histamine type 2 blockers: the role of gastric colanisation. New Enghand Journal of Anedicine $1987,317,1376-1382$
Prodhom G. Levenberger $P$, Koefter a, Bum A, Chioleno R, Schaller MD. Perret C. Spirnier O. Blondel J, Siegrist Hi, Saghafi Im, Bland D. and Franciali $P$. Nosocomial pneumonia in mechanically vemtilated patients recewing antadid, rantidine, or sucralfate as prophylaxis for stress uher a randomised controlled trial. Annats of hternal Medicine 1994, 120
$653-662$

9. Bonten MUM, Gailard CA, wan der Geest $S$, van Tiel FH, Beysens $A$. Smeels HGW, and Stobberingh $E E$. The rolle of intiragastric acidity and stress ulcer proplyiaxis on colonization and infection in mexhanically ventilated patients. A stratified, randomied. double blind stidy of sucraffete versus antacids. Amencan Joumar of Respiratory and Critical Core Medicine 4995 ; 152 . $1825-1834$

10. Reusser P. Zimmerl W. Scheidegger $D$. Marbet GA. Buser M, and Gyr Ko Rote of gastric colonization in nasocomial infections and endotoxemia: a prospective study in neurosurgical pativents of mechanical ventiation. Joumal of Mntectous Diseases $1989.160: 414.421$

11. Cade JF. Micowat E, Siganporia R, Keignlay $C$ Presneill $J$, and Suickas $V$ Uncertain relevance of gastric colonization in the seriousty ill. Intensive Care Modicine 1992. $18: 210-217$

12. Bonten $M$, Gallard $C$, vart Tiel $F$, Smeets $H$, van der Geest $S$, and Stobberingh $E$. The stomach is not a source for colonization of the upper respiratory tract and pneumonia in $1 \mathrm{CU}$ patients Chest 1994: 105:878-884

13. Cravem DE, Kunches LM, Killinsily $V$, Lichtanberg DA, Make BJ, and Mocabo WR. Risk factors for pnemmonia and falatity in patients receiving continuous mechanical ventilation. American Revien of Respiratory Disease 1986; $133792-796$.

14. Torres A, Aznar $R$, Gallell JM, Mmenez $P$. Qonzállez $J$ Ferrer $A$, Celis $R$, and Rodriguez-Foisin Re Incidence, risk and prognosis factors of nosocomial pmenmoniza in mechanically ventilated patients. American Rowew of Respirallory Disease 19g0, 142 $523-528$

Kolde MH. Ventiator-associated pneumania. A mulvariate analysis. Journal of the Amernan Medical Assaciation 1903: 2701965-1970 Troullet Jhe and Gibert $c$. Evaluation of 
chind jutgement in the dentheator and trestment of nostacomat preumonia in ventated pateris. Chest 1993. 103.547-553

17. Knaws WA Draper EA, Wagnar DP, and Zimmerman JE APACHE II a seventy of disegse elassitication system. Critcal Care Medicing $1985 ; 13818$ 829.

Bone RC Let's agree on teminology befinitions of sepsis. Criticar Cure Medrane $1991,19.973-976$

Chaste J Wau F, Brun Pierne J, Dauge MC. Bounharna A, Akesbi A, and Gibert $C$. Frospective svaluation of the protected spacimep brush for the diagnosis of pulmonary infactions in ventaleted patients American Reviow of Respiralory Disease $1984,130924-929$

20. Langer M, Mosconi P Cigada M, and Mandeli M. Longuterm respiratory support and risth af pneumonia in critically ill patients. American Review of Respiratory Disease 1989; 140 . $302-305$

24. Johanson WG, Prerce AK, Sanford JP, and Thomas GD. Nosocomial respiratory infections with gram negative bacilli: the significance of colonization of the respiratory tract. Amats of internal Medicine 1972; 77;701-706

22. Mason CMA, Nelson $S$, and Summer WR. Bacterial colonization. Pathogenesis and clinical significance. Immunotogy and Ahergy Clincs of North America 1993; 13.93-108.

Wothonson WG, Pterce AK, and Santord $\mathbb{A P}$ Changing pharyongal bacterial flota of hospitalized patients. Now England Jourdal of Mediche 1969. 281:1137-14a0

24. LaForce FM, Hopkins I and Trow R. Hwman orat defenses aganst gram-nagative fods. Anencan Rubiew of Respiratory Disease $9976: 414929$

25. lbafez \&. Panafied $A$, Ravich JM, Marse $P$. Jorda $R$, and Mata F. Gastracsophageal reflux in intubatad patients receiving enteral hutrition affect of supine ard serrirecumbent positions. I Parent Enterat Nutr 1992: 16. 419422
Torres A Serrebatles J Ros E. Plera C. Pulg de la Bellacasa d. Cobos A, lameñ $F$. and Rodrgyez-Roisin R. Pumonary aspration of gastic contents in patients recening mechancal ventitation the effect of body position. Annals of Internat Medicine 1992: $116.540-543$

Pamer LB Donelan $8 V$, Fox $G$, Bellemore $E$. and Greene wit Gastric flora in chronically mechanicaly venthated patients. Retationship to upper and lower aimwy colonzation. American Journal of Respiratory and Criticat Care Medicine 1995; 151:1063-1067.

28. Donien MuM, Gailard CA. wan Tiel FH, van der Geest $S$, and Stobberingh EE. Contimuous enteral reeding counteracts preventive measures for gastric colonization in intensive care unit patients Crifical Care Medicine $1994,22939-944$

29. Wiederman MS. Gram-negative colonization of the respiatory tract pathogenesis and clinical consequences. Semin Respir horect 1990, 5. $173-184$.

30. Andrews CP, Coalsom U. Srith JD, and Johanson WG. Jr. Diagnosis of nasocomial bacterial pneumonia in acute, diffuse lung injury. Chest 1981:80254-257.

31. Calandra T, Geram J, Heumann D, Baum gartner JD, and Glauser MP. Migh circulating levels of interleukin-6 in patients with septic shock ewolution during sepsis, prognostic value, and interplay with other cytokines. Anarican doumal of Medicine 1991, 91:23-29.

Hack CE, de Groot ER, Felt-Bersma RJF, Nujems MH, Strack Van Schinndel RuM. Eerenberg-Bemer AJM, Thiljs $\mathbb{L} S$, and Aarden LA increased plasma leveis of interleukm- 6 in sepsis. Brood 1989, 74:1704-1710.

33. Retlla al Ausina $V$ Castella d Ret $A$, and Prats G. Nosocomial respratory tract infections in muliple trama patients influence of level of consciousness with implications for therapy Chest 1992; $102: 525-529$ 


\section{Clinical spectrum of ventilator-associated pneumonia caused by methicillin-sensitive Staphylococcus aureus}

Bergmans DCJJ, Bonten MJM, Gaillard CA, de Leeuw PW, van Tiel FH, Stobberingh EE, van der Geest $S$ 


\section{Abstract}

\section{Background}

Pneumonia is the most frequently diccurring nosocomial infection among mechanically ventilated intensive care unit (ICU) patients. Due to its association with mechanical wentiation, this infection has also been called ventilatorassociated pneumonia (VAP). In most cases, VAP is preceded by colonization of the upper respiratory tract with the causative pathogen. Although Staphylococcus aureus frequently causes VAP, the cinical presentation of staphylococcal pneumonia in mechanically ventilated patients has not been described in great detail.

\section{Methods}

The incidence of tracheal colonization and its association with VAP caused by methicillinsensitive Staphylococcus aureus (MSSA) was studied prospectively in 530 consecutively admitted mechanically ventilated patients in a general ICU. Furthermore, the clinica! spectrum, outcome, and microbiological results of 27 cases of staphylococcal VAP (SVAP) were examined. Ventilator-associated pneumonia was diagnosed with protected specimen brush and/or bronchoalveolar lavage.

\section{Results}

On admission, $7 \%$ of the patients were colonized with MSSA in the trachea. Acquired tracheal colonization was demonstrated in $10 \%$ of the patients and accurred less frequently in patients with a hospital stay $>48 \mathrm{~h}$ before $1 \mathrm{CU}$ admission compared with patients admitted directly to the $1 \mathrm{CU}(6 \%$ vs. $15 \%, p<0.001)$. Moreover, colonization was acquired more frequently among trauma and neurologic/neurosurgical patients (22\%) compared with surgical and medical patients $(7 \%)(p<0.0001)$. Twenty-one patients (4\%) deveioped SVAP, the incidence being higher in patients colonized in the trachea with MSSA than in those not colonized (21\% vs. $1 \%$, p<0.00001). Staphylococcal VAP developed more often in trauma and neurologic/neurosurgical patients compared with surgical and medical patients ( $8 \%$ vs. $3 \%, p<0.05)$. Moreover, patients with a haspital stay $<48 \mathrm{th}$ before admission to the ICU had a higher incidence of SVAP compared with those with a longer hospital stay before $1 \mathrm{CU}$ admission ( $\%$ ws. $2 \%, p<0.01$ ). Crude infection. related mortality was $26 \%$.

\section{Conclusions}

Preceding colonization with MSSA in the trachea appears to be an important risk factor For the development of SVAP, and patients with a short duration of hospitalization before ICU admission have the highest incidence of VAP caused by MSSA. 


\section{Introduction}

Pheumonia is the most frequently occurring nosocomial infection among mechanically ventilated intensive care unit (ICU) patients', causing increased morbidity, mortality, and health care costs ${ }^{2,3}$. Due to its association with mechanical ventilation, this infection has also been called ventilator-associated pneumonia (VAP). Quite often. Staphylococcus aureus is the cause of VAP'A. Although trauma and/or neurosurgical patients have been reported to be at greater risk of acquiring staphylococcal VAP (SVAP) (5.8 $^{5-8}$, the clinical presentation of staphylococcal pneumonia in mechanically ventilated patients has not been described in great detail. In contrast, several studies have investigated the clinical spectrum of community-acquired pheumonia caused by $S$, aureus. The latter infection has been characterized as a rapidly developing, fulminating disease associated with high mortality, especially when complicating epidemic influenza, in the UKS. aureus was among the three pathogens identified as the most common causes of severe community-acquired pneumonia, with $100 \%$ mortality reported for cases caused by $S$. aureus ${ }^{11}$. In line with these observations, Fine et al, ${ }^{12}$ found five risk factors associated with a complicated course for patients with community-acquired pneumonia, one of these being a pneumonia caused by a high-risk pathogen such as $S$. aureus.

In the present study the incidence of colonization of the upper respiratory tract by MSSA and its association with the development of VAP caused by this species was determined in 530 mechanically ventilated ICU patients. In addition, the clinical spectrum and outcome of 27 patients with SWAP and the microbiological results are described. The diagnosis of VAP was established on the basis of positive quantitative cultures of samples obtained by protected specimen brush (PSB) and/or bronchoalveolar lavage (BAL). During the entire study period no methicillin-resistant $S$ aureus (MRSA) was isolated.

\section{Patients and Methods}

\section{Patients}

From January 1992 through June 1994, tracheal colonization and development of VAP were studied prospectively in all mechanically ventilated patients in the general ICU of the University Hospital Maastricht. The Netherlands, in order to assess the incidence of colonization of the upper respiratory tract by MSSA and its association with the development of SVAP. Age, sex. APACHE II score, medical discipline of admission, and period of hospitalization before admission to the ICU were recorded for each patient on admission, and clinical parameters (vital signs, leukocytosis, temperature, etc) were recorded daily. Colonization of the respiratory tract was monitored by culturing samples of tracheal aspirate on admission and, subsequently, at least twice weekly. Only patients needing mechanical 
ventilation with an ICU stay of at least three days were included in the final analysis.

To describe the clinical spectrum and outcome of SVAP, data on all cases of SVAP from January 1992 through June 1995 were collected prospectively as described above $(n=21)$. Because a study using topical antimicrobial decontamination of the oropharynx, which influences oropharyngeal colonization, was started in July 1994 , data regarding tracheal colonization collected afier this date were not used. However, data on the clinical spectrum and outcome of patients developing SVAP during this period were included $(n=6)$.

\section{Definition of colonization}

Tracheal colonization was defined as the isolation of MSSA from tracheal aspirates without infection. Colonization on admission was established on the basis of a positive culture for MSSA obtained within $24 \mathrm{~h}$ after admission to the ICU. Colonization was considered acquired if there were cultures positive for MSSA from at least two consecutive samples but no collonization with MSSA on admission to the ICU.

\section{Definition of preumonia}

In case of clinical suspicion of pneumonia, bronchoscopy with PSB and BAL was performed. The diagnosis was established when (A) at least three of the following criteria were met: (1) rectal temperature $338.0^{\circ} \mathrm{C}$ or $<35.5 \% \mathrm{C}$, (2) blood leukocytosis $\left(>10.10^{3} / \mathrm{mm}^{3}\right)$ and/or left shift or blood leukopenia $\left(<3.10^{3} / \mathrm{mm}^{3}\right),(3)$ more than 10 leukocytes per high-power field in Gram stain of tracheal aspirate. and (4) a positive culture from tracheal aspirate, in combination with (B) a new or progressive infilltrate on chest radiograph and (C) the presence of (1) a positive quantitative culture of a sample of secretions obtained by BAL (cut-off point $\geq 10^{4}$ cfulml) or PSB (cut-off point $\geq 10^{3}$ cfu/ml) or (2) positive cultures from blood, or (3) pleural fluid cullure unrelated to another source and obtained within $48 \mathrm{~h}$ before and after respiratory sampling. The infection was considered ICU-acquired if symptoms began at least $48 \mathrm{~h}$ after admission to the ICU $\mathrm{U}^{13}$. Pneumonia was considered staphylococcal when caused by MSSA solely or, in case of a polymicrobial pneumonia, when quantitative cultures of MSSA were above the cutoff points for PSB andor BAL or when this species was cultured from blood or pleural fluid.

\section{Bronchoscopy}

A fiberoptic bronchoscope (Pentax FB-15H/FB-15X; Pentax Medicals, Japan) was intraduced through a special adaptor (Swivel connector, Gibeck Respiration AB, Sweden) and advanced to the bronchial orifice of a lung segment containing a new or persistent infiltrate. A PSB (Microbiology brush; Mill-Rose Laboratories " USA) was then advanced to a wedged, peripheral position after dislodging the distal catheter plug to obtain lower airway secretions for microbiological analysis. 
After brushing, the bronchoscope was positioned in the adjacent subsegment and BAL was performed by infusing one aliquot of $20 \mathrm{~m}$ of sterile saline $10.9 \% \mathrm{NaCl})$ followed by three aliquots of $50 \mathrm{ml}$. The liquid recovered after the first aliquot was discarded and the remaining lavage fluid was pooled. In all cases PSB was performed first. Bronchoscopy specimens were transported to the laboratory within $15 \mathrm{~min}$ of collection and analyzed within $1 \mathrm{~h}$.

\section{Microbiology}

Cultures of tracheal aspirates were taken on the first day of admission and subsequently twice a week. Semiquantitative and quantitative microbiological analyses of the specimens were performed according to routine methods. Susceptibility to flucloxacillin, gentamicin, ciprofloxacin, and amoxicillin-clavulanate was established by determination of minimal inhibitory concentration (MIC) by a microplate broth dillution method according to NCCLS criteria. S. aureus ATCC 29213 was used as reference strain.

\section{Mortality}

Crude ICU mortality was defined as the percentage of patients dying during their ICU stay and crude hospital mortality as the percentage of patients dying during hospital stay. The crude infection-related mortality was defined as the percentage of patients who died and in whom any contribution of SVAP to the fatal outcome could not be excluded on clinical or histological grounds.

\section{Statistical analysis}

Frequency comparisons were performed by chi-square test or Fisher's exact test. A probability value of $<0.05$ was considered to denote statistical significance. Data are expressed as absolute numbers with percentages or as medians with ranges.

\section{Results}

\section{Colonization and infection by methicillin-sensitive Staphylococcus aureus}

In the 30-month study period between January 1992 through June 1994, 530 mechani-cally ventilated patients were admitted to the ICU for at least three days. Twelve of these received topical antimicrobial prophylaxis of the oropharynx and stomach with antibiotics acting against MSSA. Topical antimicrobial prophylaxis was started after the first culture samples had been obtained. The median age of the patients studied was $66 \mathrm{yr}$ (range 14-92) and the median duration of ICU stay was eight days (range 3-349). Patients were surgical $(n=231,43 \%)$, medical $(n=197,37 \%)$, neurologic or neurosurgical $(n=56,11 \%)$, or had been admitted because of multiple trauma $(n=46,9 \%)$.

On admission, colonization of the upper respiratory tract with MSSA was observed in three of 12 patients receiving topical antimicrobial prophylaxis and in 33 of the remaining 518 patients (Table 6.1 ). Thus, 36 of 530 patients $(7 \%)$ were colonized 
with MSSA on admission.

Because the 12 patients receiving topical antimicrobial prophylaxis and the 33 colonized with MSSA on admission were excluded from analysis, data on acquired colonization of the upper respiratory tract with MSSA were evaluated in the remaining 485 patients (Table 6.1). Acquired colonization was demonstrated in 48 of these 485 patients $(10 \%)$. Patients who had been hospitalized for longer than $48 \mathrm{~h}$ before admission to the ICU acquired colonization with MSSA less often than patients admitted directly to the $\operatorname{lCU}(15 / 266(6 \%)$ vs. $33 / 219(15 \%) ; p<0.001)$. Moreover, acquired colonization occurred more frequently among trauma and neurologic/neurosurgical patients $(20 / 89(22 \%))$ than surgical and medical patients $(28 / 396(7 \%), p<0.0001)$. The median ages of patients who did or did not acquire colonization were comparable: $67 \mathrm{yr}$ (range 17-88) and $66 \mathrm{yr}$ (range 14-92), respectively.

In the 30-month study period, 21 of 518 (4\%) patients analyzed developed an episode of SVAP (Table 6.1). The incidence was higher among patients colonized in the trackea with MSSA (either present on admission $(n=33$ ) or acquired during ICU stay $(n=48)$ ): 17 of 81 patients $(21 \%)$ compared with 4 of 437 not colonized patients $(1 \%)$ developed SVAP ( $p<0.00001)$. Staphylococcal VAP occurred more frequently in trauma and neurologic/ neurosurgical patients $(8 / 100(8 \%))$ than surgical and medical patients $(13 / 418(3 \%) ; p<0.05)$, and patients hospitalized $<48$ $h$ before ICU admission had a higher incidence $(16 / 241$ (7\%) $)$ compared with those with a longer duration of hospitalization before $1 \mathrm{CU}$ admission $(5 / 277$ (2\%); $p<0.01$ ).

Table 6.1 Number of patients analyzed and incidences of colonization and infection

\begin{tabular}{|c|c|c|c|c|c|c|}
\hline & \multicolumn{2}{|c|}{$\begin{array}{l}\text { Colonized on } \\
\text { addmission }\end{array}$} & \multicolumn{2}{|c|}{ Acquired colonization } & \multicolumn{2}{|c|}{ Incidence of SVAP } \\
\hline & Analyzed & Colonized & Analyzed & Colonized & Arralyzed & Infected \\
\hline Totall & 530 & $36(7 \%)$ & 485 & $48(10 \%)$ & 518 & $21(4 \%)$ \\
\hline Excluded tor amalysis & 0 & & $12 T+33 C$ & & $12 T$ & \\
\hline Sturgeryimedical pationts & 428 & & 396 & $28(76)$ & 418 & $\$ 3(3 \%)$ \\
\hline $\begin{array}{l}\text { Trama/neurologicl } \\
\text { neurosurgical patients }\end{array}$ & 102 & & 89 & $20[22 \%]$ & 100 & $8 .(8 \mathrm{~h})$ \\
\hline $\begin{array}{l}\text { Hospital stay before } 1 \mathrm{CU} \\
\text { ardonission } \approx 48 \mathrm{~h}\end{array}$ & & & 260 & $15,6 \%$ & 277 & $5(2 \%)$ \\
\hline $\begin{array}{l}\text { Hospital stay before } 1 \mathrm{CU} \\
\text { mdmission }<4 \mathrm{~g} \mathrm{~h}\end{array}$ & & & 219 & $33(15 \%)$ & 244 & $1677^{20 y}$ \\
\hline $\begin{array}{l}\text { Colonized fon admission of } \\
\text { acquitrad) }\end{array}$ & & & & & 81 & $17(2404)$ \\
\hline Nol colonized & & & & & 437 & $4(1 \%)$ \\
\hline
\end{tabular}

SVAP. staphylococcal wentiltator-associated pneumonia: T, topical antimicrabial prophylaxis: $C_{2}$ colonized on acimission. 


\section{Clinical presentation and outcome of staphylococcal ventilator-associated pneumonia}

Reason for admission, sex, age, presence of pre-existing diseases, and outcome of the 21 patients, who developed SVAP (described above) and of six patients who developed SVAP in the period from July 1994 through June 1995 are summarized in table 6.2. The median age of the 27 patients was 54 yr (range 17-91), the male/female ratio was $18 / 9$, and the median APACHE II score was 18 (range 8-31). Fourteen patients had at least one pre-existing disease. Cardiovascular diseases were present in nine patients, respiratory diseases in four patients, and malignancies in five. Severe autoimmune disease and a combination of amyloidosis resulting in chronic renal failure and chromic use of immunosuppressive drugs were present in two additional patients.

The remaining 13 patients had no underlying disease before admission to the $I C U$, although two were known intravenous drug and/or alcohol abusers. These 13 patients were admitted because of multiple trauma ( $n=5)$, acute pancreatitis $(n=1)$, neurologic disease $(n=1)$, elective craniotomy $(n=1)$, resuscitation $(n=1)$, status epilepticus ( $n=1)$, ruptured aneurysm of the abdominal aorta $(n=1)$ and hemolysis, elevated liver function tests, low platelets (HELLP) syndrome $(n=1)$. One patient was admitted because of a suicide attempt in which $10 \mathrm{ml}$ of lampoil was injected intravenously.

In five patients (No. 2, 5, 9, 11, 14) MSSA was not cultured from tracheal aspirates on the day pneumonia was diagnosed. However, in patients 2 and 5 , MSSA had previously been isolated from tracheal aspirates. Tracheal aspirate could not be obtained in patient 8 (Table 6.3).

The diagnosis of SVAP was based on positive quantitative cultures from both PSB and BAL in nine patients, once in combination with a positive blood culture. In 13 other patients the diagnosis was based on a positive quantitative culture from BAL only, and in three patients on a positive quantitative culture of PSB only. In the remaining two patients the diagnosis was made after positive blood cultures, in one patient in combination with positive cultures from pleural fluid. Three patients (No. 5, 6, 18) received systemic antimicrobial therapy at the time of bronchoscopy. Despite in vitro susceptibility of MSSA to these agents in two patients (No. 5, 18), quantitative cultures of PSB and BAL were above the cut-off points in both patients.

Ventilator-associated pneumonia seemed to be caused solely by MSSA in six patients $(22 \%)$. In all other cases VAP was polymicrobial; among the species most frequently isolated in combination with MSSA were Escherichia coli $(n=7)$. Haemophilus influenzae $(n=6)$. Pseudomonas aeruginosa $(n=5)$, and Klebsiella pneumoniae $(n=4)$ 


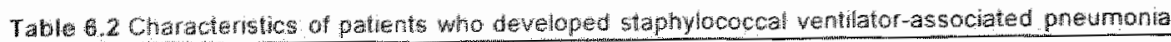

\begin{tabular}{|c|c|c|c|c|c|}
\hline Patignt & Aige & $50 x$ & Pre-exishng diseasa & Reason for admission & Outcone \\
\hline 1 & 66 & $M$ & hyperiension / COPD & ruptured AAA & 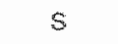 \\
\hline 2 & 17 & $M$ & none & rauma caputs & $s$ \\
\hline 3 & 79 & $M$ & rone & trauma thoracalis & $D^{*}$ \\
\hline 4 & 28 & $M$ & drug and aloohol abuse & resuscitation & $s$ \\
\hline 5 & 38 & $\mathrm{~F}$ & none & Myasthenia gravis & $S$ \\
\hline 6 & 62 & 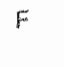 & $\begin{array}{l}\text { CUA / NDDM / adenocarcinoma } \\
\text { sigmoid }\end{array}$ & resection sigmold & $\mathrm{C}^{*}$ \\
\hline 7 & 43 & $M$ & atcohol abuse & acute pancreatitis & $D \neq$ \\
\hline 8 & 54 & M & $\begin{array}{l}\text { amyloidoss } / \text { renal failure } \\
\text { iminulnosuppressive drugs: }\end{array}$ & amyloudosis / PCP & $D^{*}$ \\
\hline 9 & 51 & $M$ & none & craniotomy & $S$ \\
\hline 40 & 28 & $M$ & none & trauma thoracalis & $S$ \\
\hline 11 & 91 & $\mathbb{F}$ & none & trauma & $D \neq$ \\
\hline 12 & 66 & $F$ & none & status epilepticus & $S$ \\
\hline 13 & 40 & $F$ & SLE / immunosuppressive drugs & actite renal failure. & $D \neq$ \\
\hline 14 & 62 & $M$ & CAD 1 COPO & ruptured AAA & $D^{*}$ \\
\hline 15 & 76 & $M$ & aortic aneurysm & trauma capitis/thoracalis & $\$$ \\
\hline 16 & 68 & $M$ & CAD $/ \mathrm{COPD}$ & exacerbation COPD & $D^{*}$ \\
\hline 17 & 75 & $M$ & none & ruptured AAA & Dt \\
\hline 16 & 45 & $F$ & breastcarcinoma $/ \mathrm{BMT}$ & Cytomegabvirus pneumonia & $\mathrm{DH}$ \\
\hline 19 & 71 & $M$ & oesophageal carcinoma / COPD & resection oesophagus & $\mathrm{Dt}$ \\
\hline 20 & 40 & $F$ & epilepsy / Down's syndrome & resuscitation & $S$ \\
\hline 21 & 77 & M & CAD / adenocarcinoma: colon & gastrointestinal bleeding & 8 \\
\hline 22 & 53 & M & CAD & trauma capitisithoracalis & $S$ \\
\hline 23 & 72 & M & $\begin{array}{l}\text { claudicatio intermitens / } \\
\text { adenocarcinoma rectum }\end{array}$ & resection recto-signoid & $S$ \\
\hline 24 & 25 & $F$ & none & HELLP syndrome & 8 \\
\hline 25 & 24 & $M$ & mone & hauma capitis & Ot \\
\hline 26 & $3 \pi$ & $M$ & none & stucide attempt & $s$ \\
\hline 27 & 67 & 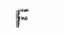 & hypertension & ruptured AAA & $D+$ \\
\hline
\end{tabular}

AAA, aneurysm abdominal aorta; BNT bone marrow transplantation: $C A D$, coronary artery disease; COPD. chrone bstrugha pulmonary disease; CVA, cerebrovascular accident; D. died, F, temale, HELLP syndrome.

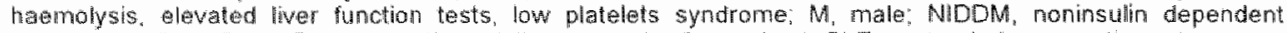
diabetes melitus, PCP. Pneumocystis canm prenmonia; S, survived; SLE, systemic lupus erythematosus.

* Degil directly related to SVAP.

i Desth possibly related to SVAP

+ Death not restated to SUAP.

The duration of stay in ICU until SVAP was diagnosed ranged from 3 to 19 d (median, 9 d). Peak body temperatures ranged from $37.6^{\circ} \mathrm{C}$ to $40.9^{\circ} \mathrm{C}$ (median, $39.4^{\circ} \mathrm{C}$ ) on the day of diagnosis. Two patients had normal body temperature, but 
one of these (No. 8) was treated with high doses of immunosuppressive drugs. The leukocyte count ranged from $3.6 \times 10^{9} / 1$ to $31.5 \times 10^{9} / 1$ (median, $95.7 \times 10^{8} / 1$ ), and in four patients more than five immature granulocytes were present in differential count.

In ail, 13 of 27 patients died during their hospital stay (crude hospital mortality, $48 \%$ ), 11 of whom died during ICU stay (crude ICU mortality, $41 \%$ ). The number of days between the diagnosis of SVAP and death ranged from 1 to $65 \mathrm{~d}$ (median, 13 d). The episode of SVAP was unlikely to have directly influenced the fatal outcome in six patients. Four of these six patients died $37,42,50$, and $65 \mathrm{~d}$ after the diagnosis of SVAP had been established, of cardiac failure $(n=2)$, septicemia due to endocarditis caused by another microorganism $(n=1)$, and septicemia from an abdominal source with intestinal microorganisms $(n=1)$. In the remaining two patients signs of bacterial pneumonia were no longer present at autopsy fone patient died $11 \mathrm{~d}$ after SVAP was diagnosed due to septicemia caused by Staphylococcus epidermidis; the other patient "admitted because of head trauma; died seven days after SVAP was diagnosed due to severe cerebral damage resulting from the initial trauma).

Staphylococcal VAP seemed to be directly related to death in five patients (No. 3 $6,8,14,16)$. These patients died within six days after SVAP had been diagnosed, except patient No. 8, who died after $13 \mathrm{~d}$ (signs of pneumonia were still obvious at autopsy). Patient 19 died because of recurrent episodes of VAP $46 \mathrm{~d}$ after the first episode, which was caused by MSSA, had been diagnosed. In addition, patient 17 also suffered from secondary peritonitis and eventually died of multiple organ failure. The contribution of SVAP to the fatal outcome in these two cases, therefore, could not be excluded. Thus, SVAP was unrelated to mortality in six patients and seemed to be directly related in five patients; SVAP was possibly related to mortality in two patients. As a result the crude infection-related mortality in the 27 patients with SVAP was $26 \%(7 / 27)$.

A closer look at these patients reveals some interesting findings. Nine patients were $\leq 55 \mathrm{yr}$ and were admitted without pre-existing diseases. The mortality in this subgroup of patients was $22 \%$; two of these patients died (No. 7 and 25). Death of both patients seemed unrelated to SVAP: patient 7, admitted with severe necrotizing pancreatitis, died in cardiac arrest without suspicion of infection $50 \mathrm{~d}$ after pneumonia had been diagnosed patient 25 died seven days after pneumonia was diagnosed because of severe cerebral damage following the head trauma for which he was admitted, and signs of bacterial pneumonia were no longer present at autopsy. In contrast, three of five patients $\leq 55 \mathrm{yr}$, but with severe pre-existing diseases died during their ICU stay (No. 8, 13, 18), and in two of these patients (No. 13 and 18) pneumonia was unlikely to have influenced the outcome. Of the remaining 13 patients, all $>55 \mathrm{yr}$ of age, eight $(62 \%)$ died, and five of these deaths seemed to be related directly to the development of SVAP. The relationship between age and crude infection-related mortality of SVAP showed a trend towards significance (Fisher's exact test $p=0.09$ ). 


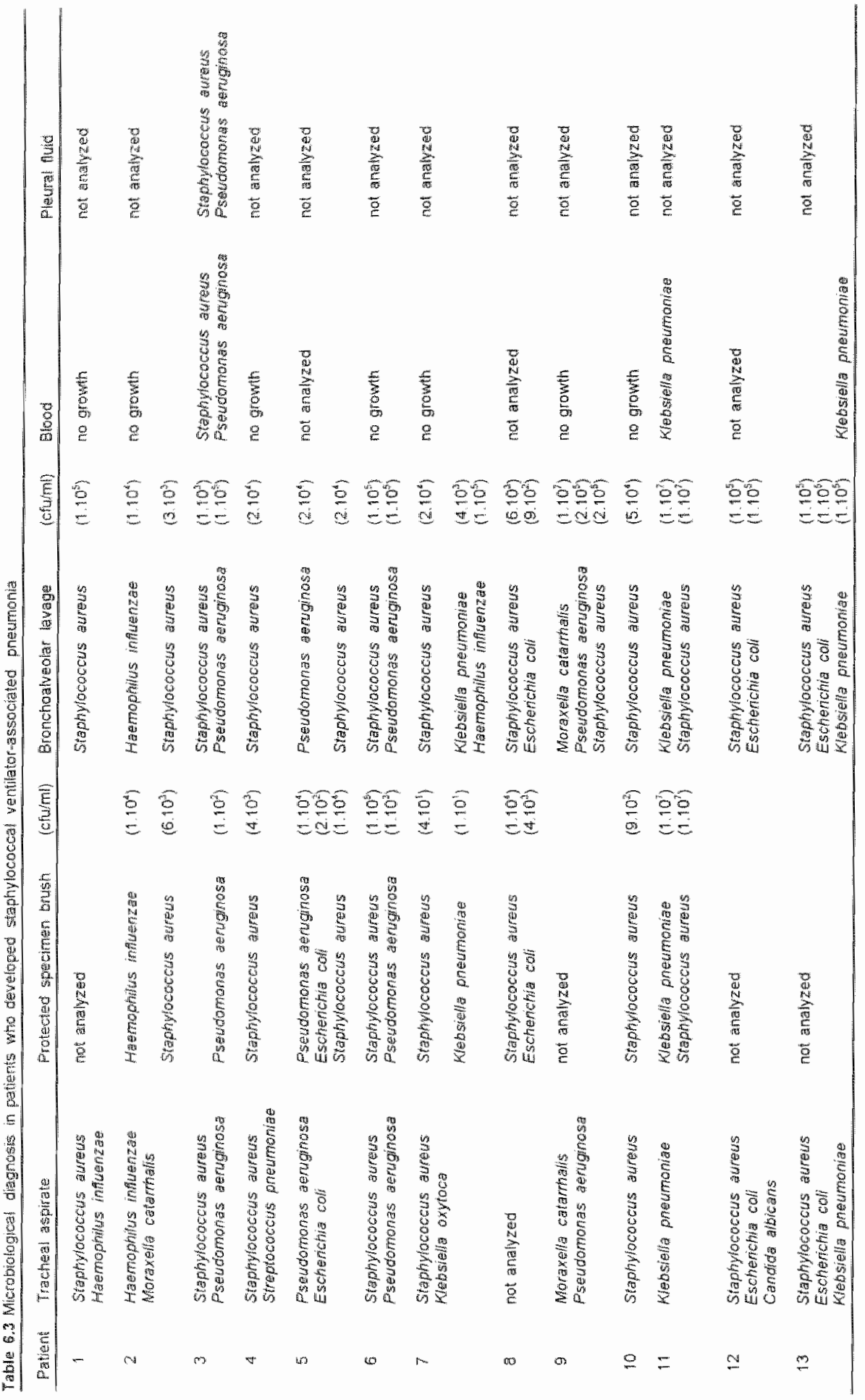




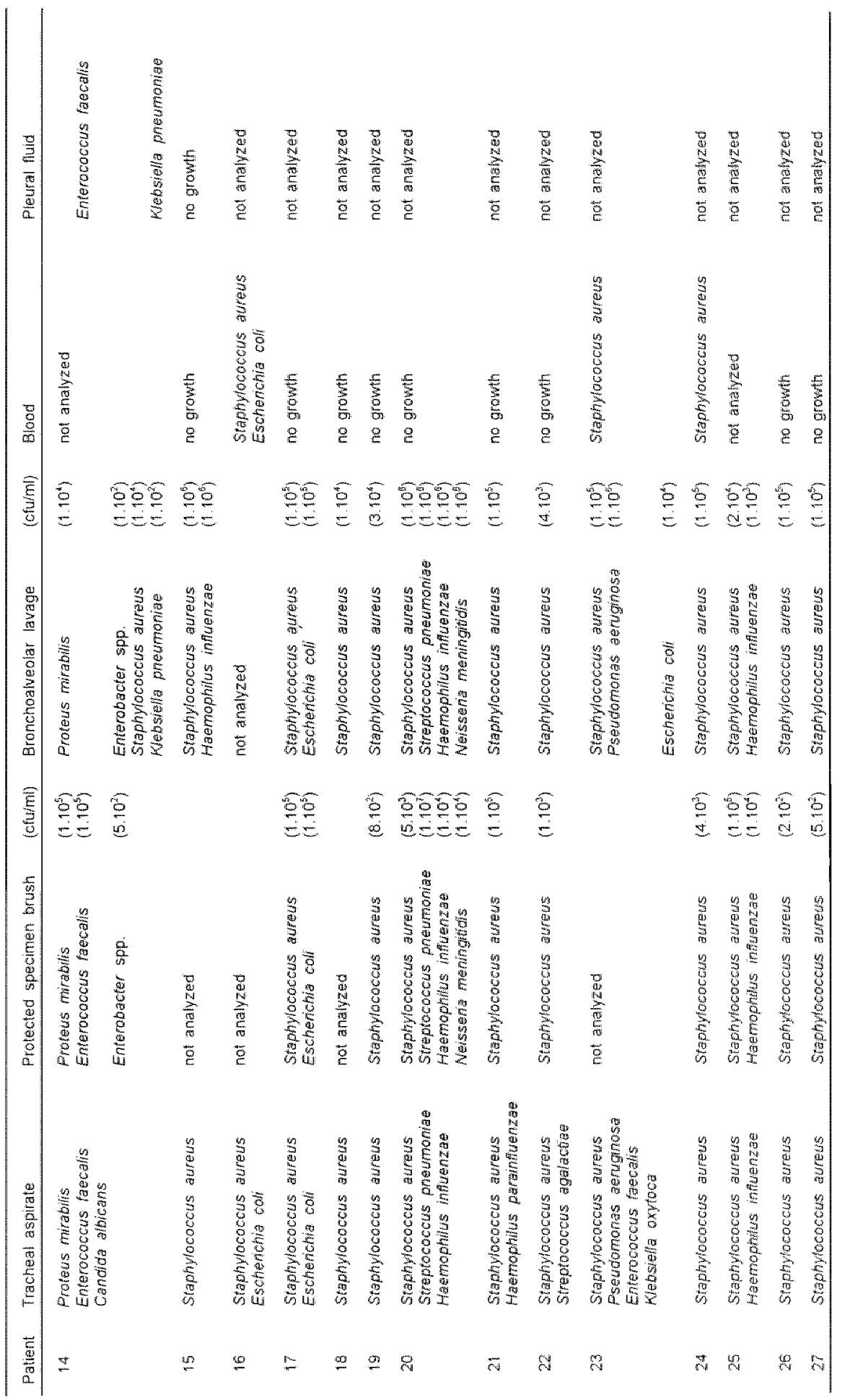


Staphylococcal VAP was accompanied by empyema in two (7\%) patients (No 4 and 14), and caviltation was suspected on chest radiograph and confirmed by computer tomographic scanning in one (4\%) patient (No. 13). A recurrent episode of VAP occurred in six patients: in five cases caused by $P$. aeruginosa and in one by Citrobacter freundii. In the group of six patients in whom VAP was caused by MSSA alone, three (50\%) died. Death was directly related to SVAP in two cases and possibly related in one case.

All cultured isolates of $S$ aureus were methicillin sensitive. All patients, except patient 14, were treated with antibiatics active against MSSA. Amoxicillinclavulanate $(n=7)$ and flucloxacillin $(n=6)$ were used most frequently as monom therapy, but were used in combination with gentamicin in two and three patients respectively. Because of concomitant infections, polymicrobial VAP, or the presence of a prosthesis, the remaining eight patients were treated with various combinations of antibiotics: ticarcillin-clavulanate $(n=2)$, ticarcillin-clavulanate plus gentamicin $(n=1)$, amoxicillin $(n=1$; because of penicillin-sensilive MSSA), cefuroxime plus gentamicin $(n=1)$, teicoplanin plus gentamicin $(n=1)$, vancomycin $(n=1)$, or vancomycin phus ceftazidime $(n=1)$. Patient 14 died on the day the definitive culture results of PSB and BAL were available and before antibiotic therapy active against penicillinmresistant MSSA was started. This patient died while receiving piperacillin for pleural empyema and fluconazole for tracheitis.

\section{Discussion}

The main feature of this study is that the clinical spectrum of VAP in which MSSA has an etiological role differs markedly from the well-known fulminating community-acquired pneumonia caused by this pathogen. Ventilator-associated pneumonia caused by MSSA was polymicrobial in most cases (78\%) and had a rather mild clinical presentation. However, despite these findings, the overall mortality of patients developing this infection was almost $50 \%$, with a crude infection-related mortality rate of $26 \%$. Prior colonization with MSSA in the trachea appears to be an important risk factor, and patients with a short duration of hospitalization before ICU admission had the highest incidence of SVAP.

In the present study the median day of admission to the ICU on which SVAP was diagnosed was day 9 . Therefore, the cases of VAP described here cannot be considered as early-onset pneumonia, which is defined as pneumonia occurring in the first four days of mechanical ventilation and which is most frequently caused by species already colonizing the upper respiratory tract before admission to the $\mathrm{ICU}^{\text {A4 }}$. In a previous study performed in the same ICU and using the same diagnostic methods, MSSA was the most important pathogen associated with VAP. after $P$ aeruginosa ${ }^{15}$. In that study the overall incidence of VAP was $22 \%$, and MSSA was involved in $35 \%$ of the cases ${ }^{15}$. This incidence of pneumonia is 
comparable to the imcidences reported by others using the same diagnostic techniques $^{4}$.

The clinical course of SVAP in the present study was associated with elevated body temperatures and leukocyte counts, a finding not surprising given that both are diagnostic criteria. Howewer, more severe presentations such as septicemia. pleural involvement; and abscess formation developed in only one patient each. In addition, other infection parameters were observed infrequently: only four patients had more than five immature leukocytes in the differential cell count, and no patient developed leukopenia. The rather mild presentation of nosocomial pneumonia is in contrast to the well-known clinical picture of fulminating communityacquired pineumonia due to MSSA especially in those recovering from influenza?. This rapidly progressive infection has been associated with high incidences of cavitation $(25 \%)$ and empyema $(10 \%)^{9}$. Moreover, the clinical presentation as described in the present study is also incompatible with the clinical course of MSSA pneumonia described by Kaye et all. ${ }^{1 \hat{}}$, who found 'an infection typical of a severe bacterial infection, with high fevers and usually significant leukocylosis, and positive blood cultures in a third of the patients. However, these data are difficult to compare to ours, because among the patients studied by Kaye and colleagues $^{16}$ "20\% had community-acquired pneumonia and the number of patients requiring mechanical ventilation was not specified.

Besides the differences in clinical presentation, two other characteristics of SVAP deserve attention. First, there seems to be a difference between the patient population developing SVAP and that developing community-acquired pneumonia due to MSSA. Community-acquired pneumonia due to MSSA develops in particular in elderly patients, notably following a wiral infection of the respiratory tract, ${ }^{9,17}$. In contrast, SVAP more frequently affects young adults who have been hospitalized for a short period before admission to the $I C U$, such as patients admitted because of trauma or neurologic/neurosurgical pathology. We found that these patients were also at risk for staphylococcal colonization. which is an important risk lactor for the development of SVAP. These observations confirm the very few data available on the epidemiology of SVAP. For instance. Espersen and Gabrielsen reported a higher incidence of nosocomiall pneumonia due to $S$. aureus among neurosurgical patients (25.9\%) compared with other patients (1.2\%). In keeping with these results, Rello and colleagues ${ }^{6,7}$ demonstrated that staphylococcal pneumonia was associated with coma, age $<25 \mathrm{yr}$, the nonuse of steroids, and preceding trauma. In another study, VAP caused by MSSA occurred more frequently in patients with cramiocephalic trauma, whereas VAP due to MRSA more frequently affected patients who had received steroids, had been ventilated for more than six days, had preceding chronic obstructive pulmonary disease, or were $>25 \mathrm{yr}^{\circ}$. Moreover, previous antibiotic therapy appeared to be the most important risk factor for developing VAP caused by MRSA M $^{3}$ The results of these siudies suggest that patients with a short duration of hospitalization prior to ICU admission are 
especially prone to develop SVAP, and that this infection is frequently preceded by tracheal colonization with $S$. aureus. In theory, colonization of the nares with S. aureus on admission to $\mathrm{ICU}$ might have been present in these patients. For reasons as yet unknown, nasal colonization may spread to tracheal colonization and cause pneumonia. This theory needs further exploration.

In contrast to VAP caused by MSSA, infections caused by MRSA have all the characteristics of ICU-acquired infections. Fortunately. MRSA is not endemic in the Netherlands. The prevalence was $0 \%$ in the European Prevalence of Infection in Intensive Care (EPIC) study, 19 , and no episode of VAP caused by MRSA has occurred in our hospital to date. A second difference between the two forms of staphylococcal infection may be that VAP is often polymicrobial $(78 \%$ in the present study). Pseudomonas aeruginosa and Enterobacteriaceae were the pathogens most frequently isolated, together with MSSA. This is in accordance with the bacterial flora colonizing the upper and lower respiratory tract of long-term: mechanically ventilated ICU patients ${ }^{20}$. The polymicrobial etiology of VAP has drawn little attention, although high incidences have been reported in the literature ${ }^{21.24}$. In an experimental model Johanson et al. ${ }^{20}$ investigated nosocomial pneumonia in baboons receiving prolonged mechanical ventilation. For the diagnosis they used cultures of lung homogenates and histologic findings as gold standards. In this modiel pneumonia was found to be polymicrobial in all cases.

Despite the relatively benign clinical presentation of SVAP and the availability of effective antibiotics, the overall mortality was $48 \%$ in the present study, and the crude infection-related mortality rate was $26 \%$. Although the data of this study cannot answer the question of whether a patient died of or with pneumonia, the data do suggest that in young patients, pre-existing diseases rather than pneumonia itself determined the outcome. In contrast, in patients over age 55, four of the eight patients who died succumbed within six days after pneumonia had been diagnosed. This finding corroborates the alleged relationship between VAP and mortality as reported by Fagon et al. ${ }^{3}$ and by Kappstein et al ${ }^{2}$.

In conclusion, the results of the present study demonstrate that in most patients SVAP is not a fulminating disease. In many cases the infection is polymicrobial, and patients with a short duration of hospitalization before ICU admission seem to be especially prone to this infection. 


\section{References}

1. Emori T and Gaymes R. An oveniew of nosocomial infections, including the role of the microblology laboratory. Chin Microbiol Rev $1993,6: 428-442$

2. Kappstein 1 Schulgen $G$, Beyer $U$, Geiger $K$ Schumacher M. and Daschner F. Prolongation of hospital stay and extra costs due to wentilator-associated pneumonia in an intensive care unit. European Joumal of Clinical Microbiology and Mfectious Diseases 1992, 11:504-508

3. Fagon JY, Chastie J, Hance AJ, Montravers $P$. Nowara A, and Gibert C. Nosocomial pnetmonia in ventilated patients: a cohort study evaluating attributable mortality and hospital stay. American Jownal of Medrine 1993; 94 $281-288$

4. Rello $J$, Quimtana $E$, Ausina $V$, Castella J. Luquin M, Net $A_{1}$ and Prais $B$. Incidence. etiology, and outcome of nosacomial pneumonia in mechanically ventilated patients. Chesi 1991: $100439-444$.

5. Espersen F and Gabrielsen J.Pneumonia due to Staphylococcus aureus during mechathical ventilation. Joumal of infectious Diseases $1981 ; 144: 19-23$

6. Rello J, Quintana E, Ausina V, Puzo C, Net A, and Prats $G$. Risk factors for Siaphylacocous aureus nosocomial pneumonia in criticaly in patients. American Reviow of Respiratory Disease 1990, 142.1320-1324.

Rello J. Ausina V. Castella J. Net A and Prats G. Noscontial respiratory tract infections in multiple trauma patients influence of level of consciousness with implications for therapy Chest 1992, 102, $525-529$

8. Rello $₫$. Torres A, Ricart M. Vallles J Gonzalez Ji Artigas A and Rodriguez-Roisin R. Wentilatorassociated pneumonia by Slaphyococcus aurews comparison of methich lin-resistant and methicthin-sensitive episodes American wounal of Respiratory and Critical Care Madicine 1994: 150:1545-1549

Waldvogel FA. Staphylococcus aureus (inal Toxic Shock Syroromej. In. Mandell GL. Bennett JE, and Dolin $R$, ediths, Principles and practice of infectious disedases. Ath ed New York: Churchill Livingstone Ine. 1995 . p $1754-1776$

10. Chickering $H$ and Park JH Sightococous aureus pneumonia Joumal of the American Medical Association $1919,72617-626$

11. Woodhead MA, Mactartane JT. Rodgers F $\mathrm{F}$ Laverick A, Pikkington R, and Mackae AD Aetiolagy and outcome of severe com mumbityacquiled pneumona foumal of infoction 1985; 10:204-210

12. Fine M, Singer DE, Hanuse BH, Lave UR, and Kapoor WN. Validation of a pheumonia prognostic index using the Medisgraups comparative hospital database. Amencan Joumal of Medicine 1993: $94: 153-159$

Pingleton $S K$, Fagon IY, and Leper KV, Jo Patient selection for climical investigation of wentilator-associated pneumonia: criteria for evaluating diagnostic techniques chest 1992 . $102: 5535-5565$

14. Langer M. Cigada M. Mandelli M Mosconi P. and Tognon G. Early-onset pneumonia: $D$ multicenter study in intensive care units Intensive Care Medicine 1987:13:342-346

Bonten $M$, Gallard $C$, van der Geest $S$, wan Tiel $F_{4}$ Beysens $A$. Smeets $H_{\text {. and }}$ Stabberingh $E$. The role of intragastric acidity and stress wher proplyyaxis on colnomiation and infection in mechanically ventilated patherts. A stratified, randomized double-blind study of sucrallete versus antacids. Amarican Journal of Respiratory and Critical Caro Medicine 1995. 152 1825-1834.

Kaye MG, Fox MJ, Bartiett JO. Bramary 8 . and Giastroth $d$. The chinical spectrum of Staphylocaccus aureus pulmonary infection Ches 1990: 97.788 .792

Woodhead MA, Macfarlane IT, Mccracken "S. Rose DH, and Finch RO Prospective study of the antiology and atcome of pneumonia in the community. Eancet 1987 $1671-674$

18. Ibelings MS and Buining HA Nederlandse resultaten van het Europose provaluntie- 


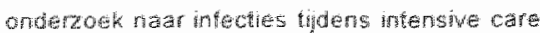
IEPIC II Aard vam de intecties. Nederbands rindschrin vor Geneskunde 19g4, 138 : $2244-2247$

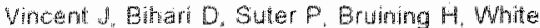

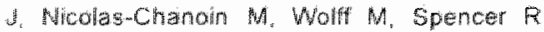
and Hemmer $M$. The prevalence of noso. comial infection in interstre care units ant Europe. Resuls of the European Prevalence of infection in Intenswe Care (EPC) study. Joumat of the Antrican Medical Association $1995,274: 639.644$.

20. Johancon $W$, Ji" Serdenteld J Gomez $P$. de Los Santos F, and Coalson H. Bacteriologic diagnasis of nosocomial pneumania following prolonged mechanical ventilation. American Review of Respiratory Disalas 1988, 137 . $259-264$

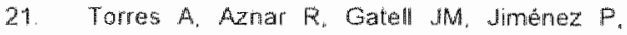
Gonzalez I. Ferrar $A$, Cellis $R$, and Rodriguez-Roisin $R$ Incidence, risk, and prognosis factors of nosocomial pneumonia in mecharimally ventilated patients. American Review of Respiraton Disease 1990: 142: $523-528$
Potginter PD and Miammond Mt. Etiology and diagrosis of preumonia requing $1 \mathrm{CH}$ adrission Chest 1992, $101199-203$

Chasine J, Viau F. Bun P, Plerre đ, Dange MC. Bouchama A. Akesbl A and Gibert $C$. Prosipective avaluation of the protected specimen brush for the diagnosis of pumonary nitections in ventiated patents. Amencar Rewien of Respiratory Disease $1984: 130,924 \cdot 929$

24. Pugin J, Auckenthaler $R$, Min N, Aanssens JP, Lew PD, and Suter PM. Diagnosis of ventilator-associated pneumonia by bacteriologic analysis of bronchoscopic and nonbronchoscopic "blind" bronchoaveolar lawage fluid American Reviow of Respirarory Disease $1991 ; 1431121-1129$ 


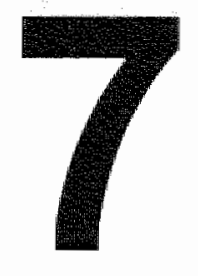

\section{Value of phenotyping} methods as an initial screening of

Pseudomonas aeruginosa in epidemiologic studies

Bergmans DCJJ, Bonten M.JM, van Tiel FH, Gaillard CA, London N, van der Geest S, de Leeuw PW, Stobberingh EE 


\section{Abstract}

\section{Background}

Ventilator-associated pneumonia (VAP) is frequently caused by Pseudomonas aeruginosa, mostly after colonization of the upper respiratory tract. When studying the epidemiology of $P$. aeruginosa in an endemic setting, determination of similarity of isolates is crucial. Genolyping techniques have become the method of choice for this purpose. However, genotyping is laborious and expensive, and therefore not feasible for all laboratories. The aim of the present study was to determine whether phenotyping techniques could be used as an initial screening method of $P$ aeruginosa in order to select isolates for further genotyping.

\section{Methods}

The distinctive capacity of four phenotyping methods (antibiotic susceptibility patterns, serotyping, phage-typing and outer membrane protein (OMP) profile analysis) was determined and compared with pulsed-field gel electrophoresis (PFGE) of enzyme restricted chromosomal DNA. In all, 91 isolates of $P$. aeruginosa were cultured from 10 patients developing VAP caused by this pathogen.

\section{Results}

Antibiotic susceptibility patterns were concordant for all isolates. Serotyping yielded five, phage-typing eight, OMP profile analysis nine and PFGE seven distinct types of $P$ aeruginosa. Compared with PFGE, the distinctive capacities were $89 \%(81 / 91)$ for serotyping. 87\% (79/91) for phage-typing, and $90 \%$ (82/91) for OMP profile analysis. Combination of two or more phenotypic techniques did not increase distinctive capacity. When serotyping results were different, PFGE types also were different (exclusiveness 100\%). However, isollates with the same serotype may have various PFGE patterns. In contrast isolates with similar PFGE patterns could have different phage-types or OMP types.

\section{Conclusions}

Of the four phenotyping techniques tested in the present study, serotyping showed the best distinctive properties, for the study of isolates of $P$. aeruginosa. Serotyping provides a good initial selection to reduce the number of isolates that need to be genotyped. 


\section{Introduction}

Ventilator-associated pneumonia (VAP) is an important nosocomial infection, frequently caused by Pseudomonas aeruginosa'. When studying routes of colonization with $P$. aeruginosa that lead to VAP, determination of similarity of isolates is crucial, especially since colonization may occur with different isolates, both at one particular body site and at different body sites ${ }^{2}$. Comparison of phenotypes, such as antibiotic susceptibility patterns, serotypes, phage-types and outer membrane protein (OMP) types, is relatively easy to perform, but lacks specificity $^{3}$. Pulsed-field gel electrophoresis (PFGE) of enzyme restricted chromosomal DNA, has a higher specificity and discriminatory power while maintaining epidemiological linkage and has, therefore, become the method of choice to compare bacterial isolates when studying nosocomial outbreaks ${ }^{4-6}$. However, PFGE is laborious and expensive, and therefore not feasible for all laboratories. The aim of the present study was to determine the usefulness of four methods of phenotyping as an initial method of screening of $P$. aeruginosa in order to select isolates for further genotyping. This was done by determination of typeability, distinctive capacity, and exclusiveness of antibiotic susceptibility patterns, serotyping, phage-typing and OMP profile analysis compared with PFGE of enzyme restricted chromosomal DNA.

\section{Materials and Methods}

\section{Isolates}

Ninety-one isolates of $P$. aeruginosa, derived from 10 patients who consecutively developed VAP caused by this species, were analyzed: 16 from oropharyngeal swabs (nine patients), 18 from tracheal aspirates (eight patients), 17 from bronchoalveolar lavage (eight patients). 14 from protected specimen brush (eight patients), eight from gastric aspirates (four patients), and 18 from rectal swabs (four patients).

\section{Typing methods}

Antibiotic susceptibility patterns were determined by measurement of MIC according to the NCCLS guidelines. Serotyping of $P$. aeruginosa isolates was performed using antisera to the International Antigenic Typing System (IATS) serotypes (Difco Laboratories, USA). Phage-typing of $P$. aeruginosa was performed using the following phages: $7,16,21,24,31,44,68,73, F 7, F 8, F 10$, $109,119 x, 352,1214, M 4, M 6, C o l 21, C o l 11$, Col18. Serotyping and phage-typing were performed on all isolates in a single rum. Outer membrane proteins of $P$. aeruginosa were isolated as described previously $y^{7.8}$ with minor modifications. The OMP types were examined by sodium dodecyl sulfate polyacrylamide gel electrophoresis (SDS-PAGE). Genome fingerprinting was carried out according to 
the method described by Grothues et al ${ }^{9}$. Pulsed-field gel electrophoresis was performed using a CHEF-DRll System (Bia-Rad Laboratories, Richmond, CA, USA) after restriction digestion with Spel (Boehringer Mannheim, Germany). Saccharomyces cerevisiae was used as marker.

\section{Comparison of strains}

Antibiotic susceptibility pattern, serotype, phage-type, OMP type and enzyme restricted chromosomal DNA patterns, produced by PFGE, were determined for all isolates of $P$. aeruginosa. Outer membrane protein profiles and PFGE patterns were compared visually on enlarged gel photographs to identify bands of identical relative mobility as fragments of identical size. The criteria for bacterial strain typing according to Tenover et al. ${ }^{10}$ were used to interpret chromosomal DNA restriction patterns produced by PFGE.

\section{Typeability}

Typeability of the various typing techniques was determined by dividing the number of typeable isolates by the total number of isolates, expressed as a percentage.

\section{Distinctive capacity}

The results of each phenotypic method were compared with the results of the PFGE of enzyme digested chromosomal DNA, which was regarded as the gold standard. Distinctive capacity was defined as the number of correctly typed isolates by the phenotypic method divided by the total number of isolates as typed by the PFGE technique, expressed as a percentage.

\section{Exclusiveness}

For the isolates of each strain type, as defined by each phenotyping technique, it was established whether they were linked to a single or to multiple PFGE types. Exclusiveness of each phenotyping technique was determined by dividing the number of isolates of one particular strain type exclusively linked to a single PFGE type by the total number of isolates, expressed as a percentage.

\section{Results}

Antimicrobial susceptibility patterns were concordant for all isolates. The MIC values were: piperacillin $\leq 8 \mathrm{mg} /$, ticarcillin/clavulanate $\leq 8 \mathrm{mg} / \mathrm{l}$, ceftazidime $\leq 2$ $\mathrm{mg} / \mathrm{l}$, imipenem/ cilastatin $\leq 1 \mathrm{mg} / \mathrm{l}$, gentamicin $\leq 1 \mathrm{mg} / \mathrm{l}$, ciprofloxacin $\leq 0.5 \mathrm{mg} / \mathrm{l}$. Serotyping yielded five different patterns in 87 isolates; four isolates were polyagglutinable. With phage-typing eight different patterns could be distinguished, arbitrarily labelled 1 to 8 . Analysis of OMP profiles yielded nine distinct patterns, arbitrarily labelled 1 to 9 (Figure 7.1). Combination of the four phenotyping me- 
thods identified 11 distinct strain types, labelled A to K (Table 7. 1). Pulsed-field gel electrophoresis of enzyme restricted chromosomal DNA showed seven different patterns, arbitrarily labelled I to VII (Figure 7.2). Type I was isolated most frequently $(n=47)$, and was isolated from five out of 10 patients. Three types ( 11,111 , and VII) were demonstrated in one patient only. Overall typeability of $100 \%$ was achieved by antibiotic susceptibility testing, phage-typing. OMP profile analysis and PFGE of enzyme restricted chromosomal DNA. Because of the four polyagglutinable isolates, typeability was $96 \%$ (87/91) for serotyping. Determination of antibiotic susceptibility patterns of the 91 isolates had no distinctive capacity, since all isolates had the same susceptibility pattern. Distinctive capacity of serotyping was $89 \%$ (81/91), and $93 \%$ (81/87) when the four polyagglutinable isolates were excluded. Distinctive capacity of phage-typing was $87 \%$ (79/91), and of OMP profile analysis 90\% (82/91). Combination of two or more phenotypic typing methods did not increase the distinctive capacity. Serotyping/phage-typing $87 \%$ (79/91), serotyping/OMP profile analysis $89 \%$ (81/91), and phage-typing/OMP profile analysis $81 \%$ (74/91). The combination of serotyping, phage-typing and OMP profile analysis had a distinctive capacity of $81 \%(74 / 91)$.

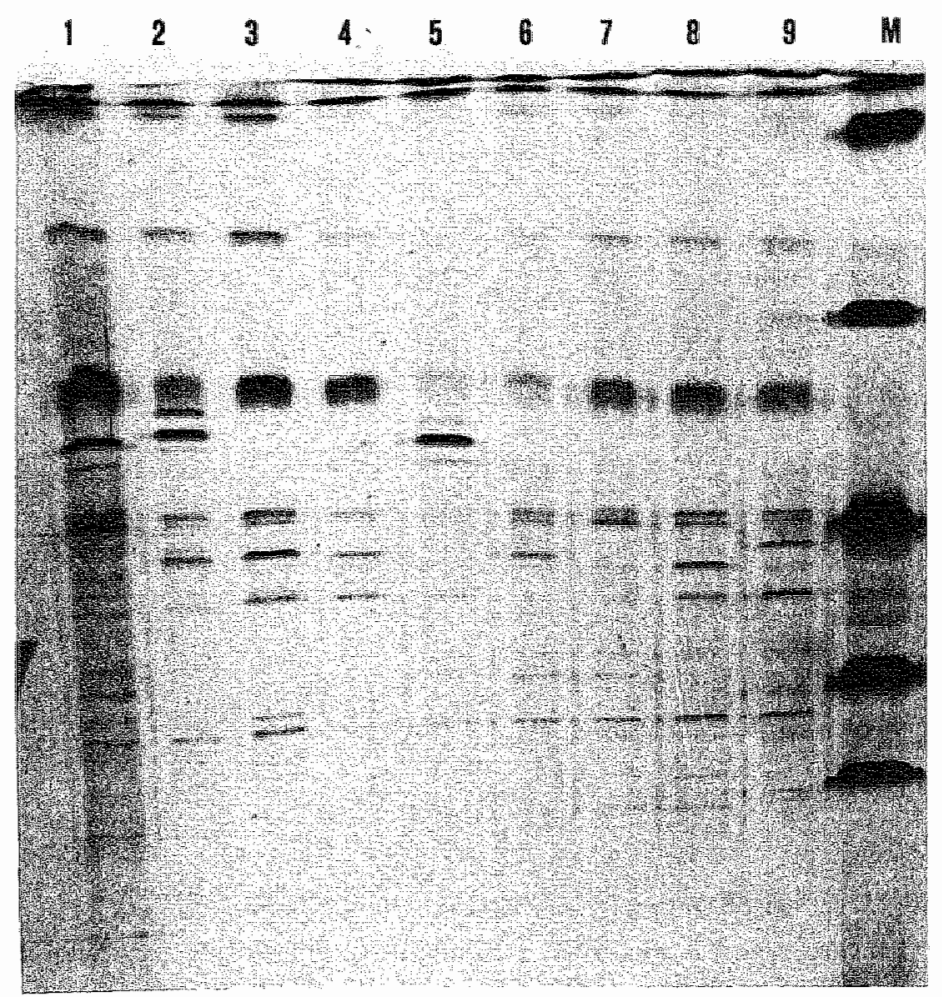

Figure 7.1 Outer membrane protein profiles of Psedomonas aeruginosa strains of the 10 patients developing $V A P$. reveating 9 distinct types labeled 1 to 9 . $M=$ marker 


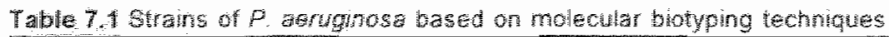

\begin{tabular}{|c|c|c|c|c|c|c|}
\hline Serotype & Phage-type" & OMP ypet & Types & PFGE & No isclates & No patients \\
\hline 3 & 6 & 4 & $G$ & V! & 9 & 2 \\
\hline$s$ & 而 & 9 & A & 1 & 33 & 4 \\
\hline 5 & 4 & 5 & $F$ & 1 & 2 & 1 \\
\hline 5 & 3 & $\theta$ & $c$ & 1 & 12 & 1 \\
\hline b & 5 & 6 & $E$ & v & 6 & 2 \\
\hline 6 & 8 & 6 & 1 & $\| 1$ & 5 & $1^{1}$ \\
\hline 6 & 8 & 2 & J & IIII & 2 & $1^{11}$ \\
\hline 7 & 2 & 8 & $B$ & IV & 6 & 2 \\
\hline 11 & 4 & 7 & D & $\|$ & 11 & 1 \\
\hline 11 & 4 & 1 & $k$ & $\|$ & 1 & 1 \\
\hline$P A$ & 7 & 3 & $H$ & VII & 4 & $\mathbb{1}$ \\
\hline
\end{tabular}

PA, polyagglutirnable.

Arbitrarity labelled 1 to

Arbirarily labelled it to 9 , see Figure 7 . 1 .

Distinct bacterial types based on serotype, phage-type and OMP lype, arbitrarily labelled $A$ to $K$.

Arbitrarly labelled 1 to wh, see Figure 72.

The same patient.

Tabilie 7.2 Exalusiveness of the phernotyping techniques

\begin{tabular}{|c|c|c|c|c|c|c|c|c|}
\hline \multirow[b]{2}{*}{ Seratype } & \multicolumn{2}{|c|}{$\begin{array}{l}\text { No. of isolates with } \\
\text { an exclusive PFGE }\end{array}$} & \multirow[b]{2}{*}{ Phage-type } & \multicolumn{2}{|c|}{$\begin{array}{l}\text { No. of isolates with } \\
\text { an exclusive PFGE }\end{array}$} & \multirow[b]{2}{*}{ OMP Hype } & \multicolumn{2}{|c|}{$\begin{array}{l}\text { No of isolates with } \\
\text { ain exclusiwe PFGE }\end{array}$} \\
\hline & Yes & No & & Yes & No & & Yes: & No \\
\hline 3 & 9 & - & 1 & . & 35 & $\mathbb{1}$ & - & 1 \\
\hline 5 & 47 & - & 2 & 6 & . & 2 & - & 2 \\
\hline 6 & 13 & $\therefore$ & 3 & . & 12 & 3 & 4 & - \\
\hline 7 & 6 & . & 4 & 12 & - & 4 & 9 & - \\
\hline 11 & 12 & . & 5 & 6 & - & 5 & . & 2 \\
\hline \multirow[t]{4}{*}{$P A$} & w & - & G & 9 & . & 6 & $\sqrt{3}$ & 5 \\
\hline & & & 7 & 4 & . & 7 &. & 11 \\
\hline & & & 8 & 7 & - & 8 & 6 & ". \\
\hline & & & & & & 9 & - & 45 \\
\hline Tolal & 91 & . & & 내4 & 47 & & 25 & 66 \\
\hline
\end{tabular}

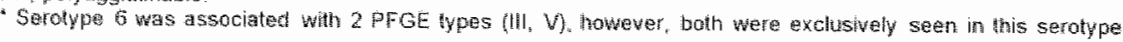

Isolates with different serotypes always differed in their PFGE pattern ( $\geq 7$ band differences; exclusiveness 100\%; table 7.2). Moreover, within a group of isolates with one and the same serotype, PFGE analysis showed $\leq 3$ band differences in 85 of 91 solates $(93 \%)$. In six of 91 isolates $(7 \%), 7$ band differences were 
present according to PFGE analysis. In summary, isolates with a different serotype also had a different PFGE type. Isolates with the same serotype did not always have the same PFGE type.

Isolates with different phage-types were associated with different PFGE patterns ( $\geq 7$ band differences) in 79 of 91 isolates $(87 \%)$. However, in 12 of 91 isolates $(13 \%)$ two different phage-types were associated with one PFGE type; exclusiveness was $48 \%$ (44/91, table 7.2). Within a group of isolates with the same phage-type, PFGE analysis showed $\leq 3$ band differences in $100 \%$ of isolates. In summary, isolates with a different plnage-type did not always have a different PFGE type. Isolates with the same phage-type always had the same PFGE type

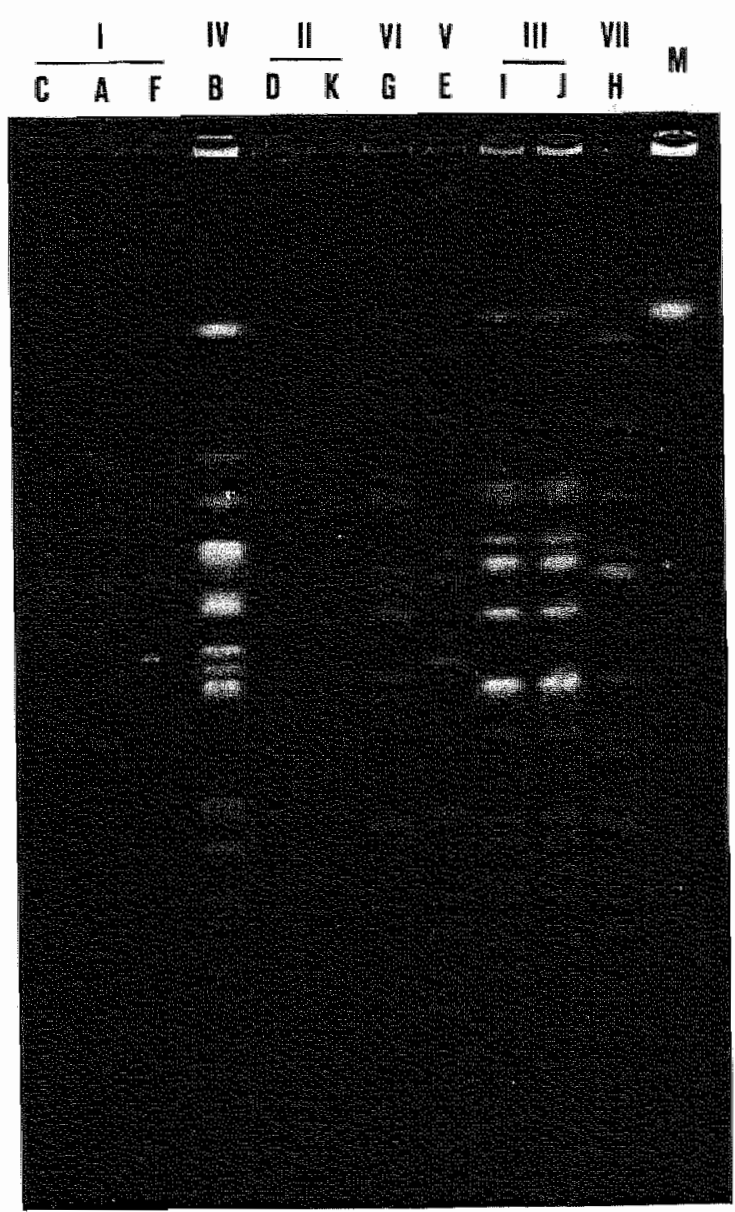

Figure 7.2 Pulsed-field gel electrophoresis patterns of 11 Pseudomonas asrughosa strains tolowing digestion with Spel. The lanes were labelled as the strains Ao K (according to the phenotyping techniques) and as PFGE type I to VII. M=maker (Saccharomycos cerovisiae) 
Different OMP types were associated with different PFGE patterns in 86 of 91 isolates (95\%). However, in five of 91 isolates (5\%) two different OMP types were associated with one PFGE lype, exclusiveness was $27 \%$ (25191, table 7.2). Within a group of isolates with the same OMP types, PFGE analysis revealed $\leq 3$ band differences in 86 of 91 isolates $(95 \%)$. In summary, isolates with a different OMP lype did not always have a different PFGE fype, and isolates with the same OMP type did not a ways have the same PFGE type.

\section{Discussion}

The results of this study show that phenotyping may well be used as an initial method of screening for epidemiologic studies of $P$. aeruginosa in an endemic setting of intensive care patients. Based on the data presented in this study, we recommend serotyping for this purpase. In case of identical serotypes of strains from different patients, identity should be confirmed by a method of genotyping.

The purpose of this study was not to determine reproducibility and discriminatory power of typing techniques, which has alleady been studied extensively ${ }^{11.13}$. Furthermore, because a number of the studied isolates are closely related, the set of isolates analyzed in the present study was unsuitable for determination of discriminatory power ${ }^{14}$. For epidemiologic studies, genotyping with PFGE of enzyme restricted chromosomal DNA of bacterial isolates currently is the typing methad of choice. However, this method is expensive and time consuming. In general, phenotyping techniques are less expensive and easier to perform. The starting point of our investigation was to determine sensitivity and specificity of four phenolyping techniques. The best phenotyping technique may be used to make a preselection out of a large series of isolates, thereby reducing the number of isolates that need to be genotyped in epidemiologic studies. The results of four phenolyping techniques were compared with PFGE of enzyme restricted chromosomal DNA, which we considered to be the gold standard. Although, the methods of analysis used (e.g. determination of distinctive capacily and exclusiveness) are not common in microbialogical studies, we feel that they are appropriate for these purposes

Various typing methods have been used to study the epidemiology of $P$. aeruginosa. Serotyping has been used most frequently. However, reported drawbacks of this method are the high frequency of polyagglutinable strains ${ }^{15}$, the fact that most clinical isolates belong to a limited number of serotypes ${ }^{16}$ and that. especially in cystic fibrosis patients, a considerable proportion of strains are nontypabie. The results of the present study partially are in line with this: among the 91 isolates five different serolypes could be distinguished, only four isolates were polyagglutinable. Although phage-typing has been reported to allow fairly detailed strain typing in $85 \%$ of clinical isolates, its reproducibility is poor ${ }^{3.12}$. Phage typing 
of a series of isolates should, therefore, always be performed in one session. Moreover, phage-typing usually can only be performed in reference laboratories where the various phages are in store. Analysis of OMPs, although laborious and time consuming, has been used in epidemiologic studies of $P$. aeruginosa, although several OMP types of $P$. aeruginosa strains showed high degrees of similarity ${ }^{17}$. In contrast, Maloney et al demonstrated considerable variation in OMP types between strains isolated from different patients ${ }^{18}$. Restriction enzyme analysis with PFGE has been reported to provide the highest discriminatory power between $P$. aeruginosa isolates ${ }^{12}$ and has, therefore, been advocated as the method of choice to investigate outbreaks of infections due to this species ${ }^{4}$. To reduce the number of isolates for PFGE when studying the epidemiology of $P$. aeruginosa in an endemic setting, a phenotyping technique as an inilial method of screening can be advocated.

Antibiotic susceptibility testing was not discriminatory in our setting because none of the $P$. aeruginosa strains were resistant to the antibiotics tested. In the presence of resistant strains the distinctive capacity of antibiotic susceptibility testing may increase. Serotyping, phage-typing and OMP profile analysis all had a good distinctive capacity, ranging from $87 \%$ to $90 \%$. Any combination of these methods did not improve distinctive capacity. Isolates with different serotypes were always associated with different PFGE patterns (exclusiveness $=100 \%$ ). This group-specific relationship between DNA fingerprint and serotype has been described ${ }^{12,19}$. Moreover, within a group of isolates with the same serotype, $93 \%$ of isolates were closely related or indistinguishable. In contrast, within a group of isolates with the same PFGE patterns, different phage-types and OMP types were seen. For phage-typing this phenomenon has been reported before by Grothues et al. ${ }^{9}$. In a study by Boukadida et al. ${ }^{20}$ both phenotyping and genotyping techniques were used in the analysis of an outbreak of gut colonization by $P$. aeruginosa in six immunocompromised children. They also found different phage-types within a group of isolates with similar PFGE types ${ }^{20}$. However, serotyping results from that study were difficult to interpret, since 8 of 13 isolates were polyagglutinable $e^{20}$. Of the four phenotypic techniques tested in the present study, serotyping showed the best discriminative properties. The phenotypic technique of choice in our laboratory, therefore, is serotyping, which also is a simple, cheap and fast method, with good reproducibility ${ }^{113}$. For example, when two patients are colonized or infected with $P$. aeruginosa with different serotypes, cross-colonization is highly unlikely. When both patients have strains with similar serolypes, PFGE is needed to confirm similarity. 


\section{References}

1 Emon 1 and Gaves R An overview of nosocomal intections, includirg the rote of the microbiotogy laboratory. Clin Microbiol Reu

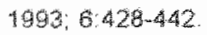

2. Noone $M$, Pitt T, Bedder M, Hewlent $A$, and Rogers KB. Psendononas autuinosa colopilstion in an intensive therapy unit: role of cross infection and host factors Brtisht Medical Journal 1983: 286-341-344.

Pitt Tl. Epidemiological typing of Psendomonas aeruginosa. Europsan Journal of Chncal Microbiology and infeclious Diseases $1988 ; 7: 238-247$

Maslow JW, Mulligan ME, and Arbeit $\mathrm{RD}$ Molecular epidemiology: application of contemporary techriques to the typing of microorganisms. Cinical Infectious Diseases $1993 ; 17: 153-164$

Tompkins LS. The use of molecular methods in infechous disearses. New England Jownal of Medicine 1992,327:1290-1297.

Bonten M, Gaillard $C$, van Tiel $F$, van der Geest S, and Stobberingh E. A lypical case of cross-acquisition? The importance of genotypic characterization of bacterial strains. infection Control and Hospital Epidemiology $1995 ; 16: 415-416$

de Wager $H$, van Boxtel R, wan den Burg $B$. Gruters $R$. Gests $F$, schppers B, and Lugtenberg B. Siderophoras and outer membrane proteins of antagonistic planturowthstimulating. root-colonizing Psoudomonas spp. Jounal of Bactoriology 1986; 165 . $585-594$.

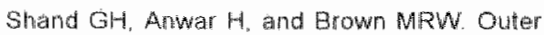
membrare proteins of polymyxin rosistant Psoudonomas aerughosa: effect of magnesium deptetion. Joumat of Antmicroblat Chemotharapy 1988; 22:811-821.

Grothues D. Koopmann U, Hardt $H$ and Tummler $\mathrm{B}$. Genome fingerprinting of Pseuctomonas aarughosa indicates colonization of cystic fibrosis siblings with closely related strains. Joumat of Chincal Microbiology 1988 ; 26: $1973-1977$.

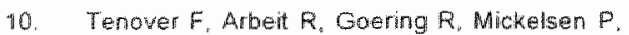
Muray $\mathrm{B}$. Persing D. and Swaminahan $\mathrm{B}$. In terpreting chromosomal DNA restriction patkerns produced by pulsed-field gel electrom phoresis; Criteria for bacterial strain typing. Jaurnal of Chnical Microbiology 1995; 33 $2233-2239$

The international Pseudomonas aeruginosa lyping study group. A multicenter comparison of methods for typing straims of Psevdomonas aeruginosa predominantly from patients with cystic fibrosis. Joumal of Infectious Diseases 1994, $169: 134-142$

12. Grundmainn $J$ Schneider $C$. Hartung $D$ Daschner $F$, and Pitt T. Discriminatory power of three DNAubased typing techniques for Pseudomonas aeruginosa. Journal of Clinical Micnobiology 1995: $333.528-534$

13. Masiow $J$ and Mulligan ME. Epidemiologic typing systems. Infection Controf and Hospitat Epidemiology 1996; 17:595-604

14. Hunter $P$ and Gaston M. Numerical index of the discriminatory abulity of typing systems: an application of Simpson's index of diversity. Jounal of Chinical Microbiology 1988; 26 2465-2466.

15. Hancock $R$, Mutharia $L$, Chan $L$, Darveau $R$ Speent D, and Pier G. Pseudomonas aeruginose isolates from patients with cystic fibrosis: at class of serum-sensitive, nonulypable strains deficient in lipopolysaccharide o side chains. Infection and immunology 1983: 42,170-177.

16. Famer $J$, Wemstein $R$, Zierd $C$, and Brokopp C Hospital oubreaks caused by pseudomonas aruginosa. impontance of serogroup 011. Wournal of Chinical Microbiology 1982. $16: 260-270$

Hamcock $R$ and Chan L. Outer membranes of enwilonmental isolates of Pseudomonas aeru ginosa. Jounal of Chical Microbiology 1988 . $262423-2424$

48. Maloney $d$, Rimland D. Stephens D. Terry $P$ and Whitney A Analysis of amikacinuesistant Pseudomonas aeruginosa developing in patients receiving amikacin. Archives of hrternal Medicine 1989; 149630.634 . 
19. Talon D. Capellier $G$, Boiloz A, Michel-Briand $Y$ Use af pulsed-fielo gel electrophoresis as an epictemiologic tool during an outbreak of Pseudonomas aeruginosa lung infections in an intensive care unit. miensive care Medicine 1995, 21.996-1002.
20

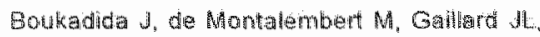
Gobin J. Grimont F, Girati D, Veron $M^{*}$ and Berche P. Qutbreak of gut colonization by Pseudomonas anghos in momurowomplomised chituren undergoing fotal digestive decontamination: analysis by pulsed-fiedd electrophoresis. Joumal of chmial Microblology 1991; $2920068-20 \% 1$. 


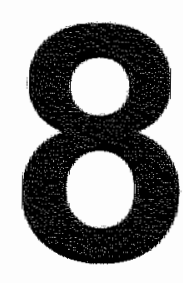

\section{Colonization with Pseudomonas aeruginosa in patients developing ventilator-associated pneumonia}

Bergmans DCJJ, Bonten MJM, Stobberingh EE, van Tiel $F H_{\text {, }}$ van der Geest $S$, de Leeuw PW, Gaillard CA 


\section{Abstract}

\section{Background}

Ventilator-associated pneumonia (VAP) is frequently caused by Pseudomonas aeruginosa, and is in most cases preceded by colonization of the respiratory tract with this microorganism. The objective of the study was to determine routes of colonization and geriotypic variation of $P$. aeruginosa among mechanically ventilated patients developing VAP caused by $P$. aeruginosa.

\section{Methods}

Colonization with $P$. aeruginosa was studied prospectively and chronologically in rectum, stomach, oropharynx and trachea in 10 mechanically ventilated patients. Ventilatorassociated pneumonia was diagnosed by bronchoscoplc techniques and genotypic similarity of $P$. aeruginosa isolates was determined by pulsed-field gel electrophoresis.

\section{Results}

From 10 patients who developed WAP 91 isalates, derived from bronchoscopic samples $(n=31)$, tracheal aspirates $(n=18)$, oropharyngeal swabs $(n=16)$, gastric aspirates $(n=8)$. and rectal swabs $(n=18)$, were genotyped. Seven different genotypes were identified. Preceding colonization with a similar genotype as the strain causing VAP occurred in the trachea in all patients, in the oropharynx in nine patients, in the stomach in five patients, and in the rectum in two patients. In three of 10 patients, distinct genotypes were demonstrated in isolates cultured either from one site or from different sites. Acquired colonization with $P$. aeruginosa occurred in eight patients "two of these were already colonized on admission with another genotype. The initial site of colonization, with the strain causing VAP "was the upper respiratory tract in eight out of 10 patients.

\section{Conclusions}

Critically ill patients developing VAP caused by $P$. aeruginosa are colonized at multiple body sites and may be colonized with multiple genotypes. In this patient population the upper respiratory tract is the predominant initial site of colonization with $P$. aeruginosa. 


\section{Introduction}

Ventilator-associated pneumonia (VAP) is frequently caused by Pseudomonas aeruginosa ${ }^{1}$, and in most cases is preceded by colonization of the respiratory tract with this microorganism ${ }^{2,3}$. The pathogenesis of colonization and infection of the respiratory tract with $P$. aeruginosa in critically ill patients is not completely understood. Results of several studies have suggested that $P$. aeruginosa preferentially colonizes the trachea rather than the oropharynx ${ }^{4,5}$. However, in these studies two important questions remained unanswered. In patients, colonized with $P$. aeruginosa, it was not determined whether colonization was restricted to the respiratory tract, and whether patients were colonized with a single or with multiple genotypes of $P$. aeruginosa.

We, therefore, prospectively studied colonization with $P$. aeruginosa prior to the development of VAP chronologically in rectum, stomach, oropharynx and trachea in 10 mechanically ventilated patients developing VAP caused by this microorganism. Pneumonia was diagnosed by bronchoscopic techniques and similarity of multiple isolates of $P$. aeruginosa was determined by pulsed-field gel electrophoresis (PFGE) of enzyme restricted chromosomal DNA.

\section{Methods}

\section{Desigm}

Rectal and oropharyngeal swabs, and tracheal and gastric aspirates were obtained on admission and subsequently twice weekly from all patients above $15 \mathrm{yr}$ of age and admitted to one of two general intensive care units $(I \mathrm{CU})$ of the University Hospital Maastricht. Out of this cohort, the first 10 patients who developed VAP caused by $P$. aeruginosa were selected, and isolates of $P$. aeruginosa were analyzed. Informed consent was obtained from the patient or, if this was not possible because of the clinical condition, from a representative of the family. The study protocol was approved by the hospital ethical committee.

\section{Microbiology}

Semiquantitative and qualitative analysis of aerobic bacteria and yeasts present in the collected samples as well as qualitative and quantitative analysis of samples of bronchoalveolar lavage (BAL) or protected specimen brush (PSB) obtained by bronchoscopy were performed as described before'. From each culture plate with growth of P.aeruginosa, three colonies were analyzed and stored separately until further processing.

\section{Definition of Colonization}

Colonization was defined as the isolation of microorganisms in the absence of infection, from tracheal aspirate, gastric aspirate, rectal swab, or oropharyngeal 
swab. Colonization on admission was established on the basis of a positive culture obtaned within $24 \mathrm{~h}$ after admission to the ICU. Colonization was designated as 'acquired' if cultures were positive from at least two consecutive samples but no colonization on admission to the $\mathrm{ICU}$. The initial site of colonization was defined as the site at which colonization was identified first. Simultaneous colonization of several sites is possible. The routes of colonization with $P$. aeruginosa leading to VAP were determined by analyzing colonization of the rectum, the stomach, the oropharynx and the trachea chronologically.

\section{Definition of ventillator-associated pneumonia}

In case of a clinical suspicion of pneumonia, bronchoscopy with BAL and PSB was performed as described elsewhere ${ }^{6}$. The diagnosis of VAP was established on the criteria listed in table 8.1

Table 1 Criteria used for the diugrosis of ventilator-associated pheumonia

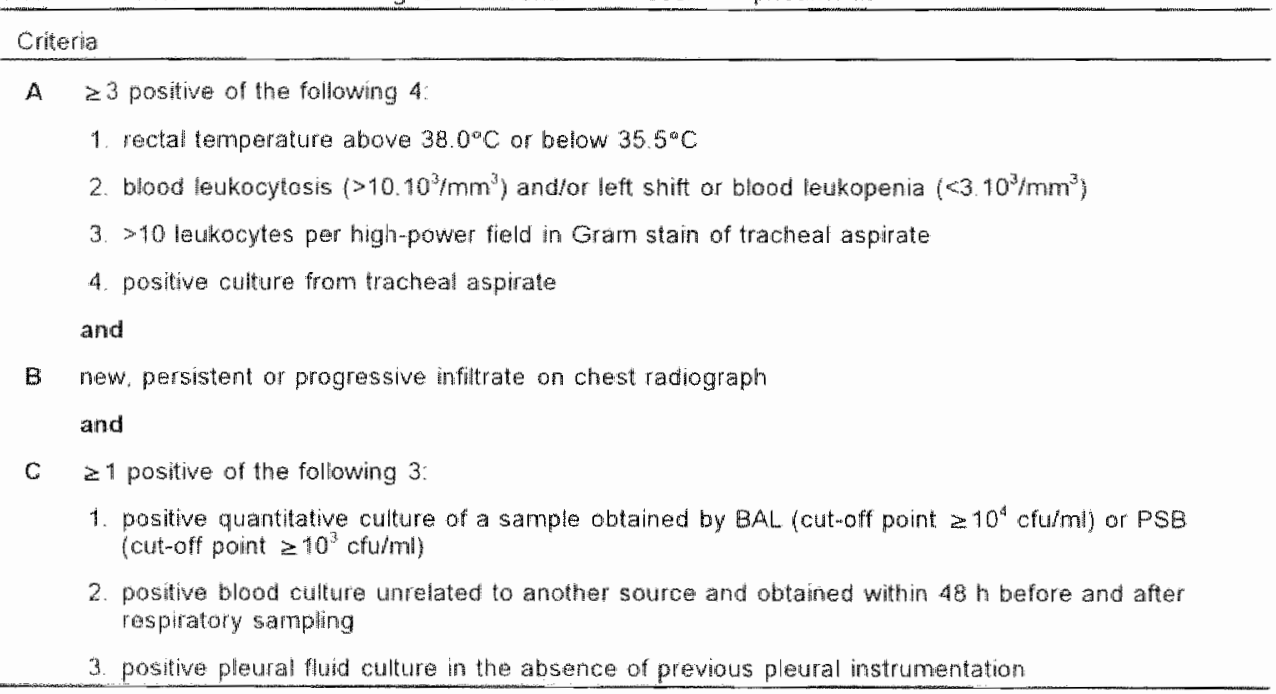

Preumonia was dagnosed if $A$ and $B$ and $C$ were positive

BAL. bronchoalveolar lavage: PSB, protected specimen brusth.

\section{Genotype analysis}

Restriction digestion of total genomic DNA was performed using Spel (Boehringer Mannheim, Germany) followed by PFGE using a CHEF-DRIl System (Bio-Rad Laboratories, Richmond, CA, USA) as described previously? ${ }^{7}$. Pulsed-field gel electrophoresis patterns were compared visually on enlarged gel photographs to identify bands of identical relative mobility as fragments of identical size. The absolute number of band differences between isolate pairs was recorded. The criteria for bacterial strain typing according to Tenover et al. ${ }^{3}$ were used to interpret chromosomal DNA restriction patterns produced by PFGE. 


\section{Results}

All analyzed patients were mechanically ventilated, endotracheally intubated, and had a nasogastric tube in place (Table 8.2). Ventilator-associated pneumonia was polymicrobial in six patients, the species isolated in combination with $P$. aeruginosa being Staphylococcus aureus $(n=3)$. Haemophilus infuenza $(n=1)$, Proteus mirabilis $(n=1)$ and in one case Klebsiella pneumoniae together with Candida albicans. The mean number of days in ICU before VAP was diagnosed was $15 \mathrm{~d}$ (range 3-39). Seven patients had received co-amoxiclav before the diagnosis. Ventilator-asscciated pneumonia was treated with piperacillin $(n=5)$, ceftazidime $(n=3)$ and co-ticarclav $(n=1)$, in two patients in combination with aminoglycosides. One patient died on the day of diagnosis before antibiotic therapy against $P$. aeruginosa was started. This patient was receiving flucloxacillin for $S$ aureus bacteraemia.

Table 8.2 Patient characteristics

\begin{tabular}{|c|c|c|c|c|c|}
\hline Patient & Age $(y r)$ & $\operatorname{Sex}$ & Diagnosis on admission & Days in 104 & Qutcome \\
\hline 1 & 28 & Male & Cardiopulmonary nesuscitation & 31 & Survived \\
\hline 2 & 79 & Male & Trauma, multiple rib fractures & 22 & Died \\
\hline 3 & 62 & Female & Sigmoid resection & 15 & Survived \\
\hline 4 & 38 & Female & Myasthenia gravis & 50 & Survivad \\
\hline 5 & 44 & Male & Trauma, spinal cord lesion C4-C5 & 106 & Survived \\
\hline 6 & 22 & Male & Trauma hepatic rupture, amputation arm & 60 & Survived \\
\hline 7 & 69 & Male & Pneumacocca! pneumonia & 7 & Survived \\
\hline 8 & 68 & Femalle & Faecal peritonitis, blowoll caecum & 39 & Survived \\
\hline 9 & 73 & Female & $\begin{array}{l}\text { Exacerbiation of Chronic Obstructive } \\
\text { Plilmonary Disease }\end{array}$ & 47 & Died \\
\hline 10 & 44 & Female & Abdominal sepsis after total proctocolectomy & 10 & Died \\
\hline
\end{tabular}

From each patient, one to three isolates per body site colomized or infected with $P$. aeruginosa were analyzed. Unfortunately, eight isolates were lost for genotyping; one from the oropharynx (patient 8), two from the trachea (patient 7 . 10), and five from the stomach. In all, 91 isolates were genotyped: 16 from oropharyngeall swabs ( 9 patients), 18 from tracheal aspirates ( 8 palients), 17 from BAL (8 patients), 14 from PSB (8 patients), eight from gastric aspirates (4 patients), and 18 from rectal swabs ( 4 patients). Pulsed-field gel electrophoresis of enzyme restricted chromosomal DNA showed seven different patterns, arbitrarily labelled I to WII. Type I was isolated most frequently $(n=47)$, and was isolated from five out of 10 patients. Within the different types, the number of band differences in one on one comparisons ranged from 0 to 3 . When different strain types were compared one on one, the number of band differences was always larger than 10 More extensive data about biolyping of these 91 isolates have been presented ${ }^{9}$. 
All 10 patients were colonized with $P$. aeruginosa in the trachea before the diagnosis of VAP. Colonization at the other sites, prior to the diagnosis of VAP. was demonstrated in the oropharynx in nine patients and in the stomach in five patients. The rectum was colonized with $P$. aeruginosa in four patients prior to the diagrosis of VAP, however, only in two of these patients with the similar genotype that caused VAP (Table 8.3). In seven patients (Pt. $1,3,4,6,7,8,10$ ) all isolates of $P$. aeruginosia, cultured from different sites showed similar PFGE patterns and were considered to be identical. In the other three patients (P.t. 2,5,9), distinct types were demonstrated in isolates cultured either from one site or from different sites.

Four patients were colonized with $P$. aeruginosa on admission; two in the rectum (Pt. 2 and 9), one in the stomach (Pt. 7) and one in rectum, stomach, trachea and oropharynx ( $\mathrm{Pt}$. 5). In patient 5, three distinct types of $P$. aeruginosa were demonstrated on admission. This patient had been hospitalized for $12 \mathrm{~d}$ before admission to our ICU. The remaining three patients colonized on admission, had either not been hospitalized previously $(n=2)$, or only for two days $(n=1)$ before admission to the ICU. Acquired colonization with $P$ aeruginosa occurred in eight patients after a mean of six days (range 3-14). Two of these patients were already colonized with $P$. aeruginosa on admission, but acquired colonization with another genotype during their ICU stay (Pt. 2 and 9 ).

The initial site of colonization for genotypes causing VAP was the upper respiratory tract (oropharynx and/or trachea) in eight out of 10 patients. However. simultaneous colonization was demonstrated in the rectum and the stomach in two of these patients (Pt. 1 and 5 respectively). The rectum was the initial site for a genotype causing VAP in patient 9 . Although two patients (Pt. 2 and 5) were initially colonized with $P$. aeruginosa in the rectum, these isolates were markedly distinct from those colonizing the upper respiratory tract and subsequently causing pneumonia. The stomach was the initial site of a genotype causing VAP in one patient (Pt. 7), and in four other patients, gastric colonization with an identical strain type was demonstrated before VAP was diagnosed. Gastric colonization with $P$. aeruginosa, occurring after pneumonia had been diagnosed, was demonstrated in four patients.

The fact that five gastric isolates could not be genotyped did not influence our findings. Three of the five missing isolates from colonized gastric aspirates were cultured for the first time seven to $17 \mathrm{~d}$ after VAP had been diagnosed. Moreover, the missing isolates from oropharynx $(n=1)$ and trachea $(n=2)$, in three patients, and the other missing isolates of the stomach $(n=2)$ in two patients were not obtained from an initial site of colonization. In each case, the patient was already colonized with a genotype, identical to the type causing VAP. Identification of different genolypes at these sites, compared with the genotypes already found at other body sites of the individual patient or compared with the genotypes causing VAP, would only strengthen our observation that critically ill patients can be colonized with multiple genotypes of $P$. aeruginosa. 


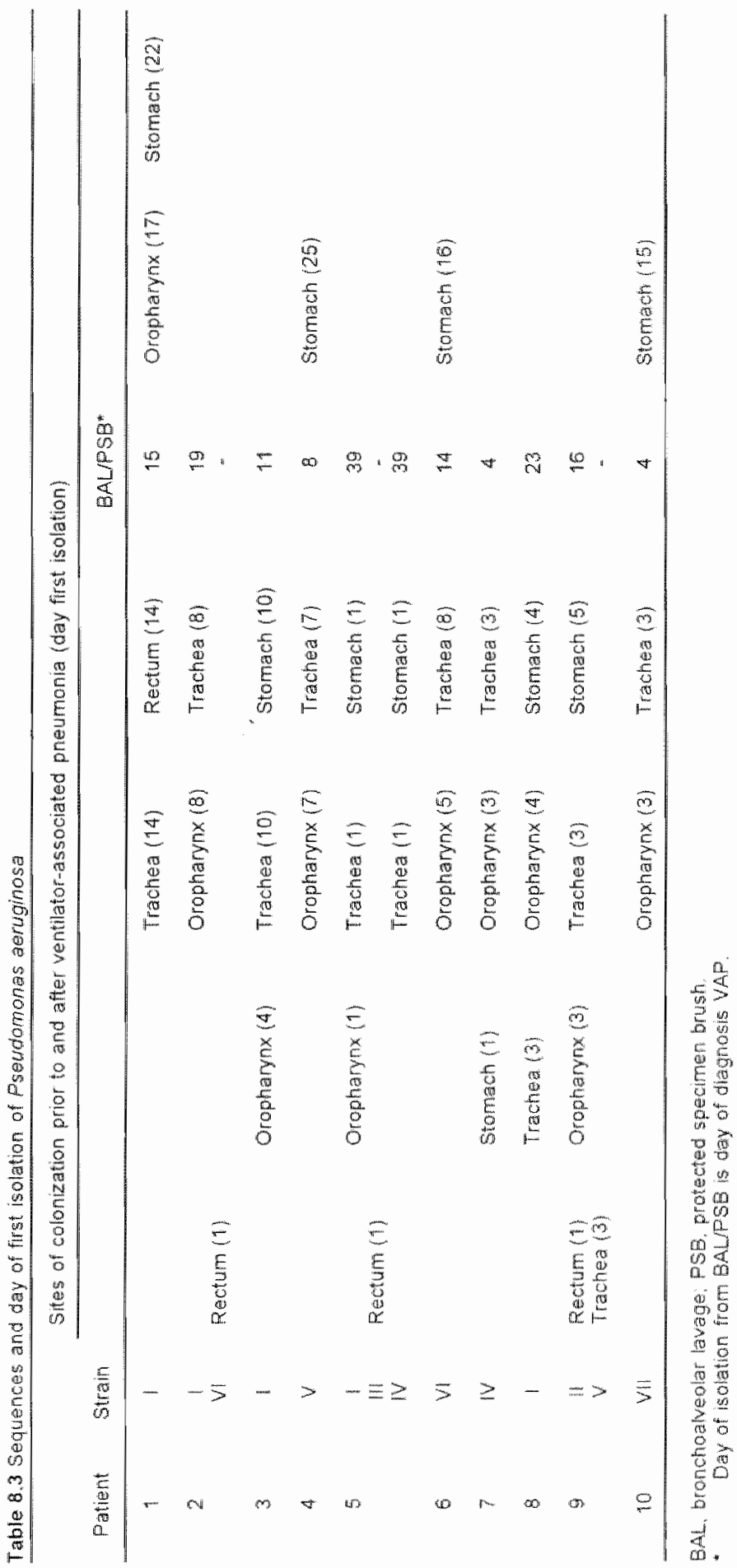




\section{Discussion}

The results of this study demonstrate that critically ill patients developing VAP due to $P$. aeruginosa are colonized with strains of this species at multiple body sites. In addition, in three of 10 patients, two or three different genotypes of $P$ aeruginosa were found at different body sites. Previous findings that the upper respiratory tract is the most important initial site of colonization for strains causing VAP were confirmed, but no preference for tracheal rather than oropharyngeal colonzation was found.

In order to study whether collonization with $P$. aeruginosa in mechanically ventilated patients was restricted to the upper respiratory tract, and whether these patients are colonized with a single or with multiple genotypes, we performed a conceptual study with only 10 patients, but with much attention to monitoring of colonization, accurately diagnosing VAP and genotyping of isolates. We think that our findings add new and important information to the understanding of the complex pathogenesis of infection and colonization of the respiratory tract with P. aeruginosa.

Among critically ill patients, colonization of the respiratory tract is facilitated by several variables. A decrease of the local immune mechanisms may allow respiratory epithelial cells to become 'stickier' for pathogenic bacteria ${ }^{\text {to }}$. A loss of fibronectin, possibly induced by increased lewels of proteases"1, nutritional deprivation:, and changes in the expression of cellsurface carbohydrates ${ }^{12}$ have been associated with increased adherence of bacteria ${ }^{13}$. Moreover, colonization is also influenced by bacterial factors, such as the presence of pili which facilitate bacterial adherence to epithelial surfaces ${ }^{14}$. The analyses of the present study demonstrate the close relationship between colonization and infection of the respiratory tract with $P$. aeruginosa. Colonization with $P$. aeruginosa prior to the diagnosis of VAP was found in the trachea in all patients and in the oropharynx in mine of 10 patients. Both sites were equally frequently the initial sites of colonization. In a previous study of colonization with $P$. aeruginosa we also found that tracheal colonization was an important risk factor for oropharyngeal colonization, and conversely, oropharyngeal colonization was an important risk factor for tracheal colonization ${ }^{2}$. Niederman et al. have identified sequences of colonizalion with $P$. aerugimosa in four patients, and in all patients the tracheobronchial tree was colonized before the oropharynx ${ }^{4}$. The results of the present sludy also demonstrate that colonization with $P$. aeruginosa in critically ill patients is not limited to the upper and lower respiratory tract. Whether p. aeruginosa also colonizes epithelial cells of other sites more easily during critical illness remains to be established.

Five out of 10 patients acquired colonization and infection with a simillar genotype of $P$, aeruginosa (Strain 1), which strongly suggests the occurrence of cross-acquisition. The design of the present study did not allow epidemiologic analyses. However, based on this finding we initiated a study to determine the 
importance of cross-colonization and cross-infection in our ward

Since genotyping has not been perfomed in other studies evaluating routes of colonization, the possibility of cross-acquisition in these studies, therefore, has not been determined ${ }^{2.45}$. However, if cross-acquisition is important the initial colonization of the respiratory tract may have been a result of frequent manipulation of respiratory equipment or nasogastric tubes by hospital personnel with contaminated hands, a route of colonization that has been well established $^{15.16}$. In contrast, rectum and stomach were evident endogenous sources of strains causing VAP in two of our patients. However, data on the importance of the stomach as a source of bacteria are controversial 1,2,17,18. The rectum was the most common primary site of colonization with $P$. aeruginosa among 153 patients admitted to a surgical ICU ${ }^{19}$. In that study, 10 patients acquired colonization with $P$. aeruginosa (6.5\%), of whom one patient developed pneumonia $^{19}$. In another study, Murthy et al. demanstrated that among 186 admissions to three hospital wards, the rectum was the most commonly observed colonization site for $P$. aeruginosa. In all, 20 patients acquired colonization with $P$. aeruginosa in that study, of which only two acquired oropharyngeal collonization $^{20}$. In both studies, the incidence of colonization and infection with $P$. aeruginosa were lower than those in our $1 \mathrm{CU}^{1}$, and study populations and methods were different when compared with the present study. Furthermore, the absence of data on gastric and tracheal colonization in one study ${ }^{20}$ and gastric and oropharyngeal colonization in the other ${ }^{19}$ precludes a formal comparison of those results with our data

In conclusion, our results demonstrate that critically ill patients developing VAP caused by $P$, aeruginosa are colonized with these species at multiple body sites and with multiple genotypes, suggesting that it is mot only the respiratory tract epithelium that becomes suitable for colonization with $P$. aeruginosa during critical illness. These findings emphasize the need of genotyping when studying the pathogenesis of VAP caused by $P$. aeruginosa. Our data also underscore the importance of the upper respiratory tract as the initial site of colonization with $P$. aeruginosa in this patient population. However, the relative importance of endogenous and exogenous sources for colonization remains to be established. 


\section{References}

1. Bonten M. Gaillard $C$, wain der Geest $s$, wan Tiel $F$, Beysens $A_{4}$ Smeets $H_{\text {, }}$ and Stobberingh $E$. The role of intragastric acidity and stress wher proptylaxis on colonization and intection in mechanically ventitated patients. A stratlied, randomized, double blind study of sucrafate rersis antacids. Amenican Joumal of Respratory and Critical Care Mediche 19g5: 152:1825-1034

2. Bonten M. Bergmans D, Ambergen $A$ de Leeww P. van der Geest S, Stobberingh $E$, and Gallard $\mathrm{C}$. Risitk lectors for pneumonia, and colonization of respiratory tract and stomach in mechanically ventilated cu patients. Annericam Joumal of Respiratory and Chical Care Medicine 1996; 154:1339.1346.

Johanson W. Jr. Plierce A, Sanford J, and Thomas $G$. Nosocomial respiratory infections with Gram-negative bacilit the significance of colonization of the respitatory tract Annals of Internal Medicine 1972; 77:701-706.

4. Niederman M, Mantovani $R$, Schoch P. Papas $J$ and Fein A. Patterns and routes of tracheobronchial colonization in mechanically ventilated patients: the role of nutritional stiatus im colonization of the lower airway by Pseudo monas species. Chest 1989, 95: 155-161.

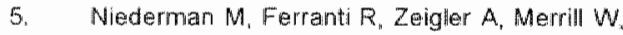
and Reynolds H. Respiratory infection complicating longuterm tracheostomy: The implicahion of persistent Grammegative tracheobronchal colonization. Chest $1924: 85: 3944$.

Bergmans D, Eonten M. Gailland $C$, de Leeuw $P$, van Tiel $F$, Stobberingh $E$, and van der Geest $S$ Clinical spectrum of ventilatorassociated pnemonia caused by methio cllim-sensitive staphyococus aureus. European Joumal of Chinical Microbiology and Infectious Diseases $1996 ; 15$ 437-445.

Grothues D, Koopmann U, Hardt $H$, and Tummler B. Genome fingerprinting of Pseudomonas aeruginosa indicates colomization of cystic fibrosis siblings with closely related strains. Jounat of Chincal Mhorobiology 1988 ; $26: 1973-1977$

Tenover F, Arbeit R. Goerng R. Mickelser P: Murray $B$, Persing $D$, and Swaminathan $B$.
Interpreting chomosomal DNA restriction patterns produced by pulsed-field gel electropharesis: Criteria for bacterial strain typing Jownal of Chical Microbiology 1995 . $33: 2233-2239$

Bergmans DCul. Bonten MJM. Gailard CA, van Thel FH, Londion NHHJ, van der Geest $S$. de Leeww PW, and Stobberingh EE. Value of phenotyping methods as an intial screening of Pseucomonas aeruginosa in epidemiogic studies. Infection 199\%: 25:350-354

10. Todd $T$, Franklin $A_{\text {a }}$ Mankinenmin $P$, Gurman $G$ and llwin $R$. Augmented bacterial adherence to tracheal epithelial cells is associated with Gram-negative pneumonia in an intensive care umit population. American Rewiew of Respiratory Disease 1989; 140 : $1585-1589$

11. Dal Mogare AR, Toews GB, and Pierce $A K$. Increased salivary elastase precedes. Gram-negative bacillary colonization in postoperativie patients. Amencan Review of Respirafory Disease 1987: $135671-675$

12. Weinmeister $K D$ and Dal Nogare AR. Buccal cell carbohydrates are altered during critical illness. Americam Journal of Respiratory and Crifical Care Medicine 1994, 150:131-134.

13. Johanson $W_{*}$ Higuchi $\$$, Chaudhuri $T$, and Woods D. Bacterial adherence to epithelial cels in bacilary colonization af the respiratory tract. Amorican Raview of Respitatory Disease $1930 \cdot 12155-63$.

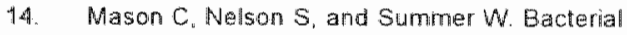
colonization. Pathogenesis and clinical significance. Mmunology and Allorgy Clinics of North Amprica 1993: 13:93-108.

15. Noone MR. Pitt $T L$, Bedder M. Hewlett AM: and Rogers KB. Psewdomonas aeruginosa colcnisation in an intensive therapy unit: fole of cross infection and host factors Britsh Madical Journal $1983,286: 3411 \times 344$.

16. Widmer AF. Wenzel RP. Tirilla $A_{4}$ Bale MJ, Jones RN, and Doebbeling BN. Outbreak of Pseudomonas aerughosa infections in a surgical intensive care unit probable transmission via hands of a heath care 
worker. Chnical Infectaus Disectses 1993 $46: 372-376$.

17. Prodhom $G$, Leuenberger P, Koerfer J, Blum

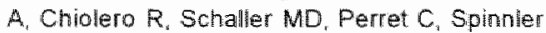
O. Blandel J, Siegrist $H$, Saghafi $L$, Blanc $D$, and Francioli $P$. Nosocomial pneumonta in mechanically ventilated patients receiving antacid, ranimidine, or sucraflate as prophylaxis for stress ulcer: a randomized controlled trial. Annals of Internal Medicine 1994; 120 : $653-662$.

18. Bonten MJM, Gaillard $C_{\text {, de Leuw } P W}$ and Stobberingh EE. Role of colonization of the upper intestinal tract in the pathogenesis of vertilator-associated pneumoria. Cinical Infections Diseases 1997: 24:309-319.
19. Kropece A, Hulebner J. Riftes Maver U. Benzing $A$, Seiger $K$, and Duschner $F D$ Exogenous or endogenous resenoirs of nosocomial Pseudomonas aenginosa and Staphyococcus aureus infections in a sugicat intensive care umit infenswe Gare Mediche $1993,19: 161-165$.

20. Murthy SK, Batch AL. Smith RP, Desjardin EK, Hammer MC. Conroy UV, and Michelsen PB. Oropharyngeal and fecal carriage of Pseudomonas aeruginosa in hospital patients Jounat of Clinical Mcrobiology $4989 ; 27$ $35-40$. 


\section{Cross-colonization with Pseudomonas aeruginosa of patients in an intensive care unit}

Bergmans DCJJ, Bonten MJM, van Tiel FH, Gaillard CA, van der Geest S, Wilting RM, de Leeuw PW, Stobberingh EE 


\section{Abstract}

\section{Background}

Ventilator-associated pneumonia (VAP) caused by Pseudomonas aerugnosa is usually preceded by colonization of the respiratory tract. During outbreaks, colonization with $P$. aenginosa is mainly derived from exogenous sources. The relative importance of different pathways of colonization of $P$. aeruginosa has rarely been determined in nonepidemic settings.

\section{Methods}

In order to determine the importance of exogenous colonization, all isolates of P. aeruginosa obtained by surveillance and clinical cultures from two identical intensive care units (ICUs) were genotyped with pulsed-field gel electrophoresis.

\section{Results}

A total of 100 patients were studied, 44 in ICU 1 and 56 in ICU 2. Twenty-three patients were colonized with $P$. aeruginosa, seven at the start of study or on admission and 16 of the remaining 93 patients became colonized during the study. Eight patients developed VAP due to $P$. aeruginosa. The incidence of respiratory tract colonization and VAP with $P$. aeruginosa in our $1 \mathrm{CU}$ was similar to that before and after the study period, and therefore represents an endemic situation. Genotyping of 118 isolates yielded 11 straintypes: eight in one patient each, two in three patients each, and one type in eight patients. Based on chronological evaluation and genotypical identity of isolates, eight cases of cross-colonization were identified. Eight $(50 \%)$ of 16 episodes of acquired colonization and two (25\%) of eight cases of VAP due to P. aeruginosa seemed to be the result of cross-collonization.

\section{Conclusions}

Even in nonepidemic settings cross-colonization seems to play an important part in the epidemiology of colonization and infection with $P$, aeruginosa. 


\section{Introduction}

Ventilator-associated pneumonia (VAP) is the most important nosocomial infection among mechanically ventilated patients in intensive care units (ICUs) and is associated with increased morbidity and mortality: especially when caused by Pseudomonas aeruginosa". Ventilator-associated pneumonia is almost always preceded by colonization of the upper respiratory tract with the causative microorganism². However, the exact routes of colonization leading to VAP and the relative importance of different pathways of colonization is a matter of controversy ${ }^{3,4}$

Respiratory tract colonization with $P$. aeruginosa may originate from endogenous sources such as the intestine or the stomach ${ }^{5.7}$, or from exogenous sources such as contaminated equipment or other patients colonized with $P$. aeruginosa $a^{8-10}$. Understanding the relative importance of these routes of colonization is crucial in order to the development of effective preventive measures against infection. If, for example, cross-colonization occurs frequently, improved compliance with infection control measures will be necessary, but such a measure will be less effective if most infections are from endogenous sources. In the latter case, modulation of bacterial colonization of the gastrointestinal tract may be more appropriate. The clinical observation of three episodes of VAP due to $P$. aeruginosa in a short period of time was the starting point for the present study. Infection was assumed to be the result of cross-colonization of microorganisms. In order to determine the importance of exogenous and endogenous colonization of $P$. aeruginosa we initiated an analysis of colonization and infection with this pathogen.

\section{Patients and methods}

\section{Setting}

The study was performed in two identical eight-bed intensive care units (ICU 1 and ICU 2) of the University Hospital Maastricht, a 700-bed hospital. Both ICUs contained a mixed population of surgical, medical, neurosurgical, and trauma patients who were randomly admitted. The units have different nursing staff and medical equipment, but the medical staff and paramedic care providers (physiotherapists, radiographic personnel, and the nutrition support team) have patient contacts in both ICUs. No outbreaks of multiple resistant microorganisms have occurred during the last five years.

\section{Patients}

All patients admitted to ICU 1 and ICU 2 (ventilated or nonventilated) were studied prospectively with regard to respiratory tract colonization and the development of VAP and other ICU-acquired infections in two study periods. from 6 November 
1993 to 15 December 1993 in ICU 1 (40 days) and from 17 November 1993 to 15 January 1994 in $1 \mathrm{CU} 2$ (60 days). The following data were recorded on admission: age, sex, medical specially, length of time in hospital before admission to the ICU, diagnosis on admission. reason for intubation, previous medical history, and APACHE II score". During the stay in ICU clinical parameters (temperature, leukocyte count, chest radiograpgh etc.) were recorded daily. All 16 mechanically ventilated patients receiving enteral nutrition with an expected duration of ventilation of $\geq 3 \mathrm{~d}$ were included in a prospective study on the influence of continuous and intermittent enteral feeding on respiratory and digestive tract colonization $^{12}$. Another six patients were included in a study on sequences of colonization within the patient.

\section{Surveillance cultures}

Patients were subjected to microbiological examination of endotracheal aspirates and urine on admission and then twice weekly. In addition, more extensive examination was performed on the patients included in the two prospective studies mentioned above. Gastric aspirates and oropharyngeal swabs were cultured daily from the 16 patients in the study on the effects of intermittent enteral feeding, and from the six patients studied to determine sequences of colonization cultures were obtained twice daily $(08.00$ and 16.00 hours) from six body sites (nose oropharynx, sputum, gastric aspirate, rectum, and groin) during their stay in ICU The results of all clinical cultures were also included in the analysis. No cultures were taken from nonintubated patients with an ICU stay of less than $24 \mathrm{~h}$.

\section{Definitions}

\section{Colonization}

Colonization was defined as the isolation of microorganisms from specimens taken from any body site in the absono of infection Colonization on admission was defined as that occurring within $48 \mathrm{~h}$ after admission to the ICU. When colonization occurred more than $48 \mathrm{~h}$ after admission to the $\mathrm{ICU}$, without colonization on admission, it was defined as acquired colonization.

\section{Ventilator-associated pneumonia}

Ventilator-associated pneumonia was diagnosed by bronchoscopy with protected specimen brush (PSB) and bronchoalveolar lavage (BAL). The diagnosis was established when (A) at least three of the following criteria were met, (1) rectal temperature above $38.0^{\circ} \mathrm{C}$ or below $35.5^{\circ} \mathrm{C},(2)$ blood leukocytosis $\left(>10.10^{3} / \mathrm{mm}^{3}\right)$ and/or left shift or blood leukopenia $\left(<3.10^{3} / \mathrm{mm}^{3}\right)$, (3) more than 10 leukocytes per high-power field in Gram stain of tracheal aspirate, and (4) a positive culture from tracheal aspirate, in combination with (B) a new or progressive infiltrate on chest radiograph, and (C) the presence of (1) a positive quantitative culture of a sample of secretions obtained by BAL (cut-off point $\geq 10^{4} \mathrm{cfu} / \mathrm{ml}$ ) or PSB (cut-off point $\left.\geq 10^{3} \mathrm{cfu} / \mathrm{m} /\right)$, or (2) positive cultures from blood unrelated to another source 
obtained within $48 \mathrm{~h}$ before and after respiratory sampling and with the same species as cultured from tracheal aspirate, or (3) positive pleural fluid cuture in the absence of previous pleural instrumentation. Pneumonia was considered to be ICU-acquired if symptoms began $\geq 48 \mathrm{~h}$ after admission to the ICU

\section{Endogenous colonization}

Endogenous colonization was defined as colonization occurring with a strain of P. aeruginosa that had not previously been isolated from another patient

\section{Exogenous colonization or Cross-colonization}

Defined as colonization occurring with a strain of P. aeruginosa with similar pulsed-field gel electrophoresis (PFGE) typing results to that of isolates from another patient present in one of both ICUs.

\section{Colonization pressure and antibiotic pressure}

For each study day the point prevalence of $P$ aeruginosa colonization in the ICU was calculated as follows: number of patients colonized with $P$. aeruginosa on that day divided by the total number of patients present in the ICU on that day. Subsequently, for each patient who was not colonized with $P$. aeruginosa on admission or at the start of the study, the mean point prevalence of $P$ aeruginosa colomization for all days in the ICU until acquisition of $P$, aeruginosa or until discharge (if the patient did not acquire colonization) was calculated. This calculated number reflects the colonization pressure with $P$. aeruginosa for the period in the ICU that the patient was not colonized.

Antibiotic pressure was determined as follows: the percentage of days that noncolonized patients received antibiotic therapy that provided $P$. aeruginosa a selective growth advantage (lamino)penicillins, first and second generation cephalosporins, macrolides, glycopeptides etc.) was calculated until acquisition of $P$. aeruginosa or until discharge from the $\mathrm{ICU}$.

\section{Microbiology and bacterial typing}

Semiquantitative microbiological analysis of surveillance and clinical cultures were performed and PSB and BAL were analyzed quantitatively. All isolated species were identified according to methods routinely used in the medical microbiology laboratory. Specimens were incculated immediately after sampling, seven days a week. From each culture plate with growth of P.aeruginosa three colonies were analyzed and stored separately until further processing. All isolates of $P$, aerugino. sa were stored al a temperature of $-70^{\circ} \mathrm{C}$. From each patient and each body site found to be colonized with $P$. aeruginosa isolates were randomly selected for bacterial typing. The antibiotic susceptibility pattern was determined by measurement of minimal inhibitory concentrations using the micro-broth-dilution method according to the NCCLS guidelines. P. aeruginosa ATCC 27853 and Escherichia coli ATCC 25922 and 35218 were used as reference strains. Susceptibility to the 
following antibiotics was determined: piperacillin, co-ticarclavulanate, ceftazidime, imipenem, gentamicin, tobramycin, amikacin, ciprofloxacin, and ofloxacin. Pulsedfield gel electrophoresis was carried out according to the method described by Grothues et al. ${ }^{13}$ using a CHEF-DRll System (Bio-Rad Laboratories, Richmond, CA, USA) after restriction digestion with Spel (Boehringer Mannheim, Germany). Saccharomyces cerevisiae was used as marker

Pulsed-field gel electrophoresis patterns were compared visually on enlarged gel photographs to identify bands of identical relative mobility as fragments of identical size. The absolute number of band differences between pairs of isolates was recorded. The criteria of Tenover et al. ${ }^{14}$ were used to interpret chromosomal DNA restriction palterns produced by PFGE for typing of bacterial strains. Indistinguishable isolates (no band differences) and closely related isolates (2-3 band differences) were considered to be the same genotype, while possibly related and different isolates (4-6 and $\geq 7$ band differences, respectively) were considered different genolypes.

\section{Statistical analysis}

Data are expressed as absolute numbers with or without percentages, as means with standard deviation (SD), or as medians with ranges. Frequency comparisons were performed by the Mann-Whitney test or chi-square test, a probability value of less than 0.05 being considered statistically significant.

\section{Results}

\section{Patients}

In all, 100 patients were studied of whom 65 were mechanically ventilated. During the study period in ICU 1 (40 days) 44 patients were studied, 40 patients were adlmilted and four were present at the start of the study. In ICU 2 (60 days) 56 patients were studied, 50 of whom were admitted and six were present at the onset of the study. The characteristics of the patients admitted to both ICUs were comparable (Table 9.1). Furthermore, the occupancy rate of beds was similar in both ICUs, $91 \%$ in ICU 1 and $93 \%$ in ICU 2 .

\section{Surveillance of colonization}

In all, 1370 specimens were taken from 73 patients (243 endotracheal aspirates, 159 urine samples, 383 blood/pus/intravascular lines, 47 urine catheters, 28 PSB/BAL fluid samples, 199 oropharyngeal swabs, 40 rectal swabs, 191 gastric aspirates, 41 nose swabs, and 39 groin swabs). No cultures were taken from 27 patients because their stay in the ICU was less than $24 \mathrm{~h}$ and they were not intubated Most of these patients were postoperative neurosurgical patients and patients admitted after autointoxication. $P$ aeruginosa was isolated from 69 specimens (22 endotracheal aspirates, two urine samples, 15 blood/pust 
intravascular lines, three urine catheters, seven PSB/BAL fluid samples, 11 oropharyngeal swabs, two rectal swabs, five gastric aspirates, one nose swab, and one groin swab) obtained from 23 patients. Eight of them developed VAP. Surveillance cultures were positive for $P$ aeruginosa before this species was isolated from clinical cultures in $77 \%$ of cases

Colonized patients had a longer median stay in the ICU than noncolonized patients ( 25 vs $3 \mathrm{~d}, p<0.0001$ ), were more frequently intubated $(96 \%$ vs. $62 \%$, $p<0.01$ ), and had a longer median duration on mechanical ventilation ( 17 vs. 2 d, $p<0.0001$ ), but did not differ significantly with respect to the other characteristics (data not shown).

Four (4.4\%) of the 90 patients admitted to the ICUs were colonized with $P$. aeruginosa on admission, four $(10 \%)$ of 40 in ICU 1 and none of 50 in ICU 2 . In addition, three out of 10 patients who were present in the ICU at the start of the study were already colonized, one in ICU 1 and two in ICU 2. Thus, 93 patients were not colonized with $P$. aeruginosa at the onset of the study or on admission to the $\mathrm{ICU}$, and $16(17 \%)$ of them acquired colonization with $P$. aeruginosa, four of 39 in ICU 1 and 12 of 54 in ICU 2.

Table 9.1 Patient characteristics

\begin{tabular}{|c|c|c|c|}
\hline & ICU1 & $\| \mathrm{CU} 2$ & Tokal \\
\hline Number of patients studied & 44 & 56 & 100 \\
\hline Number of colonized patients & 9 & 14 & 23 \\
\hline - prior to study-period & 1 & 2 & 3 \\
\hline - on admission & 4 & 0 & 4 \\
\hline - acquired & 4 & 12 & 16 \\
\hline Number of pneumonias & 3 & 5 & 8 \\
\hline Median age (range) & $64(0-92)$ & $61(0-79)$ & $61(0-92)$ \\
\hline Male/temales & $25 / 19$ & $30 / 26$ & $55 / 45$ \\
\hline Median APACHE II scare (range) & $21(5-33)$ & $18(2-41)$ & $19(2-41)$ \\
\hline Mediam days in ICU (trange) & $3(1.535)$ & $4 \mid 1-68\}$ & $4(1-535)$ \\
\hline Hospital stay prior to ICU" & $2(0-147)$ & $2(0-115)$ & $2(0-147)$ \\
\hline \multicolumn{4}{|l|}{ Medical specilially } \\
\hline - surgery/trauma & 12 & 12 & 24 \\
\hline - medical & 10 & 17 & 27 \\
\hline - putmonology & 5 & 6 & 11 \\
\hline - neurology/neurasurgery & 7 & 10 & 17 \\
\hline - paediatrics & 4 & 1 & 5 \\
\hline - cardiology & 3 & 4 & 7 \\
\hline - other & 3 & 6 & 9 \\
\hline Mortality & $13(30 \%)$ & $14[25 \%$ & $27(275)$ \\
\hline
\end{tabular}

- Median number of days in hospital before admission to lov 


\section{Ventilator-associated preumonia}

During the study period eight $(8 \%)$ of 100 patients developed VAP caused by $P$ aeruginosa (Table 9.1), three in ICU 1 and five in ICU 2 , with a mean duration from admission to $1 C U$ to diagnosis of VAP of $7.3 \mathrm{~d}$ (SD 3.1). The incidence of VAP caused by $P$. aeruginosa was $8 \%$ in the total study population. However, the incidence among ventilated patients was $12 \%$ (eight of 65 ) and $20 \%$ (eight of 41 ) for patients venthated for $\geq 3 \mathrm{~d}$. The overall incidence of VAP caused by $P$. aeruginosa during the total study period was 0.9 per 100 patients days. In periods of two morths the incidence of VAP caused by $P$. aeruginosa ranged from 0.4 to 0.9 per 100 patient days in the year following the study period, suggesting that the incidence of VAP during the period of study was not exceptional in our ICU

\section{Microbiological typing}

In all. 118 isolates of $P$. aeruginosa were genotyped, cultured from the following sites: 61 endotracheal aspirates, seven blood samples, two intravascular lines, 21 PSB/BAL fluid samples, 18 oropharynx, and nine stomach samples. In two patients ( $\mathrm{Pl}$. B and S) $P$. aeruginosa was cultured only once during ICU stay. Unfortunately these isolates were lost in the process of storage and could not be genotyped.

Antimicrobial susceptibility patterns were similar for isolates of all but one patient (i.e, susceptible to piperacillin, co-ticarclavulanate, ceftazidime, imipenem, gentamicin, tobramycin, amikacin, ciprofioxacin, and ofloxacin). One patient (Pt. J) was colonized with a strain of $P$. aeruginosa resistant to gentamicin and tobramycin (type $X$ ), and such a strain was not isolated from any other patient. We assumed therefore that cross-colonization with this strain did not occur and isolates from this patient were not genotyped. Using PFGE: 11 different genotypes could be distinguished (type 1 to 11). Eight genotypes were found in single patients only, whereas one genotype (type 2) was isolated from eight patients and two genotypes (type 3 and type 7) were isolated from three patients. Two patients $(\mathrm{Pt} . \mathrm{U}$ and $\mathrm{W}$ ) were colonized with two different genotypes each.

\section{Incidence of cross-colonization}

Genolype 2 was isolated from eight patients, five in ICU 1 and three in ICU 2 (Figure 9.1). Patient M (ICU 2) was colonized with genotype 2 at the start of the study. Patient $T$ (ICU 1) acquired genotype 2, presumably via cross-colonization from patient $M$. Subsequently, genotype 2 colonized patient $O(I C U 1)$ and patient $K(\mid C U 2)$. Since patients $M$ and $K$ were not in ICU 2 simultaneously, patient $K$ most probably acquired genotype 2 via patient $T$ in ICU 1 . Acquisition of genotype 2 by patient $D$ could have been the result of cross-colonization with patients $U$ or $\mathrm{R}$ from ICU 1 as donor; or with patient $K$ in ICU 2 as donor. Patients $K$ and $D$ were in ICU 2 simultaneously, but cultures of patient $D$ only became positive six days after discharge of patient $K$. This delay may have been caused by sampling 
error or because colonization initially occurred in numbers below the detection threshold of culture techniques. Three other patients in ICU 1 were colanized with genotype 2 when they were admitted (Pt, Q, R and U). Two of them were admitted directly from the community and one patient had been admitted to a general hospital ward one day before ICU admission. Cultures from all three patients were taken within $24 \mathrm{~h}$ of admission. In patient $\mathrm{Q}$, admitted directly from the community. genotype 2 was cultured from the endotracheal aspirate on admission. This patient had been treated in the ICU four months earlier and was colonized with $P$. aeruginosa during that time as well. Unfortunately no strains from that period were genotyped. Thus, four patients ( $P t$. $T$ and $O$ in $I C U 1$, and $K$ and $D$ in ICU 2) appeared to have acquired genotype 2 by cross-colonization. At the start of the study, patient H (ICU 2) was colonized with genotype 3. Subsequently. colonization with this genotype was demonstrated in patient $A$;on the day of the study) and patient I (both in ICU 2). Although cultures from patient I only became positive with genotype 3 after discharge of patients $A$ and $H_{2}$ all three patients were treated simultaneously in ICU 2 for a number of days. Finally, patient C (ICU 2) acquired colonization with genotype 7 , presumably from an endogenous source. Subsequently, two other patients in $1 C U 2$ (Pt. F and $N$ ) acquired colonization with this genotype. All other patients acquired colonization with a uinique genotype which was therefore presumed to be derived from endogenous sources. In all, eight episodes of crossmcolonization were demomstrated (four patients with genotype 2 , two patients with genotype 3 , and two palients with genotype 7 ). Fifty percent of all patients acquiring colonization with $P$. aeruginosa did so via crosscolonization, the other 50\% most probably being colonized from endogenous sources. In two $(25 \%)$ of eight patients with VAP caused by $P$. aeruginosa, colonization probably accurred via cross-colonization. The three episodes of VAP within a short period of time that initiated this study were caused by three different genotypes of $P$. aeruginasa.

\section{Collonization pressure and antibiotic pressure}

A tendency towards a higher rate of cross-colonization in $1 \mathrm{CU} 2 \mathrm{was}$ observed; two of $39(5 \%)$ patients in ICU 1 and six of $54(11 \%)$ in $1 C U 2(p=0.2$; chi-square test). The fact that more episodes of cross-colonization occurred in ICU 2 may be related to the higher colonization pressure in this ward. Mean colonization pressure was 40\% (SD 11\%) in ICU 2 and 35\% (SD 9\%) in 1CU 1 (p<0.05; MannWhitney test). The mean antibiotic pressure for patients was comparable in both "CUs. However mean antibiotic pressure was higher for patients who acquired colonization than for those who did not $(68 \%$ (SD $45 \%$ ) and $37 \%$ (SD $43 \%$ ) respectively; $p<0.05$; Mann-Whitney test) 

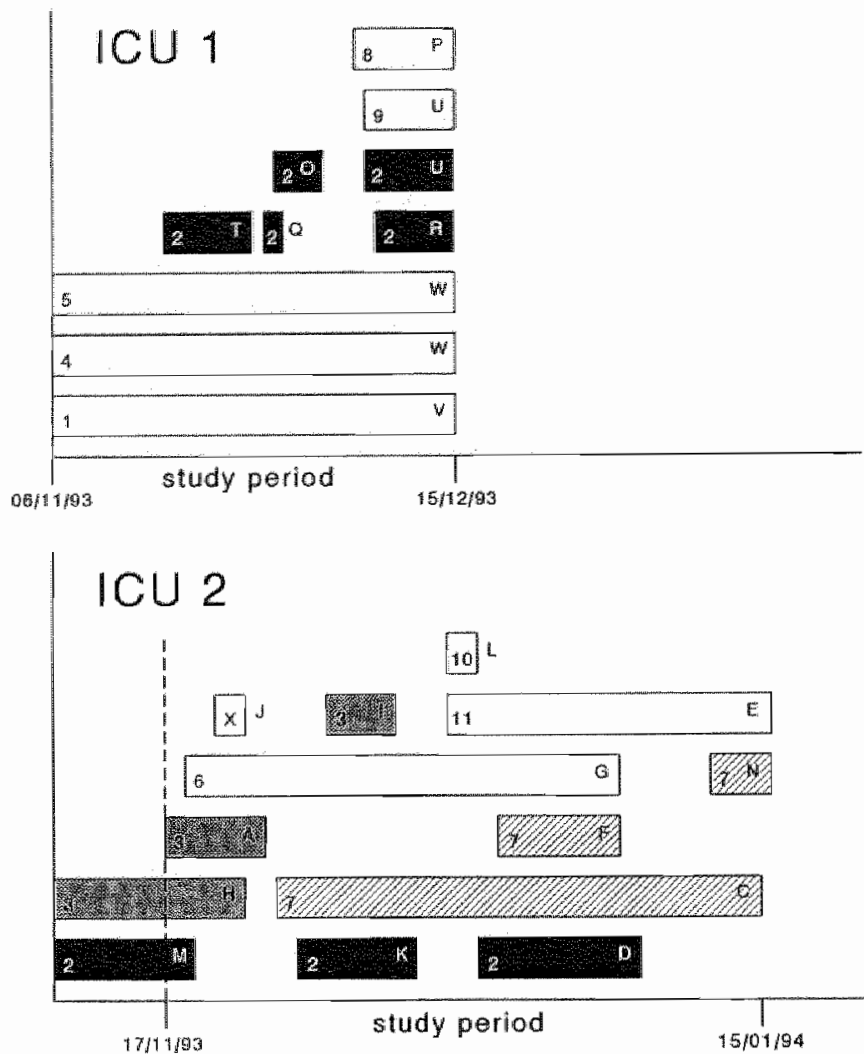

genotype 2

genotype 3 genotype 7 other

Figure 9.1 Colonization of $P$. aeruginosa genotypes. Each hortzontal bar represents the length of time a patient was cotonized during the study period. Paltent characters (in capitals) and genotypes (in numbers) are depicted within or just adjecent to the bars. Genotypes collonizing more than one patient (type 2, 3 and 7 ) have marked bars, Blank bars represent the genotypes that were found in single patients only flype $1,4,5,6,8,9,40$, and 111 . Type $x$ represents the stlatin resistant to gentamin and tobramycin.

\section{Discussion}

Our findings suggest that cross-colonization may be an important route of colonization and infection for $P$. aeruginosa even when overall incidence rates do not suggest the occurrence of an outbreak. The epidemiology of $P$. aeruginosa may therefore be described as a silent epidemic, sharing similarities with the epidemiology of other nosocomial pathogens such as vancomycin-resistant 
enterococci, methicillin-resistant Staphylococcus aureus, and ceftazidme-resistant Gram-negative bacill. The results also show that survellance in combination with molecular biotyping may be used as a method to perform continuous quality improvement. Finally, our findings emphasize the constant need of improving compliance with infection control measures, and warrant further studies to elucidate the relative importance of endogenous and exogenous colonization with $P$. aeruginosa and to determine variables that influence both routes of colonization and infection.

The incidence of VAP due to $P$. aeruginosa (12\% of mechanically ventilated patients) during the period of study is representative for our ICU. During 1994, the year following this study, 58 of 276 (21\%) mechanically ventilated patients admitted to our ICU developed VAP. in 28 (48\%) of the cases due to $P$. aeruginosa, either alone or in combination with other microorganisms (1.e., $10 \%$ of all mechanically ventilated patients) ${ }^{15}$. In a large study performed in 1992 and 1993 in our ICU the incidence of VAP was $22 \%$, with $P$. aeruginosa involved in $58 \%$ of patients (i.e., $13 \%$ of all mechanically ventilated patients) ${ }^{16}$. The incidence of VAP has therefore remained fairly stable throughout the years. Moreover, the clinical observation of three episodes of VAP within a short period of time appeared to be caused by three different genotypes. The period under study therefore reflects our endemic setting and not an outbreak. Comparison of incidence rates to those of other ICUS is difficult, mainly because of different patient populations. However, the incidence of VAP ranges from $15 \%$ to $24 \%$ in settings where VAP was also diagnosed by bronchoscopy ${ }^{17} 20$, and the proportion caused by $P$. aeruginosa varied from $14 \%$ to $55 \%{ }^{17-22}$.

Observations of similar genotypes of $P$. aeruginosa colonizing and infecting several patients strongly suggest the occurrence of cross-colonization, not only between patients in the same ward but also between patients from different wards. Although contaminated equipment might have been a source, regular examinations of nebulizers and sinks were always negative for $P$ aeruginosa, and the polyclonal character of the epidemiology make this possibility fairly unlikely

The possibility of cross-colonization of P. aeruginosa in nonepidemic situations has rarely been studied. O son and coworkers ${ }^{23}$ addressed this issue in a study of 270 patients admitted to a medical/surgical ICU ward 63 (23\%) palients were colonized with $P$. aeruginosa on admission, $33(16 \%)$ acquired colonization, twelve $(36 \%)$ of whom were found to be due to cross-colonization in a prospective survellance study carried out in five 1 CUs during a six month period, Chetchotisakd et al. ${ }^{24}$ did not find an important role for cross-colonization, only 14 $(10 \%$ ) of 137 isolates of bacteria ( $P$. aeruginosa, $E$. coli, Klebsiella pneumoniae. Enterobacter cloacae, enterococci) cultured from patients with suspected infection being acquired by cross-colonization. Although molecular biotyping methods were used to determine identity of isolates, they may have underestmated the true incidence of cross-colonization. Only a single isolate from a suspected site of 
infection was analyzed, without inchuding isolates from colonized patients. It is evident that infections with $P$. aeruginosa only form the tip of the iceberg of the complete epidemiology $y^{2.23}$, and its epidemiology can only be studied reliably when survellance of colonization is included. Moreover, patients may be colonized or infected with multiple genotypes of $P$. aeruginosa, and analysis of a single isolate will not accurately represent the whole epidemiology ${ }^{25}$.

The difference in the number of cases of cross-colonization between both ICUS in the present study (two in ICU 1 and six in ICU 2) may be associated with the higher colonization pressure in ICU 2 compared with ICU 1. However, differences in complance with infection control measures, which was not monitored, may be another explanation of this difference. In addition, antibiotic pressure was clearly higher for pattents who acquired $P$. aeruginosa. These findings suggest that both endogenous colonization (e,g., intestinal colonization), and exogenous colonization play a role in the epidemiology of respiratory tract colonization with $P$. aeruginosa In this regard, the epidemiology of $P$ aeruginosa may share similarities with endemic situations of other nosocomial pathogens such as vancomycin-resistant enterococci. These bacteria are also frequently acquired via cross-colonization ${ }^{26}$ and acquisition seems to be influenced by a high colonization pressure and by a high antibiotic pressure, providing these bacteria with a selective growth advantage ${ }^{27}$. However, the present study does not allow us to determine the precise relative impact of both exogenous and endogenous colonization of $P$. aeruginosa. Since the study was started abruptly after the clinical suspicion of cross-colonization, surveillance was not uniform in all patients. More importantly. no surveillance cullures of the rectum were performed. Since rectal colonization may be a source of respiratory tract colonization ${ }^{7.28,29}$, cases of endogenous colonization may have been missed. The relative importance of endogenous and exogenous colonization in the pathogenesis of VAP therefore remains to be established. 


\section{References}

1. Fagon d. Chastre d. Hance A, Montravers P. Nowara $A$, and Gibert $C$. Nosocomial pneumonia in ventiated patients: a cohort study evaluating attributable mortality and hosptal stay. American Joumal of Medicine 1993; 94 $281-288$

2. Bonten $M$, Bergmans $D$, Ambergen $A$ de Leeuw $P$, van der Geest $S$, Stobberingh $E$. and Gaillard $C$. Risk factors fol pneumonia and colanization of respiratory tract and stomach in mechanically ventilated ICU patients. American Joumal of Respiratory and Critcal Care Medicine 1990; 154:1339-1346.

3. Bonten MM, Gaillard CA de Leew PVW, and Stobberingh EE. Role of colonization of the upper intiestinal tract in the pathogenesis of ventilator-associated pneumonia. Clunical Infortious Diseases $1997,24: 309-319$

4. Niederman MS and Craven DE Editorial response: Devising strategies for preventing nosocomial pneumonia - Should we ignore the stomach? Clinical Infectious Diseases 1997; $24,320-323$.

Atherton $S$ and White D. Stomach as source of bacteria colonising respiratory tract during artificial ventitation. Lancet 1978 , 11:968-969.

Torres $A_{4}$ El-Ebiary $M$, González J, Ferrer M, Puig de la Bellacasa ${ }^{\prime}$, Gené $A_{*}$ Martos $A_{2}$ and Rodriguez Roisin R. Gastric and pharyn. geal flora in nosocomial pneumoria acquired duning mechanical ventilation. American Rewew of Respiratory Diseas 1993: 148 : $352-357$.

Murthy $S$, Battch $A$ sinith R, Desjarion $E$ Hemmer $M$, Conroy $J$, and Michelsen $P$. Oropharyngeal and fecal carrage of pseudo. monas aeruginosa in hospital patients Journat of chinical Microbiology 1989; $27 \cdot 35-40$.

Whitby UL and Rampling A Pseudomonas aeruginosa contamination in domestic and hospital environment fancet 1972 , $1,15-97$

Favero M, Carson L., Bond W. and Petersen N. Pseudomonas aeruginosai growth in distilled water from hospitals. Science 1971 . $173: 836-838$
10. Gundmann $H$. Kropec A Hartung $D$, Bener $R$, and Daschner F. Psudomonas aengum nosa in a neonatal intenswe care unit. reservoirs and ecologis of the nosocomial pathogen Joural of Infections Diseases. 1993: $168: 943947$.

11. Knaus WA, Draper EA Wagner DP. and Zimmerman JE. APACHE II: a severity of disease classfication system. Criticat Care Madicine 1985, $13.818-829$

Bonten MNM, Gamard $C, A$, van der Hulst $R$, de Leeuw PW wan der Geest $S$, Stobberingh EE. and Soeters PB. Intermittent enteral faeding: The influence on respiratory and digestive tract colonization in mechancally wentiated intensive-care-unit palients. Amemcan Joumal of Respiratory and Critical Care Madicine 1996; $154: 394-399$.

13. Grothwes D, Koopmann U, Hardt $H$, and Tummler B. Gemome fingerprinting of Pseudo. monas aenghosa indicates colonization of cystic fibrosis siblings with closely related strains. Joumal of Clintical Microbiology 1988 ; 26: $1973-1977$

14. Tenover FC, Arbeit RD, Goerimg RV. Mickeisen PA, Murray BE, Persing DH, and Swaminathan B. Hnferpreting chromosomal DNA restriction pattiens produced by pulsed-field gel electrophoresis: Criteria for bacterial strain typing. Joumal of Clinical Microbiology 1995; $332233-2239$

Bergmans DCu, Bonten MJM, Gantard CA. van The HH. war der Gest 5 , de Leeuw PW. and stobberingh EE. Indications for antibiotic use in ICU pattents: oneyear prospective sumellance Journal of Antimicrobia Chemoherapy $1997,30.527-236$

Bonten MUM, Gaillard CA, wan der Geest $S$. van Tiel FH, Beysens A. Smeets Hov, and Slobberingh $E E$. The role of intragastric acidity and stress uker prophylaxis on colonization and infection in mechanically veritated patents A stratified, randomized double blind study of sucratate versus antacids. Amarican Jownal of Rasphatory and Crifical Care Mediche 1995.152. $1825-1834$ 
17. Fagon JV. Chastre J. Domart $Y$. Troullet JL. Pierre J. Dame $C_{\text {, and Giber } C \text {. Mosocomal }}$ preumonia in patients receiving continuous mechanical ventlatom prospective analysis of 52 episodes wh use of a proteded specimen brugh and quantitative cuture technique. Anerican Revicw of Respiratony Disease $1989,13987 \%, 804$

19. Torres A, Aznap R, Gatell JM, Jiménez $P$. Gonzalez $\downarrow_{*}$ frerer $A$, Celis $R$, and Rodriguez-Roisin $R$. Incidence, risk, and prognosis fiactors of nosocomial pneumionia in mechanically wenthated patients. American Review of Respiratory Disease 1990, 142 . $523-528$

19. Chevret $S$ Hemmer M, Carlet $J$, Langer $M$, and European Cooperative Sroup on Nosocomiall Pneumonia. Incidence and risk factors of preumonia acquired in intensive care units: results from a inulticenter prospective study on 996 patients. Intensive Care Madicine $1993 ; 19: 256-264$.

20. Papazian L, Bregeon $F$, Thirion $X$, Gregoire $R$, Saux $P$, Denis JP, Perim $G$, Chatrel J, Dumon $J F$, Afrray JP, and Gouin F. Effect of ventilator-associated pneumonia on mortality and morbidity. American Journal of Respiratory and Critical Care Medicine 1996: $154.91-97$

21. Craven DE, Steger KA, Barat LM, and Duncan RA. Nosocomial pheumonia: epidemiology and infection control intensive Care Medicine 1992: 18:53-59.

Bonten MJM, Gathard CA, van Tiel FH, Smeets HGW, van der Geest $S$ and Stobberingh EE. The stomach is not a source for colonization of the upper respiratory tract and preumonia in ICU patiants. Chest 1994; $105: 878-884$

Olson B, Weinstein RA, Nathan C, Chambertin W. and Kabins SA Epidemiology of endemic Pseudomonas aruginosa: why infection control efforts thave falled. Joumal of Infoctious Diseases 1984; 150:808-816.
24. Chetchotsakd $\mathrm{P}$. Phelps $\mathrm{CL}_{\mathrm{n}}$ and Harstein $\mathrm{As}$ Assessment of bacterial cross-iransmision as a cause of infections in patients in intensive care units Clinical Intectious Diseases $1994:$ 1.920.937.

25. Bergmans $D$, Bonten $M$, van Tiel $F$, Gaillard C. Lonuton N. wan der Geest $S$, de Leeuw $P$. and Stobberingh $E$. Value of phenotyping methous as an initial screening of Pseudomonas asughosa in epidemiclogic studiesi thection 1997, 25,350-354

26. Bonten $M$. Hayden MK, Nathan $C$, wan Voorhis J. Matushek $M$, Slaughter $S$, Rice and Weinstein RA. Epidemiology of colonisation of patients and emvironment with wancomycin-resistant enterococci. Lancet $1996 ; 348: 1615-1619$

27. Bonten $M$, Slaughter $\$$. Ambergen $A_{1}$, Hayclen $M$, van Voorhis d, Nathan $C$, and Weinstein $R$. The role of 'colorization pressure' in the spread of vancomycinmresistant enterococci: an important infection control variable. Archives of Mternal Medicine 1998; 158 $1127-1132$

23. Noone MR, Pift TL, Bedder M, Hewlett AM, and Rogers KB. Pseudomonas aeruginosa colonisation in an intensive therapy unit: role of cross infection and host factors. British Medical Journal $1983 ; 286 \cdot 341-344$.

29. Kropec $A$, Huebner J, Riffel $M$, Bayer U, Benzing $A$, Geiger $K_{n}$ and Daschner F. Exogenous or endogenous reservoirs of noso. comial Psaviomonas aeruginosa and Staphy lococcus aureus infections in a surgical intensive care unit Intensive Care Medicine 1953 19:161-165. 


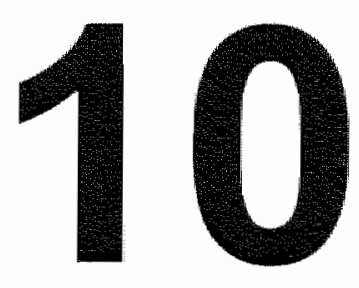

\section{Prevention of ventilator- associated pneumonia by oral decontamination: \\ A prospective, randomized, double-blind, placebo- controlled study}

Bergmans DCJJ, Bonten MJM, Gaillard CA, Paling JC, van der Geest $S$, van Tiel FH, Beysens AJ, de Leeuw PW, Stobberingh EE 


\section{Abstract}

\section{Background}

Prevention of weintilator-associated pneumonia (VAP) remains a challenge for intensive care medicine. Colonization of the intestinal tract has been assumed to be important in its pathogenesis, but relative impacts of oropharyngeal, gastric or intestinal colonization have not been elucidated. Our aim was to prevent VAP by modulation of oropharyngeal colonization, without influencing gastric and intestinal colonization and without systemic prophylaxis.

\section{Methods}

In this prospective, randomized, placebo-controlled double-blind study 87 patients received topical antimicrobial prophylaxis (gentamicin/colistin/wancomycin $2 \%$ in Orabase, q6h) in the oropharynx and 139 patients received placebo. Colonization was monitored in oropharynx, trachea, stomach and intestine. Ventilator-associated pneumonia was diagnosed on quantitative cultures obtained via bronchoscopic techniques.

\section{Results}

Baseline characteristics were comparable in both groups. Topical prophylaxis eradicated oropharymgeal and tracheal colonization present on admission (75\% vs. $4 \%, p<0.00001$, and $52 \%$ vs. $16 \%, p=0.002$, respectively) and prevented acquired oropharyngeal colonization ( $10 \%$ ws. $61 \%, \mathrm{p}<0.00001$ ). Colonization rates in stomach and intestine were not affected. Incidences of VAP were $10 \%$ in study and $27 \%$ in control patients $(p=0.002)$, resulting in a relative risk reduction for VAP of $0.62(95 \% \mathrm{Cl}: 0.25-0.81)$. This was associated with fewer antibiotic courses per patient (0.95 \pm 0.68 vs. $1.27 \pm 0.87, p=0.018$ ). but with similar durations of ventilation and intensive care unit (ICU) stay. Although ICU mortality tended to be lower among study patients ( $29 \%$ ws. $38 \%, p=0.15$ ), this difference did not persist during follow-up.

\section{Conclusions}

Modulation of oropharyngeal colonization resulted in a $62 \%$ relative risk reduction for VAP. Oropharyngeal colonization is of paramount importance in the pathogenesis of VAP. and a targeted approach to prevent colonization at this site is a very effective method of infection prevention. 


\section{Introduction}

Ventilator-associated pneumonia (VAP) is the most frequently occurring nosocomial infection among mechanically ventilated patients, with reported incidences as high as $78 \% \%^{1.2}$. Usually two types of VAP are distinguished early onset VAP, when diagnosed within the first four days of mechanical ventilation. and late onset VAP, occurring thereafter. Since VAP has been associated with increased morbidity, longer hospital stay, increased health care costs and higher mortality rates ${ }^{3,4}$, prevention of this infection is a major challenge for intensive care medicine.

Early-onset VAP is caused by pathogens presumably colonizing the respiratory tract at the time of intubation, such as Streptococcus pneumoniae, Staphylococcus aureus and Haemophilus influenzae. Latewonset VAP is frequently caused by enteric Gram-negative bacteria and Pseudomonas spp. These bacteria may be transmitted from exogenous (e.g. other colonized patients or contaminated common sources) or from endogenous sources (e.g., the stomach or intestine). Because of concomitant colonization of the upper respiratory and digestive tract with these bacteria, the gastropulmonary route of colonization has been considered to be important in the pathogenesis of late onset VAP ${ }^{5}$. Based on the presumed relevance of gastric colonization, modulation of gastric colonization has been attempted as a measure to prevent VAP. However, neither the use of sucralfate for stress-ulcer prophylaxis ${ }^{6-11}$, nor modulation of enterall feeding ${ }^{12.13}$ have proven unequivocally to reduce the incidence of VAP. In addition, administration of nonabsorbable antibiotics into the stomach and the intestine, reduced colonization at these sites, but did not influence the incidence of VAP ${ }^{\text {it }}$. Finally, sequential analyses of colonization failed to demonstrate an important role of the gastropulmonary route in several recent studies ${ }^{10,13: 95.17}$

Selective decontamination of the digestive tract (SDD) decreases incidences of VAP ${ }^{18-22}$, by eradicating microorgamisms from the intestine, the stomach and the oropharynx by nonabsorbable antibiotics in combination with systemic antibiotic prophylaxis during the first days of intensive care unit (ICU) admission. However, the constant threat of selection and overgrowth of antibiotic resistent microorganisms, lack of formal cost-benefit analyses and absence of beneficial effects on mortality rates have limited a wide-spread use of $\mathrm{SDD}^{23}$. From conceptual point of view, it has remained unclear which part of SDD prevents VAP. The importance of gastric and intestinal colonization has been questioned, and systemic antibiotics during the first days of intubation may prevent early-onset but not late-onset VAP ${ }^{2 / 4}$

We hypothesized that decontamination of the oropharynx, without modulating gastric and intestinal colonization, and without systemic antibiotic prophylaxis. would reduce the incidence of VAP in critically ill intensive care patients 


\section{Methods}

\section{Setting}

The study was conducted in three ICUs from September 1994 to December 1996. ICU 1 and $I \mathrm{CU} 2$ are located in the University Hospital Maastricht; both harbour a mixed population of medical, surgical, trauma and neurologic patients. ICU 3 is located in the University Hospital Groningen and is a surgical and trauma ICU.

\section{Patients}

Adult patients ( $\geq 16 \mathrm{yr}$ ) admitted to one of these ICUS who were intubated within $24 \mathrm{~h}$ of admission and who needed mechanical ventilation with an expected duration of $>2$ d could be included. Patients were randomized to receive either topical antimicrobial prophylaxis (TAP), consisting of an Orabase with $2 \%$ gentamicin, $2 \%$ colistin and $2 \%$ vancomycin or to placebo Orabase without antibiotics. Active medication and placebo could not be visibly distinguished. Orabase was applied in the buccal cavities on a gloved finger, q6h. The application of Orabase was started within $24 \mathrm{~h}$ of intubation. Patients in whom the application of Orabase was not possible or contraindicated, were not eligible for the study. No prophylactic antibiotics were administered via the nasogastric lube or systemically as part of the study regimen. Patients were studied until extubation or death. Since $\geq 95 \%$ of the first episodes of VAP occur within the first three weeks of wentilation $^{8,10}$, application of Orabase was limited to $21 \mathrm{~d}$. Patients were evaluable if they had been included in the study for $>2 \mathrm{~d}$.

Sucralfate (Ulcogant Suspension, E.Merck, Germany) was used for stressulcer prophylaxis, unless patients were receiving $\mathrm{H}_{2}$-antagonisls or $\mathrm{H}^{+} \mathrm{K}^{+} \mathrm{ATP}$ Tase inhibitors on admission. Stress-ulcer prophylaxis was discontinued when enteral feeding was started. All patients had a nasogastric tube. In general, all patients were in supine position during controlled mechanical ventilation and if possible in semirecumbent position during weaning. Moreover, all ventilated patients received daily chest physiotherapy, and endotracheal suctioning was performed by the nursing stafif if necessary.

\section{Study design}

This study was a prospective, randomized, double-blind, placebo controlled study Since patients, physicians and investigators were blinded to treatment allocation during data collection and analyses in fact the study was triple-blinded. Randomization was conducted per hospital and was executed by the department of clinical pharmacy of the University Hospital Maastricht. The inclusion scheme amed to create two separate control groups in ICU 1 and ICU 2. One control group was studied in the presence of patients receiving TAP and a second control group was studied in an ICU where no TAP was used. After nine months of study the inclusion scheme was reversed for another six months (Figure 10.1). To secure the double-blind study design, only the study-supervisor and the haspita! 
pharmacist were aware of this inclusion scheme. In ICU 3, all patients were randomized to receive either TAP or placebo during the whole siudy period (Figure 10.1). This inclusion scheme was chosen to assess whether TAP influences infection rates in control patients treated simultaneously in the same $\mathrm{ICU}^{25}$. The study protocol was approved by the ethical committee of both hospitals. Informed consent was obtained from the patient or, if this was not possible, from a representative of the family.

$\operatorname{ICU} 1$

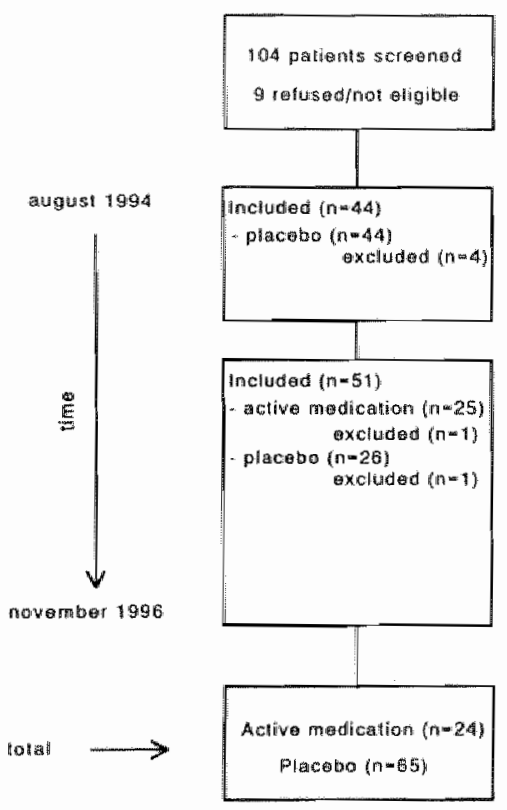

1002

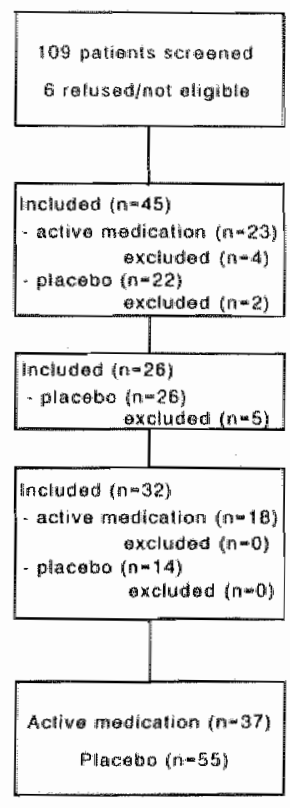

$\mathrm{ICU} 3$

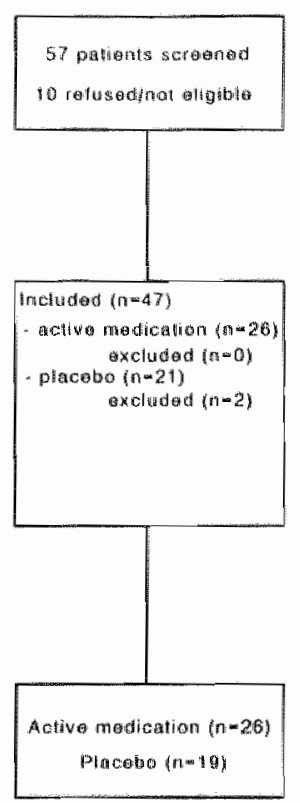

Figure 10.1Trial profite

\section{Data collection}

Demographic data (e.g., age, sex, medical specialty, pre-existent diseases and length of hospital stay before admission to ICU) and APACHE II scores ${ }^{26}$ were recorded on admission. Number of days in $I C U$ and on mechanical ventilation, surgical procedures, parameters of infection (temperature, leukocyte counts and differential counts, chest radiograph interpretations, culture results) and antibiotic use were monitored prospectively. Surveillance cultures were taken on admission and subsequently twice weekly (monday and thursday) of oropharynx "trachea, stomach and rectum. The results of survellance cultures of oropharynx, stomach and rectum were not reported to the $I \mathrm{CU}$ attendings 


\section{Microbiological analysis and monitoring of resistance}

Semiquanitative and/or quantitative microbiological analysis of culture samples were performed according to standard microbiological methods ${ }^{27.28}$. Antibiotic susceptibility was determined by means of a microbroth dilution method according to the MCLS guidelines. Pseudomonas aeruginosa ATCC 27853, Escherichia coli ATCC 25922 and ATCC 35218, Staphylococcus aureus ATCC 29213 and Enterocaccus faecalis ATCC 29212 were used as reference strains. The criteria for susceptibility and resistance, according to the NCCLS guidelines, were used Colonization was analyzed for Enterobacteriaceae, Pseudomonadaceae and Staphylococcus aureus (i.e., potentially pathogenic microorganisms or PPMO). enterocacci and Candida spp. Vancomycin-susceptibility was tested for all enteracacci.

\section{Definitions}

Colonization was defined as the isolation of microorganisms (i.e. bacterial or yeast species) in two or more consecutive specimens of one site, in the absence of infection. Colonization on admission was defined as colonization demonstrated within $24 \mathrm{~h}$ after admission to ICU. Eradication of colonization was defined as the disappearance of microorganisms in two or more consecutive cultures from a body site that was colonized on admission, and is expressed as the proportion of colonized patients in whom eradication occurred. Acquired colonization was defined as colonization demonstrated $>24 \mathrm{~h}$ after $/ \mathrm{CU}$ admission, in patients without colonization on admission.

All patients were examined daily for the presence of VAP. When VAP was suspected on clinical grounds and chest radiograph, bronchoscopy with protected specimen brush (PSB) and bronchoalveolar lavage (BAL) were performed. The diagnosis of VAP was established on the basis of the criteria listed in table 10.1. Pneumonia was considered ICU-acquired when diagnosed $\geq 48 \mathrm{~h}$ after admission to ICU. Pneumonia was classified early-onset when diagnosed within the first 4 d of mechanical ventilation, and late-onset when occurring thereafter

Nosocomial infections, ather than VAP, were diagnosed according to Centers for Disease Control (CDC) definitions ${ }^{29}$. Antibiotic use was analyzed in courses. A course was defined as an episode of clinical or suspected infection in which antibiotics, either consecutively or in combination, were prescribed.

\section{Outcome variables}

The incidence of VAP was the primary outcome variable of the study. Colonization of oropharymx, trachea, stomach and rectum, number of days in ICU and on mecthanical ventilation, other nosocomial infections, antibiotic use and mortality were secondary outcome variables.

\section{Statistics}

Data are expressed as absolute numbers with or without percentages, as means 
with SD or as medians with ranges. Chi-square or Fisher's exact test were used to compare proportions, $t$ test or Wilcoxon-Mann-Whitney test to compare means. For each patient the time until event (i.e., diagnosis of VAP or end of study) and death was determined to calculate the probability of remaining without VAP and survival using Kaplan-Meier survival analysis. Groups were compared by log-rank test. Incidence rates of pneumonia were compared using risk ratios with $95 \% \mathrm{Cl}$. A probability value $<0.05$ was considered to denote slatistical significance and all reported P-values are two-sided. Statistical analysis was performed using SPSSIPC statistical package.

Table 10.1 Diagnasis of preumonia

Critteria:

A 3 positive of the following 4 :

1. rectal temperature above $38.0^{\text {a }} \mathrm{C}$ or below $35^{\circ} 5^{\circ} \mathrm{C}$

2. blood leuknoytosis $\left(>10.10 \% \mathrm{~mm}^{3}\right)$ andlor left shift or blood levkopenia $\left(<3.10^{4} / \mathrm{mm}^{3}\right)$

3. $>10$ leukocyles per high-power field in Gram stain of tracheal aspirate

4. positive culture from tracheal aspirate

and

B new, persistent or prongressive infillate on chest radiograph

and

c $\geq 1$ positive of the following 3 :

1. positive quartitative culture of a sample obtained by BAL. (cut-off point $\geq 10^{\circ}$ cfulml) or PSB (cut-off point $\geq 10^{3 i} \mathrm{cfu} / \mathrm{ml}$ )

2. positive blood culture unrellated to another source and obtained within 48 h before and after respiratory sampling

3. positive pleural fluid cuture in the absence of previous pleural instrumentation

Pneumonia was diagnosed when $A$ and $B$ and $C$ were positive. $B A L$ bronchoalveolar lavage; PSB, protected specimen brush.

\section{Results}

\section{Patients}

During the 28 months study period 213 eligible patients were admitted to ICU 1 and 2. Fifteen patients were not included because of mandibular fixation after facial trauma $(n=2)$, severe intraoral mucosal haemorrhages due to inrombocytopaenia $(n=2)$, and refusal to give informed consent $(n=11)$. Seventeen of 198 included patients were ventilated and/or intubated $\leq 2$ d or succumbed within 2 d (Figure 10.1). Although 93\% of all longterm ventilated patients were included the number of patients studied simultaneously was lower than expected. Overall, the median daily proportion of all patients being included was $14 \%$ (range $0-86 \%$ ), which means that per day on average one patient was included in each 
7-bed ICU. The low inclusion rate was a result of an unexpected high admittance rate of children and shortterm ventilated postoperative neurosurgical patients, which were not eligible for our study. In addition, several patients remained in ICU long after the $21 \mathrm{~d}$ of study. As a result, we were unable to assess whether TAP influences infection rates in control patients. Since the baseline characteristics of both contral groups were comparable (data not shown), these patients were grouped. Consequently, there were more control than study patients.

In ICU 3 , informed consent was refused by 10 eligible patients. In this ICU 47 patients were included, two of whom were not evaluable since they were ventilated $<2$ d (Figure 10.1). In all, 226 patients were evaluable; 87 study patients and 139 control patients. Baseline characteristics were comparable for both groups (Table 10.2). The baseline characteristics of the patients who were not evaluable $(n=19)$ were comparable to those of evaluable patients (data not shown).

Table 10.2 Baseline characteristios of the study pattents and controls

\begin{tabular}{|c|c|c|}
\hline Characteristic & $\begin{array}{c}\text { Study Patients } \\
(n=87)\end{array}$ & $\begin{array}{l}\text { Controts } \\
(n=139)\end{array}$ \\
\hline Malenfemale & $59 / 20$ & $100 / 39$ \\
\hline Meari age $\left(y r_{i} \pm S D\right)$ & $57.6 \pm 19.0$ & $58.4 \pm 16.5$ \\
\hline APACHE II score (mean \pm SD) & $21.0 \pm 6.8$ & $21.6 \pm 7.4$ \\
\hline Days im hospital prior to $1 \mathrm{Cu}$ : median (range) & $2(0-66)$ & $2(0-48)$ \\
\hline $\begin{array}{l}\text { Medical specialty; no. of patients }(\%) \\
\text { medical* } \\
\text { surgent } \\
\text { trauma } \\
\text { neurologyt } \\
\text { other } \$\end{array}$ & $\begin{array}{c}34(39) \\
29(33) \\
17(20) \\
6(7) \\
1(1)\end{array}$ & $\begin{array}{c}44(32) \\
59(42) \\
26(19) \\
8(6) \\
2(1)\end{array}$ \\
\hline Antibiotic use on admission; no. of patients (\%) & $41(47)$ & $58(42)$ \\
\hline 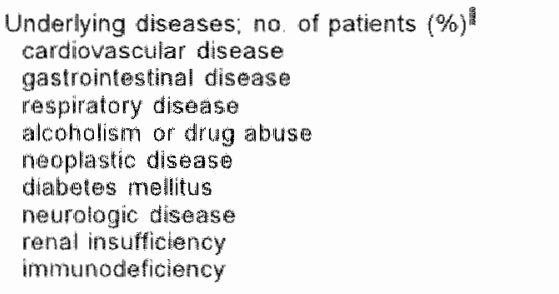 & $\begin{array}{l}34(39) \\
22(25) \\
25(29) \\
10(12) \\
13(15) \\
12(14) \\
20(23) \\
4(5) \\
3(3)\end{array}$ & $\begin{array}{l}68(49) \\
29(21) \\
37(27) \\
18(13) \\
15(11) \\
24(17) \\
22(16) \\
6(4) \\
3(2)\end{array}$ \\
\hline $\begin{array}{l}\text { Raason for intubation; mo of patients }(\%) \\
\text { respiratory failure } \\
\text { trauma } \\
\text { shoch ar hypoxic acidosis } \\
\text { cardiopulmonary failure } \\
\text { preumonia on admission } \\
\text { netrohogic disease } \\
\text { electiwe }\end{array}$ & $\begin{array}{l}32(37) \\
10(12) \\
10(12) \\
4(5) \\
10(12) \\
6(7) \\
15(17)\end{array}$ & $\begin{array}{l}41(30) \\
19(14) \\
26(19) \\
9(7) \\
14(10) \\
9(7) \\
21(15)\end{array}$ \\
\hline
\end{tabular}

* Including pumonology and cardiolog.

+ including cardiopumonary surgery and urology.

* Including neurosungery.

\$. Gynaecology and ENT.

More than one condition possible per patient. 


\section{Colonization}

Colonization rates on admission in oropharynx, trachea, stomach and rectum with PPMO, enterococci and Candida spp. were comparable for study and control patients (Table 10.3). TAP eradicated oropharyngeal colonization with PPMO present on admission (75\% of study patients vs. $4 \%$ in controls; $p<0.00001$ ) and reduced rates of acquisition of colonization with PPMO at this site $(10.3 \%$ vs. $60.9 \%, \mathrm{P}<0.00001)$. In addition, TAP was associated with eradication $(52.0 \%$ of study and $15.8 \%$ of control patients; $p=0.002$ ), and with a tendency towards prevention of acquisition with PPMO in the trachea ( $35.6 \%$ vs. $47.5 \% ; p=0.08$ ). Importantly, in both groups colonization rates of the stomach and rectum were not influenced (Table 10.3).

Acquisition of enterococcal colonization occurred more frequently in control patients $(28.8 \%$ vs. $2.5 \%$ in oropharynx; $p<0.00001$, and $35.9 \%$ vs. $17.6 \%$ in the stomach; $p=0.008$ ). Acquired enterococcal colonization was comparable in trachea and rectum. Although no antifungal agents were used, rates of acquired colonization with Candida spp. were comparable in both groups at all body sites (Table 10.3).

\section{Ventilator-associated pneumonia}

During the study period VAP was diagnosed in nine (10.3\%) study and $38(27.3 \%)$ control patients $(p=0.002$; Table 10.4), after $9 d$ (range 2-18) and $6 d$ (range 2-19) in study and control patients respectively $(p=0.27)$. Therefore, administration of TAP resulted in a relative risk for VAP of $0.38(95 \% \mathrm{Cl} ; 0.19-0.75)$, a relative risk reduction of $0.62(95 \% \mathrm{Cl}, 0.25-0.81)$, and an absolute risk reduction of 0.17 (95\% $\mathrm{Cl}$; 0.07-0.27), which implies that six patients needed to be treated to prevent one episode of VAP. Approximately 20\% of the episodes of VAP were early onset (two of nine study patients and eight of 38 control patients). Ventilator-associated pneumonia was accompanied by bacteraemia in three control and in none of the study patients. In both study groups a similar distribution of etiologic pathogens was observed (Table 10.4). The difference in the incidence of VAP persisted after day 21 (Figure 10.2), demonstrating that ceasing TAP was not associated with a rebound effect on the incidence of VAP. Of the patients that were ventilated for more than $21 \mathrm{~d}$, VAP was diagnosed in one study patient and in four control patients after the application of trial medication was stopped. For the entire ICU stay, administration of TAP resulted in a relative risk for VAP of $0.49(95 \% \mathrm{Cl}$; $0.28-0.86)$, a relative risk reduction of $0.51(95 \% \mathrm{Cl}, 0.14-0.72)$, and an absolute risk reduction of $0.15(95 \% \mathrm{Cl} ; 0.05-0.26)$. A clinical suspicion of VAP with negative or nonsignificant culture results from bronchoscopy occurred with equal frequency in both study groups $(24(27.6 \%)$ and $40(28.8 \%)$ in study and control patients, respectively). 


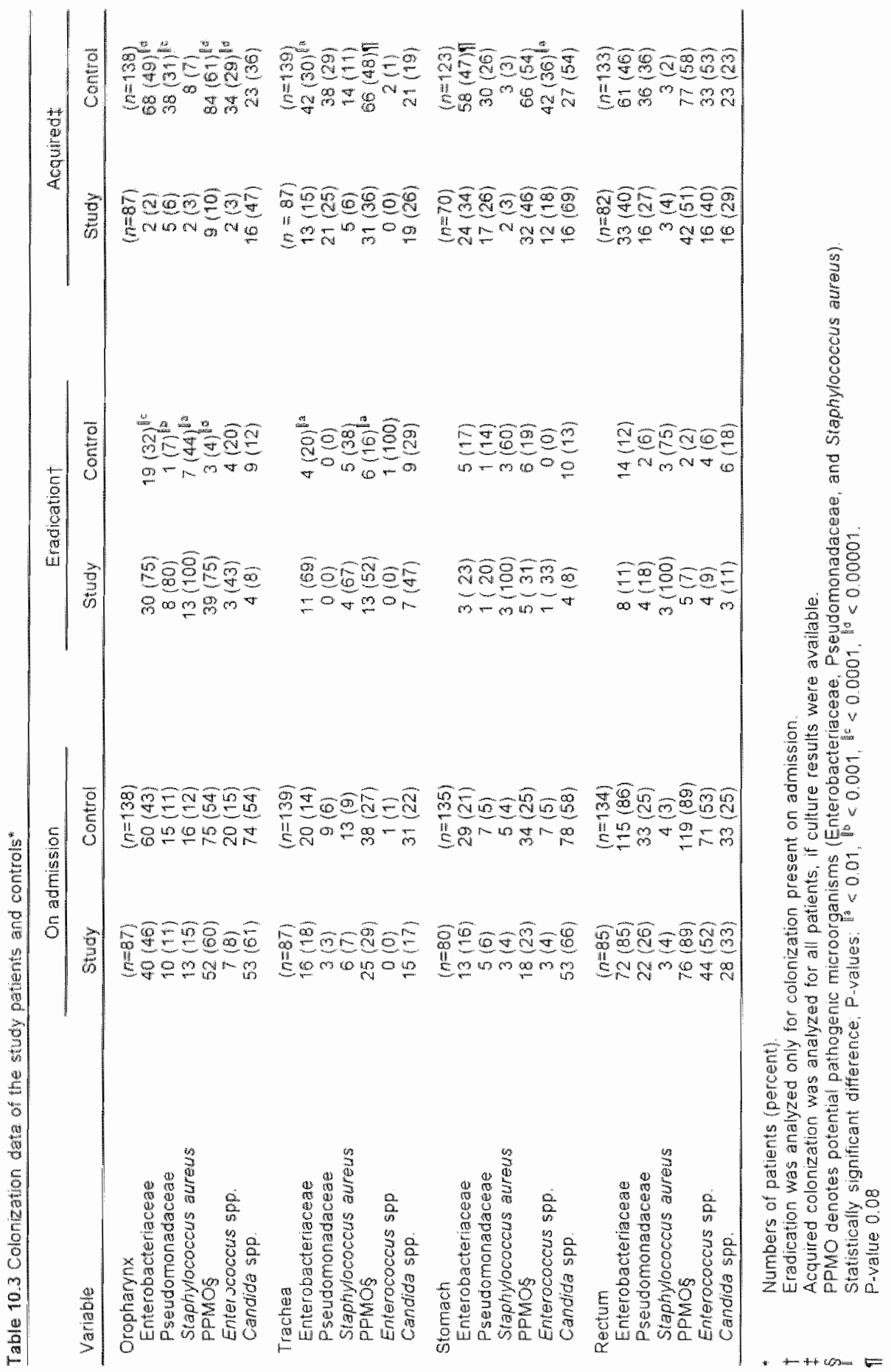


Table 10,4 Ontcome data of the study patients and controls.

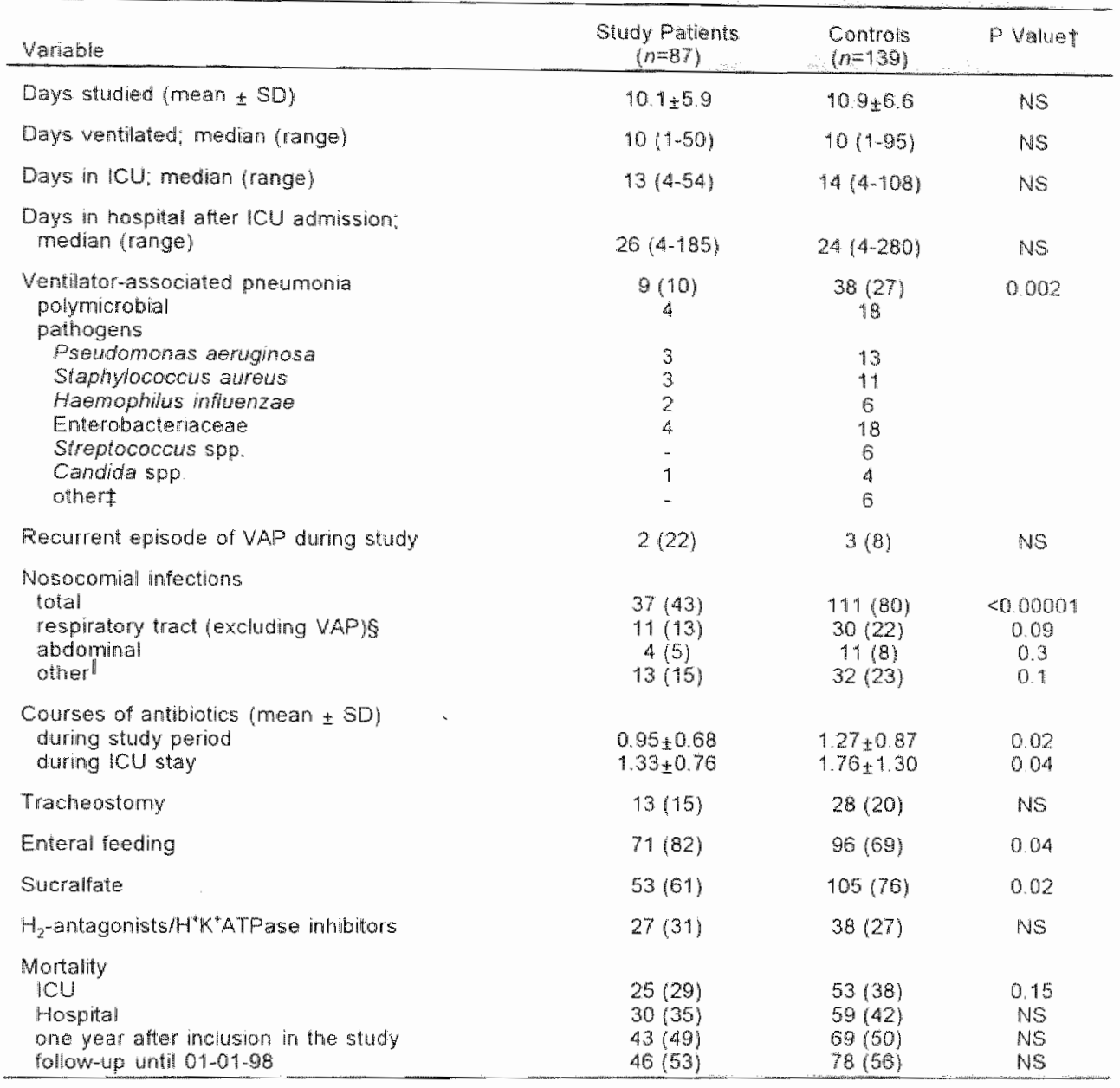

- Numbers (percent), unless stated otherwise

Nis denotes not significant.

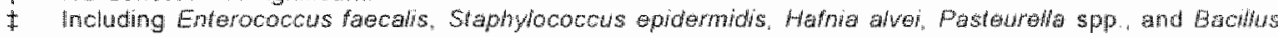
spp.

5 Including simusitis, tracheobronchitis, and lung empyema

including uninary tract infections, CNS infections, tissue infections, IV-line related infections and sopsis e. C. .

\section{Secondary outcome variables}

The number of days in study, on mechanical ventilation, in $\| \mathrm{CU}$ and in hospital were comparable for study and control patients (Table 10.4). There were differences in the use of enteral feeding and sucralfate: study patients received enteral feeding more frequently ( $81.6 \%$ vs. $69.1 \% ; p=0.04$ ), and control patients were more likely to receive sucralfate for stress ulcer prophylaxis $(75.5 \%$ vs. $60.9 \% ; \mathrm{p}=0.02) . \mathrm{H}_{2}$-antagonists and/or $\mathrm{H}^{*} \mathrm{~K}^{+} \mathrm{ATP}$ ase inhibitors were administered to 
approximately $30 \%$ of patients in both groups. Mean durations of enteral feeding, use of sucralfate, and $\mathrm{H}_{2}$-antagonists and/or $\mathrm{H}^{+} \mathrm{K}^{+}$ATPase inhibitors were comparable in both patient groups.

Although ICU mortality tended to be lower in study patients (25 (29\%) vs. 53 $(38 \%) ; p=0.15$ ), this difference did not persist during follow-up (Table 10.4; Figure 10.3). In subgroup analyses, mortality rates were similar for trauma patients ( $n=43)$ receiving and not receiving TAP (12\% vs. $15 \%$ at ICU discharge).

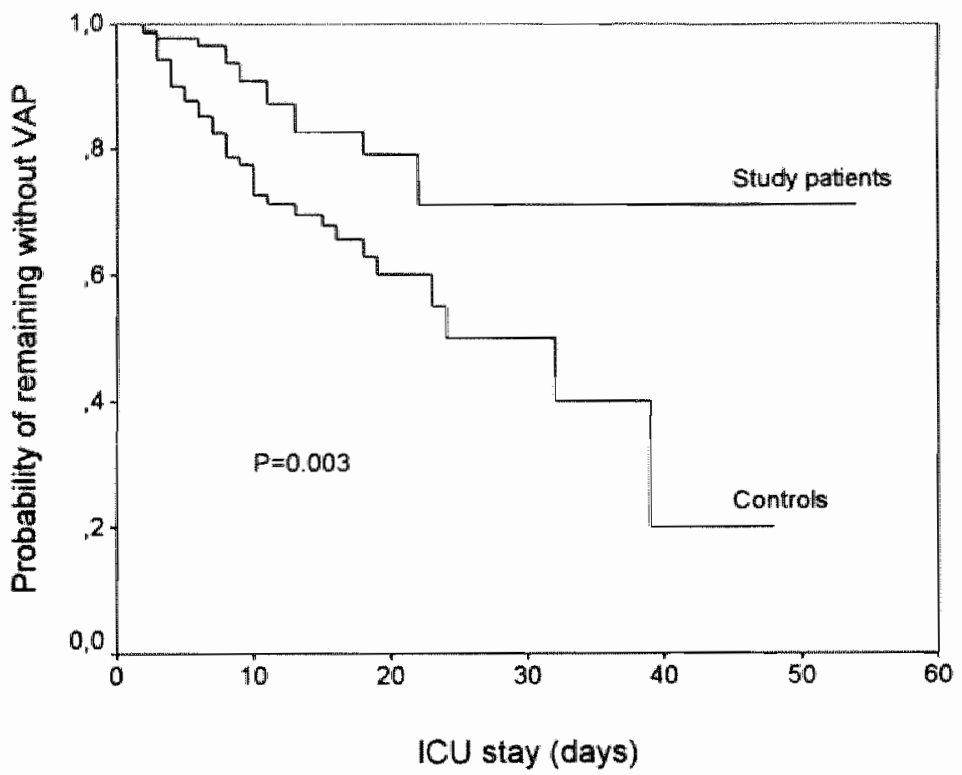

Figure 10.2 Probability of remaning free d ventiator-assaciated pneumonia during tota ICU stay in study patients and controls $(p=0.003)$.

\section{Systemic antibiotic use and resistance}

On admission, systemic antibiotics were prescribed for $41(47 \%)$ study and 58 $(42 \%)$ control patients. Mean numbers of courses of antibiotics per patient, were $0.95 \pm 0.68$ for study patients and $1.27 \pm 0.87$ for control patients during study period $(p=0.018)$ and $1.33 \pm 0.76$ vs. $1.76 \pm 1.30(p=0.044)$ respectively, during total $\mid \mathrm{CU}$ stay (Table 10.4).

No vancomycin resistant enterococci (VRE) were isolated in both hospitals before, during or after the study. No increase in the number of patients colonized or infected with microorganisms resistant to gentamicin was observed during the study. 


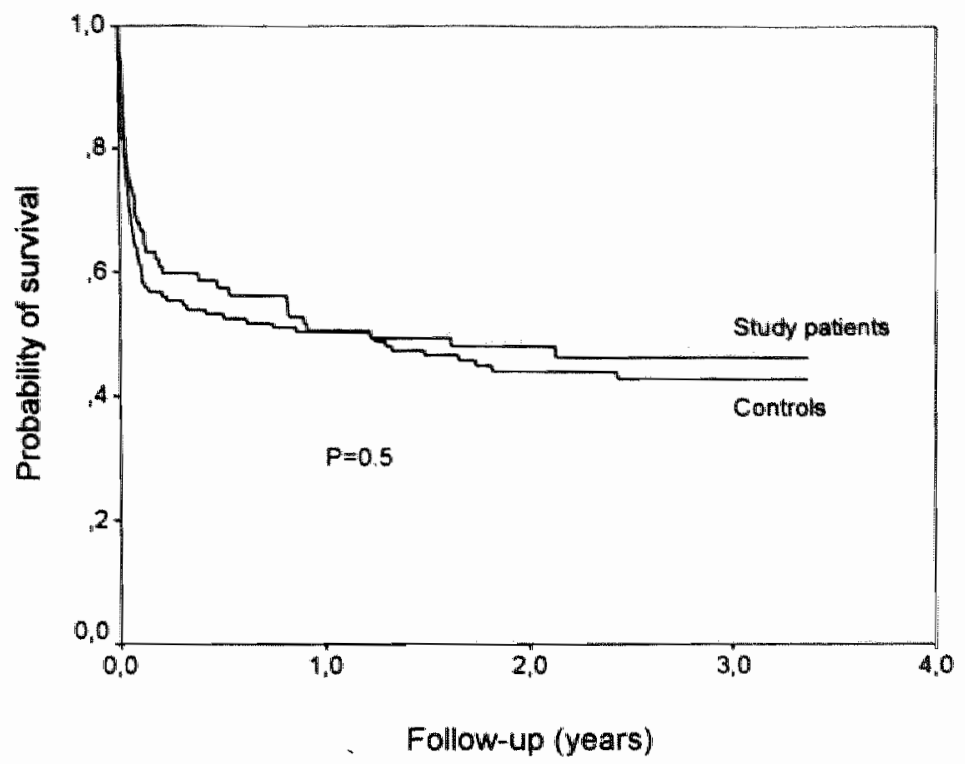

Figure 10.3 Probability of survival during prolonged followi-up in study patients and controls $(p=0.5)$.

\section{Discussion}

The main feature of this study is that modulation of oropharyngeal colonization, without influencing gastric and intestinal colonization and without systemic antibiotic prophylaxis, resulted in a relative risk reduction of $62 \%$ in the incidence of VAP. This finding underscores the pivotal role of oropharyngeal colonization in the pathogenesis of VAP, and strongly suggests that modulation of colonization at this site will effectively prevent VAP

The present study shows that prevention of colonization of the oropharynx, and not the stomach, reduces the incidence of late-onset VAP. The effects of oropharyngeal decontamination have been studied previously in two smaller studies. In a double-blind study, Pugin et al. ${ }^{2}$ randomized 52 patients 10 receive either a solution of polymyxin $\mathrm{B}$, neomycin and vancomycin or placebo in the retropharynx. Colonization with aerobic Gram-negative bacteria was significantly reduced in oropharynx and stomach resulting in a relative risk reduction of VAP of 0.79 . Rodriquez-Roldan et al ${ }^{30}$ used an oropharyngeal paste containing tobramycin, amphotericin $\mathrm{B}$ and polymyxin $\mathrm{E}$. Decontamination of oropharymx and trachea was established in 10 of 13 patients receiving active medication and none developed pneumonia. Eleven $(73 \%)$ of 15 patients receiving placebo medication 
developed preumonia. Our findings expand the results of both studies. Incidences of VAP in the control groups of both studies (78\% and $73 \%$ respectively) were extremely high, and not comparable to incidences found in other ICU studies, ${ }^{4-11,13}$. This is probably due to the use of clinical and microbiological criteria, instead of bronchoscopic techniques, in the diagnosis of VAP, or due to patient selection. Furthermore, since gastric colonization was significantly decreased in the study by Pugin et al. their findings do not contribute to the determination of the relative importance of gastric and oropharyngeal colonization ${ }^{2}$.

Our findings demonstrate that VAP can be prevented effectively by modulation of oropharyngeal colonization. Importantly, the relative risk reduction of VAP in the present study is similar to the relative risk reductions reported in the metaanalyses of $\mathrm{SDD}$ (ranging from $53 \%$ to $78 \%$ ) oropharyngeal decontamination, indeed, represents the effective part of SDD, and that the majority of antibiotic use in SDD is unlikely to add beneficial effects. A similar preventive effect on the incidence of VAP can be achieved with only a fraction of the antibiotics used in SDD. The data, therefore, question the concept of SDD, a method of infection prevention that is still used in many ICUs. However: antibiotic use bears the constant threat of induction or selection of resistant microorganisms. Absence of resistance problems and very strict control, as in the present study, are mandatory. This is supported by three studies failing to show any benefit from the full concept of SDD on the incidence of VAP. These studies were executed in France, Spain and South Africa, countries where antibiatic resistance levels of $\| C U$ pathogens are much higher and not comparable to our situation $^{31.33}$. For instance, infections due to MRSA were reported in each study. Since infection rates represent the tip of the iceberg, colonization rates were likely to be even higher. Endemic colonization with multiple resistant bacteria will abolish the beneficial effects of any prophylaxis based on antibiotics. This is a scenario that is, unfortunately, emerging.

ldeally, modulation of oropharyngeal colonization should be established with 'nonantibiotic' methods. One potential appraach might be the use of chlorhexidine for oropharyngeal decontamination. An oral rinse of $0.12 \%$ chlorhexidine reduced the incidence of respiratory tract infections among 353 cardio-surgical patients from $9 \%$ in control patients to $3 \%$ in patients receiving oropharyngeal decontamination with chlorhexidine $e^{3.4}$. The difference was mainly caused by a reduction of infections with Grammegative pathogens. However, how prolonged chlorhexidine use will affect oral, oesophageal and gastric mucosa in critically ill ICU patients is unclear, as is the risk of chlorhexidine resistance after longterm application.

Multiple strategies to prevent VAP have been developed and tested during the last 15 years, and guidelines for the prevention of hospital-acquired pneumonia have been formulated recently ${ }^{23}$. In addition to standard infection control measures. several other preventive measures were considered to have probable 
effectiveness ${ }^{23}$, the use of sucralfate for stress-ulcer prophylaxis, modulation of enteral feeding, positioning of patients, and subglottic secretion drainage. However, no significant differences in the incidence of VAP were reported in the only wo prospective, randomized, double-bind placebo-controlled studies comparing sucralfate to antacids and $H_{2}$-antagonists ${ }^{10.11}$. Beneficial effects of intermittent enteral feeding on gastric colonization and on the incidence of VAP are unproven ${ }^{12.35}$, and effects of acidified enteral feeding and postpyloric feeding on the incidence of VAP have never been determined. Placing patients in semirecumbent instead of supine position may reduce gastroesophageal aspiration, but up till now the effects on the incidence of VAP ${ }^{36,37}$ have not been studied. Finally, suctioning of subglottic secretions which accumulate above the inflated endotracheal cuff has been shown to reduce incidences of early-onset VAP. but not of late-onset VAP ${ }^{38.39}$.

How should our findings be applied together with the results of other studies on prevention of VAP? There is strong evidence that modulation of oropharyngeal colonization will influence the development late-onset VAP. However, in settings where early-onset represents a bigger problem, other strategies, such as subglottic secretions drainage or targeted systemic prophylaxis during the first 24 $h^{24}$ may be more appropriate.

In a previous study in our "hospital, topical antimicrobial prophylaxis of the oropharynx and stomach with colistin, tobramycin and amphotericin B was associated with overgrowth and infections due to Gram-positive species, such as Enterococcus faecalis and coagulase-negative staphylococcila.4, findings that have been reported by others as well ${ }^{31,33,42,43}$. Since our aim was to perform a conceptual study to determine the effects of modulation of oropharyngeal colonization on the incidence of VAP and to elucidate the pathogenesis of VAP, we included vancomycin in our prophylactic regimen. We are well aware of the emergence of vancomycin resistant enterococci in many countries and the Hospital Infection Control Practices Advisory Committee (HICPAC) recommendathons to avoid the prophylactic use of vancomycin ${ }^{4}$. However, neither wancomycinresistant enterococci (VRE) nor methicillin-resistant Staphylococcus aureus (MRSA) had been isclated on a regular basis in the Netherlands and in the ICUs of both hospitals, at the stant of the study, and systemic vancomycin was used only sporadically ${ }^{45}$, In addition, the duration of topical antibiotic prophylaxis was limited to a maximum of $21 \mathrm{~d}$ in order to minimize the risk of induction of resistant strains. Finally, susceptibilities for vancomycin were determined for all enterococci isolated during the study. A plan of enforced infection control had been developed. had vancomycin resistant strains emerged. With all these control measures, we felt assured to use vancomycin as a prophylactic agent in a setting with llow vancomycin use, an overall low incidence of antibiotic resistance, and complete absence of VRE and MRSA. Although acquired resistance in Gram-negative bacteria is also a potential threat of topical antimicrobial prophylaxis, the susceptibilities of Gram-negative bacteria to gentamicin was approximately $90 \%$ in 
our ICU and this did not decrease during the study.

The reduction in the incidence of VAP was associated with a decrease in antibiotic prescription, but other outcome parameters such as duration of mechanical ventilation, duration of $1 \mathrm{CU}$ stay and mortality rates were not affected. The effect of VAP on mortality rates remains controversial. Fagon et al. ${ }^{4}$ found an attributable mortality of VAP of $27 \%$, and even of $43 \%$ when caused by Pseudomonas spp. or Acinetobacter spp. Moreover, in a cohort study by the same investigators nosocomial pneumonia was independently associated with death in mechanically

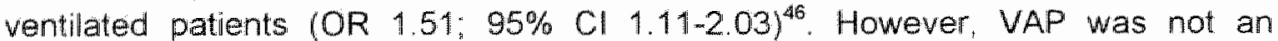
independent risk factor for death in two other multivariate analyses ${ }^{47.48}$; and was not associated with increased mortality in two recent matched cohort studies ${ }^{49,50}$. Furthermore, significant reductions in the incidence of VAP as determined in five meta-analyses of SDD studies, hardly decreased mortality rates ${ }^{18-22}$. Inappropriate antibiotic use is an important variable contributing to attributable mortality of VAP $^{5152}$. Therefore, comparisons of attributable mortality rates of VAP in various studies is difficult. For example, cases of inappropriate antibiotic therapy for VAP due to multiple resistant pathogens occur infrequently in our setting, and occur probably more often in settings with endemic lewels of resistant pathogens. Under the circumstances tested, VAP did not have an attributable mortality. However, there was a tendency towards a reduction of ICU-related mortality associated with the $62 \%$ relative risk reduction of VAP. However, when prolonging patient followup, differences between both study groups vanished completelly. Reported mortality rates usually reflect ICU mortality. Our data show that this may overestimate the benefits of an intervention.

Several potential insufficiencies of our study must be addressed. Incidences of VAP may have been influenced by several variables which were not equally distributed in both study groups. For instance, more control patients received sucralfate and study patients were more likely to receive enteral feeding. However, since sucralfate has been associated with lower incidences of VAP in some studies and enteral feeding has been assumed to be a risk factor for VAP, both of these discrepancies would have favoured the control rather than the study patients. If so, the true beneficial effects of oropharyngeal decontamination would have been even higher.

Another concern is whether aspiration of antibiotics into the lungs influenced the diagnostic yield of bronchoscopic samples. However, negative bronchoscopic results obtained because of a clinical suspicion of VAP occurred with equal frequency in both control and study patients, suggesting that leakage of antibiotics in the lower respiratory tract did not occur. Moreover, from a number of study patients samples of tracheal aspirate were obtained for determination of gentamicin and vancomycin levels during the study period (day 3, 7,14 , and 21). All gentamicin levels were below threshold of detection (i.e., $\quad 60.03 \mathrm{mg} / \mathrm{l}$ ). Vancomycin levels were below threshold of detection (i.e., $\quad 0.05 \mathrm{mg} / \mathrm{l}$ ) in most 
samples and very low concentrations in the remaining (median $0.25 \mathrm{mg} /$ ))(data not shown).

In conclusion, our study demonstrated that modulation of oropharyngeal colonization, without influencing gastric and intestinal colonization, effectively reduces the incidence of late-onset VAP. This finding proves the pivotal role of oropharyngeal colonization in the pathogenesis of this infection. When compared with other preventive strategies for VAP, prevention of oropharyngeal colonization is by far the most effective. Not withstanding the impact of VAP on morbidity and antibiotic use, our findings do not support the concept that VAP has attributable mortality. 


\section{References}

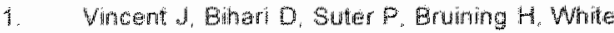
$J$. Micolas-Chamoin $M$. Wotf $M$, spencer $R$. and Hemmer M. The prevalence af nosocomalal infection in intensive care units in Europer resuls of the european prewance of infection in intensive care (EPIC study. Journal of the Amenican Medical Association 1995,274335644

2. Pugin $d$, Auckenthaler R, Lew $D$, and Suter $P$ Oropharyngeal decontamination decreases incidence of ventilator-associated pneumonia: a randomized, placebo-conirolled, doublebind clinical trial vournal of the American Maclical Association 4991: 265 2704-2710

3. Kappstein I. Schulgen G, Beyer $U$, Geiger $K$ Schumacher M, and Daschner F. Prolongation of hospitall stay and extra costs due to wentiatorassociated pmeumona in an intensive care tunit. European Joumal of Chincal Microbiology and Infectious Diseases $1992 ; 11.504-508$

4. Fagon JW, Chastre ل. Hance A. "Momtravers $P$. Novara $A$, and Gibert $C$. Nospcomial pneumonia in ventilated patients: a cohort study evaltating atrributable mortaity and hospital stay. American Jounal of Medicine 1993; 94 : $281-288$

Heyland D and Mandell L. Gastric colonization by Grammegative bacilit and nosacomial prietmonia in the intensive care unit patient: evidence for causation. Chest 1992, 101 $187-193$

6. Drks MR craven DE, coll $\mathrm{GR}$, Manming $M$, Buble RA, Grvin GM. Kunches LM, Farber HW. Wedel SA and McCabe WR. Nosocomial pratumonia in intlibated patients given sucralfate as compared with antacids or histamine ype 2 blockers: the role of gastric colonisation. New England Jouna of Madicine 1987; $3171376-1392$

Simms HH. DeMara E. MoDonald L, Peterson D. Robinson A, and Burcharc KW. Role of gastric colonization in the development of pneumonia in critically itf trauma patients: results of a prosprecthe randomzed triat. Jounal of Trauma 1991:31:531-536

Prodhom G, Leuenberger $P$, Koerfer $J$, Blum
A. Chiolero R. Schater MD. Perret C. Spimnier O. Blondel d. Siegnit H. Saghafl L. Blane D. and Francioli P. Nosocomial pneumonia in mechanicaly ventilated patients recewing antacid, ranitidine, or sucralfate as prophylaxis for stress ulicer a ramdomized controlled trial. Anoals of Mntemal Medicine 1994; 120. $653-662$.

Ben-Menachem T, Fogel R, Palkel RV. Touchette M. Zarowitz BJ. Hadzijahic N, Divine $G$, Verter d, and Bresalier RS. Prom phylaxis for stressmelated gastric hemorhage in the medical intensive care unit a riandow mized, controlled, single-blind study. Annais of internal Medicine 1994, 121: $560-575$

10. Bonten MuM. Galiard CA, wan der Geest $S$, vam Tiel FH, Beysens $A_{n}$ Smeets HGW, and Stobberingh $E E$. The role of intragastric acidity and stress ulcer prophylaxis an colonization and infection in mechanically ventilated patients. A stratified, randomized. double blind study of sucralfate versus antacids. American Jounal of Raspiratory and Critical Care Medicine 1995. 152 : $1825-1834$

11. Caok D, Guyatt $G$ Marshall J Leasa D. Fuller $H$, Hail R. Peters S, Rutledge F. Grifith L.

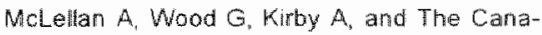
dian Critical Care Trials Group. A comparison of sucralfate and ranilidine for the prewention of upper gastrointestinal bleeding in patients requiring mechanical ventilation. New Englana Jound of Medicine 1998, 338:791,797.

Lee $B$. Chang $R$, and Jacobs S. Intermittent hasogastric feeding a simple and efrective method to reduce preumonia among vitutilated ICU patients. Clin intensiwe Care 1990; 1: $100-102$

13. Bonten $M$, Gaillard $C_{\text {, wan Thel }} F$. Smeets $H$ vart der Geest $S$, and Stobberingh $E$. The stomach is not a source for colonization of the upper respinatory tract and pneumonia im lCU patients. Chest 1994: 105:878-884.

14. Brunbuisson C. Legrand P. Rauss A, Richard C. Montravers F" Besbes M, Meakins $J$, Soussy $\mathrm{CJ}$, and Lemaire F. Intestinal decontamination for control of nosocomial muthresistant Gram-negative bacilli: study of 
an outbreak in an intenstve care unit. Annats of Jnternal Medicine 1989; 110:873-881.

de Latore F. Pont T. Ferrer A, Rosselio d. Palomar $M$, and Planas M. Patern of tracheal colonization duting mechanical wentlation. American Jound of Respiratory and Cntroal Care Medicine 1995; $152: 1028-1033$.

46. Cade 4, McOwal E, Siganporia R, Keighley $C$ Preshell J, and Sinickas V. Uncertan relevance of gastric colonization in the seriousily itl. miensive Care Madicine 1992; 18:210-217.

Reusser $P$. Zmmmerl $W$. Scheidegger $D$, Marbet $G A$, Buser $M$, and Gyr $K$. Fole of gastric colonization in nosocomial infections and condotoxemia: a prospective study in neurosurgical patients on mechanical ventilation. Journal of hrfectious Diseases 1989: $160 \cdot 414-421$.

18. Vandenbroucke-Grauts $\mathrm{C}$ and Vandenoroticke J. Effect of selective decontamination of the digestive tract on respiratory tract infections and mortaity in the intensive care unit. Lancel $1991,338: 859 \times 862$

19. Heytand DK, Cook Dil, Jaeschke $R$, Griffith $L$, Lee HN, and Guyati Gid. Selective deconta. mination of the digestive tract an overvew. Chest 1994, 105:1221-1229.

Kollet MH. The role of selective digestive tract decontamination on mortalify and respiratory tract infections: a meta altalysis. Chest 1994 ; 105. $1101 \% 1109$

21. Selective Decontamimation of the Digestive Tract Trialists Collaborative Group Metam amalysis of randomized controlled trials of selective decontamination of the digestive vact Entish Medical Joumal 1993; 307 . $525-532$.

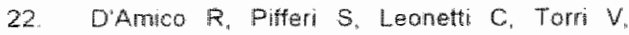
Tinazz: $A$, and Liberati A. Effectiveness of antibiotic prophylaxis in critically in adull patsents: Systematio rewew of randomized controlled trials. Brifsh Medica Jownal 1990 ; 316:1275-1285

23. American Thoracic Saciety Ad Hoc Commitee of the Scientific Assembly on Microbiology Ta. Hosplalacuuired pneumonia in adiuts: Diagnosis, assessment of severify, mitial wrimicrobial therapy. and preventatue strategies. A consensus statement. Amarican

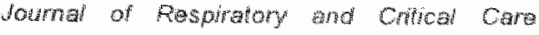
Medicne 1995, $153: 1711-1725$

24. Sivent Jit. Tomes A, El-Ebiery M, Castro P. de Batie J, and Bonet A Protectwe entect of intrawanously adnustured cefuroxine aganst nosocomial pheumonia in patients with strem tural coma. Amencan foumal of Respiraton and Gritical cart Mediche 1997; 155 $1729-1734$

Bonten M.J. Gatlard CA, Johanson WO, Jr. van Tien FH. Smeets HOW. wan der Geest $\mathrm{S}$. and Stobberingh EE. Colanization in patients receining and not tecelving topical ant. microbial prophylaxis. Anencan Jounal of Respiratony and Critical Care Modicine 1994 $150: 1332-1340$

Knats WA, Draper EA, Wagner DP, and Zimmerman JE APACHE It a severity of disease classification systam. Criticat care Medicine 1985: $13.818-829$

27. Stokes EJ and Ridgway GL. Clincal bacterio. logy. Sth ad London: Edward Arnold: 1900

28. Isenberg HD. Clinical microbiology procedirest handbook. Washington, D. C. American Society for Microbiology, 1992

29. Center's for Disease Contral (CDC) CDC defunitions for nosocomial infections, 1988 American Reviaw of Respiratory Disease 1989: 139:1058-1059

30. Rodriguezmoldan J, Aluma-follesta A. Lopez $A$, Carrillo $A_{1}$ Garcia $J$ leon $J$ and Martinez-Petus A Prevention of vosocomal lung infection in ventiated patents use of an antimicrabial pharyugeat nomabs on bable paste Crition Care Mediche 1990, 18.1239-1242

Gastimne Holl M, Delatour F, Funisson F. and Chevret $S$. A controlled trial in intensive care unils of selective decontamination of the digestive tract with nonabsorbable antibiolics Now England Jounal of Medichn 1992, 326 $594-599$

32. Ferer M, Tores A González J, Puig de da Beliacasa d. El-Ebary M. Roca M, Gateil M and Rocriguez-Roisin $R$ Utiaty of sellective digesive decontamination in mecharically 
vertitated patients Anwas of Internat 40 Medinge 1904: 120.389-395

Hammond Mins, Potgieter PO, saunders GL. and Forder As. Double-blind sudy or selective decomamination of the digestive tract in intensive care. Lancet $1992,340.549$

34. DeRisg A, II. Ladowshi JS, Dilon TA, Justicite JW, and Poterson AC. Chlorhexidine gluconate $0.12 \%$ oral rinse reduces the incidence of total nosoromial respiratory infection and monprophylactic systemic antibiotic use in patients undergaing heart surgery. Chest 1996:109:1550-1561.

35. Bonten MuM, Gillard $C A$, van der tulst $R$, de Leevw PW: wan dar Geest $S$, Stobberingh EE, and Soeters PB. Intermittent enteral feeding: The influence on respiratory and elgestive tract colonization in mechanically wentilated intensive-care-unt patients. Anorican Joumal of Respiratory and Critical Care Mediche 1996. $154394-399$

36. Torres A. Serra-Batles d. Ros E. Piena $C$ Puig de la Bellacasa J. Cobos A. Lomeña $F$. ard Rodriguez-Roisin R. Pulmonary aspiration of gesstric contents in patients receiving mechanical ventilation: the effect of body position. Annals of Anternal Medicine 1992; $116.540-543$

37. Orozco-ievi $M$. Torres A. Ferrer M Plera $C$, Elmebiary M, Puig de la Bellacasa $J$, and Rodriguez-Roisin R. Semirecumbent position protects from putmonary aspiration but not completely from gastroesophageal refux in mecthanically vantlated patients. American Hownal of Raspiratory and Critical Cara Marding 1995, 152.1387-1390

38. Manul P. Auboyer C. Jospe R, Ros A Guerin $C$. Eu Khouri 2 . Galltez $M$, Dumont $A$, and Gavdin O Prevention of nosocomal pneumonia in untubated patients respective role of mechanical subglotic secretions dramage and strass ulcer prophylaxis. Intensiva Caro Madione 1992; 18:20-25.

Valles A Artigas A. Rello $\downarrow$ Bonsoms $N$. Fomtanals: D, Blanch L., Fermandez $R$, Baigorri $F$, and Mestre \& Continuous aspiration of subghthe secretions in preventing ventim latorassociated pneumonia. Anrials of Interna Hedicine 1995; 122:179 186 .
Bonten M. van Tie: F wari der Geest $s$. Stobberingh $E$. and Gallard $C$. Enrerococcus faecalis pneumonia complicaning topical amimorichobial prophylaxis. New England Joumal of Madicine 1993; 328:209-210

4. Bonten $M$. Gallard $C$ van Tiêt $F$, wan de? Geest S, and stobberingh E. Colonization and inflection with Enterococcus faecalis in intenswe care units the role of antimicrobial agents. Anfinicrobial Agents ano Chemotherapy $1995 ; 392783-2786$

Whiever J liokazu $G$. Nathan $C$, Kabins $S A$. and heinstein RA. A randomized doublew blind placebo-controtled trial of selective decontamination in a medical-surgical intensive care unit Clinical intectous Diseases 1995; $20: 861-86$ ?

43. Sipkens YWJ, Buuke El, Uirich $C$, and var Asselt GJ Enterococcus faecalis colonisation and endocarditis in frve intersive care patients as late sequelae of selective decontemination Intensive Care Mecicine 1995; 21:231-234.

44. Hosptal Infection Control Practices Advisory Commitee (HICFAC). Recommendations for preventing the spread of wancomycin resistance. Infection Controf and Hospital Epida... miology 1995; 16:105-113

Bergmans DCuh, Bonten MuM, Gaillard CA, van Tiel FH, van der Geest 5 , de Leeuw PW, and Stowberingh EE. Indications for antibiotic use in ICU patients: a one-year prospective survellance. Journal of Antimicrobial Chemotherapy 1997; $39,527-535$

46. Fagon JY, Chastre J, Vuagnat A, Troullet JL Nowara A, and Gibent C. Nosocomial pnewmonia and morialfty among patients in intensive cane units. Nowmal of the American Medical Association 1996, 275:866-869

47. Kolle MH. Venthator-associated pneumonia. A mullivariate analysts. Journat of the American Medical Association 1993; 270.1965m1970.

48. Craven DE, Kunches LM, Kilnsky $V$, Lichtenberg DA, Make BJ. and McCabe WR Risk factors for pneumonia and fatality in patients receiving continuous mechanical ventilation. American Review of Respiratory Drsase \#986; $133,792-790$ 
49. Papazian L. Bregeon F. Thirion $X$, Gregoire $R$, Saux P. Demis JP. Perin G, Charrel W, Dumon MF, Afray UP. and Goun F. Effect of venti lator-associated pheumonia on mortality and morbidity. American Joumat of Respiratory and Critical Care Medicine 1996; 154:94-97.

50. Bonten MUM. Froon AHM, Gailland CA, Greve JW, de Leeuw PW, Drent M, Stobberingh EE. and Butrman WA. The Systemic mitammatory response in the development of ventlatorassociated pneumonia. American Joumal of Respiratory and Crifical Care Medicine 1997: $156: 1105-1113$
51. Cels $\mathrm{R}$, Torres $A$, Gatell $\mathrm{M}$, Ameta $M$, Rodriguaz-Roisin $R_{r}$ and Agustividal A. Nosocamial pheumonia: a multivarate analysis of risk and prognosis. Chast jas8; $93318-324$

52. Torres $A$, Aznar Re, Gatell JM, Jimenez $P$. Gonzalez J. Ferrer $A$. Celis $R$, and Radriguez-Roisin the troldence, Tisk, and prognosis factors of nosocomial pheumomat in mechanicaly vertilated patimts. American Review of Respiratory Disease 1900; $142.523-528$ 


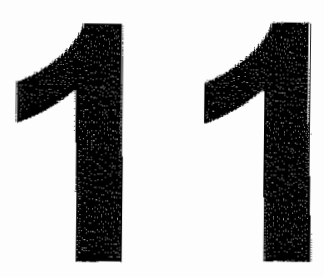

General discussion 


\section{General discussion}

The hypotheses for the studies as described in the present thesis were based on the conclusions of the thesis 'The role of colonization of the upper intestinal tract in the pathogenesis of Ventilator-Associated Pneumonia', by Marc JM Bonten'. He concluded that in the pathogenesis of ventilator-associated pneumonia (VAP): 1 the gastropulmonary route of colonization was not important, 2. that oropharyngeal colonization might be of pivotal importance, and, 3. that cross-acquisition within the intensive care unit ( $\mathrm{ICU}$ ) might be more important than generally expected.

These conclusions and suggestions were fully confirmed in the present thesis, the main finding being that oropharyngeal colonization is of pivotal importance in the pathogenesis of VAP. Prevention of this infection, which is a major aim of intensive care medicine, can be established by targeted modulation of colonization in the oropharynx

The last decade has witnessed the increasing problem of antibiotic resistance as a consequence of excessive and/or inappropriate antibiatic use ${ }^{2}$. Surveillance studies on the incidence of infections, indications for antibiotic use and knowledge about antimicrobial susceptibilities of pathogens are indispensible to allow critical assessment of antibiotic use ${ }^{2,3}$. Antibiotic use in ICUS is approximately tenfold greater than in general hospital wards and is associated with a considerable part of the total hospital antibiotic consumption and $\operatorname{costs}^{4}$. In the ICU population described in this thesis, one in every three patients has at least one infection during ICU stay. Since almost all ICU-acquired infections occur in intubated patients on mechanical ventilation, this patient group is responsible for the majority of antibiotic use and related costs. The respiratory tract is by far the most important site of infection and infections in this area account for half of the total ICU antibiotic use. Reduction of ICU antibiotic use, therefore, may be achieved either by shortening the duration of therapy for respiratory tract infections, or by preventing respiratory tract infections and identification of episodes of unnecessary antibiotic use. Prevention of infections can also be expected to decrease related morbidity and mortality.

Since respiratory tract infections are the most common of all ICU-acquired infections, prevention of these has the greatest impact on antibiotic use. Such a reduction may also be facilitated by applying more specific criteria to diagnose nosocomial pneumonia. Adding the results of bronchoscopic examinations to the criteria for diagnosing VAP may help to reduce antibiotic use in patients with a clinical suspicion of pneumonia but with nonsignificant quantitative cultures from bronchoscopic samples. As shown in this thesis, withholding of antibiotics in these patients, indeed, did not increase mortality rates or recurrence rates for VAP. Moreover, in our patients with bronchoscopically proven VAP, empiric antimicrobial therapy was frequently adjusted on the basis of the bronchoscopy data, mostly by narrowing the antibiotic coverage. Implementation of bronchoscopy in the routine work-up of patients with a clinical suspicion of VAP may influence clinical practice 
and decrease the number of patients receiving antibiotic therapy.

The most important conclusion of this thesis is that, in addition to duration of mechanical ventilation, colonization of the upper respiratory tract is the most important risk factor for the development of VAP. Relationships between duration of ventilation and increased risk for tracheal colonization and VAP are obvious ${ }^{k, 7}$. Moreover, tracheal colonization is one of the diagnostic criteria for VAP. However; oropharyngeal colonization appeared to be an independent risk factor for VAP Interestingly, gastric colonization with enteric Gram-negative bacteria (EGB) and Pseudomonadaceae was not a risk factor for VAP. In contrast to the hypothesis of the gastropulmonary route of colonization ${ }^{\circ}$, oropharyngeal and tracheal colonization were risk factors for acquired gastric colonization with Pseudomonadaceae. Taken together, the data of the risk factor analyses did not support an important role for the gastropumonary route of colonization in the pathogenesis of VAP. Instead, the oropharynx and trachea were the initial sites of colonization prior to the development of VAP and should be the actual target for prevention. The final study of this thesis demonstrated that modulation of oropharyngeal colomization, without influencing gastric and intestinal colonization and without systemic antibiotic prophylaxis, effectively reduced the incidence of VAP by $62 \%$. These data confirm the results of two simall studies on oropharyngeal decontamination by Pugin and coworkers ${ }^{9}$ and by Rodriquez. Roldan and coworkers ${ }^{t 0}$. Notwithstanding the impact of VAP on morbidity and antibiotic Use, VAP did not have attributable mortality in our setting. In view of the results of selective digestive tract decontamination ${ }^{11}$, oropharyngeal decontamination appears to represent the effective part of this regimen. A similar preventive effect on the incidence of VAP can be achieved with only a fraction of the antibiotics used in selective digestive decontamination. Moreover, when compared with other preventive strategies for VAP (e.g., stress-ulcer prophylaxis with sucralfate, modulation of enteral feeding etc.), prevention of oropharyngeal colonization is by far the most effective.

An important part of $1 \mathrm{CU}$ infections is caused by Enterobacteriaceae. Pseudomonas aeruginosa and Staphylococcus aureus. These different species are usually lumped together and labelled as potentially pathogenic microorganisms. However, individual species have specific properties with regard to preferred site, time and route of colonization and clinical spectrum of infection. Furthermore, there are differences between the clinical spectra of commumityacquired infections and hospital-acquired infections caused by the same species of bacteria (e.g. S. aureus). The association between development of WAP and preceding upper respiratory tract colonization, especially in the oropharynx, appears to account for all pathogens.

$S$. aureus is known to colonize the nares of many people. Old age, diabetes mellitus and prior infection with influenza are risk factors for community-acquired infection with this pathogen ${ }^{2}$. In contrast to community-acquired pneumonia, we 
found that VAP caused by $S$. aureus occurs more frequenty in young patients admitted to ICU for trauma or neurologic diseases, with a short ( $\leq 48 \mathrm{~h}$ ) duration of hospitalization prior to ICU admission. Moreover, when compared with community-acquired pneumonia, VAP caused by $S$ aureus has a less fulminating course.

Enteric Gram-negative bacteria belong to the commensal intestinal flora. An infection on admission to $I C U$ and oropharyngeal colonization with EGB on admission were found to be independent risk factors for VAP caused by these species and were also associated with increased mortallity. Severity of illness on admission to ICU probably is a risk factor for oropharyngeal colonization with EGB which may also represent a lack of clinical improvement during ICU stay, a finding that has also been reported by Johanson and coworkers ${ }^{13}$.

Respiratory tract colonization with $P$. aeruginosa on admission to ICU occurs less frequently and mainly strikes patients with chronic obstructive pulmonary

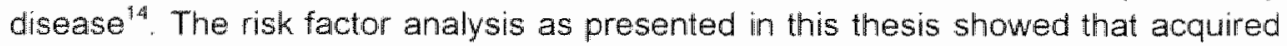
respiratory tract colonization with $P$. aeruginosa is, even more than than is the case for $E G B$, strongly related to the duration of mechanical ventilation. The upper respiratory tract is clearly the initial site of colonization for $P$. aeruginosa, before VAP develops. Although suggested by some ${ }^{15}$, $P$, aeruginosa did not show a preference for the trachea or oropharynx in our studies. Colonization with $P$. aeruginosa is not limited to the respiratory tract, and many critically ill patients are colonized at multiple body sites and with multiple genotypes. Therefore, genotyping is crucial when studying the pathogenesis and epidemiology of colonization or infection with $P$. aeruginosa. Since genotyping methods are expensive and laborious, these techniques are not feasiblle for all laboratories. In general, phenotyping techniques are less expensive and relatively easy to perform, but they lack specificity ${ }^{16}$. Nevertheless, phenotyping techniques may be used to make a preselection out of a large series of isolates for further genotyping The appropriate phenotyping technique for this purpose appears to be serotyping, which showed the best discriminative power among four phenotyping techniques (antibiotic susceptibility patterns, serotyping, phage-typing and outer membrane protein profile analysis) in comparison to pulsed-field gel electrophoresis of enzyme restricted chromosomal DNA.

Another important property of $P$. aeruginosa is its ability to survive and multiply in an inanimate, aqueous environment. Pseudomonas aeruginosa, therefore, is a notorious pathogen involved in outbreaks originating from exogenous sources (contaminated equipment or colonized patients), spreading rapidly via the hands of health care workers or via equipment used on several patients. Cross-colonization may even be important in nonepidemic (i.e. endemic) situations. In general, several factors have a bearing on this complex phenomenon. For instance, compliance with infection control measures is essential in infection control, and effective handwashing has been shown to reduce the rate of nosocomial infections. Achieving $100 \%$ handwasting compliance is unattainable: studies 
evaluating compliance report percentages of about $30 \%$. Antibiotic use providing certain bacteria with a selective growih advantage, which can be expressed as antibiotic pressure, also plays a role. In addition, the number of patients already colonized (i.e. colonization pressure) may be an impontant factor in the risk of occurrence of cross-colonization. This means that in the epidemiology of respiratory tract colonization, for $P$. aeruginosa, both endogenous and exogenous colonization play a role. The epidemiology of $P$. aeruginasa may, therefore be described as a sillent epidemic, similar to the endemic nature of other nosocomial pathogens, including the multiple resistant strains (i.e. vancomycin-resistant enteracocci, methicillin-resistant $S$. aureus and ceftazidime-resistant Gramnegative bacilli). The relative impact of both exogenous and endogenous colonization of $P$. aeruginosa in the pathogenesis of VAP remains to be established. The studies show that surveillance in combination with molecular biotyping may be used to perform continuous quality improvement and stress the importance of infection control measures

\section{Answers to the questions}

1. What is the incidence of infections in critically ill patients admitted in our ICU? Thirty-six percent of patients admitted to $I \mathrm{CU}$ had at least one infection during ICU stay. Of all infections, 53\% were $1 \mathrm{CU}$-acquired and almost all of these occurred in ventilated patients. Respiratory infections were the single most common infection accounting for $43 \%$ of all infections.

2. What are the indications for antibiotic use and the related costs in a general ICU ward?

In mechanically ventilated patients $51 \%$ of antibiotic prescriptions were used for bacteriologically proven infections, $31 \%$ for non-bacteriologically proven infections and $18 \%$ for prophylaxis. Half of the prescriptions of antibiotics for therapy were administered for respiratory tract infections, $94 \%$ of total antibiotic costs were spent in intubated patients and non-bacteriologically proven infections consumed $25 \%$ of total antibiotic costs.

3. Does addition of quantitative culture results of sampies obtained by bronchoscopic techniques to the generally used criteria for diagnosing VAP influence antibiotic prescription?

The number of patients receiving antibiotic therapy decreased by implementation of bronchoscopic techniques in the routine workup of a clinical suspicion of VAP, without affecting recurrence rates or mortality. In addition, empiric antimicrobial therapy was adjusted in $19 \%$ of the patients with proven VAP, in most cases by narrowing the antibiotic coverage.

4. What are the risk factors for the development of colonization of stomach. oropharym, and trachea with EGB and Pseudomonadaceae?

The duration of mechanical wentilation was an independent risk factor for acquired colonization in stomach, oropharynx and trachea. As far as EGB is concerned, surgical and trauma patients tended to become colonized more frequently than medical and neurologic patients, and so did patients recenving 
enteral feeding. In the case of Pseudomonadaceae, acquired colonization of the oropharynx was associated with preceding tracheal colonization, and vice versa. Acquired gastric colonization was strongly related to prior colonization of the oropharynx and trachea.

5. What are the risk factors for the development of VAP caused by EGB and Pseudomonadaceae?

The duration of mechanical ventilation was an independent risk factor for VAP, regardless of the causative pathogen. In addition, oropharyngeal colonization with EGB on admission and an infection on admission were risk factors for VAP caused by EGB. Acquired colonization of the oropharynx with Pseudomonadaceae was a risk factor for VAP by these species. Gastric colonization was not a risk factor for deveiopment of VAP.

6. Does the clinical spectrum and outcome of staphylococcal VAP differ from that of staphylococcal community-acquired pneumonia?

Community-acquired pneumonia due to $S$. aureus particularly develops in elderly people after a viral respiratory tract infection and is associated with high mortality. VAP caused by this pathogen is not a fulminating disease and occurs more frequently in younger patients with a short duration of hospitalization before ICU admission.

7. Can phenotyping techniques be used as an initial method of screening for $P$. aeruginosa in order to reduce the number of isolates that need to be genotyped?

Serotyping has the best distinctive properties for an initial screening compared with antimicrobial susceptibility patterns, phage-typing and outer membrane protein profile analysis.

8. Is the respiratory tract the most important initial site of colonization with $P$. aeruginosa or is colonization with this pathogen not restricted to the respiratory tract?

The upper respiratory tract is the most important initial site of colonization prior to the development of VAP caused by $P$. aeruginosa. Multiple body sites may be colonized with this species.

9. Are patients admitted to $1 \mathrm{CU}$ colonized with a single or with multiple genotypes of $P$. aeruginosa?

Patients admitted to ICU can be colonized at multiple body sites with multiple genotypes.

10. Does cross-colonization influence the rates of colonization and infection with $P$. aeruginosa in an ICU where colonization with this species is endemic?

Both endogenous and exogenous colonization are significantly involved in the epidemiology of colonization and infection of the respiratory tract with P. aeruginosa. Moreover, even in nonepidemic settings cross-colonization seems to play an important role.

11. Can VAP be prevented by modulation of oropharyngeal colonization, without influencing gastric and intestinal colonization and without systemic prophylaxis? 
Topical antimicrobial prophylaxis of the oropharynx resulted in a $62 \%$ relative risk reduction for VAP. Oropharyngeal colonization is of paramount importance in the pathogenesis of VAP, and a targeted approach to prevent colonization at this site is a very effective method of infection prevention.

\section{Concluding remarks and future research}

An important question emerging from this thesis as well as from other studies, is whether or not prevention of VAP is worthwhile. Notwithstanding the impact of VAP on morbidity and antibiotic use, the mortality attributable to VAP remeins a matter of debate. In our studies, VAP did not come out as a risk factor for mortality, and a $62 \%$ relative risk reduction of the incidence of VAP did not reduce mortality. Several factors are relevant to this issue. Although sensitivity and specificity of the diagnosis of VAP increases by adding the results of bronchoscopic examinations, the latter is not a goid standard. A certain percentage of the episodes diagnosed as VAP, may still reflect extensive colonization rather than infection. Moreover, VAP may be a compartmentalized, and not a systemic inflammation. Recent studies analyzing cytokine responses to VAP underscore this hypothesis ${ }^{13}$. However, the localized lung process can initiate a systemic response evolving in severe sepsis or multiple organ failure with considerable mortality.

Importantly, the pathogens cultured most frequently in our ICU are susceptible to empiric antimicrobial therapy and so far no resistance problems have been encountered (neither vancomycin-resistant enterococci nor methicillin-resistant $S$. aureus have been isolated in our ICU). Thus, the infections that occur, including VAP, can usually be treated effectively and a fulminating clinicall spectrum develops only in a minority. In certain settings, VAP did have attributable mortality when caused by high-risk (Pseudomonas spp. or Acinetobacter spp.) or multiple resistant pathogens ${ }^{19}$. In these cases, inappropriate antibiotic use has been identified as an important variable contributing to attributable mortality of VAP ${ }^{20}$. Therefore, it may depend upon the occurrence of multiple resistant or high-risk. pathogens and its associated antibiotic use whether VAP has attributable mortality Nevertheless, VAP carries a number of risks and consequences for individual patients and still warrants effective prevention.

According to our studies, prevention of VAP should be targeted on modulation of oropharyngeal colonization. Increased adherence of microorganisms to epitheliat cells precedes colonization in critically ill patients and the mechanisms responsible for this increase have, in part, been elucidated. Prevention of aaherence of microorganisms to oropharyngeal epithelium, by increasing mucosal immunity, is an attractive alternative to oropharyngeal decontamination. The advantage of this approach is that prevention is established very early in the process of colonization thereby reducing the necessity for antibiotics. Research on the development and application of local immunomodulators for the oropharynx is still in its infancy.

Due to the constant threat of selection and induction of antibiotic resistance 
which is associated with antibiotic use, modulation of oropharyngeal colonization should, ideally, be established with "non-antibiotic' methods. Future research should determine whether the application of disinfectants (chlorhexidine, povidoneiodine etc) for oropharyngeal decontamination is as effective as antibiotics and whether these agents are well tolerated by critically ill patients during prolonged application. Moreover, other means by which oropharyngeal colonization can be modulated need to be explored.

Subglottic secretions drainage has shown promising results on the incidence of mainly early-onset VA.P, in early trials. Several studies on this technique are now in progress.

Interventions attempting to modulate gastric colonization failed to demonstrate beneficial effects in terms of lowering the incidence of VAP, and studies on the sequences of colonization do not support the importance of the gastropulmonary route of colonization ${ }^{27}$. Nevertheless, the stomach is a potential source of colonization, especially in a patient receiving enteral feeding, and bacteria from the stomach can eventually colonize the respiratory tract and cause VAP in, at least, some patients. Preventive strategies that interfere with the gastropulmonary route of colonization, like enteral feeding and body position, have not been studied frequently. Moreaver, some of these studies were poorly designed ar had surroglate endpoints. Well designed studies with sufficient monitoring of colonization sequences and bronchoscopic diagnosis of VAP to evaluate these strategies are warranted. A study comparing the effects of supine with semirecumbent body position during mechanical ventilation on colonization and VAP is ongoing in our institute.

Strategies to prevent VAP continue to undergo evaluation. Based on new insights in the pathogenesis of VAP, newly reported risk factors and development of drugs and equipment new strategies are developed and studied. For instance, biological response modifiers, which are immunomodulators that have the ability to modify host defense mechanisms, may increase the host pulmonary defense against invading pathogens. A continuing series of studies on the palliative treatment of the sepsis syndrome with antilipopolysaccharide antibodies (ES, HA-1A), antibodies to tumor necrosis factor, interleukin-1 receptor antagonists, cyclooxygenase inhibitors and platelet-activating factor antagonists are reported, but beneficial effects of these immunomodulators on VAP remain to be established ${ }^{22}$ Other strategies attempt to prevent the development of VAP or accelerate the resolution of pneumonia once it has been acquired. These include the use of monoclonal antibodies to specific bacterial antigens, granulocyte colony-stimulating factor and interferon-gamma. Moreover, new biomaterials are being tested for application in endotracheal lubes on which the formation of biofilms and colonization with pathogens is decreased.

Another approach in the prevention of VAP is the application of composite interventions. Preliminary results of trials evaluating the combination of preventive strategies (e.g., subglottic secretions drainage and semirecumbency compared 
with intubation with a standard endotracheal tube and supine position) have been reported in abstract form ${ }^{2324}$.

Surprisingly, a scheduled change of antibiotic classes used for the empiric treatment of suspected Gram-negative bacterial infections reduced the incidence of VAP attributed to antibiotic-resistant Gram-negative bacteria in patients undergoing cardiac surgery ${ }^{25}$. This concept of 'crop rotation' is intriguing and should be explored further ${ }^{26}$.

A further question is whether shortening the duration of antimicrobial therapy for respiratory tract infections is possible. A prospective study designed to perform a cost-benefit analysis on the implementation of bronchoscopy as a diagnostic tool in the assessment of VAP is still warranted. Moreover, addition of microscopic analysis of bronchoalveolar lavage fluid to the criteria for the diagnosis of VAP and optimalization of the culture techniques of bronchoscopic samples may help to further increase the specificity of the diagnosis. The relative impact of exogenous and endogenous colonization of $P$. aeruginosa, and other species, in the pathogenesis of VAP remains to be established. An interesting approach to the problem of colonization in endemic situations is the development of mathematical models, analyzing the contribution of several factors (e.g. compliance with handwashing protocols, antibiotic pressure, cohorting, colonization pressure) to the endemicity. These models can identify, for individual species, which strategy for infection prevention will prove to be most effective in that setting.

In this thesis, the studies on the diagnosis of VAP demonstrate that increasing the specificity of the diagnosis, by implementation of bronchoscopic techniques, antibiatic use may be rationalized. The studies on the pathogenesis of VAP show that colonization of the oropharynx is the single most important feature in the development of this infection. As a corollary, our preventive trial indicates that VAP can be prevented succesfully by modulation of colonization in the oropharynx. 


\section{References}

1. Eonten MUM. The role of colonization of the upper intestinat tract in the pathogenesis of vertilator-associated pineumonia [thesis]. Naastricht, The Nethertands: Puksuniversitet Limburg; 1994

2. Goldmann $D$, Woingtein $R$, Wenzel R Tablan $O$. Quma $R$. Gaynes $R$, Schlosser J, and Martone W. Strategies to prewent and control the emergence and spreat of antimicrobial resistant microorganisims in hospitals. A challenge to hospital leadership. Joumal of the American Medica Association 1996; 275 $234-240$

3. Wincent $J$ Bihari $D$, Suter P. Bruming $H$. White I. Nicalas-Chanain M, Wolff $M$, Spencer $\mathbb{R}$ and Hemmer $M$. The prevalence of nosocomial infection in intensive care units in Europe. Results of the european prevalence of untection in intensiwe care (EPIC) study. Joumal of the American Medical Assaciation $1995 ; 274: 639 \sim 644$

4. Röder B, Nielsen S, Magnussen P. Engquist $A$ and Frimodt-Moller $N$. Artiblatic usage in an intensive care unit in a Damish university hospital. Journal of Antimicrobial Chemo therapy $1993 ; 32: 633-642$

Bonten MJM, Gaillard C.A Wouters EFM, van Tiel $\mathrm{FH}$, Stobberingh $E \mathrm{E}$, and van der Geest S. Problems in diagnosing nosocomial pneum. monia in mechamically ventilated patients: a review Critical Car Medicine $1994: 22$ 1683.1691

Lianger $M_{4}$ Mosconi $P$. Cigada $M$ and Mandelli M. Long-term respiratory support and risk of pneumonia in critically ill patients. American Rowiow of Respiratoy Disease 1989. 140 : $302-305$

Johanson W. Pierce A Sanford $J$ and Thomas G. Nosocomial respiratory infections with Grammegative bacilli: the significance of colonization of lhe respiratory tract. Anmals of Internal Medicine 1972; 77:701-706.

8. Torres A, El-Ebiary $M$, Gonzalez J, Ferrer $M$, Puig de la Bellacasa $*$, Gene $A_{4}$ Martos A, and Rodriguez-iRolsin R. Gastric and pharyngeal flora in nosocomial pheumonia acquired during mechanica wertilation. American
Rewiew of Respiratory Oisease 1993, 148 . 352-357.

9. Pugin J, Auckenthaler R. Lew D. and Suter P. Orophanyngeal decontamination decreases incidence of ventilator-associated pneumona: a randonized, placebo-controlled. doubleblind clinical trial Journal of the American Medical Association 1991; 265:2704-2710

10. Rodriguiez-Roidán J Altuna-Cuesta $A_{6}$ Lopoz A. Carrillo A, Garcia J Leon J, and Martinez-Pelus A Prevention of nosocomial lung imfection in ventilated patients: use of an amtimicrobial pharyngal nonabsorbabie paste. Critical Care Medicine 1990; 18:1239-1242.

11. Banten MMM and Weinstein RA, Selective decontamination of the digestive tract: a measure whose time has passed? Curr Ophn Infect Dis 1996: $9270-275$

12. Waldvogel F. Staphylacoccus aureus tinch. Toxic Shock Syndrome). In: Mandell $G$. Bennett $J$, and Dolin $R$, editors Primciples and practice of infectious diseases, the ed New Vark: Churchill Livingstone Inc. 1995. p. $1754-1776$

Johamson WG, Pierce $A K$ and Sanford sP. Changing pharyngeal bacterial flora of hospitalized patients. New England Joumal of Madicine 1969: 281:1137-1140.

Rello d, Ausina V. Ricart M, Puzo C. Quntana E. Net A, and Prats $G$. Risk factors for infection by Pseudomonas abruginosa in patients with ventilator-associated pmeumonia. Interisive Care Medicine 1994, 20;193-198

15. Niederman Mantovani $R$, Schom P' Papas $J$, and Fein A. Patterns and rowtes of tracheobranchial colonization in mechanically venth lated patients: the role of nutritional status in colonization of the lower airway by Pseudomonas species Chest 1989; 95:155-161.

16. Pitt TL. Epidemiological typing of Pseudomonas aeruginosa. European Joumal of Chincal Horobiology and hirectious Diseases $1988 ; 7238-247$

17. Simmons $\mathbb{B}$, Bryank J, Neiman $K$, Spencer $L$, and Airheant $K$. The role of handwashing in 
prevention of endemic intensive care unit Hifections. Infection Control and Hospitalf Epidentiology 1990, 11:589m594.

18. Bonter MW, Froon AHM, Gailard CA Greve JW, de Leewh PW. Drent M, Stobberingh EE. and Buurman WA. The systemic inflammatory response in the development of ventislator-assciciated pneurnonia. American Joumal of Respiratory and Critical Care Medicine $1997 ; 156: 1105-1113$

19. Fagon J, Chastre J, Hance A, Montravers $P$, Novara $A$, and Gibert $C$. Nosocomial pneumonia in ventilated patients: a cohort study evaluating attributable mortality and hospital stay. American Jownal of Medicine 1993:94: 281:-288.

20. Torres $A$, Aznar $R$, Gatell JM, dimenez $P$, González $J_{1}$ Ferrer $A_{1}$ Celis $R_{i}$ and Rodriguez-Roisin $\mathbb{R}$ incidence, risk, and prognosis fiactors of mosocomial pneumonia in mechanically ventilated patients. American Review of Respiratory Disease 1990: 142 $523-528$.

21. Bonten MJM, Gaillard CA, de Leeuw PW, and Stobberingh EE. Role of colonization of the upper intestinal tract in the pathogenesis of ventilator-associated pneumonia. Cinical Infectious Diseases 1997, 24:309-319.

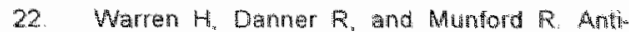
endotoxit monochonal antibodies. New England Joumal of Medicin 1902 ; 320 $1453-1157$

23. Grow E. Buw Hoi A, Stephan F. Nowara $A$ Gutmann $L$, Safar $M$, and Fagon J. Bacteriow logical evaluation of continuous subglottic aspiration for praventing tracheal colonization in ventilater patients. Amarican Joumat of Respiratory and Critical Car Medicine 1995 . 151:A720

24. Renz $C$, Christenson B, Bhorade $S$, Pohtman A, Noukwu M, Arnow P. and Hall S. Prevention of ventilator associated preumonit. Outcome and resource utilization. American Nownal of Respiratory and Cribal Cano Madicine 1997: 156:419

25. Kollef MH, Vlasnik $J$, Sharpless $L$, Pasque $C$ Murphy $D$, and Freser $V$. Scheduled change of antibiotic classes. A strategy to decrease the incidence of ventitator-associated pneumonia. American Joumal of Respiratory and Crifical Care Medicine 1997, 156 $1040-1048$

26. Niederman MS. Is 'crop rotation' of antibiotics the solution to 'mesistant' problem in the ICU? American Jaurnal of Resplratory and Critical Care Medicine 1997; 156:1029-1031. 


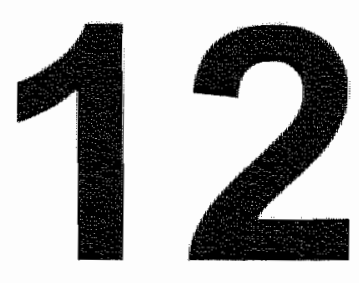

Summary 


\section{Summary}

Critically ifl patients admitted to the intensive care unit (ICU) who require mechanical ventilation are prone to develop ventilator-associated pneumonia (VAP). Development of this infection is associated with a prolonged ICU stay, additional health care costs, and increased antibiotic use, morbidity and mortality. This thesis deals with the pathogenesis, diagnosis, and prevention of VAP.

In chapter 1 the general aims of the studies and the main questions addressed in this thesils are described.

The pathogenesis of VAP is complex and not completely understood. However, VAP is almost always preceded by colonization of the respiratory tract with microorganisms. In chapter 2 the pathogenesis of VAP is reviewed, with special emphasis for (endogenous and exogenous) colonization, and the related literature on prevention of this infection has been critically assessed. The gastropulmonary route of colonization, which for many years has been considered to be the main pathway for pathogens that cause VAP. appears to be of limited importance. Oropharyngeal colonization as an antecedent to VAP has regained attention and several studies strongly suggest a pathogenetic role for colonization in the oropharym. Although intestinal colonization frequently occurs in critically ill patients, secondary colonization of the respiratory tract seems infrequent. The relevance of this rectopulmonary route of colonization remains largely undetermined. In addition to these endogenous sources, some data suggest that cross-colonization from exogenous sources may be an important route of colonization, not only in epidemic silluations.

Based on the presumed pathogenesis of VAP several preventive strategies have been studied. Conversely, the results of these studies helped to clarify the pathogenesis of VAP. Two guidelines have been formulated for the prevention of VAP, one by the American Thoracic Society and the other by the Centers for Disease Control and Prevention. Interestingly, a critical assessment of studies that evaluated preventive strategies revealed that selective digestive decontamination (1.e., eradication of microorganisms from intestine, slomach and oropharynx by nonabsorbable antibiotics, which are combined with systemic antibiotic prophylaxis) has proven to prevent VAP most effectively, but due to its potential side-effects and a lack of effect on secondary outcome parameters, this method of intection prevention is not recommended in either guidelines. The use of sucralfate for stress-ulcer prophylaxis is recommended in both guidelines although scientific evidence is failing.

In the first study of this thesis (chapter 3) the incidence of infections and indications for antibiotic use in our ICU have been studied. In our population one in every three patients has at least one infection during ICU stay. Almost all ICUacquired infections occur in ventilated patients and the respiratory tract is by far 
the most important site of infection, accounting for half of the total ICU antibiotic use. In the analysis of indications for antibiotic use, the distinction between bacteriologically proven and non-bacteriologically proven infections was helpful to identify unnecessary antibiotic use. Together with the data on antibiotic consumption and infection rates it may help to develop strategies to reduce antibiotic use. In our setting, prevention of respiratory tract infections has the greatest potential to reduce antibiotic use. The application of more specific criteria to diagnose these infections would help to rationalize antibiotic use even further. In chapter 4 we investigated whether adding the results of protected specimen brush and bronchoalveolar lavage to the generally used criteria for diagnosing VAP influences antibiotic prescription by intensive care physicians. The results of this study show that the number of patients receiving antibiotic therapy decreases by implementation of bronchoscopic techniques in the routine work-up of a clinical suspicion of VAP, without affecting recurrence rates or mortality. In addition, this implementation frequently resulted in adjustment of empiric antimicrobial therapy in patients with proven VAP, in most cases by narrowing the antibiotic coverage.

In chapter 5 a risk factor analysis for the development of colonization of stomach, oropharynx and trachea, and the development of VAP with enteric Gram-negative bacteria and Pseudomonadaceae was performed. The duration of mechanical ventilation is an independent risk factor for acquired colonization in stomach, oropharynx and trachea and for VAP. Surgical and trauma patients and patients receiving enteral feeding tend to become colonized more frequently with enteric Gram-negative bacteria than others. In the case of Pseudomonadaceae, acquired colonization of the oropharynx is associated with preceding tracheal colonization, and vice versa. Importantly, oropharyngeal colonization with enteric Gram-negative bacteria on admission and acquired colonization of the oropharynx with Pseudomonadaceae are risk factors for VAP by these species. Acquired gastric colonization is strongly related to prior colonization of the oropharynx and trachea, but did not prove to be a risk factor for development of VAP.

The clinical presentation and outcome of staphylococcal VAP is described in chapter 6. Preceding colonization with Staphylococcus aureus in the trachea appeared to be an important risk factor for the development of staphylococcal VAP. In contrast to community-acquired pneumonia due to $S$. aureus, which particularly develops in elderly people after a viral respiratory tract infection and which is associated with high mortality. VAP caused by this pathogen is not a fulminating disease and occurs more frequently in younger patients with a short duration of hospitalization before ICU admission.

In chapters 7,8 and 9 some microbiological and clinical aspects of Pseudomonas aeruginosa infections are described. Determination of similarity of isolates of $P$. aeruginosa is important when studying routes of colonization. Genotyping techniques are the methods of choice for this purpose but are expensive and 
laborious. In chapter 7 the usefulness of four methods of phenotyping (antimicrobial susceptibility patterns, serotyping, phage-typing, and outer membrane protein profile analysis) as an iritial method of screening for $P$. aeruginosa is presented. Serotyping has the best discriminative properties to reduce the number of isolates that need to be genotyped.

The results of these phenotyping and genotyping methods are used in chapter 8 to study routes of colonization with $P$. aeruginosa leading to VAP. This study shows that the upper respiratory tract is the predominant initial site of colonization with $P$. aeruginosa prior to the development of VAP, and that multiple body sites may be colonized with multiple genotypes of this species

In chapter 9 the influence of cross-colonization on the rates of colonization and infection with $P$. aeruginosa in an ICU where colonization with this species is endemic was assessed. It appeared that both endogenous and exogenous colonization are involved in the epidemiology of colonization and infection of the respiratory tract with this species. Moreover, cross-colonization seemed to be an important route of colonization and infection with $P$. aeruginosa, even in nonepidemic settings.

The most important conclusion of chapter 3 of this thesis was that the respiratory tract is by far the most important site of infection in mechanically ventilated ICU patients and that prevention of these infections has the greatest potential to reduce antibiotic use. The multivariate analysis in chapter 5 identified colonization of the upper respiratory tract as an independent risk factor for the development of VAP due to enteric Gram-negative bacteria and Pseudomonadaceae. Moreover, gastric colonization did not prove to be a risk factor for this infection. In addition, chapters 6,8 and 9 provided evidence that VAP due to $S$ aureus and $P$. aeruginosa was preceded by colonization of the upper respiratory tract. According to the data from these studies and the studies reviewed in chapter 2 , we hypothesized that decontamination of the oropharynx alone, without modulating gastric and intestinal colonization, and without systemic antibiolic prophylaxis, reduces the incidence of VAP in critically ill intensive care patients. In chapter 10 this hypothesis was tested in a prospective, randomized, placebo-controlled, double-blind study. Modulation of oropharyngeal colonization, indeed, effectively reduced the incidence of VAP by more than $60 \%$. Oropharyngeal colonization proved to be of paramount importance in the pathogenesis of VAP, and a targeted approach to prevent colonization at this site is a very effective method of infection prevention. 


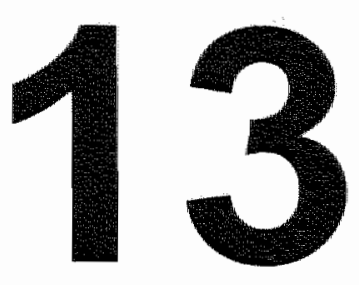

Samenvatting 


\section{Samenvatting}

Ernstig zieke patienten die zijn opgenomen op een intensive care (IC) en die mechanische beademing behoeven zijn vatbaar voor het krijgen van een beademings-gerelateerde longontsteking (ook wel 'ventilator-associated pneumonia' of VAP). Deze infectie leidt tot een langere opname duur, een toename van antibiatica gebruik, extra kosten en mogelijk een lagere overlevingskans voor de patient. Dit proefschrift behandelt de pathogenese, diagnose en preventie van VAP.

Hoofdstuk 1 beschrijft de doelen van de diverse studies in dit proefschrift en de belangrijkste wragen die we hebben getracht te beantwoorden.

De pathogenese van VAP is zeer complex en niet volledig duidelijk. VAP wordt bijna altijd voorafgegaan door kolonisatie van de bovenste luchtwegen met microorganismen. Hoofdstuk 2 bestaat uit een overzicht van de pathogenese van VAP met speciale aandacht voor (endogene en exogene) kolonisatie en een bespreking van de literatuur over preventie van VAP. De gastropulmonale route van kolonisatie, die vele jaren als de belangrijkste route voor het ontstaan van VAP werd beschouwd, lijkt veel minder belangrijk dan altijd werd aangenomen. Kolonisatie van de orofarynx als antecedent van VAP is opnieuw in de belangstelling gekomen en er zijn sterke aanwijzingen dat orofaryngeale kolonisatie een bellangrijke rol in de pathogenese van VAP speelt. Hoewel kolonisatie van de tractus digestivus (colon en rectum) universeel voorkomt bij mensen (gezond en ziek) lijkt verspreiding van kolonisatie naar de luchtwegen zelden plaats te vinden. De relevantie van deze rectopulmonale route van kolonisatie bliff grotendeels onbekend. Naast deze endogene bronnen suggereren sommige studies dat kruis-kolonisatie vanuit exogene bronnen (bijvoorbeeld andere patiënten) een belangrijke route van kolonisatie kan zijn, zowel in epidemische als in endemische situaties

Op basis van deze pathogenetische modellen zijn diverse preventieve strategieën ontwikkeld en vervolgens getoetst. De resultaten van deze studies hebben vervolgens weer bijgedragen tot het ophelderen van de pathogenese van VAP. Richtlijnen voor de preventie van VAP zijn opgesteld door de 'American Thoracic Society" en door de 'Centers for Disease Control and Prevention'. Kritische beschouwing van de trials waarin de preventie van VAP werd bestudeerd suggereert dat selectieve darm decontaminatie (elimineren van micro-organismen in de maag, darm en orofarynx met behulp van niet-resorbeerbare antibiotica, gecombineerd met systemische profylaxe) de meest effectieve manier van preventie is. Echter, door het potentiële gevaar voor selectie en inductie van antibiotica resistentie en het ontbreken van effect op mortaliteit wordt deze methode van infectie preventie niet aanbevolen. Het gebruik van sucralfaat voor stress ulcus profylaxe wordt wel door beide richtlinnen aangeraden, terwijl het wetenschappelijke bewijs hiervoor ontbreekt 
In de eerste studie van dit proefschrift (hoofdstuk 3) is de incidentie van infecties en indicaties voor antibiotica gebruik in IC bepaald. In onze populatie heeft eén op de drie patienten ten minste één infectie gedurende opname op de $1 \mathrm{C}$. Bijna alle IC verworven infecties treden op bij beademde patienten en de luchtwegen zijn verreweg het belangrijkste focus voor infecties. Voor deze luchtweginfecties wordt de helft van alle antibiotica voorgeschreven. Het onderscheid tussen bacteriologisch bewezen en niet-bacteriologisch bewezen infecties in de analyse van de indicaties voor antibiotica gebruik bleek waardevol ter opsporing van onnodig antibiotica gebruik. Samen met de resultaten van antibiotica consumptie en de incidentie van infecties kunnen strategieen ontwikkeld worden om het antibiotica gebruik terug te dringen. Het toepassen van meer specifieke criteria om de diagnose infectie te stellen zou het antibiotica gebruik verder rationaliseren. In hoofdstuk 4 is bestudeerd of het toevoegen van de resultaten van "protected specimen brush' en 'bronchoalveolaire lavage" aan de doorgaans gebruikte klinische criteria voor de diagnase van VAP, het voorschrijven van antibiotica kan beinvloeden. De resultaten tonen aan dat het aantal patienten met antibiotica afneemt door het implementeren van de resultaten van deze bronchoscopische technieken in het diagnostisch traject van een klinische verdenking op VAP. Het aantal recidieven van VAP en de mortaliteit worden hierdoor evenwel niet beinvloed. Bovendien leidt deze implementatie frequent tot het aanpassen van de empirische antimicrobiële behandeling bij patiënten met VAP, in de meeste gevallen door het versmallen van het antimicrobiële specirum.

In hoofdstuk 5 is de ontwikkeling van kolonisatie in orofarynx, trachea en maag en de ontwikkeling van VAP veroorzaakt door intestinale Gram-negatieve bacterièn en Pseudomonadaceae door middel van een risico factor analyse bestudeerd. De duur van mechanische beademing is de belangrijkste risico factor voor het verwerven van kolonisatie in de orofaryn, trachea en maag en voor VAP. Chirurgische en trauma patiënten en patienten die enterale voeding krijgen, raken vaker gekoloniseerd met intestinale Gram-negatieve bacteriën dan andere patiènten. Voor Pseudomonadaceae geldt dat verworven kolonisatie van de orofarynx geassocieerd is met voorafgaande kolonisatie van de trachea, maar ook omgekeerd. Kolonisatie van de orofarynx met intestinale Gram-negatieve bacterièn bij opname op de IC en verworven kolonisatie van de arofarynx met Pseudomonadaceae zijn risico factoren voor VAP veroorzaakt door deze bacteriesoorten. Verworven kolonisatie in de maag is sterk gerelateerd aan voorafgaande kolonisatie van de orofarynx en trachea, maar is geen risico factor voor VAP.

De klinische presentatie en uitkomst van VAP veroorzaakt door Staphylococcus aureus is beschreven in hoofdstuk 6 . Voorafgaande kolonisatie in de trachea bleek een belangrijke risico factor voor $S$, aureus VAP. Een beademingsgerelateerde pneumonie ten gevolge van deze bacteriesoort is geen fulminant ziektebeeld en treedt vooral op bij jongere patiënten met een kort verblijf in het 
ziekenhuis voorafgaande aan opname op de $1 \mathrm{C}$. Dit in tegenstelling tot een buten het ziekenhuis opgelopen pneumonie (ook wel "community-acquired pneumonia") veroorzaakt door $S$. aureus, die manifesteert zich met name bij oudere patienten na een virale infectie van de luchtwegen en heeft een hoge mortaliteit.

In de hoofdstukken 7,8 en 9 worden enkele microbiologische en klinische aspecten van infecties veroorzaakt door Pseudomonas aeruginosa beschreven. Typering van $P$. aeruginosa isolaten is belangrijk bij de bestudering van routes van kolonisatie. Genotypering is voor dit doel de methode van eerste keuze maar is duur en arbeidsintensief. In hoofdstuk 7 wordt de toepasbaarheid van vier fenotyperings methodes (antibiogram, serotypering faagtypering en buitenmembraan-eiwit profiel) als initiële typeringsmethode voor $P$ aeruginosa beschreven. Serotypering is gelet op het hoogste onderscheidend vermogen het meest geschikt als initiële typeringsmethode. Alleen voor isolaten met hetzelfde serotype is verdere genotypering noodzakelijk.

De resultaten van deze feno- en genotyperingen worden in hoofdstuk 8 toegepast om de routes van kolonisatie van $P$. aeruginosa leidend tot VAP te bestuderen. Deze studie toont aan dat de bovenste luchtwegen de belangrijkste initiële plaats van kolonisatie met $P$. aeruginosa is voorafgaande aan VAP, en dat meerdere plaatsen van het lichaam gekoloniseerd kunnen zijn met meerdere genotypes van deze bacteriesoort.

In hoofdstuk 9 is de invloed van kruis-kolonisatie op de incidentie van kolonisatie en infectie met $P$. aeruginosa bepaald op een IC waar kollonisatie met deze bacterie endemisch is. Het blikt dat zowel endogene als exogene kolonisatie betrokken zijn bij de epidemiologie van kolonisatie en infectie van de luchtwegen. Bovendien lijkt kruis-kolonisatie, aok in niet-epidemische situaties, een belangrijke route van kolonisatie en infectie met $P$. aeruginasa te zijn.

In hoofdstuk 3 van dit proefschrift beschreven wij dat de luchtwegen verreweg het belangrijkste infectiefocus vormen bij mechanisch beademde IC patienten en dat preventie van deze infecties de beste mogelijkheden biedt om antibiotica gebruik te verminderen. De multivariant analyse in hoofdstuk 5 identificeerde kolonisatie van de bovenste luchtwegen als onathankelijke risico factor voor VAP veroorzaakt door intestinale Gram-negatieve bacterien en Pseudomonadaceae. Bovendien bleek kolonisatie van de maag geen risico factor voor deze infectie te zijm. Daamaast leverden hoofdstuk 6,8 en 9 additioneel bewijs dat VAP veroorzaakt door S. aureus en P. aeruginosa wordt voorafgegaan door kolonisatie van de bovenste luchtwegen. Naar aanleiding van de resultaten van deze studies en de studies uif het overzicht van hoofdstuk 2 werd de hypothese geformuleerd dat decontaminatie van alleen de orofarynx, zonder modulatie van kolonisatie van maag en darm en zonder systemische profylaxe, de incidentie van VAP bij ernstig zleke IC patienten zou reduceren. In hoofdstuk 10 is deze hypothese getest in een prospectieve, dubbel-blind gerandomiseerde, placebo-gecontroleerde studie. Modulatie van orofaryngeale kolonisatie is een effectieve manier om de incidentie 
van VAP te reduceren met meer dan $60 \%$. Kolonisatie van de orofarynx is derhalve van cruciaal belang in de pathogenese van VAP en een gerichte benadering ter preventie van kolonisatie op deze plaats is een effectieve methode van infectie preventie. 


\section{Dankwoord}

'... U bent familie van dhr. J? Het moment is uiterst ongelukkig maar zou ik $U$ toch even iets mogen vragen? Min naam is Dennis Bergmans, ik ben onderzoeker op de intensive care waar Uw vader zojuist is opgenomen. Zoals U gezien heeft wordt hij kunstmatig beademd. Het buisje in zijn mond loopt tot in zijn longen, de beademings-apparatuur die aan de slangen vast zit helpen hem met ademhalen omdat hij daarvoor zelf nu te ziek is. Een van de problemen die bij beademing kunnen optreden is het ontstaan van een longontsteking. Uit eerder onderzoek is gebleken dat dit bij één op de vier of vijf mensen gebeurt en dat de bacteriën die de longontsteking veroorzaken bijna altijd eerst in de mondholte aamwezig zijn. Momenteel doen wij onderzoek naar hoe we deze longontsteking het beste

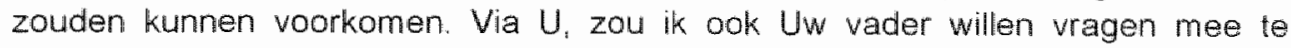
werken aan dit onderzoek. in het onderzoek wordt, door middel van een mondpasta met daarin antibiotica, getracht de mondholte vrij van bacterien te houden. Immers, wanneer dit lukt zou ook de kans op een longontsteking kleiner moeten zijn. De mondpasta wordt vier maal per dag door de verpleegkundige in de mond gestreken...

Bij het verrichten van klinisch wetenschappelijk onderzoek moet 'informed consent' worden verkregen van de patiënt alvorens mag worden aangevangen met de studie. Bij kunstmatig beademde patiënten is dit meestal niet mogelijk door de aanwezigheid van een beademingstube waardoor het onmogelijk is te spreken, door de ernst van de ziekte of door sedatie. In die gevallen mag de directe familie 'informed consent' geven. Het bovenstaande stukje tekst is, in het kort, de informatie die ik patiënten of thun familieledien gaf. Gevolgd door een wat moeizamer verhaal over het hoe en waarom van de clubbel-blinde en vooral ook placebo-gecontroleerde opzet van de studie. De overwegingen om wel of niet deel te nemen aan een onderzoek of daarvoor, in naam van een familielid, toestemming te verlenen blijven vaak onduidelijk en zijn heel persoonlijk. Ter illustratie wil ik twee reacties voorleggen die mij zijn bijgebleven. De dochter van een patiënte die zojuist was opgenomen met ernstige neurologische schade van een hersenbloeding eiste zelf de mondpasta te 'proeven' alvorens te besilissen. Ze wilde weten hoe die mondpasta aanvoelde en smaakte om in te schatten hoe dit voor haar moeder zou zijn. De senior-vice-president van een middelgrote bank en tevens broer van een patiënt die werd opgenomen met een massale maagbloeding zei, met een stem en intonatie die zijn maatschappelijke functie waardig was: 'Natuurlijk kerel, doen, we smeren hem vier keer per dag van die rommel in zijn bek en we slepen hem erdoor!'. Mlijn dank aan alle patiënten die hebben toegestemd in de studies die we hebben verricht, maar zeker ook aan alle echtgenoten en echtgenotes, dochters en zonen, vaders en moeders, broers en zussen die de kracht en de moed hadden om op zo'n moeilijk moment over mijn vraag na te denken en een weloverwogen beslissing te memen voor hun familielid. 
Irma, 'mijn allerliefste meisje min', dit boekje heeft nogal wat van ons beide gevergd. Op de momenten dat ik wankel is jouw wertrouwen en steun grenzeloos. Ik ken geen groter hart dan het jouwe, dank je wel.

Dr MuM Bonten, beste Marc, na de transfer van Carlo heb je de jouw zo vertrouwde spitspositie in het ICIP-team verlaten om net iets achter de aanval te gaan spelen. Daar heb je je ontwikkeld tot een van die zeldzame spelers die anderen kunnen laten scoren en daarbij zelf de nodige doelpunten meepikken. Jouw dwingende spel en hoge baltempo zijn alleen soms moeilik te volgen voor sommige van je medespelers. Inmiddels heb je voor een nieuw team gekozen waar je de nodigle ruimte krijgt om jouw spel te doen gelden. Ik vond het een eer om samen met jouw te mogen spelen en ik ben blij dat je mij in je spel hebt betrokken. Gelukkig ballen we, zij het op afstand, voorlopig nog wel even verder.

Dr EE Stobberingh, beste Ellen, elke onderzoeker heeft lemand nodig zoals jij. lemand die praktische zaken snel kan regelen, altijd aanspreekbaar en aanwezig is en weet wat het betekent om onderzoek te doen. Bovendien doe je dit alles zonder een plek op de woorgrond op te eisen, iets wat je vaker juist wel zou mogen doen. Ik will je speciaal bedanken voor je interesse en steun bij al die zaken buiten het onderzoek

Prof dr PW de Leeuw, beste Peter, graag will ik je bedanken voar de grote vrijheid die je mij en Marc hebt gegeven om de diverse studies te doen. Jouw heldere kijk op resultaten en nauwgezelheid zijn van grote waarde gebleken.

Dr $S$ van der Geest, beste Siebe, menigmaal hebben we aan het bed van een nieuwe patiënt staan te discussiëren over het wel of niet includeren in een studie Je was altijd het aanspreekpunt op de intensive care. Jouw vriendelike aard en toegankelijkheid blijven sterke punten.

Dr FH van Tiel, beste Frank, jouw betrokkenheid bij het microbiologische gedeelte van dit proefschrift heb ik zeer gewaardeerd. Je nauwgezetheid en corrigerende vermogen bij de vele versies van artikelen blijt mij verbazen.

Dr CA Gaillard, beste Carlo, met name in de voorbereiding van de studies in dit proefschrift heb jij een belangrijke rol gespeeld, mijn dank daarvoor.

Monique Coomans en Ingrid Stulens, wat had ik zonder jullie gemoeten. De stroom kweken was bijna niet te overzien en toch werd altijd de klus geklaard. Jullie enthousiasme en werklust zijn aanstekelijk en onvervangbaar, de bijgeleverde "ins en outs" van de belgische leefwijze waren meer dan welkom. Nancy London en Christel Driessen en ook de anderen van het research laboratorium medische microbiologie bedankt voor de helpende hand 
De studies zoals beschreven in dit proefschift zijn niet uitvoerbaar zonder de volledige medewerking van de intensive care afdeling. De verpleegkundigen en coördinatoren van de afdelingen D3 en E3 wil ik hier dan ook speciaal bedanken. Niet alleen voor het afnemen van de kweken, het aanbrengen van de mondpasta en het verzamelen van data maar $\mathrm{m} . \mathrm{n}$. omdat jullie ervoor hebben gezorgd dat ik elke dag weer met plezier naar mijn 'hok' kwam. Ik verheug mij op de hernieuwde samenwerking in de toekomst.

Drs JC Paling, beste Hans, bedankt voor het coördineren van de TAP-trial in het AZG. De 'groningse data' zijn een meerwaarde voor de studie. Mijn dank ook aan alle artsen en verpleegkundigen van de chirurgische intensive care en de medewerkers van de medische microbiologie en de apotheek voor jullie inzet.

Tiny Raadschilders wil ik bedanken voor de randomisatie en productie van de mondpasta. De stafleden en assistenten van de vakgroep Longziekten dank ik voor het verrichten van alle bronchoscopieën. Voor de statistische ondersteuning van Ton Ambergen en de data-invoer van Rob Wilting ben ik beide zeer erkentelijk. Rebecca, Nicole, Martijn en Stephanie, jullie waren achtereenvolgens mijn kamergenoten. Het zuurstof gebrek, de koortsige temperatuur en de hoge luchtvochtigheid werden, ruimschoots gecompenseerd door jullie prettige aanwezigheid.

Tiny Wouters, een verblijf in jouw kamer, zittend op het krukje en jij achter het toetsenbord is inmiddels een begrip binnen de vakgroep. Niet alleen als synoniem voor een op handen zijnde proefschrift maar ook voor een perfecte lay-out. Wanda Lenaers, Jeanny Kaethoven en Eric Rooijakkers, gedrieën ontworpen jullie de mooie kaft, heel erg bedankt.

Tot slot wil ik als voorzitter van AV Dikke Stella nog even het woord richten tot de geachte leden. Beste Steven, Rogier, Edgar en Michiel, van elke kilometer die wij gezamelijk al lopende hebben doorgebracht heb ik intens genoten. In feite is er voor een onderzoeker met een beperkt aëroob vermogen niets mooiers dan te hard van start gaan en tegen het einde nog net gepasseerd te worden. Altijd was er een van jullie bereid dit te doen, mijn dank hiervoor. Squashen kunnen jullie alle vier niet 


\section{Publicaties}




\section{Abstracts}

1. Bergmans DCu, Howstra L. Hoeks APG, Tordoir JHM Kitsiaar PJEHIM. Compliance in polytetrafuoroetryleen en veneuze fremorodistale bypasses. Nederlands Tidschntt yoor Gerneskunde 1994; 138 121:1099-1100

2. Beuk RJ, Bergmans DCJU, Kurvers HA.w. Hofstra $L$, Kitslaar PJEHM, Leunissen KML, Tordoir JHM Ischemia of the hand as a complication of hemodialysis access fistuas: Related to high flow triough the fistula or quality of collateral supply? Blood Purfication $1994: 12(3): 189$

Bergmans DCuJ, Bomen MidM, Gaillaro CA, van Tiel FH, de Leeuw PW: Stabberingh EE, van der Geest $S$. The clinicat spectrum of Ventilator Associated Pnetmonia caused by Staphylococcus aureus. Netherlands Joumat of Medicine 1995; 46 (5):A77.

4. Berginans DCu, Bonten MJM: Gaithard CA. van Tiel $F H$, van der Geest $S$, Stobberingh EE. Initial sites of colonization in mechanically ventilated loupatients and the sequences to tracheal colonization. American Journal of Respiratory and Critical Care Medicine 1995: 151 (4):A719.

5. Bergmans DC.JJ. Bonten MJM, Stobberingh EE. Gaillard CA, van Tiel FH, Drent $M_{\text {: }}$ wan der Geest $S$. Discrepancies between quantitative cultures of protected specimen brush and pronchoakeolal lavage in ICU patients American Journat of Respiratory and Critca Care Medicine 1995. 151 (4) 1490

Hotstra Leunissen KML, Bergmens DCdA, Kustaar PJEHM, Howks APG, Tordor JHM. Mismatch in elastic properties around anastomoses of interposition grafts for hemodialysis access. Nephrology, Dialysis. Transplantation 1995; 10.569

Bergmans, DCu, Bonten Mun, Gallind CA van Tiel FW, de Leeuw PW, wan der Geest $\mathrm{S}$, Stobberingh EE. Antibiotica georuik op de intensive care-afdeling: Prospectief onderzaek gedurende 1 jaar. Nederlands Tjodschrift woor Geneeskunde 1995: $139(38)$ 1957.

8. Hofstra ll., Bergmans DCJ., Hoeks APG. Daemen MUAP, Leunissen KML. Kitslazar P.SEHM. Tordoir JHM. The effect of shear rate and anastarnotic mismatch in elastic properties on the development of stencsis in graft AV fistulas. Intenation anglology 1995: 14 (1) Supplement $1209-210$

Bonten Mum, Gergmans OCJJ, Gailard CA van Tiel FH, de Leuw P, van der Geest $S$. Stobberingt EE. Assessment of microbiolo. gical cotonization: Intutence of samplte frequencies. Infection Control and Hosplat Epidgmpology 1995; 16 (4) part 2 (supplement) 40 .

10. Bergmans DCJ, Bonten M, M. wan Tiel FH, Gallard CA, de Leeuw PW, van der Geest 5 Stobberingh EE. The influence of bronchoscopic techniques for diagnosing wentilatorm associated pneumonia on antibiotio prescription. Notheriands Journal of Madiche $1996 ; 48$ (5):A91.

11. Bergmans DCJu, Bonten MJM, van Tiel FH, Stobberingh EE. Krussokolonisatie met Psevdomonas aeruginosa bij intensive care patienten. Naderlanos Tijoschrift woor Medische Microbiologit 1997: 5 (2) Supplement:551.

12. Bergmans DCJU, Bonten MJM, Gallard CA, wan der Geest $\mathrm{S}$, de Leenw PW. Paling JC. van Tiel FH. Stobberingh EE. Topical antimicrabial prophylaxis of the oropharymx to prewent ventilator-associated pheumonia: Prospective randomised double-blind controlled study. Europoan Jounal of internat Madicino 1997: 8 Supplement 134.

13. Bonten MuM, Bergmans DCab. Spenter JQ. van der Gest S. Thte HT, Stobbeningh EE Respiratory tract colonization (RTC) with Pseudomonas aruginosa $\left(\mathrm{FA}_{\mathrm{A}}\right)$ in intensive care (ICU): From endogenous or exogenous origin? European Joumad of Intarna Medichng 1997, a Supplement $1: 28$

1.4. Bonten MuM. Bergmans DCjJ. Ambergun AW varn der Gegst $S$, Stobbangh $E E$. The Effect of collonzation pressure (CP), antibiotic pressure $A \mathrm{AP}$ and intensity of patient care on acquisition of respiratory tract colonization (RTC with Pseudomonas aerughosa (PA) European Joumal of Iotemal Madiche 1997 a Supplement 1115

Bomten MM. Bergmans DCut. Speniger Jo. wan der Geast S, Thie r.T. Stobberingh EE. 
Respratory trat colonizan 1 RTC wh Psevonomas aerughosa (PA) in intensve care (IC) From endogenous or exogernous

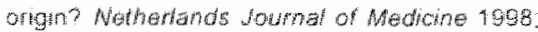
$52(4), 451-4,52$

16. Bergmane DCu. Bonten MuM, Gaiflurd CA. wan wer Geest S, de Leesw PW, Paling MC, wan Ties FH. Stobberingh EE. Topical antmicrobia prophylaxis of the orophanyn to prewent wentilator-wasciated pneumonia: Prospective randomised doublemblind confrolled study. Nemertands Jommal af Madicine 1998: 52 (4),A52-A53

\section{Artikelen}

1. Hofstra L, Bergmans DCuJ. Hoeks APQ. Tordoir aHM Kitsladr P.EEH Compliance and distemsiblity in the reversed saphenous vein graft VASA - Supptementum 42 . 190340.42

2. Bergmans DCJJ, Bontell MJM, Gamard CA wan Tiel FH, wan der Geest S. Stobberingh EE. In witno antibacterial activity of sucralfate. European Jownal of Chinical Microbiology \& Infecious Diseases $1994,13(7), 615-620$.

3. Hofstra $L$ Bergmans DCuJ Hoeks APG, Tordoir JHM, Kitslaar PJEHM. Asserssment of inhomogeneities in elastic properties of in situ and reversed saphenous vein grafts in humans European Joumal of Vascular Surgeny 1994, 8:670-676

Hofstra L. Bergmans DC U. Hoeks APQ. Kis laar PJEHM, Leunissen KML. Tardail JHM. Mismatch in elastic propenties around and stomases of interposition grafts for hemodalysis chcoss. Jaumed of the Amarican Socioty of Maphrology 1994:5 (5) 1243-1250

Hofstra L, Bergmans DCJJ Leunissem KML Hoeks APO Kitslaa PJEHM, Daemen MJAP. Tordoir HHW Anastomotic intimal hyperplasia in prosthette arteriomenons fistulas for hemodialysis is associated with intial high flow velocity and not with mismatch in elastic. properties. woumal of the American Society of Nephrology 1995, 6 (6) 1625-1633
EWropean Houmal of Chinal Microbiology \& infectious Diseases $1996,15(0) 437-445$

Bonten: MUM. Bergmans DCW, Ambergen AW de hetw PW wan der Gest S. Stobberungh $E E$, Gallard $C A$. Risk factors for pneymonia, and colonization of respiratory tract and stomach in mecharically ventilated lCHpatients American Joumal of Respirapory and Critical Care Medine 1996, 154 (5)1339. 4346

Hofsira L, Bergmans DCJJ, Leunissen KML Hoeks APG, Kislata PJEHM. Tordoir JHM Prosthetic arteriowemous fistulas and wenous anastomotic stenosis: Unfluence of a high flow welocity on the wewelopment of intmal hyperplasta. Blood Punfication 1996; 14:345. 349.

Bergmans DCJ.J. Bonten MJM de Leevw PW: Stobbenngh EE. Reproducbulity of quanitative cultures of endomacheal aspirates from mechanically ventilated patients. Journal of Chinical Microbiology 4997: 35 (3):796-798

Bargmans DCu, Bonten MJM, Gatlland CA. van Tiel FH, van der Geest $S$, de Leeuw $P$ W Stobberingh EE. Indications for antibionic use in ICU patients: A one-year prospective survellance Journal of Antimiorobial Chemotherapy $1997,39(4), 527-535$

11. Bonten MuM, Bergmans DC.du, Stobberingh EE, van der Geest S de Leeuw PW, wan Tiel FH, Gaillard CA Implementation of broncho. scopic fechniques in the diagnosis of ventilator-associated preumonia to reduce antibiotic use. American Joumal of Respiram lory and Critical Care Medicine 1997. 156 (6) 18201824

Bergmans. DCu. Bonten MuM, van Tiel FH, Gatllard CA, van der Geest $S$ de leew $P M$, Stobberingh EE. Value of phenotyping methods as an mulal screening of Pseudomonas aengimasa in epidemiologic studies Infection 1997, $25,6,350-354$

Bergmans DCH. Bonten MuM, wan Thel FW, Gallard CA Wilting RM, wan der Geest $S$, de Leeuw PW, Stobberingh EE Cross. colonization with Pseudomonas aerughosa of patients in an intensive cale unitt Thorax $1998: 53: 12) 1053-1058$ 
Bergmans DC.u. Bonten MuN, Stobberngh EE, wan Thel FH, van der Geest S. de Leeuw PW. Gaillard CA. Colonization with Pseudomonas aeruginosa in patients developing ventilator-associated pneumonia. Infection control and Hospital Epidemiology 1998: $19(1), 853-855$

Bergmans DCU. Bonten MuM. Gailard CA. Paling $\mathrm{JC}_{\mathrm{i}}$ vam der Geest $\mathrm{S}$, van Thel $\mathrm{FH}$. Beysens A. de Lêu PW, Stobberngh EE Prevention of ventilator-associated pheumonia: by oral decontamination: A prospective. randomized, double-blind placebo controlled sifudy. Submitted for publication.

16. Bonter MuM. Bergmans DCJ, Speijer JG. Stobberingh EE. Characteristics of poyclonal endemicity of Pseudomonas aeruginosa colonization in intensive care units: implications for infection control, Submitied for publication.

\section{Overige}

1 Geromens DCWJ, Bonten MuM, Slobberngh EE Bachericidal efect of sucratiate Europesh Joumai of Gastroenterology is fepatology 1993.5(5) 397. [Letter]

2. Tordoir HHM, Hofstra L, Bergmans DCW. Hoeks APG Leunissen KML Kitsbar PJEHM. Stretch warsus standard expandad PTFE gratts for hemodialysis access. In: Henry Ml. Ferguson RM. editors. Vascular access fol hemodialysis-IV. WL Gore Associates, Ine; and Precept Press, 1995, p. 277-285 [Chapter]: 


\section{Curriculum vitae}


Dennis Bergmans werd geboren op 29 april 1970 te Weert. In 1988 behaalde hij het WWO diploma aan de Philips van Horne Scholengemeenschap te Weert. In hetzelfde jaar startte hij met de studie Geneeskunde aan de Universiteit Maastricht. Als $3 e$ en 4 e-jaars student was hij werkzaam als student-assistent bij het skillslab van de faculteit geneeskunde (Drs $M$ Franssen), de vakgroep Chirurgie (Dr L Hofstra en Prof dr PJEHM Kitslaar) en de vakgroepen Interne Geneeskunde/Medische Microbiologie (Dr MJM Bonten en Dr CA Gaillard/Dr EE Stobberingh). Voor de bijdrage aan het onderzoek naar 'Neurale buissluiting' bij de vakgroep Anatomie/Embryologie ( $\mathrm{Dr} \mathrm{H}$ van Straaten) in het kader van het wetenschaps-keuzeblok werd de Studentenprijs 1992 toegekend door het Bestuur van de Stichting Wetenschapsbeoefening der Rijks Universiteit Limburg. Het artsexamen werd behaald in 1997.

Het in dit proefschrift beschreven onderzoek werd grotendeels uitgevoerd tijdens een aanstelling als onderzoeker bij de vakgroep Interne Geneeskunde van het Academisch Ziekenhuis Maastricht van september 1994 tot en met december 1996 onder leiding van Dr M.M Bonten, Dr EE Stobberingh en Prof dr PW de Leeuw. Hiervoor is de studie geneeskunde tijdelijk onderbroken.

Voor een deel van het onderzoek werd de Posterprijs 1998 toegekend door de Nederlandsche Internisten Vereeniging en in hetzelfde jaar een prijs van de Stichting Hippocrates Studiefonds voor onderzoek verricht voór het artsexamen. Sedert 1 oktober 1998 is hij in opleiding tot internist in het Diaconessenhuis te Eindhoven (opleider: Dr HR Haak). 